\title{
Cognitive correlates of cerebrospinal fluid biomarkers for Alzheimer's disease
}

Citation for published version (APA):

Reijs, B. (2018). Cognitive correlates of cerebrospinal fluid biomarkers for Alzheimer's disease. [Doctoral Thesis, Maastricht University]. Ridderprint. https://doi.org/10.26481/dis.20180221br

Document status and date:

Published: 01/01/2018

DOI:

10.26481/dis.20180221br

Document Version:

Publisher's PDF, also known as Version of record

\section{Please check the document version of this publication:}

- A submitted manuscript is the version of the article upon submission and before peer-review. There can be important differences between the submitted version and the official published version of record.

People interested in the research are advised to contact the author for the final version of the publication, or visit the DOI to the publisher's website.

- The final author version and the galley proof are versions of the publication after peer review.

- The final published version features the final layout of the paper including the volume, issue and page numbers.

Link to publication

\footnotetext{
General rights rights.

- You may freely distribute the URL identifying the publication in the public portal. please follow below link for the End User Agreement:

www.umlib.nl/taverne-license

Take down policy

If you believe that this document breaches copyright please contact us at:

repository@maastrichtuniversity.nl

providing details and we will investigate your claim.
}

Copyright and moral rights for the publications made accessible in the public portal are retained by the authors and/or other copyright owners and it is a condition of accessing publications that users recognise and abide by the legal requirements associated with these

- Users may download and print one copy of any publication from the public portal for the purpose of private study or research.

- You may not further distribute the material or use it for any profit-making activity or commercial gain

If the publication is distributed under the terms of Article $25 \mathrm{fa}$ of the Dutch Copyright Act, indicated by the "Taverne" license above, 


\section{COGNITIVE CORRELATES of CEREBROSPINAL FLUID BIOMARKERS for ALZHEIMER'S DISEASE}




\section{COLOFON}

Layout \& Cover design: Design Your Thesis, www.designyourthesis.com Printed by: Ridderprint BV, www.ridderprint.nl

ISBN: 978-94-6299-841-4

Copyright $\odot 2018$ B.L.R. Reijs, Maastricht

All rights reserved. No part of this publication may be reproduced or transmitted in any form by any means, without the prior written permission of the author. 


\title{
COGNITIVE CORRELATES OF CEREBROSPINAL FLUID BIOMARKERS FOR ALZHEIMER'S DISEASE
}

\author{
PROEFSCHRIFT \\ Ter verkrijging van de graad van doctor aan de Universiteit Maastricht, op gezag van \\ de Rector Magnificus, Prof. Dr. Rianne M Letschert, \\ volgens het besluit van het College van Decanen, \\ in het openbaar te verdedigen op woensdag \\ 21 februari 2018 om 12:00 uur
}

Door

Babette Louise Richelle Reijs

Geboren op 6 december 1985 te Mook en Middelaar 


\section{PROMOTOR}

Prof. dr. Frans RJ Verhey

\section{CO-PROMOTORES}

Dr. Pieter Jelle Visser

Dr. Inez HGB Ramakers

\section{BEOORDELINGSCOMMISSIE}

Prof. dr. Rudolf Ponds (voorzitter)

Dr. Jurgen Claassen (Radboud UMC, Nijmegen)

Prof. dr. Caroline van Heugten

Prof. dr. Eric Salmon (University of Liège)

Dr. leke Winkens

The research described in this thesis was performed at the Department of Psychiatry and Neuropsychology, School for Mental Health and Neuroscience, Maastricht University, Alzheimer Center Limburg, Maastricht, the Netherlands.

Printing of this thesis was kindly supported by Alzheimer Nederland 


\section{CONTENTS}

$\begin{array}{lll}\text { CHAPTER } 1 & \text { General Introduction }\end{array}$

CHAPTER 2 Memory correlates of Alzheimer's disease cerebrospinal fluid 19 markers: a longitudinal cohort study

Journal of Alzheimer's disease, 2017

CHAPTER 3 Effect of key Alzheimer's disease cerebrospinal fluid markers on specific cognitive decline in subjects in Mild Cognitive Impairment: results from the DESCRIPA study In preparation

CHAPTER 4 Relation of odour identification with Alzheimer's disease markers in cerebrospinal fluid and cognition Journal of Alzheimer's disease, 2017

CHAPTER 5 Emerging cerebrospinal fluid markers of Alzheimer's disease related pathology In preparation

CHAPTER 6 Association between later life lifestyle factors and Alzheimer's disease biomarkers in non-demented individuals: a longitudinal descriptive cohort study Journal of Alzheimer's disease, 2017

CHAPTER 7 The central biobank and virtual biobank of BIOMARKAPD: a resource for studies on neurodegenerative diseases

Frontiers Neurology, 2015

CHAPTER 8 General discussion

$\begin{array}{lll}\text { ADDENDUM } & \text { Summary } & 151\end{array}$

Samenvatting (Dutch summary) 153

Knowledge valorization $\quad 155$

$\begin{array}{ll}\text { Author affiliations } & 159\end{array}$

List of publications $\quad 165$

$\begin{array}{ll}\text { Thesis defences from MHeNs } & 167\end{array}$

Dankwoord (Acknowledgments) 183

$\begin{array}{ll}\text { Curriculum Vitae } & 185\end{array}$ 


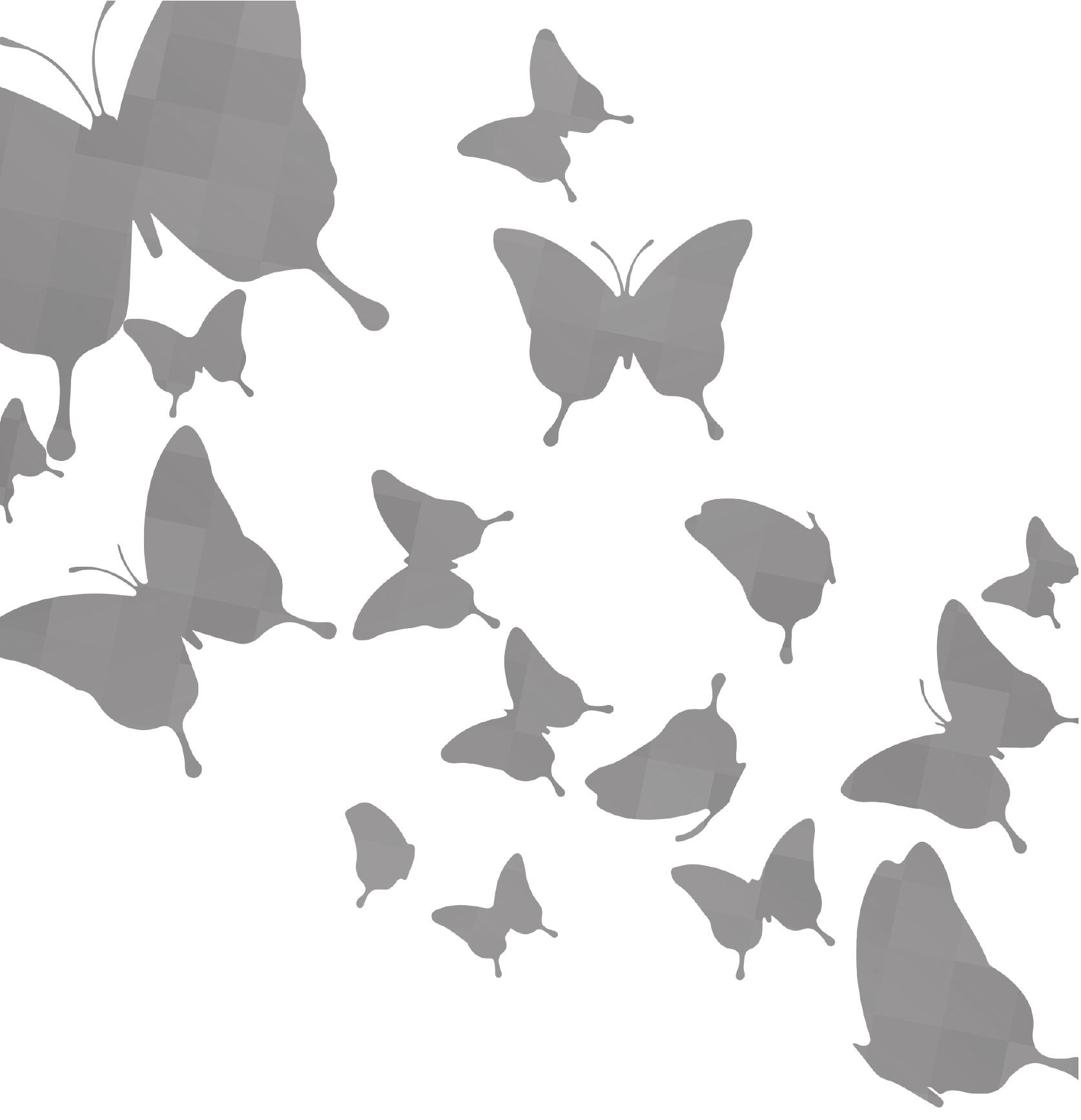


General introduction 



\section{GENERAL INTRODUCTION}

Alzheimer's Disease (AD) is the most common form of dementia. Dementia is a fatal disease and places a huge burden on patients, caregivers and society. In 2017, the number of individuals with dementia increased to 47 million worldwide, as a result of the aging population. Since it is expected that this number will continue to double every 20 years [1], dementia is considered a global health crisis. This prospect emphasizes the urgent need to better understand the pathophysiology of AD. At present, there are no effective disease-modifying treatments available. For future disease modifying treatments to be most effective, AD needs to be detected in an early stage, before the onset of clinical symptoms when neuronal damage is still limited. Uncertainty about the long predementia phase of neurodegeneration may in part account for our failure to find effective disease-modifying treatments for AD [2]. The key pathological hallmark of $A D$ is amyloid pathology and this is present up to 15 years before the onset of clinical symptoms [3-5]. However, the rate of decline varies greatly between individuals. To facilitate treatment development there is an urgent need to better understand the pathophysiology of $A D$, to diagnose $A D$ before the onset of dementia, and to better understand predictors of disease expression. Furthermore, detecting $A D$ in an early stage and a better understanding of clinical disease progression will benefit present patient care. To this end, we examined associations between AD biomarkers, risk factors, and cognitive decline across the clinical spectrum of $A D$ ranging from preclinical $A D$ to mild dementia. In our studies, we examined established AD markers and risk factors, but also markers and risk factors that have emerged in the last years.

\section{Clinical spectrum of Alzheimer's Disease}

Clinical diagnosis of AD-type dementia is based on progressive cognitive impairment, involving memory impairment and impairment of at least one other cognitive domain such as attention, mental speed, executive functioning, language or visuospatial skills, interfering with daily living [6]. Individuals with mild cognitive impairment (MCI) have cognitive impairment, but this impairment does not significantly interfere with daily living. Individuals with amnestic form of $\mathrm{MCl}$, i.e. impairments in the memory domain, are at risk to progress to $\mathrm{AD}$-type dementia $[7,8]$. The $\mathrm{MCl}$ stage may in turn be preceded by a preclinical stage of up to 15 years in which $A D$ brain abnormalities are present while there is no impairment on cognitive testing [5], although subjects may experience subjective cognitive decline (SCD) $[9,10]$. 


\section{Markers for AD pathology}

Characteristics of $A D$ pathology are aggregation of amino acid peptide 1-42 of amyloid-beta (aß42) in extracellular amyloid plaques, hyperphosphorylated tau ( $p$-tau) resulting in intracellular neurofibrillary tangles [11] and progressive neurodegeneration particularly affecting the hippocampus and entorhinal cortex.

$\mathrm{A} \beta 42$ and tau pathology can be assessed by positron emission topography (PET) and in cerebrospinal fluid (CSF). In CSF, a 342 concentration is decreased, probably due to accumulation of this peptide in plaques, and tau is increased reflecting neuronal injury. Amyloid and tau biomarkers are now being used in research criteria for $A D$, to diagnose $A D$ across the clinical spectrum from normal cognition to dementia. Cognitively normal subjects with abnormal amyloid are referred to as preclinical $A D$, individuals with $\mathrm{MCl}$ and abnormal amyloid as prodromal $\mathrm{AD}$, and individuals with dementia and abnormal amyloid as AD dementia (National Institute on Aging-Alzheimer's Association workgroups on diagnostic guidelines for Alzheimer's disease (NIA-AA criteria))[12-14]. In addition to markers for a $\beta 42$ and tau, many other $A D$ markers have emerged in the past few years, but their role in $A D$ pathophysiology, and their utility for diagnosis and prognosis, is still unclear.

\section{AD biomarkers and cognition}

The first clinical signs of $A D$ are cognitive impairment. Clinical onset of AD-type dementia involves impairment in multiple cognitive domains and is preceded by gradual cognitive decline over time. However, the domain-specific course of cognitive decline and the association with CSF AD biomarkers remains poorly understood. While memory impairment is the dominant feature of $A D$ it is not yet clear which type of memory (e.g. episodic, semantic or working memory), is most impaired and how CSF biomarkers for $\mathrm{a} \beta 42$ and tau correlate with memory performance across the clinical spectrum of $A D$. Moreover, there is evidence that non-memory domains including executive functioning $[15,16]$, as well as odour identification $[17,18]$ may be affected in the early stage of the disease $[15,16]$, but their association with AD biomarkers remains unclear.

\section{Risk factors for AD}

The main risk factors for $A D$ are increasing age [19], low educational level [20, 21], female gender [22], and the presence of the apolipoprotein E (APOE)- $\varepsilon 4$ allele [23, 24]. APOE has 3 polymorphisms $\varepsilon 2, \varepsilon 3$ and $\varepsilon 4$, with a prevalence of respectively $8.4 \%, 77.9 \%$ and $13.7 \%$ [25]. In $A D$, the frequency of the $\varepsilon 4$ allele is increased to $40 \%[25]$. It is has been estimated that the risk for AD-type dementia is increased by 2 to 3 times with one $\varepsilon 4$ allele and by a factor 12 with two $\varepsilon 4$ alleles [26]. The $\varepsilon 2$ allele reduces the risk for AD relative to 
the $\varepsilon 4$ allele. Furthermore, there is increasing evidence that potentially modifiable lifestyle factors, such as social inactivity [27], cognitive and physical inactivity [28-30], alcohol consumption [31], smoking [28, 29] and sleep deprivation [28, 29, 32, 33], may also influence the risk for dementia. However, the relation of these risk factors with $A D$ pathology remains unclear.

\section{AIM AND OUTLINE OF THIS THESIS}

In this study, we aim to investigate the relation between established AD biomarkers and cognition across the clinical AD spectrum, and we test for a number of emerging markers and risk factors their role in AD pathophysiology, association with cognitive test performance and utility for diagnosis and prognosis.

As emerging markers we will test:

- Odour identification. Several studies have indicated that olfactory dysfunction is an early sign of $A D$ and may be useful as a diagnostic and prognostic marker [17, 18]. However, the relation of odour identification with AD biomarkers (CSF a $\beta 42$ and tau) and cognition is still unclear.

- CSF markers. While dysregulation of a $\beta 42$ and tau are key characteristics of AD many other molecular processes are involved as well. We will test a number of emerging CSF biomarkers related to pathways dysregulated in AD including complement factors $\mathrm{C} 3 \mathrm{a}, \mathrm{C} 5 \mathrm{a}$ and the membrane attack complex (MAC), the amyloid binding protein serum Amyloid-P (SAP), and the neuronal injury marker heart fatty acid binding protein (hFABP).

As emerging risk factors we will test social inactivity [27], cognitive and physical inactivity [28-30], alcohol consumption [31], smoking [28, 29] and sleep deprivation [28, $29,32,33]$.

We will address the following research questions:

1. What is the relationship of established AD CSF biomarkers ( $a \beta 42$ and tau) with performance on memory domains and specific non-memory domains?

2. What is the relationship between lifestyle factors and established AD biomarkers? Do lifestyle factors influence the association between established AD biomarkers and conversion to AD-type dementia in individuals with $\mathrm{MCI}$ ? 
3. What is the relationship between odour identification and established AD CSF biomarkers, and cognitive decline? Does APOE-e4 carriership influence these associations?

4. What is the relationship between emerging CSF biomarkers and established AD CSF biomarkers, and cognition. Does APOE-e4 carriership influence these associations?

\section{Outline of the thesis}

The outline of the thesis is shown in figure 1.

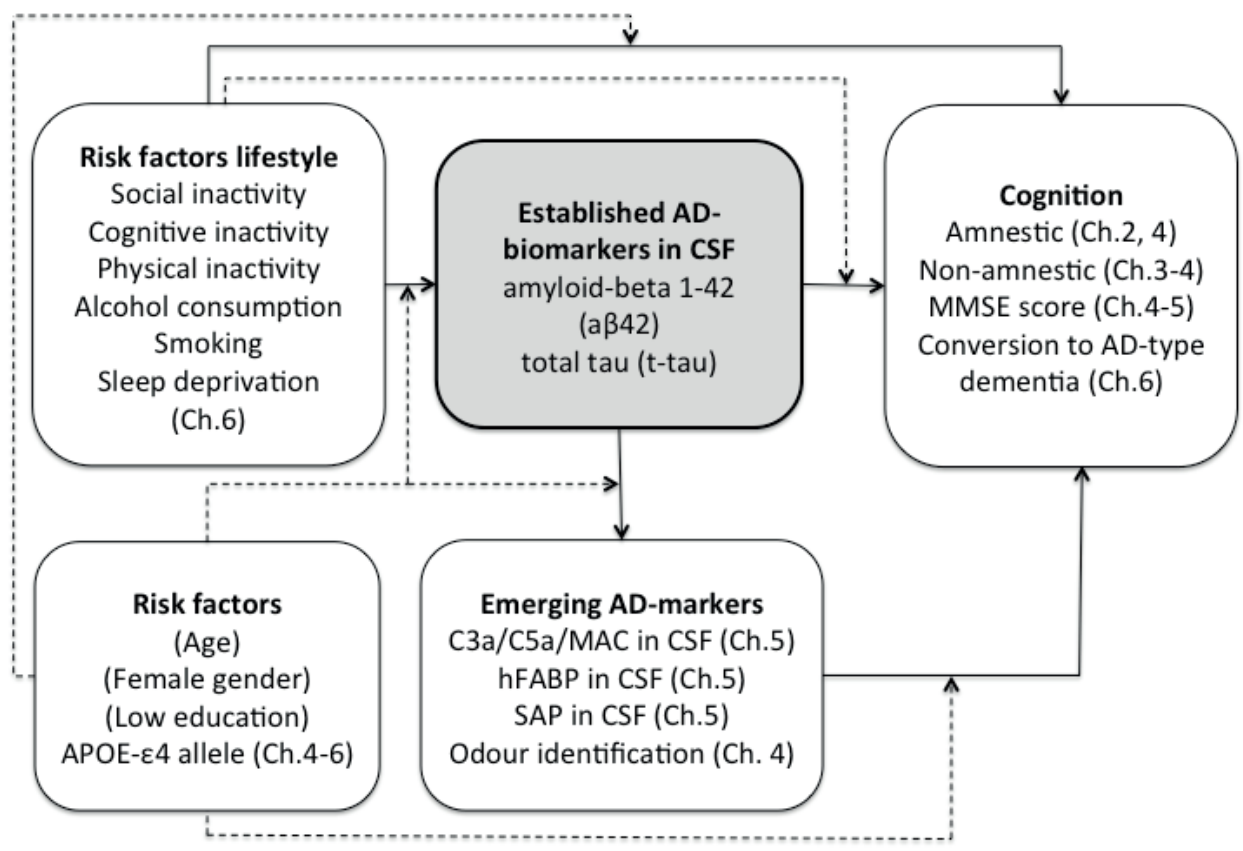

Figure 1. Thesis outline

Chapter 2 describes the association of established CSF markers (a $\beta 42$ and tau) with performance on tests assessing different memory domains at baseline and at followup. Paper-and-pencil as well as computerized memory tests were used for the analysis. Individuals were recruited from the memory clinic based European EDAR study. 
Chapter 3 describes the association of established CSF markers for AD and domain specific cognitive decline over time in individuals with $\mathrm{MCl}$. Individuals were recruited from memory clinics from the DESCRIPA study.

Chapter 4 describes the association of established CSF markers with performance on the Brief Odour Identification test (B-SIT) at baseline, and the association of the B-SIT with performance on several cognitive domains at baseline and over time in individuals from the EDAR study.

Chapter 5 describes the association between emerging CSF markers, such as C3a, C5a, MAC, hFABP and SAP, and a 342 and tau concentrations at baseline and over time. In addition, the association between these emerging CSF biomarkers and MMSE score at baseline and over time is examined. Furthermore, it is investigated whether APOE-e4 carriership influences these associations. This study was performed with participants of the EDAR study.

Chapter 6 describes the association between lifestyle factors and established CSF AD markers and hippocampal volume in individuals with subjective cognitive decline (SCD) and mild cognitive impairment ( $\mathrm{MCl})$. In addition, the effect of lifestyle factors on developing AD-type dementia in individuals with $\mathrm{MCl}$ is examined. Individuals were recruited for The KUOPIO L-MCI study (a population-based study) and from the memory-clinic based DESCRIPA study.

Chapter 7 - Future biomarker development, in this chapter an overview is provided of CSF and blood samples collected for the European study BIOMARKAPD funded by Joint Programming Initiative Neurodegenerative Diseases (JPND). The biobank was set-up to support validation of emerging biomarkers for the diagnosis of neurodegenerative disorders. Samples are accessible for researchers in the field of dementia and other neurodegenerative diseases.

Chapter 8 describes the main results of the present thesis and provides a general discussion. 


\section{REFERENCES}

[1] Prince M, Bryce R, Albanese E, Wimo A, Ribeiro W, Ferri CP (2013) The global prevalence of dementia: a systematic review and metaanalysis. Alzheimers Dement 9, 63-75 e62.

[2] Sperling RA, Jack CR, Jr., Aisen PS (2011) Testing the right target and right drug at the right stage. Sci Transl Med 3, $111 \mathrm{~cm} 133$.

[3] Fagan AM, Xiong C, Jasielec MS, Bateman RJ, Goate AM, Benzinger TL, Ghetti B, Martins RN, Masters CL, Mayeux R, Ringman JM, Rossor MN, Salloway S, Schofield PR, Sperling RA, Marcus D, Cairns NJ, Buckles VD, Ladenson JH, Morris JC, Holtzman DM, Dominantly Inherited Alzheimer N (2014) Longitudinal change in CSF biomarkers in autosomal-dominant Alzheimer's disease. Sci Transl Med 6, 226ra230.

[4] Jack CR, Jr., Holtzman DM (2013) Biomarker modeling of Alzheimer's disease. Neuron 80, 1347-1358.

[5] Jansen WJ, Ossenkoppele R, Knol DL, Tijms BM, Scheltens P, Verhey FR, Visser PJ, Amyloid Biomarker Study Group (2015) Prevalence of cerebral amyloid pathology in persons without dementia: a meta-analysis. JAMA 313, 1924-1938.

[6] McKhann G, Drachman D, Folstein M, Katzman R, Price D, Stadlan EM (1984) Clinical diagnosis of Alzheimer's disease: report of the NINCDS-ADRDA Work Group under the auspices of Department of Health and Human Services Task Force on Alzheimer's Disease. Neurology 34, 939-944.

[7] Farias ST, Mungas D, Reed BR, Harvey D, DeCarli C (2009) Progression of mild cognitive impairment to dementia in clinic- vs community-based cohorts. Arch Neurol 66, 1151-1157.

[8] Petersen RC, Smith GE, Waring SC, Ivnik RJ, Tangalos EG, Kokmen E (1999) Mild cognitive impairment: clinical characterization and outcome. Arch Neurol 56, 303-308.

[9] Jessen F, Wiese B, Bachmann C, Eifflaender-Gorfer S, Haller F, Kolsch H, Luck T, Mosch E, van den Bussche H, Wagner M, Wollny A, Zimmermann T, Pentzek M, Riedel-Heller SG, Romberg HP, Weyerer S, Kaduszkiewicz H, Maier W, Bickel H, German Study on Aging C, Dementia in Primary Care Patients Study G (2010) Prediction of dementia by subjective memory impairment: effects of severity and temporal association with cognitive impairment. Arch Gen Psychiatry 67, 414-422.

[10] Jessen F, Amariglio RE, van Boxtel M, Breteler M, Ceccaldi M, Chetelat G, Dubois B, Dufouil C, Ellis KA, van der Flier WM, Glodzik L, van Harten AC, de Leon MJ, McHugh P, Mielke MM, Molinuevo JL, Mosconi L, Osorio RS, Perrotin A, Petersen RC, Rabin LA, Rami L, Reisberg B, Rentz DM, Sachdev PS, de la Sayette V, Saykin AJ, Scheltens P, Shulman MB, Slavin MJ, Sperling RA, Stewart R, Uspenskaya O, Vellas B, Visser PJ, Wagner M, Subjective Cognitive Decline Initiative Working G (2014) A conceptual framework for research on subjective cognitive decline in preclinical Alzheimer's disease. Alzheimers Dement 10, 844-852.

[11] Blennow K, Hampel H, Weiner M, Zetterberg H (2010) Cerebrospinal fluid and plasma biomarkers in Alzheimer disease. Nat Rev Neurol 6, 131-144. 
[12] Albert MS, DeKosky ST, Dickson D, Dubois B, Feldman HH, Fox NC, Gamst A, Holtzman DM, Jagust WJ, Petersen RC, Snyder PJ, Carrillo MC, Thies B, Phelps CH (2011) The diagnosis of mild cognitive impairment due to Alzheimer's disease: recommendations from the National Institute on Aging-Alzheimer's Association workgroups on diagnostic guidelines for Alzheimer's disease. Alzheimers Dement 7, 270-279.

[13] McKhann GM, Knopman DS, Chertkow H, Hyman BT, Jack CR, Jr., Kawas CH, Klunk WE, Koroshetz WJ, Manly JJ, Mayeux R, Mohs RC, Morris JC, Rossor MN, Scheltens P, Carrillo MC, Thies B, Weintraub S, Phelps CH (2011) The diagnosis of dementia due to Alzheimer's disease: recommendations from the National Institute on Aging-Alzheimer's Association workgroups on diagnostic guidelines for Alzheimer's disease. Alzheimers Dement 7, 263-269.

[14] Sperling RA, Aisen PS, Beckett LA, Bennett DA, Craft S, Fagan AM, Iwatsubo T, Jack CR, Jr., Kaye J, Montine TJ, Park DC, Reiman EM, Rowe CC, Siemers E, Stern Y, Yaffe K, Carrillo MC, Thies B, Morrison-Bogorad M, Wagster MV, Phelps CH (2011) Toward defining the preclinical stages of Alzheimer's disease: recommendations from the National Institute on Aging-Alzheimer's Association workgroups on diagnostic guidelines for Alzheimer's disease. Alzheimers Dement 7, 280-292.

[15] Hamel R, Kohler S, Sistermans N, Koene T, Pijnenburg Y, van der Flier W, Scheltens P, Aalten P, Verhey F, Visser PJ, Ramakers I (2015) The trajectory of cognitive decline in the pre-dementia phase in memory clinic visitors: findings from the 4C-MCl study. Psychol Med 45, 1509-1519.

[16] Tabert MH, Manly JJ, Liu X, Pelton GH, Rosenblum S, Jacobs M, Zamora D, Goodkind M, Bell K, Stern Y, Devanand DP (2006) Neuropsychological prediction of conversion to Alzheimer disease in patients with mild cognitive impairment. Arch Gen Psychiatry 63, 916-924.

[17] Morgan CD, Nordin S, Murphy C (1995) Odor identification as an early marker for Alzheimer's disease: impact of lexical functioning and detection sensitivity. J Clin Exp Neuropsychol 17, 793-803.

[18] Velayudhan L (2015) Smell identification function and Alzheimer's disease: a selective review. Curr Opin Psychiatry 28, 173-179.

[19] Matthews F, Brayne C, Medical Research Council Cognitive F, Ageing Study I (2005) The incidence of dementia in England and Wales: findings from the five identical sites of the MRC CFA Study. PLoS Med 2, e193.

[20] Evans DA, Hebert LE, Beckett LA, Scherr PA, Albert MS, Chown MJ, Pilgrim DM, Taylor JO (1997) Education and other measures of socioeconomic status and risk of incident Alzheimer disease in a defined population of older persons. Arch Neurol 54, 1399-1405.

[21] Ott A, Breteler MM, van Harskamp F, Claus JJ, van der Cammen TJ, Grobbee DE, Hofman A (1995) Prevalence of Alzheimer's disease and vascular dementia: association with education. The Rotterdam study. BMJ 310, 970-973.

[22] Brookmeyer R, Gray S, Kawas C (1998) Projections of Alzheimer's disease in the United States and the public health impact of delaying disease onset. Am J Public Health 88, 1337-1342. 
[23] Suri S, Heise V, Trachtenberg AJ, Mackay CE (2013) The forgotten APOE allele: a review of the evidence and suggested mechanisms for the protective effect of APOE varepsilon2. Neurosci Biobehav Rev 37, 2878-2886.

[24] Morris JC, Roe CM, Xiong C, Fagan AM, Goate AM, Holtzman DM, Mintun MA (2010) APOE predicts amyloid-beta but not tau Alzheimer pathology in cognitively normal aging. Ann Neurol 67, 122-131.

[25] Farrer LA, Cupples LA, Haines JL, Hyman B, Kukull WA, Mayeux R, Myers RH, Pericak-Vance MA, Risch N, van Duijn CM (1997) Effects of age, sex, and ethnicity on the association between apolipoprotein E genotype and Alzheimer disease. A meta-analysis. APOE and Alzheimer Disease Meta Analysis Consortium. JAMA 278, 1349-1356.

[26] Michaelson DM (2014) APOE epsilon4: the most prevalent yet understudied risk factor for Alzheimer's disease. Alzheimers Dement 10, 861-868.

[27] Carlson MC, Helms MJ, Steffens DC, Burke JR, Potter GG, Plassman BL (2008) Midlife activity predicts risk of dementia in older male twin pairs. Alzheimers Dement 4, 324-331.

[28] Barnes DE, Yaffe K (2011) The projected effect of risk factor reduction on Alzheimer's disease prevalence. Lancet Neurol 10, 819-828.

[29] Norton S, Matthews FE, Barnes DE, Yaffe K, Brayne C (2014) Potential for primary prevention of Alzheimer's disease: an analysis of population-based data. Lancet Neurol 13, 788-794.

[30] Wilson RS, Scherr PA, Schneider JA, Tang Y, Bennett DA (2007) Relation of cognitive activity to risk of developing Alzheimer disease. Neurology 69, 1911-1920.

[31] Fratiglioni L, Winblad B, von Strauss E (2007) Prevention of Alzheimer's disease and dementia. Major findings from the Kungsholmen Project. Physiol Behav 92, 98-104.

[32] Osorio RS, Pirraglia E, Aguera-Ortiz LF, During EH, Sacks H, Ayappa I, Walsleben J, Mooney A, Hussain A, Glodzik L, Frangione B, Martinez-Martin P, de Leon MJ (2011) Greater risk of Alzheimer's disease in older adults with insomnia. J Am Geriatr Soc 59, 559-562.

[33] Yaffe K, Laffan AM, Harrison SL, Redline S, Spira AP, Ensrud KE, Ancoli-Israel S, Stone KL (2011) Sleep-disordered breathing, hypoxia, and risk of mild cognitive impairment and dementia in older women. JAMA 306, 613-619. 



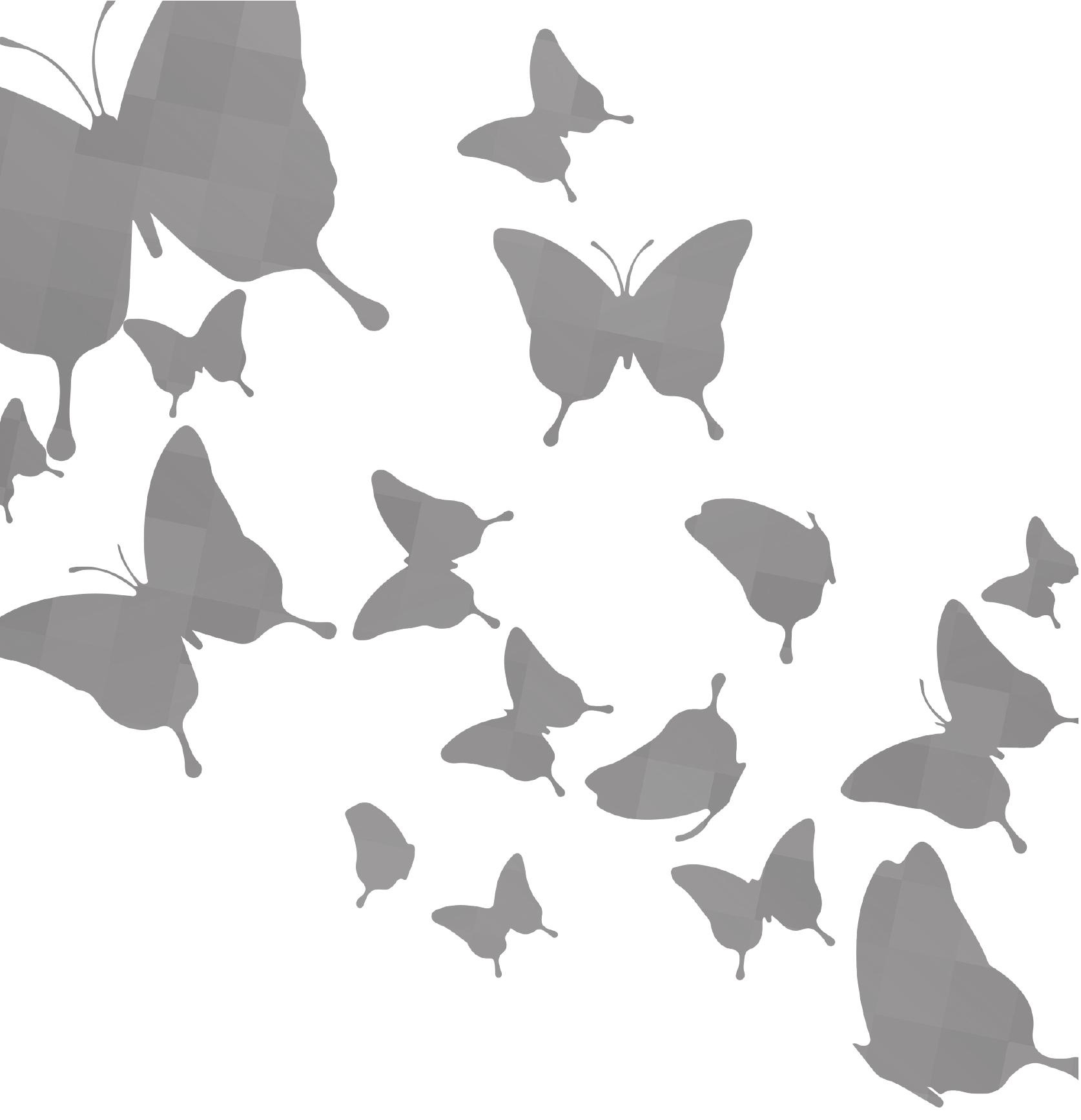




\section{Memory correlates of Alzheimer's disease cerebrospinal fluid markers: a longitudinal cohort study}

Babette L.R. Reijs

Inez H.G.B. Ramakers

Sebastian Köhler

Charlotte E. Teunissen

Marleen Koel-Simmelink

Pradeep J. Nathan

Magda Tsolaki

Lars-Olof Wahlund

Gunhild Waldemar

Lucrezia Hausner

Rik Vandenberghe

Peter Johannsen

Andrew Blackwell

Hugo Vanderstichele

Frans R.J. Verhey

Pieter Jelle Visser

Published in: Journal of Alzheimer's

Disease (JAD) 2017;60:1119-1128.

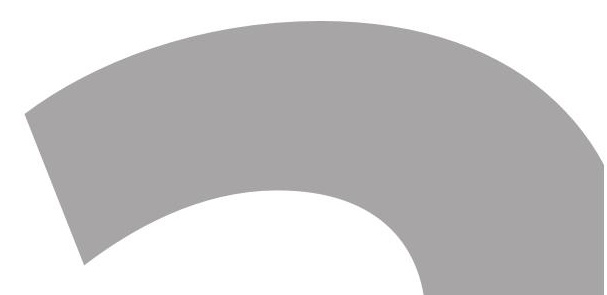




\section{ABSTRACT}

Background: Performance on episodic, semantic, and working memory tests is impaired in Alzheimer's disease (AD)-type dementia, but it is unclear which type of memory test is most strongly associated with early AD biomarkers in cerebrospinal fluid (CSF), and most useful for monitoring disease progression.

Objective: To examine the association between beta amyloid 1-42 (aß42) and tau in CSF with performance on different memory domains at baseline, and how these CSF markers are related with memory decline.

Methods: We included 263 individuals with normal cognition, mild cognitive impairment $(\mathrm{MCl}), A D$-type dementia and non- $A D$ dementia from the European EDAR study. Assessment included CSF a 342 and t-tau analyses with INNO-BIA AlzBio3 Luminex assay, the CERAD wordlist learning and delayed recall, animal fluency test, and the CANTAB Paired Associates Learning (PAL) and Spatial Working Memory (SWM) tasks. Follow-up assessments were performed within 3 years after baseline.

Results: At baseline, decreased CSF a $\beta 42$ correlated most strongly with the PAL total errors adjusted and the wordlist delayed recall and increased CSF t-tau with the wordlist delayed recall. Over time, decreased CSF a 342 was associated with decline on the wordlist learning, whereas increased CSF t-tau were associated with decline in scores on the wordlist learning, wordlist delayed recall and animal fluency. Associations were independent of baseline diagnosis.

Conclusion: Tests assessing episodic verbal and visuospatial memory are most useful for detection of $A D$ pathology. Tests for episodic verbal memory and semantic memory are most useful for tracking memory decline. 


\section{INTRODUCTION}

Alzheimer's disease (AD) is the most common cause of dementia. Due to increased life expectancy, the number of dementia cases is expected to grow and this will pose medical and socioeconomic problems [1]. Early detection of AD pathology is important to facilitate care and is a necessity for when effective disease-modifying medications become available. Memory dysfunction is an early and the most prominent clinical sign of $A D$ [2], which makes memory assessment useful to detect $A D$ at an early symptomatic stage but also to track disease progression. Memory domains that are known to be impaired in AD-type dementia include episodic memory [3], in which a specific event is consciously remembered, semantic memory, in which conceptual knowledge of facts is stored [4], and working memory, in which recently stored memory is manipulated [5, 6]. In addition, the modality in which memory is presented may be impaired differentially in AD. Research shows that verbal and visual/spatial information are processed in different brain regions [7-9].

Key characteristics of AD pathology are beta amyloid 1-42 (aß42) plaques and tau neurofibrillary tangles accumulating in the brain $[10,11]$. These abnormalities already occur decades before the clinical onset of AD-type dementia [12]. Previous research found that tau pathology markers measured in cerebrospinal fluid (CSF) were associated with episodic memory impairment [11, 13, 14], but information is limited whether the association is similar across different memory domains. A better understanding of the relation between CSF markers with impairment in the different memory domains may aid to select memory tests that are most sensitive to the early identification of individuals with $A D$ pathology.

In this study, we examined the relation between AD-related amyloid and tau pathology in CSF and performance on tests for episodic, semantic and working memory. In addition, we investigated how AD pathology was associated with decline over time on these tests. Since tau has been more closely associated with cognition than a $\beta 42$ $[13,15]$, supporting the assumption that a $\beta 42$ is abnormal before the increase in tau concentrations, we expect to find a stronger association of tau with memory tests than with a $\beta 42$. Furthermore, since episodic memory is often first impaired in AD [16, 17], we expect to find the strongest associations between CSF markers and episodic memory. To examine whether the association between $A D$ markers and memory performance is different along the $A D$ continuum, we tests whether the relation was dependent on diagnostic group. 


\section{MATERIALS AND METHODS}

\section{Individuals}

We selected 263 individuals from the European study "Beta amyloid oligomers in the early diagnosis of $A D$ and as marker for treatment response" (acronym: EDAR) based on the availability of both CSF and memory test performance results at baseline. Individuals were recruited from seven memory clinics across Europe between 2008 and 2010 and represented individuals with normal cognition $(n=46)$, mild cognitive impairment $(M C l)$ $(n=73)$, AD-type dementia ( $n=80)$, non-AD dementia ( $n=47$, FTD $(n=25)$, DLB $(n=11)$, $\operatorname{VaD}(n=10)$ and Posterior Cortical Atrophy $(n=1))$ and 17 unclassified individuals without dementia (see below). Follow-up assessments were performed in 120 individuals within three years after baseline.

Individuals with normal cognition were recruited among patients attending the memory clinic $(n=20)$ or from other settings (partners from patients or via advertisements, $n=26)$. Inclusion criteria for individuals with normal cognition were: age above 40 years, a Mini Mental State Examination score (MMSE [18]) above the $10^{\text {th }}$ percentile according to age and education adjusted local norms (unpublished data from Maastricht Aging Study), and no cognitive impairment on neuropsychological tests (see below for a definition of cognitive impairment). Individuals with normal cognition from outside the memory clinic did not differ from individuals with normal cognition from the memory clinic with respect to age, gender, educational level, MMSE score, CSF markers and neuropsychological test scores. Inclusion criteria for individuals with $\mathrm{MCl}$ were: memory clinic referral for the evaluation of cognitive complaints, age above 60 years, a MMSEscore above 19, one or more cognitive impairments (see below) on neuropsychological tests according to Petersen's criteria [19], and absence of a clinical diagnosis of dementia. Inclusion criteria for individuals with dementia were: age above 40 years, a MMSE-score above 18 and a clinical diagnosis of probable or possible AD according to the NINCDSADRDA criteria [20], fronto-temporal dementia (FTD) [21], vascular dementia (VaD) according to the NINDS-AIREN criteria [22] or Lewy body dementia (DLB) [23]. Exclusion criteria for all individuals were contra-indications for lumbar puncture or any disorder probably related to cognitive impairment other than neurodegeneration.

A total of 17 individuals without dementia could not be classified to a diagnostic subgroup because they had no cognitive complaints but showed cognitive impairment on one or more cognitive tests with a z-score below minus two (ten individuals) or because of missing test scores (seven individuals). They were included in the total group analyses only. All individuals provided informed consent and the medical ethics committee at each centre approved the study. 
Follow-up data was available for 120 individuals, representing 26 individuals with normal cognition, 43 with $\mathrm{MCl}, 42$ with AD-type dementia at baseline, and 9 individuals without dementia who could not be classified to a diagnostic group. Individuals with non-AD dementia $(n=6)$ were excluded in the longitudinal analyses due to the small sample size.

\section{Definition cognitive impairment}

Cognitive impairment was defined as a z-score corrected for age, gender and education below 1.5 (or above 1.5 for timed tasks) of a reference population on at least one of the following tests: the one-minute animal fluency test [24], wordlist learning and delayed recall of the Consortium to Establish a Registry for Alzheimer's Disease neuropsychological battery (CERAD) [25], Trail Making Test (TMT) part A and B [24], and figures copy test of the CERAD [25]. Z-scores for the CERAD learning and delayed recall, TMT A and B and copy figures were calculated according to the CERAD-Plus norms [25, 26]. For the animal fluency test, $z$-scores were calculated according to the norms by van der Elst et al. [27].

\section{Baseline and follow-up assessment}

Baseline assessments included clinical history, physical examination, neuroimaging, routine laboratory tests for blood and CSF, the MMSE and the Clinical Dementia Rating scale (CDR [28]), Functional Assessment Questionnaire (FAQ [29]) and a neuropsychological examination consisting of standard psychometric paper-andpencil tests and two Cambridge Neuropsychological Test Automated Battery (CANTAB) tests. Follow-up assessments were similar to baseline, excluding laboratory tests and neuroimaging. They were performed once or twice within three years after baseline at individually varying time points. In the analysis follow-up visits were categorized in sixmonths intervals (6 months, 12 months, up to 36 months). Follow-up was not planned for control individuals and for individuals with a non-AD type dementia in the original study plan, but a selection of centres performed follow-up in these individuals.

\section{Memory tests}

Performances on a variety of memory domains were measured using paper-and-pencil tests as well as computerized tests of the CANTAB.

The paper-and-pencil based verbal learning task of the CERAD [25], is a verbal episodic memory and learning task in which a list of 10 unrelated words were visually presented and repeated over three trials. Outcome measures were the total number of words recalled across three trials with a maximum of 30 (i.e. wordlist learning) and the total 
number of words recalled after a ten-minutes interval (i.e. wordlist delayed recall) and recognized (i.e. wordlist recognition). The animal fluency [27] is a categorical semantic memory task for which the outcome measure is the number of animal names generated in one-minute.

The Paired Associates Learning (PAL) of the computerized CANTAB [30,31], is a visuospatial episodic memory task in which individuals were asked to pair a token with its location as follows. One or more white boxes revealed a unique token. Subsequently, a target token was presented in the centre of the screen and the individual was asked to click on its corresponding box location. Task difficulty gradually increased from two to eight tokens and box locations. Outcome measure was the total number of errors made across all difficulty stages adjusted for the stages not attempted due to previous failure, which has been found a promising marker for early $\operatorname{AD}[30,32]$

In the Spatial Working Memory (SWM) task of the CANTAB [33, 34] individuals had to search for one blue token in a number of boxes. The token appeared in a new location each time and the individual was asked not to return to a box where a token has already been found. The latter is called a between-search error and was the outcome measure. Task difficulty gradually increased from three to eight boxes.

\section{CSF and DNA collection, storage and analysis}

CSF was collected via a lumbar puncture in $10 \mathrm{~mL}$ polypropylene tubes, centrifuged at 4 degrees at $2000 \times g$ and stored at $-80^{\circ} \mathrm{C}$ within one hour after collection. $A \beta 42$ and total tau (t-tau) concentrations were measured with INNO-BIA AlzBio3 Luminex assay (Fujirebio, formerly Innogenetics, Gent, Belgium). All CSF analyses were performed at the end of the study at the VU University Medical Centre (VUmc) in Amsterdam in the Netherlands using the same batch of reagents. CSF concentrations below 389 (pg/ml) for a 342 and above 98 (pg/ml) for t-tau were considered abnormal according to local cut-off values for this assay at the VUmc [35]. Investigators that collected the clinical data were blinded to the CSF results. APOE genotype was determined by Polymerase Chain Reaction (PCR) of genomic DNA extracted from EDTA anticoagulated blood.

\section{Statistical analyses}

Data was analysed with IBM SPSS statistics version 22. Baseline characteristics were examined with one-way ANOVAs for continuous variables and $X^{2}$-tests for categorical variables. The relationship between CSF concentrations at baseline (predictor) and memory performance at baseline and memory decline over time (outcome) were analysed by linear mixed models analyses corrected for age, gender, and education and 
with random effects for individual intercepts within centre (nested design). If required for a better fit according to likelihood ratio tests, random slopes were also included to allow for heterogeneity in individual trajectories over time. An interaction effect of diagnosis at baseline was included in a second model to examine a possible moderator effect. For the main analyses, raw memory scores were used in order to preserve the initial scale for better interpretability. To allow for direct comparison between tests, i.e. which memory test was most strongly associated with CSF markers, z-scores were calculated for each test based on the mean and standard deviation of the total group multiplied by 100 . Furthermore, in individuals without dementia (i.e. normal cognition and $\mathrm{MCl}$ group) we tested the association of low memory scores (below $10^{\text {th }}$ percentile for verbal memory tests and above $90^{\text {th }}$ percentile for CANTAB tests based on the normal cognition group and amyloid pathology (score below 389), tau pathology (score above 98) and combined pathology (both abnormal versus at least one normal) with logistic regression. A $p$-value of $<0.05$ for two-sided tests was considered statistically significant.

\section{RESULTS}

Baseline characteristics for the total group and the diagnostic subgroups are presented in Table 1. Individuals were on average old 68 years old, had 10 years of education and the majority was male (56\%). Individuals with $\mathrm{MCl}$ and $\mathrm{AD}$-type dementia were older and less educated than individuals with normal cognition. Females were more common in the $\mathrm{MCl}$ group than in the normal cognition and non-AD type dementia group. As expected, individuals with AD-type dementia scored poorer on the MMSE, CDR, FAQ, and memory tests than individuals with $\mathrm{MCl}$ and normal cognition; and individuals with $\mathrm{MCl}$ or non-AD dementia scored poorer on these measures than individuals with normal cognition. Differences in CSF a $\beta 42$ and $\mathrm{t}$-tau concentrations were as expected (table 1). APOE genotyping was available for 237 individuals ( $90 \%)$. The number of carriers of one or more APOE $\varepsilon 4$ alleles was higher in the AD-type dementia (58\%) and $\mathrm{MCI}(52 \%)$ group than in the non-AD dementia group (30\%), but it did not differ from the normal cognition group (43\%).

The average follow-up interval was $1.35(\mathrm{SD}=0.54)$ years. Individuals with follow-up in the total group and in the subgroups did not differ on age, gender, education and MMSE score from individuals with only baseline data. Twenty-six percent of individuals with $\mathrm{MCl}$ at baseline converted to dementia (i.e. 32 non-converters, 10 to AD-type dementia, 1 to vascular dementia). 


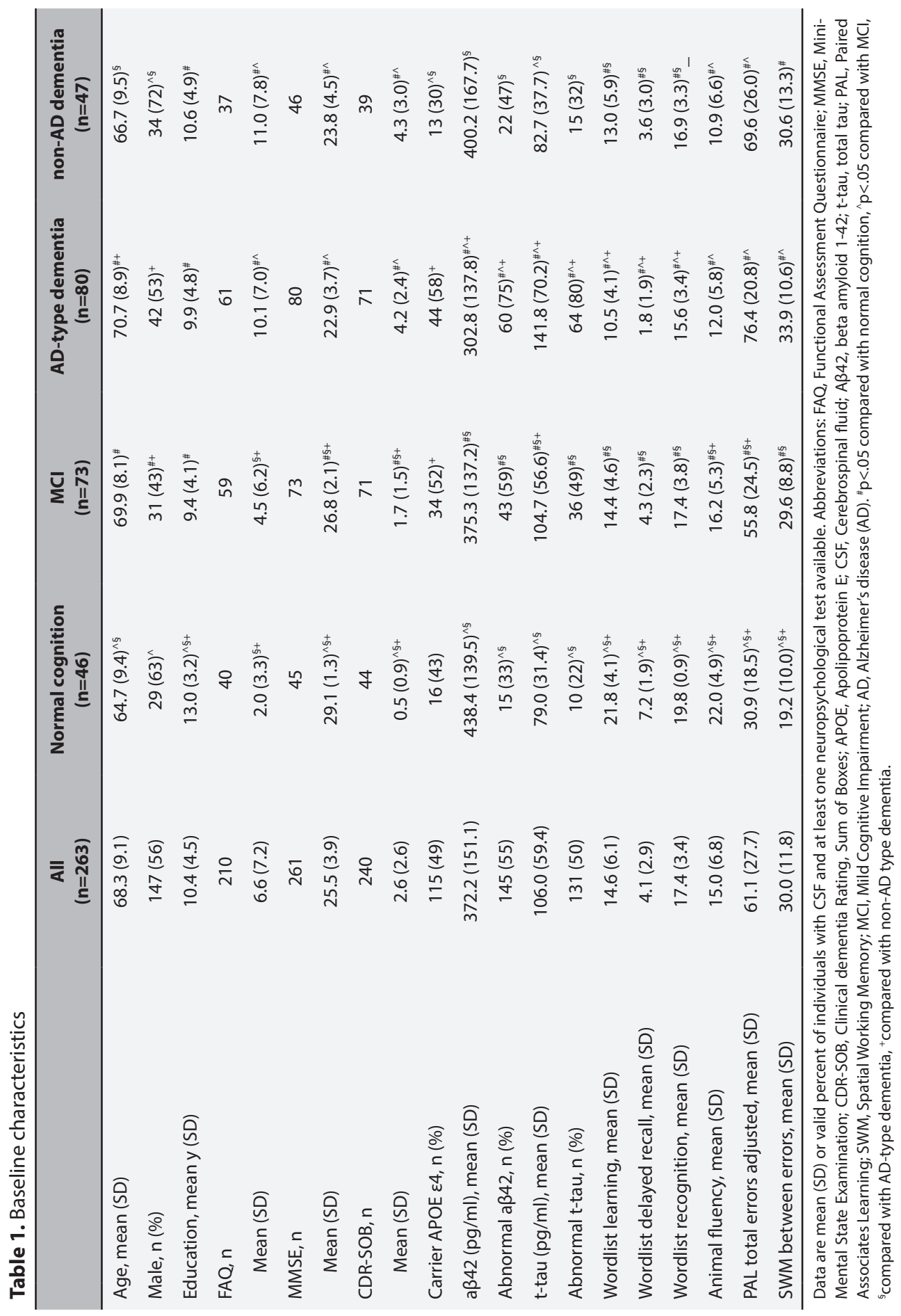




\section{CSF markers and memory performance at baseline}

In the total group, decreased CSF a 342 and increased CSF t-tau concentrations were associated with poorer performances on the wordlist learning, wordlist delayed recall, wordlist recognition and the PAL total errors adjusted (table 2). Decreased CSF a 342 concentrations were also associated with poorer performance on the SWM between errors. The association between CSF a 342 and memory performance was strongest for the PAL total errors adjusted and the wordlist delayed recall (z-scores table 2, Figure $1)$, whereas for CSF t-tau the association was strongest for the wordlist delayed recall ( $z$-scores table 2, Figure 1). The association between a 342 and memory performance was independent of t-tau concentrations and vice versa, and independent of diagnostic subgroup.

Post hoc analyses revealed that in individuals without dementia, the wordlist immediate and delayed recall were predictive of abnormal amyloid and tau concentrations (table 3).

\section{CSF markers and memory decline over time}

In the total group, lower CSF a $\beta 42$ concentrations at baseline were associated with faster decline in performance over time on the wordlist learning, whereas higher CSF $\mathrm{t}$-tau concentrations were associated with faster decline in performance on the wordlist learning, wordlist delayed recall and animal fluency (table 4). The strength of association between CSF t-tau and memory decline was similar between the wordlist learning, wordlist delayed recall and animal fluency (z-scores table 4).

The association between baseline CSF concentrations and decline in memory performances over time did not differ between diagnostic groups, except for the SWM between errors. For this test, decreased CSF a 342 and increased t-tau concentrations were more strongly associated with decline in performance in the $\mathrm{MCl}$ group than in the AD-type dementia group (slope difference raw scores: $a \beta 42 \beta=-0.019, p=0.022$; $t$-tau $\beta=0.073, p=0.002$ ). 


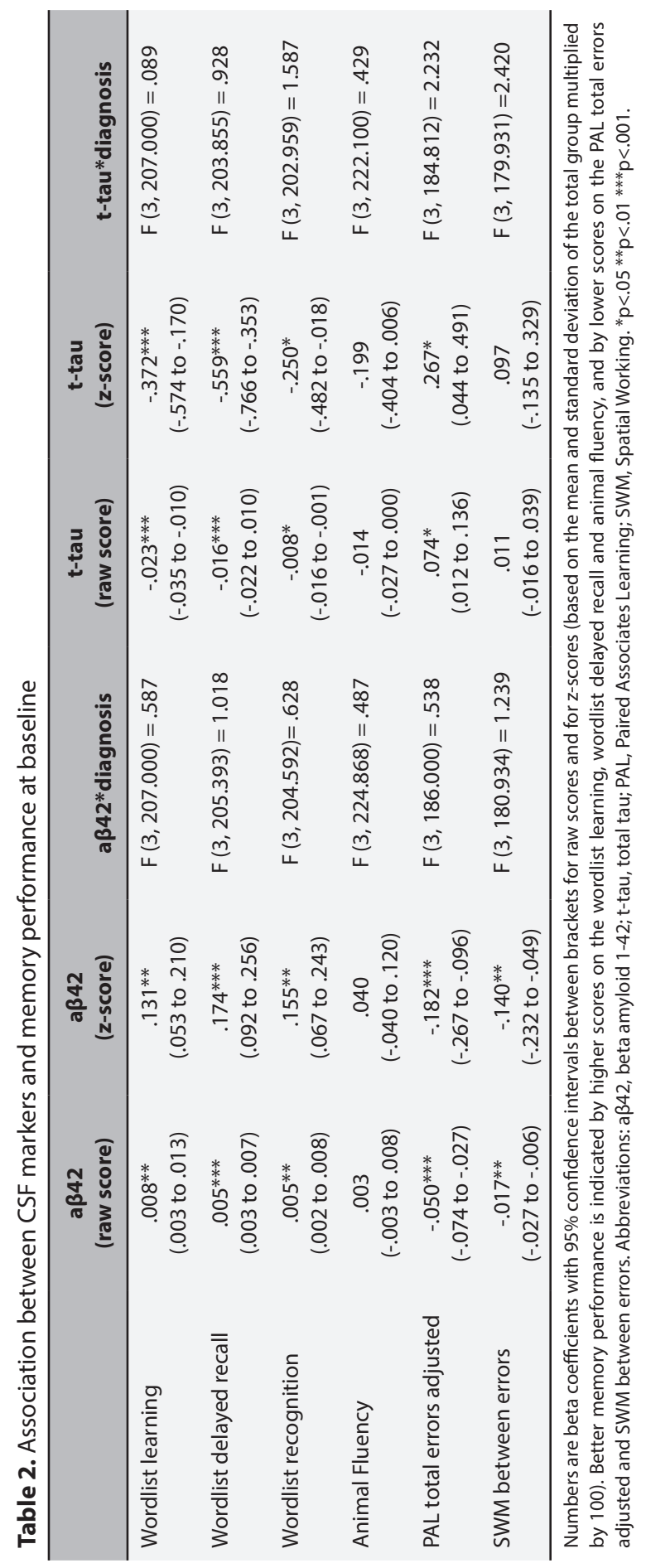



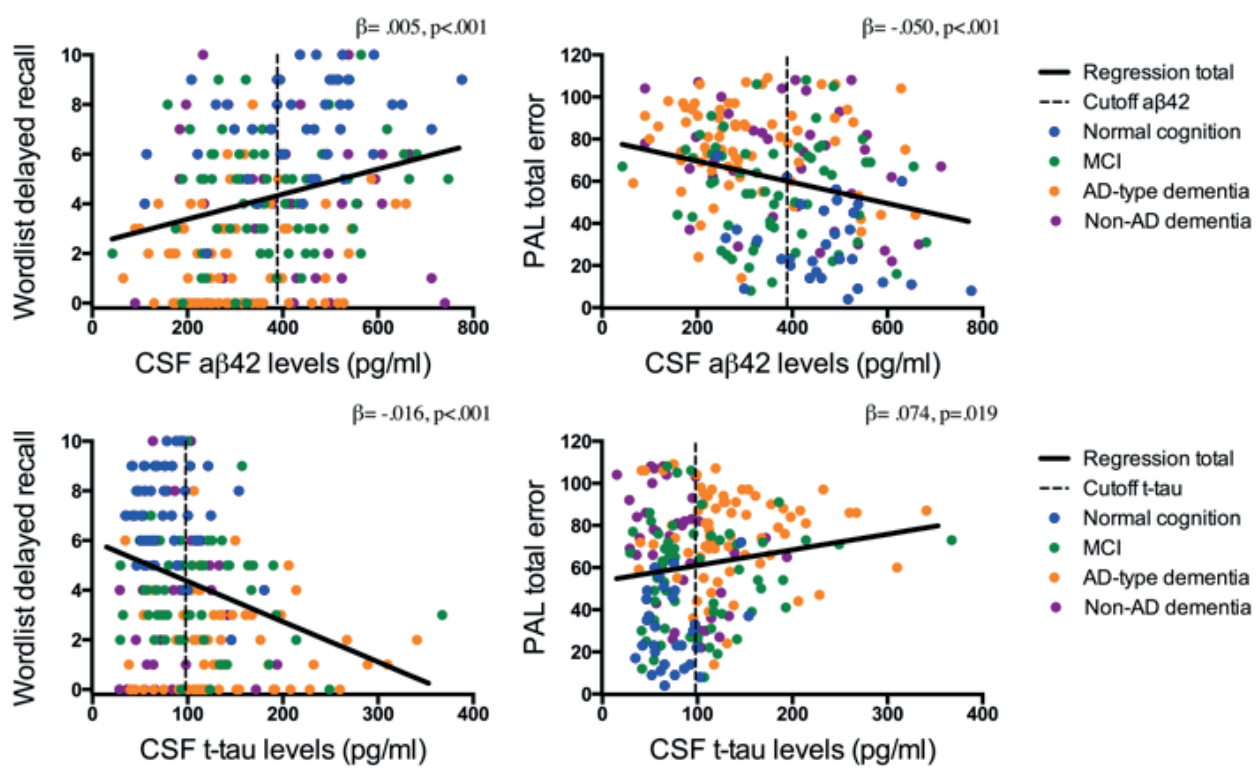

Figure 1. Associations at baseline between CSF markers and wordlist delayed recall and PAL total errors adjusted

Figure displays count of individuals with normal cognition (blue), $\mathrm{MCl}$ (Green), AD-type dementia (Orange) and non-AD dementia (purple), cut-off lines for a $\beta 42$ and t-tau, and regression lines corrected for age, education, gender and centre.

Table 3. Association of low memory scores with presence of CSF pathology at baseline in individuals without dementia

\begin{tabular}{|c|c|c|c|c|}
\hline & $\mathbf{n}$ & aß42+ & t-tau+ & a $\beta 42+$ and t-tau+ \\
\hline Wordlist learning & 110 & $\begin{array}{c}2.24^{*} \\
(1.05 \text { to } 4.81)\end{array}$ & $\begin{array}{c}2.96^{* *} \\
(1.32 \text { to } 6.64)\end{array}$ & $\begin{array}{c}2.98^{*} \\
(1.20 \text { to } 7.38)\end{array}$ \\
\hline Wordlist delayed recall & 110 & $\begin{array}{c}2.18 \\
(.97 \text { to } 4.92)\end{array}$ & $\begin{array}{c}2.36^{*} \\
(1.04 \text { to } 5.38)\end{array}$ & $\begin{array}{c}3.35^{* *} \\
(1.37 \text { to } 8.19)\end{array}$ \\
\hline Wordlist recognition & 111 & $\begin{array}{c}1.18 \\
\text { (.51 to } 2.70)\end{array}$ & $\begin{array}{c}1.11 \\
(.47 \text { to } .260)\end{array}$ & $\begin{array}{c}1.23 \\
(.49 \text { to } 3.10)\end{array}$ \\
\hline Animal Fluency & 116 & $\begin{array}{c}.78 \\
(.34 \text { to } 1.76)\end{array}$ & $\begin{array}{c}1.59 \\
(.70 \text { to } 3.63)\end{array}$ & $\begin{array}{c}1.36 \\
(.56 \text { to } 3.34)\end{array}$ \\
\hline PAL total errors adjusted & 89 & $\begin{array}{c}1.60 \\
\text { (.68 to } 3.77)\end{array}$ & $\begin{array}{c}1.18 \\
\text { (.49 to } 2.88)\end{array}$ & $\begin{array}{c}1.60 \\
(.62 \text { to } 4.19)\end{array}$ \\
\hline SWM between errors & 89 & $\begin{array}{c}1.32 \\
\text { (.48 to } 3.64)\end{array}$ & $\begin{array}{c}1.49 \\
(.53 \text { to } 4.20)\end{array}$ & $\begin{array}{c}1.03 \\
(.33 \text { to } 3.27)\end{array}$ \\
\hline
\end{tabular}

Numbers are odds ratios with $95 \%$ confidence intervals between brackets. A $342+$ is defined as an abnormal score below 389 and tau+ as an abnormal score above 98. For a $342+$ and t-tau+ both biomarkers are abnormal (versus at least one normal). For the memory tests, impairment is defined as a score below the $10^{\text {th }}$ percentile for verbal tasks or above the $90^{\text {th }}$ percentile for CANTAB tasks based on the normal cognition group. Abbreviations: a 342 , beta amyloid 1-42; t-tau, total tau. ${ }^{*} \mathrm{p}<.05{ }^{* *} \mathrm{p}<.01$ 


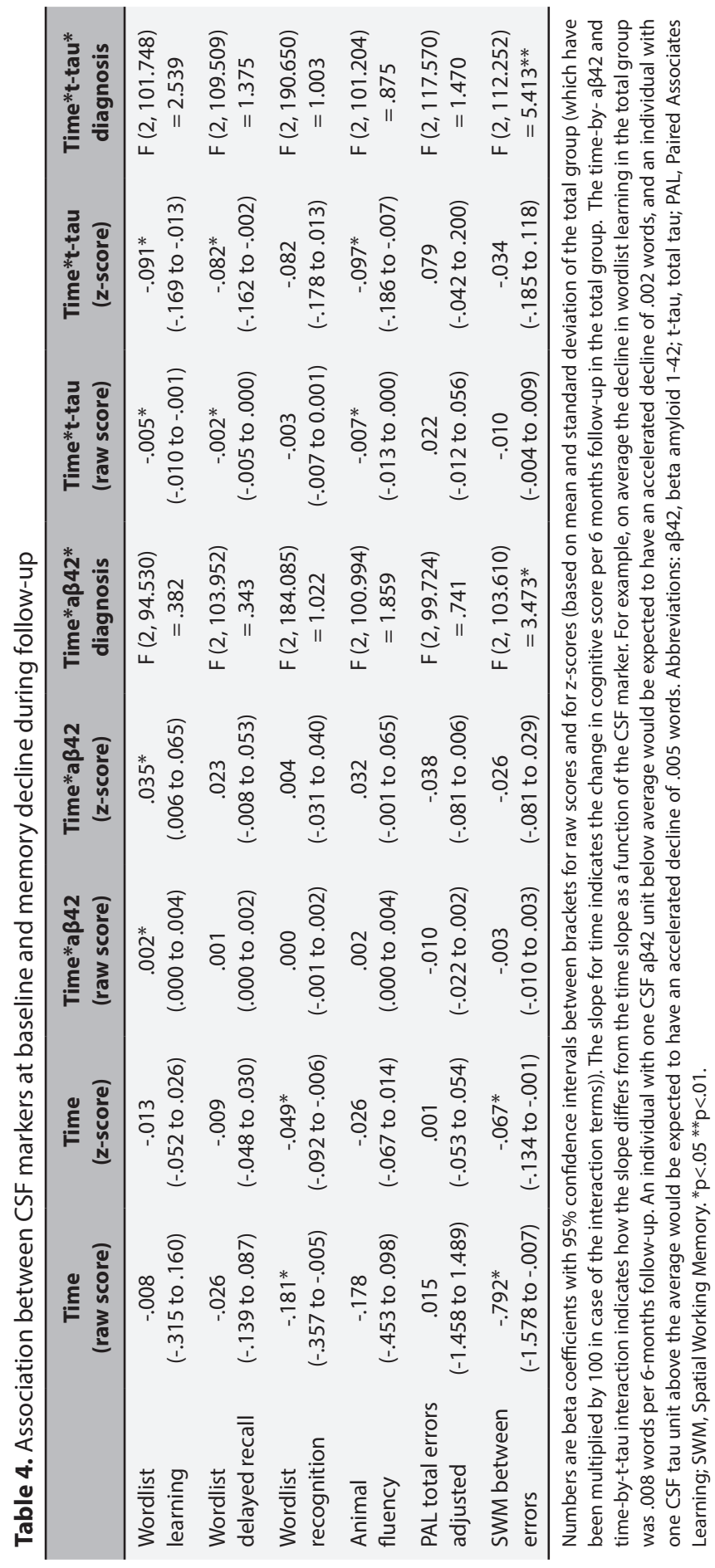




\section{DISCUSSION}

The present study revealed differential associations between AD markers in CSF and performance on several memory domains. In all individuals CSF markers correlated with poorer performance on nearly all memory domains at baseline, but most strongly with episodic verbal and visuospatial memory. CSF a 342 at baseline was associated with decline on episodic verbal memory, whereas CSF t-tau correlated with decline in performance on episodic verbal and semantic memory.

The observation that CSF markers were cross-sectionally related to memory function is in line with previous studies [13-15, 36, 37], while there were also some differences. For example, Rolstad et al. [37] found an association between CSF tau and working memory and semantic memory in individuals with various levels of impairment; while in our study working memory was associated with a 342 and not with tau. Also, in our study no association between CSF markers and semantic memory was found, but these results were just above threshold of statistical significance. In addition, we found that the association between CSF markers and memory performance was similar across diagnostic groups, while other studies reported that some of the associations between CSF markers and memory performance were observed in specific diagnostic groups only $[15,36,37]$. These differences may be explained by the statistical approach. Unlike previous studies, we first tested the interaction between clinical diagnosis and the predictor variable and only performed analysis in separate diagnostic groups if this interaction was statistically significant.

When memory scores were dichotomised, we found that in individuals without dementia abnormal verbal episodic memory was associated with abnormal CSF a 342 and tau, although the odds ratio were moderately high. This indicates that memory has limited value to pre-screen individuals with underlying AD pathology.

The association between CSF markers and memory decline over time was weaker than the association with baseline scores. For CSF a 342 , a weak correlation was found with decline on a single episodic verbal memory task. Some other studies also found no or only a weak association between CSF a 342 and cognitive decline $[11,38]$. Others found that abnormal amyloid was associated with greater decline on the 'Preclinical Alzheimer Cognitive Composite (PACC), which is a compound score that includes tests for episodic verbal memory, attention, and global cognitive functioning [39, 40]. An early decline in the verbal fluency has been reported in individuals in predementia phase of AD [41]. We did find an association between CSF tau but not a $\beta 42$ on decline in the fluency. 
Previous studies did report an association of abnormal a $\beta 42$ with decline in fluency, and that addition of a fluency measure in a cognitive compound score increased the sensitivity to detect cognitive decline in cognitively normal aß42-postives [42-44].

CSF a 342 has been found abnormal even decades before the onset of clinical symptoms [12]. Conceivably, with a longer follow-up time the association between CSF a 342 and episodic memory might have been stronger in individuals in milder disease stages. Increased CSF t-tau correlated with decline in performance on episodic verbal and semantic memory. Although the strength of the association of CSF tau with decline on episodic spatial memory was similar to that of performance on the verbal tests, there was greater heterogeneity (the standard deviation was larger) such that the association was not statistically significant.

Our finding that both cross-sectional and longitudinal associations of memory performance were stronger for CSF tau than for CSF a $\beta 42$ suggests that alterations in tau concentrations reflect neuronal damage better and are in closer temporal proximity to alterations in memory function as opposed to CSF a $\beta 42$, which is consistent with previous findings $[11,45,46]$. In particular, tau pathology in temporal and basal frontal brain regions has been associated with episodic memory, semantic memory, working memory and visuospatial processing [46].

The present study has a few limitations. First, the relatively small sample size of the subgroups may have resulted in a type II error. Second, the follow-up time was relatively short, which limits the interpretation of the data. Possibly, with a longer follow-up time a different association between $A D$ pathology markers and change in memory scores would have become apparent. Another limitation is that we did not have follow-up data available for all individuals. However, as individuals with follow-up data did not differ on age, education or MMSE scores from individuals with only baseline data, we expect no selection bias. Third, differences between tests may not only due to type of memory domain tested but also by way of administration (paper pencil versus computerised) and difficulty of the test. Finally, individuals without dementia referred to the memory clinic for an evaluation of their complaints were in our study classified as $\mathrm{MCl}$ or normal cognition based on z-scores on neuropsychological tests, which included the wordlist learning, wordlist delayed recall and animal fluency, limiting the range of scores in this group

This is the first time that the relationships were examined of CSF markers with the computerized PAL total errors adjusted and the SWM between errors of the CANTAB, which have both been found useful for detecting cognitive decline [30, 32, 47, 48]. 
The correlation of the PAL total errors adjusted with CSF a 342 was similar to that of the paper-and-pencil memory tests, while the association with CSF tau was somewhat weaker suggesting that the tests reflect AD pathology differently. Moreover, CSF markers correlated less strong with decline on the PAL total errors adjusted than on verbal episodic memory tests.

In conclusion, CSF markers correlated most strongly with tests assessing verbal and visuospatial episodic memory. Over time, CSF tau correlated with decline on episodic verbal and semantic memory tests. This implies that memory tests may have some value as a screen for the presence of abnormal CSF biomarkers. In addition, verbal episodic and semantic memory tests may be useful to track disease progression, for example in drug trials. Future studies with a longer follow-up time are recommended to examine the long-term prognostic value of these CSF markers for detecting memory decline. In addition, it would be of interest to test how AD CSF markers relate to decline on functional and non-memory measures relative to memory tests.

\section{Acknowledgments}

The EDAR study was funded by the European Commission as part of the $6^{\text {th }}$ Framework Programme (contract \# 37670). We thank Nico Rozendaal for the provision of the IT infrastructure, Innogenetics for the provision of INNO-BIA AlzBio3 kits, and Cambridge Cognition for the provision of CANTAB tests. 


\section{REFERENCES}

[1] Prince M, Wimo A, Guerchet M, Ali GC, WUY-T, Prina M (2015) World Alzheimer Report 2015: The global impact of dementia. An analysis of prevalence, incidence, costs and trends, Alzheimer's Disease International, London.

[2] Cummings JL (2004) Alzheimer's disease. N Engl J Med 351, 56-67.

[3] Hodges JR (2000) Memory in dementias In The Oxford Handbook of Memory, Tulving E, Craik FIM, eds. Oxford University Press, NY, USA.

[4] Verma M, Howard RJ (2012) Semantic memory and language dysfunction in early Alzheimer's disease: a review. Int J Geriatr Psychiatry 27, 1209-1217.

[5] Belleville S, Peretz I, Malenfant D (1996) Examination of the working memory components in normal aging and in dementia of the Alzheimer type. Neuropsychologia 34, 195-207.

[6] Gold CA, Budson AE (2008) Memory loss in Alzheimer's disease: implications for development of therapeutics. Expert Rev Neurother 8, 1879-1891.

[7] Bonner-Jackson A, Mahmoud S, Miller J, Banks SJ (2015) Verbal and non-verbal memory and hippocampal volumes in a memory clinic population. Alzheimers Res Ther 7, 61.

[8] Budson AE (2009) Understanding memory dysfunction. Neurologist 15, 71-79.

[9] Budson AE, Price BH (2005) Memory dysfunction. N Engl J Med 352, 692-699.

[10] Braak H, Braak E (1997) Frequency of stages of Alzheimer-related lesions in different age categories. Neurobiol Aging 18, 351-357.

[11] Jack CR, Jr., Knopman DS, Jagust WJ, Petersen RC, Weiner MW, Aisen PS, Shaw LM, Vemuri P, Wiste HJ, Weigand SD, Lesnick TG, Pankratz VS, Donohue MC, Trojanowski JQ (2013) Tracking pathophysiological processes in Alzheimer's disease: an updated hypothetical model of dynamic biomarkers. Lancet Neurol 12, 207-216.

[12] Jansen WJ, Ossenkoppele R, Knol DL, Tijms BM, Scheltens P, Verhey FR, Visser PJ, Amyloid Biomarker Study Group (2015) Prevalence of cerebral amyloid pathology in persons without dementia: a meta-analysis. JAMA 313, 1924-1938.

[13] Wagner M, Wolf S, Reischies FM, Daerr M, Wolfsgruber S, Jessen F, Popp J, Maier W, Hull M, Frolich L, Hampel H, Perneczky R, Peters O, Jahn H, Luckhaus C, Gertz HJ, Schroder J, Pantel J, Lewczuk P, Kornhuber J, Wiltfang J (2012) Biomarker validation of a cued recall memory deficit in prodromal Alzheimer disease. Neurology 78, 379-386.

[14] Ivanoiu A, Sindic CJ (2005) Cerebrospinal fluid TAU protein and amyloid beta42 in mild cognitive impairment: prediction of progression to Alzheimer's disease and correlation with the neuropsychological examination. Neurocase 11, 32-39.

[15] Rami L, Fortea J, Bosch B, Sole-Padulles C, Llado A, Iranzo A, Sanchez-Valle R, Molinuevo JL (2011) Cerebrospinal fluid biomarkers and memory present distinct associations along the continuum from healthy subjects to AD patients. J Alzheimers Dis 23, 319-326. 
[16] Backman L, Jones S, Berger AK, Laukka EJ, Small BJ (2005) Cognitive impairment in preclinical Alzheimer's disease: a meta-analysis. Neuropsychology 19, 520-531.

[17] Rabin LA, Pare N, Saykin AJ, Brown MJ, Wishart HA, Flashman LA, Santulli RB (2009) Differential memory test sensitivity for diagnosing amnestic mild cognitive impairment and predicting conversion to Alzheimer's disease. Neuropsychol Dev Cogn B Aging Neuropsychol Cogn 16, 357-376.

[18] Folstein MF, Folstein SE, McHugh PR (1975) "Mini-mental state". A practical method for grading the cognitive state of patients for the clinician. J Psychiatr Res 12, 189-198.

[19] Petersen RC (2004) Mild cognitive impairment as a diagnostic entity. J Intern Med 256, 183194.

[20] McKhann G, Drachman D, Folstein M, Katzman R, Price D, Stadlan EM (1984) Clinical diagnosis of Alzheimer's disease: report of the NINCDS-ADRDA Work Group under the auspices of Department of Health and Human Services Task Force on Alzheimer's Disease. Neurology 34, 939-944.

[21] Neary D, Snowden JS, Northen B, Goulding P (1988) Dementia of frontal lobe type. J Neurol Neurosurg Psychiatry 51, 353-361.

[22] Roman GC, Tatemichi TK, Erkinjuntti T, Cummings JL, Masdeu JC, Garcia JH, Amaducci L, Orgogozo JM, Brun A, Hofman A, et al. (1993) Vascular dementia: diagnostic criteria for research studies. Report of the NINDS-AIREN International Workshop. Neurology 43, 250260.

[23] McKeith IG, Galasko D, Kosaka K, Perry EK, Dickson DW, Hansen LA, Salmon DP, Lowe J, Mirra SS, Byrne EJ, Lennox G, Quinn NP, Edwardson JA, Ince PG, Bergeron C, Burns A, Miller BL, Lovestone S, Collerton D, Jansen EN, Ballard C, de Vos RA, Wilcock GK, Jellinger KA, Perry RH (1996) Consensus guidelines for the clinical and pathologic diagnosis of dementia with Lewy bodies (DLB): report of the consortium on DLB international workshop. Neurology 47, 1113-1124.

[24] Lezak MD, Howieson DB, Bigler ED, Tranel D (2012) Neuropsychological assessment Oxford University Press, New York.

[25] Morris JC, Mohs RC, Rogers H, Fillenbaum G, Heyman A (1988) Consortium to establish a registry for Alzheimer's disease (CERAD) clinical and neuropsychological assessment of Alzheimer's disease. Psychopharmacol Bull 24, 641-652.

[26] Pflüger MA, C.; Monsch, A. U. (2003) in Zeitschrift für Klinische Psychologie und Psychotherapie, pp. 64-67.

[27] van der Elst W, van Boxtel MP, van Breukelen GJ, Jolles J (2006) Normative data for the Animal, Profession and Letter M Naming verbal fluency tests for Dutch speaking participants and the effects of age, education, and sex. J Int Neuropsychol Soc 12, 80-89.

[28] Hughes CP, Berg L, Danziger WL, Coben LA, Martin RL (1982) A new clinical scale for the staging of dementia. Br J Psychiatry 140, 566-572. 
[29] Pfeffer RI, Kurosaki TT, Harrah CH, Jr., Chance JM, Filos S (1982) Measurement of functional activities in older adults in the community. J Geronto/ 37, 323-329.

[30] Fowler KS, Saling MM, Conway EL, Semple JM, Louis WJ (2002) Paired associate performance in the early detection of DAT. J Int Neuropsychol Soc 8, 58-71.

[31] Swainson R, Hodges JR, Galton CJ, Semple J, Michael A, Dunn BD, Iddon JL, Robbins TW, Sahakian BJ (2001) Early detection and differential diagnosis of Alzheimer's disease and depression with neuropsychological tasks. Dement Geriatr Cogn Disord 12, 265-280.

[32] Junkkila J, Oja S, Laine M, Karrasch M (2012) Applicability of the CANTAB-PAL computerized memory test in identifying amnestic mild cognitive impairment and Alzheimer's disease. Dement Geriatr Cogn Disord 34, 83-89.

[33] Owen AM, Downes JJ, Sahakian BJ, Polkey CE, Robbins TW (1990) Planning and spatial working memory following frontal lobe lesions in man. Neuropsychologia 28, 1021-1034.

[34] Robbins TW, James M, Owen AM, Sahakian BJ, Lawrence AD, McInnes L, Rabbitt PM (1998) A study of performance on tests from the CANTAB battery sensitive to frontal lobe dysfunction in a large sample of normal volunteers: implications for theories of executive functioning and cognitive aging. Cambridge Neuropsychological Test Automated Battery. J Int Neuropsychol Soc 4, 474-490.

[35] Jongbloed W, Kester MI, van der Flier WM, Veerhuis R, Scheltens P, Blankenstein MA, Teunissen CE (2013) Discriminatory and predictive capabilities of enzyme-linked immunosorbent assay and multiplex platforms in a longitudinal Alzheimer's disease study. Alzheimers Dement 9, 276-283.

[36] Grambaite R, Hessen E, Auning E, Aarsland D, Selnes P, Fladby T (2013) Correlates of Subjective and Mild Cognitive Impairment: Depressive Symptoms and CSF Biomarkers. Dement Geriatr Cogn Dis Extra 3, 291-300.

[37] Rolstad S, Berg Al, Bjerke M, Blennow K, Johansson B, Zetterberg H, Wallin A (2011) Amyloidbeta(4)(2) is associated with cognitive impairment in healthy elderly and subjective cognitive impairment. J Alzheimers Dis 26, 135-142.

[38] Wallin AK, Blennow K, Andreasen N, Minthon L (2006) CSF biomarkers for Alzheimer's Disease: levels of beta-amyloid, tau, phosphorylated tau relate to clinical symptoms and survival. Dement Geriatr Cogn Disord 21, 131-138.

[39] Donohue MC, Sperling RA, Salmon DP, Rentz DM, Raman R, Thomas RG, Weiner M, Aisen PS, Australian Imaging B, Lifestyle Flagship Study of A, Alzheimer's Disease Neuroimaging I, Alzheimer's Disease Cooperative S (2014) The preclinical Alzheimer cognitive composite: measuring amyloid-related decline. JAMA Neurol 71, 961-970.

[40] Mormino EC, Papp KV, Rentz DM, Donohue MC, Amariglio R, Quiroz YT, Chhatwal J, Marshall GA, Donovan N, Jackson J, Gatchel JR, Hanseeuw BJ, Schultz AP, Aisen PS, Johnson KA, Sperling RA (2017) Early and late change on the preclinical Alzheimer's cognitive composite in clinically normal older individuals with elevated amyloid-beta. Alzheimers Dement. 
[41] Raoux N, Amieva H, Le Goff M, Auriacombe S, Carcaillon L, Letenneur L, Dartigues JF (2008) Clustering and switching processes in semantic verbal fluency in the course of Alzheimer's disease subjects: results from the PAQUID longitudinal study. Cortex 44, 1188-1196.

[42] Burnham SC, Raghavan N, Wilson W, Baker D, Ropacki MT, Novak G, Ames D, Ellis K, Martins RN, Maruff P, Masters CL, Romano G, Rowe CC, Savage G, Macaulay SL, Narayan VA, Alzheimer's Disease Neuroimaging I, Group AR (2015) Novel Statistically-Derived Composite Measures for Assessing the Efficacy of Disease-Modifying Therapies in Prodromal Alzheimer's Disease Trials: An AIBL Study. J Alzheimers Dis 46, 1079-1089.

[43] Lim YY, Snyder PJ, Pietrzak RH, Ukiqi A, Villemagne VL, Ames D, Salvado O, Bourgeat P, Martins RN, Masters CL, Rowe CC, Maruff P (2016) Sensitivity of composite scores to amyloid burden in preclinical Alzheimer's disease: Introducing the Z-scores of Attention, Verbal fluency, and Episodic memory for Nondemented older adults composite score. Alzheimers Dement (Amst) 2, 19-26.

[44] Saxton J, Lopez OL, Ratcliff G, Dulberg C, Fried LP, Carlson MC, Newman AB, Kuller L (2004) Preclinical Alzheimer disease: neuropsychological test performance 1.5 to 8 years prior to onset. Neurology 63, 2341-2347.

[45] Jack CR, Jr., Knopman DS, Jagust WJ, Shaw LM, Aisen PS, Weiner MW, Petersen RC, Trojanowski JQ (2010) Hypothetical model of dynamic biomarkers of the Alzheimer's pathological cascade. Lancet Neurol 9, 119-128.

[46] Brier MR, Gordon B, Friedrichsen K, McCarthy J, Stern A, Christensen J, Owen C, Aldea P, Su Y, Hassenstab J, Cairns NJ, Holtzman DM, Fagan AM, Morris JC, Benzinger TL, Ances BM (2016) Tau and Abeta imaging, CSF measures, and cognition in Alzheimer's disease. Sci Transl Med 8, 338 ra366.

[47] Blackwell AD, Sahakian BJ, Vesey R, Semple JM, Robbins TW, Hodges JR (2004) Detecting dementia: novel neuropsychological markers of preclinical Alzheimer's disease. Dement Geriatr Cogn Disord 17, 42-48.

[48] Egerhazi A, Berecz R, Bartok E, Degrell I (2007) Automated Neuropsychological Test Battery (CANTAB) in mild cognitive impairment and in Alzheimer's disease. Prog Neuropsychopharmacol Biol Psychiatry 31, 746-751. 


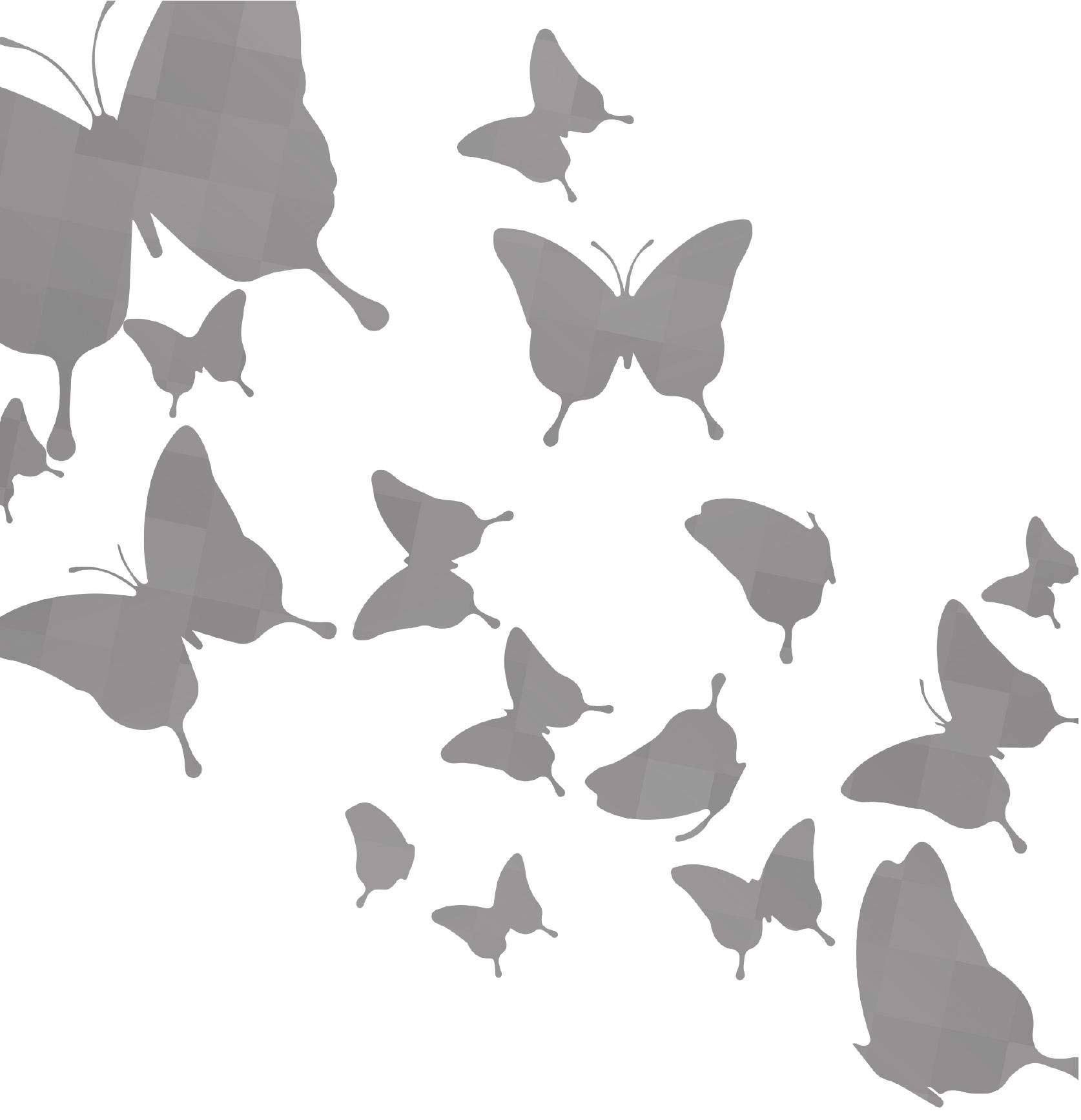




\section{Effect of key Alzheimer's disease}

cerebrospinal fluid markers on specific cognitive decline in subjects with Mild Cognitive Impairment: results from the DESCRIPA study

Inez H.G.B. Ramakers

Babette L.R. Reijs

Sebastian Koehler

Lieke van Praag

Philip Scheltens

Harald Hampel

Hilkka Soininen

Marcel Olde Rikkert

Marcel M. Verbeek

Luiza Spiru

Kaj Blennow

Yvonne Freund-Levi

Asa Wallin

Magda Tsolaki

Frans R.J. Verhey

Stephanie J.B. Vos

Pieter Jelle Visser

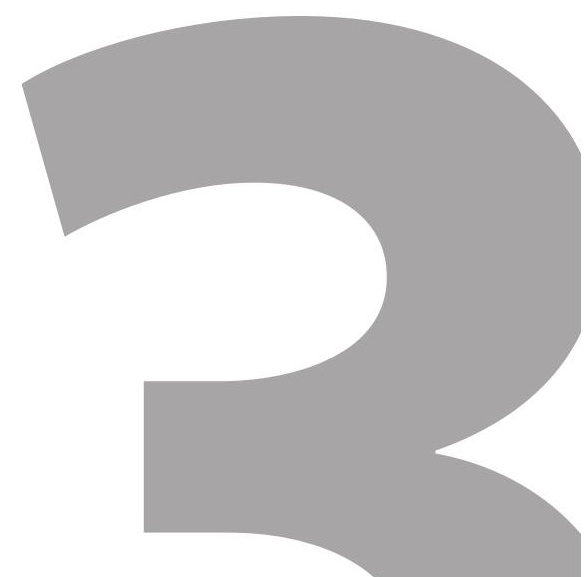

In preparation 


\section{ABSTRACT}

Background: Subjects with $\mathrm{MCl}$ often have decreased $\beta$-amyloid ${ }_{(1-42)}$ protein (A $\left.\beta 42\right)$ and increased tau levels in cerebrospinal fluid (CSF) characteristic of Alzheimer's disease (AD). Cognitive decline in the $A D M C l$ stage is characterized by a large interindividual variability in affected cognitive domains and rate of decline. The aim of this study was to investigate the relation between individual key CSF biomarkers for AD and the course of domain specific cognitive decline over time in subjects with Mild Cognitive Impairment $(\mathrm{MCl})$.

Methods: Subjects with $M C I(n=152)$ were selected from the DESCRIPA study. The mean age was 68.7 years, $51 \%$ were female. Amyloid $\beta_{(1-42)}$ protein (A $\left.\beta 42\right)$, and total tau (t-tau) were measured in CSF using commercially available single-parameter ELISA methods. We classified subjects according to NIA-AA criteria into 4 groups: subjects with both biomarkers normal (reference, $n=39$ ), subjects with normal $A \beta 42$ and abnormal t-tau (SNAP, $n=31$ ), subjects with abnormal $A \beta 42$ and normal $t$-tau (IAP, $n=27$ ), and subjects with both biomarkers abnormal ( $A D$ high likelihood ( $A D-H L, n=55)$. The measured cognitive domains included general cognitive functioning, memory, information processing speed, executive functioning, and verbal fluency.

Results: Compared to subjects with both normal $A \beta 42$ and t-tau levels (reference group), subjects with AD-HL had lower MMSE scores at baseline and had more decline over time in all cognitive domains. Subjects with SNAP had more decline in memory, executive performance, and fluency scores. Cognitive decline of subjects with IAP did not differ from the reference group.

Conclusions: In subjects with $\mathrm{MCl}$, a SNAP and AD-HL CSF biomarker profile was associated with cognitive decline over time. Without $t$-tau abnormalities, no cognitive decline could be identified. 


\section{INTRODUCTION}

$A D$ is characterised by a long predementia stage in which cognitive function gradually declines. The cognitive decline is not limited to episodic memory, as previous studies also showed a breakdown in non-memory abilities [1-4]. Moreover, the decline shows a large interindividual variability [1].

Subjects with $\mathrm{MCl}$ are at increased risk for $A D$. Recent criteria indicate that increased tau and decreased $\beta$-amyloid ${ }_{(1-42)}$ protein (Aß42) concentrations in the cerebrospinal fluid (CSF) can be used for the diagnosis of $A D$ in subjects with $\mathrm{MCl}$. We hypothesize that the variability in cognitive decline in predementia $A D$ is associated with the $A D$ CSF biomarker profile. Previous studies on the relation between CSF AD biomarkers and cognitive decline mainly used general measures or composite scores for measuring cognitive decline [5-8]. More knowledge into the specific consequences of abnormal CSF $\mathrm{A} \beta 42$ and tau concentrations in subjects with $\mathrm{MCl}$ on cognition, will not only help further understanding of $A D$ pathogenesis, but can also aid to predict the clinical cognitive decline more accurately.

The aim of this study was to investigate the relation between key in-vivo AD biomarkers in CSF and domain specific cognitive decline over time in clinical subjects with $\mathrm{MCI}$.

\section{METHODS}

\section{Subjects}

Subjects were selected from the "Development of screening guidelines and criteria for predementia Alzheimer's disease" (DESCRIPA) study. The DESCRIPA study is a multicenter, prospective cohort study of 881 non-demented subjects selected from 20 outpatient memory clinics in 11 European countries [9]. Inclusion criteria were an age of 55 years or older and being a new referral for the evaluation of cognitive complaints. Exclusion criteria were a diagnosis of dementia according to the DSM IV criteria [10] at baseline and any somatic, psychiatric, or neurological disorders that may have caused the cognitive impairment, as described in detail elsewhere [9].

For the present study, we selected subjects with $\mathrm{MCl}$ defined as a Clinical Dementia Rating Scale (CDR) score of 0.5 from whom baseline CSF and neuropsychological test performances were available $(n=152)$. Subjects received annual neuropsychological 
follow-up assessments comparable to baseline up to 3 years. At follow-up, a diagnosis of dementia and AD was made according to the DSM-IV criteria [10] and the NINCDSADRDA criteria [11].

\section{Baseline assessment}

At baseline, all subjects underwent standardized physical and neurological examinations, assessment of global cognitive functioning using the Mini Mental State Examination (MMSE) [12], and a neuropsychological assessment, as described in detail elsewhere [9, 13]. In a subgroup also a lumbar puncture was performed for the collection of CSF [14].

\section{Neuropsychological assessment}

The measured cognitive domains included general cognitive functioning (MMSE), memory (immediate and delayed recall of the 15-Word Learning Test (15-WLT) [15] or immediate and delayed recall of the word list of the Consortium to Establish a Registry for AD (CERAD) [16]), speed of information processing (Trail Making Test (TMT), part A) [17], executive functioning (TMT, part B), and verbal fluency (fluency animals, 60 seconds) [18]. Cognitive performances were converted to z-scores based on age, sex and education adjusted test specific normative data.

\section{CSF collection, storage and analysis}

CSF was collected via a lumbar puncture. The procedure for the collection and analysis of CSF in the DESCRIPA study has been described elsewhere [14]. In short, samples from the DESCRIPA study were collected and stored in polypropylene tubes. Samples were centrifuged after collection and stored at $-80{ }^{\circ} \mathrm{C}$ until analysis. Subjects whose CSF was not collected in polypropylene tubes or was defrosted before the final CSF measurements, were excluded from the analyses. All CSF analyses were performed at the end of the study, using the same batch of reagents, at the Clinical Neurochemistry Laboratory, Sahlgrenska University Hospital, Mölndal, Sweden. A $1-42$ and total-tau (t-tau) levels were measured using commercially available single-parameter ELISA methods (respectively Innotest ${ }^{\oplus}$ beta-amyloid (1-42) and Innotest ${ }^{\circledR}$ hTAU-Ag; Fujirebio, formerly Innogenetics, Ghent, Belgium).

\section{CSF measures}

We dichotomized scores for $A \beta 42$ and t-tau as normal or abnormal based on predefined cut-offs. Concentrations below $536 \mathrm{ng} / \mathrm{L}$ for $A \beta 42$, and above $349 \mathrm{ng} / \mathrm{L}$ for t-tau were classified as abnormal [19]. We classified subjects according to NIA-AA criteria [20] in 4 groups: subjects with normal $A \beta 42$ and normal t-tau levels (reference group), subjects with normal $A \beta 42$ and abnormal t-tau, (Suspected Non-Alzheimer Pathophysiology 
(SNAP, [21-23]), subjects with isolated abnormal $A \beta 42$ and normal t-tau (Isolated Amyloid Pathology, IAP, [24]), and subjects with both abnormal $A \beta 42$ and abnormal t-tau levels (AD high likelihood (HL)).

\section{Statistics}

Statistical analyses were performed using the Statistical Package for Social Sciences (SPSS) version 20 for Mac OS X. Baseline and change in cognitive test performances between the four different CSF biomarker profiles were analyzed by using slope analyses with linear mixed models. The analysis included the baseline score and available followup scores. Covariates in all analyses were age, sex, and educational level. Centre was included as a random effect. Three models with increasing complexity of the underlying covariance structure were tested. A model with a more complex covariance structure was chosen only if this reduced the -2 log likelihood, as assessed with a $x^{2}$ test.

\section{RESULTS}

\section{Baseline subject characteristics}

The baseline characteristics are presented in Table 1. The total group had a mean age of 68.7 years and $51 \%$ were female. The CSF subgroups consisted of 39 subjects (26\%) with normal $A \beta 42$ and normal t-tau levels (reference group), 31 subjects (20\%) with SNAP, 27 subjects (18\%) with IAP, and 55 subjects (36\%) had both abnormal A 342 and abnormal t-tau levels (AD-HL). Differences between the biomarker groups were found for age $(p<0.001)$ and for the presence of at least one Apolipoprotein e4 (APOE e4) allele $(p<0.001)$.

At baseline, a main effect for biomarker group was found for the MMSE score only $(p=0.021$ ) (Table 2). Post-hoc comparisons showed that subjects of the AD-HL group had lower MMSE scores than subjects who had normal levels of both CSF markers $(p=0.003)$ or subjects with SNAP ( $p=0.038)$. No baseline main effect for group was found for other cognitive tests. 

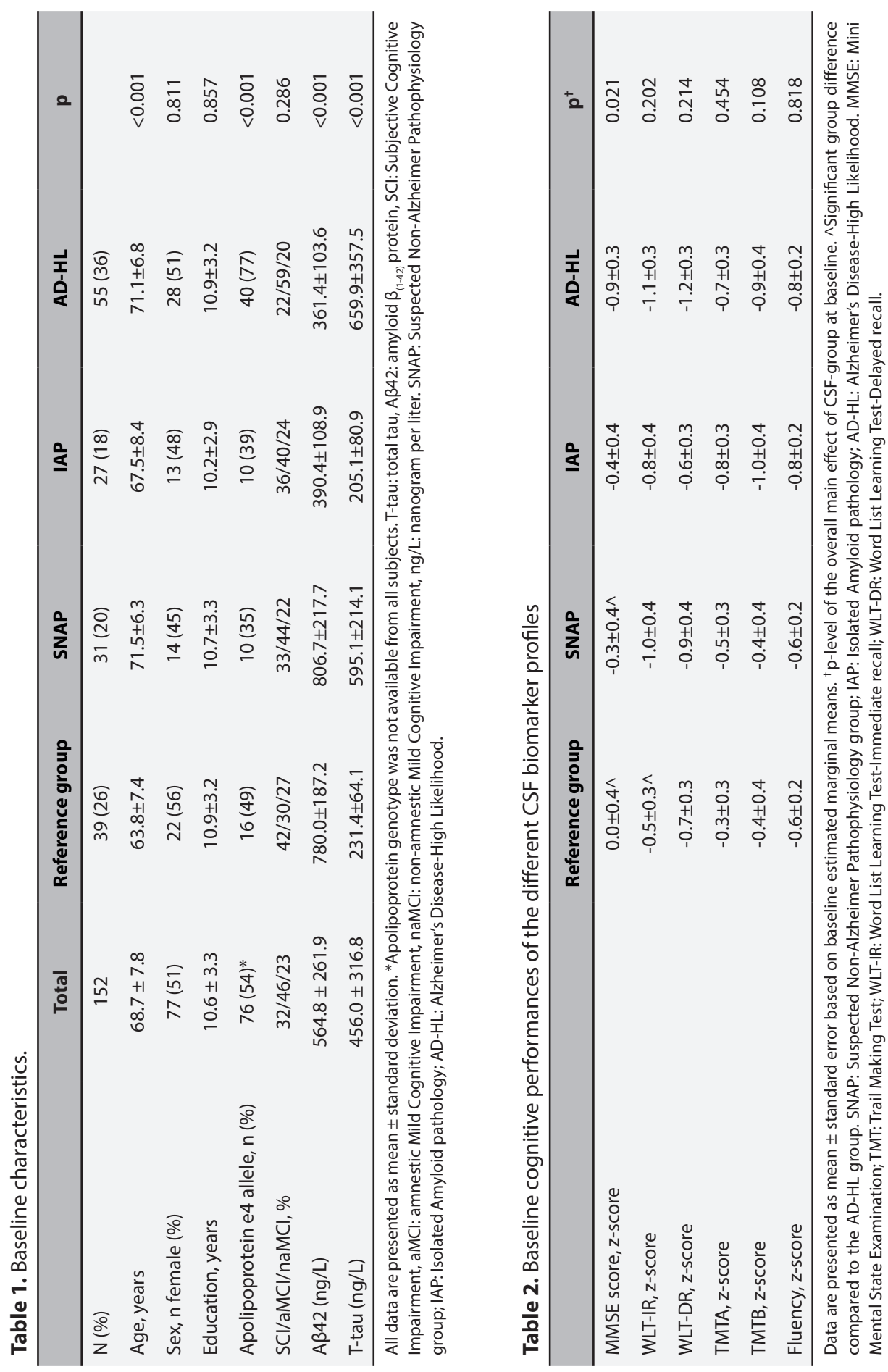


\section{Relation between CSF AD biomarker profile and cognitive decline}

Subjects with both normal $A \beta 42$ and $t$-tau levels (blue line) showed a significant increase over time in WLT-immediate $(\beta=0.28, p<0.001)$ and delayed recall scores ( $\beta=0.25, p=0.001$, Table 3, Figure 1). Subjects of the AD-HL group (purple line) showed a significant decline in WLT delayed recall $(\beta=-0.17, p=0.017)$, MMSE score $(\beta=-0.54$, $p<0.001)$, and fluency scores $(\beta=-0.13, p=0.039)$. Subjects with SNAP (red line) showed a significant decline in TMT part $B(\beta=-0.24, p=0.043)$ and a trend for a decline in fluency $(\beta=-0.15, p=0.058)$. Subjects with IAP (green line) showed no change on any of the cognitive tests.

Difference in slope relative to the reference group (normal $A \beta 42$ and normal t-tau levels) are represented in Table 3 and Figure 1. Compared to subjects with both normal Aß42 and normal t-tau levels, subjects of the AD-HL group had significantly more decline in WLT immediate $(\beta=-0.40, p<0.001)$ and delayed recall $(\beta=-0.42, p<0.001)$, MMSE score $(\beta=-0.59, p<0.001)$, TMTA $(\beta=-0.26, p=0.047)$ and fluency score $(\beta=-0.21, p<0.020)$. Additionally, a trend in this direction was found for performances on the TMTB ( $\beta=$ $0.27, p=0.06$ ). Subjects with SNAP had significantly more decline in immediate $(\beta=-$ $0.24, p=0.034)$ and delayed recall $(\beta=-0.30, p=0.008)$ WLT performances, TMT $B(\beta=-$ $0.37, p=0.021)$ and fluency scores $(\beta=-0.23, p=0.025)$ compared to the reference group. The decline of subjects with IAP did not differ from the reference group on any of the cognitive tests.

Subjects of the AD-HL group had significantly more decline than subjects with IAP on the WLT immediate $(\beta=-0.29, p=0.011)$ and delayed recall $(\beta=-0.24, p=0.028)$, MMSE score $(\beta=-0.61, p<0.001)$ and on the fluency test $(\beta=-0.22, p=0.030)$. Compared to the SNAP group, subjects with AD-HL only had significantly more decline on the MMSE score ( $\beta=-0.36, p=0.029$ ). Subjects with SNAP had significantly more decline than subjects with IAP on the verbal fluency test only $(\beta=-0.25, p=0.032)$. 


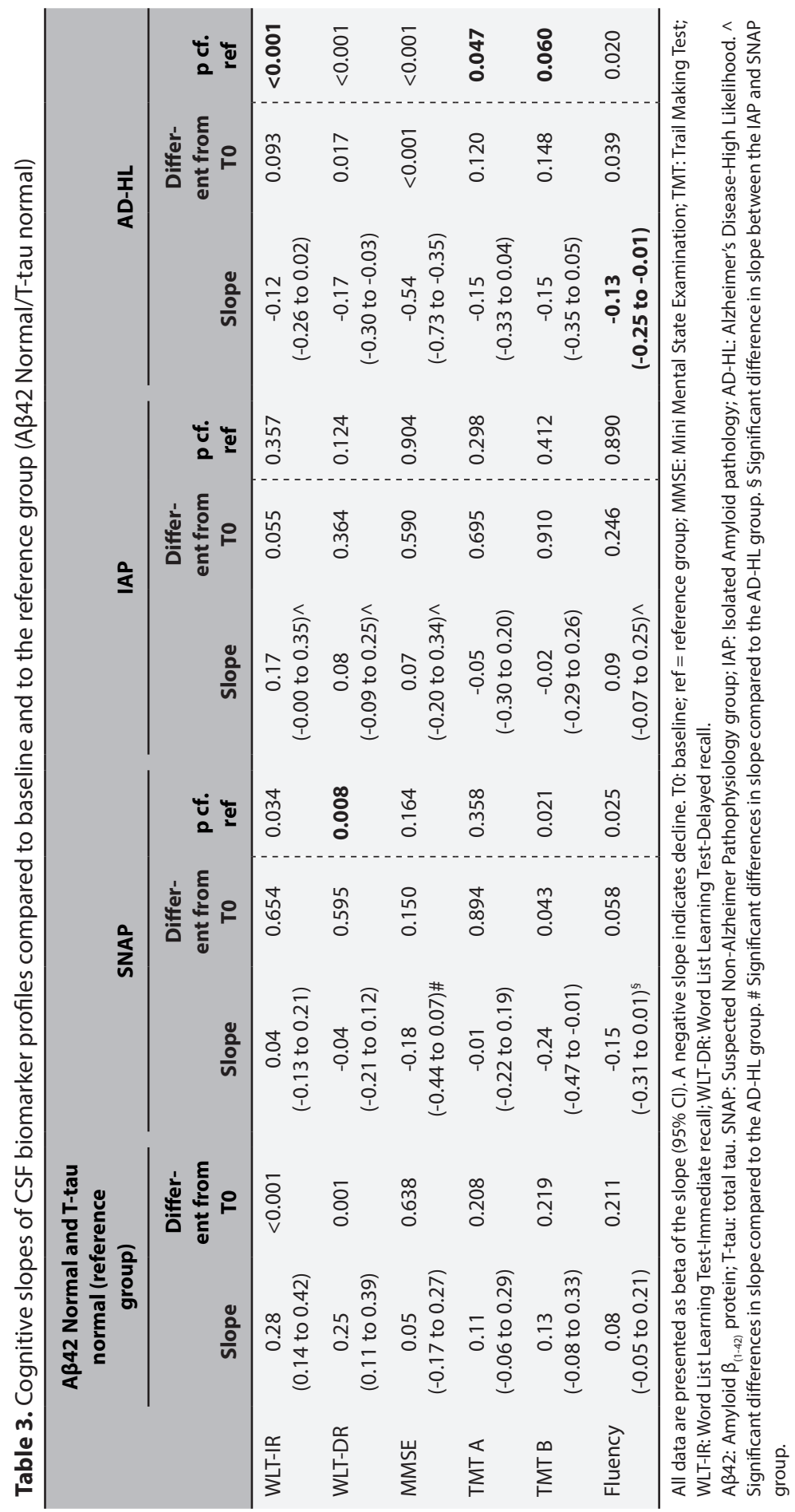



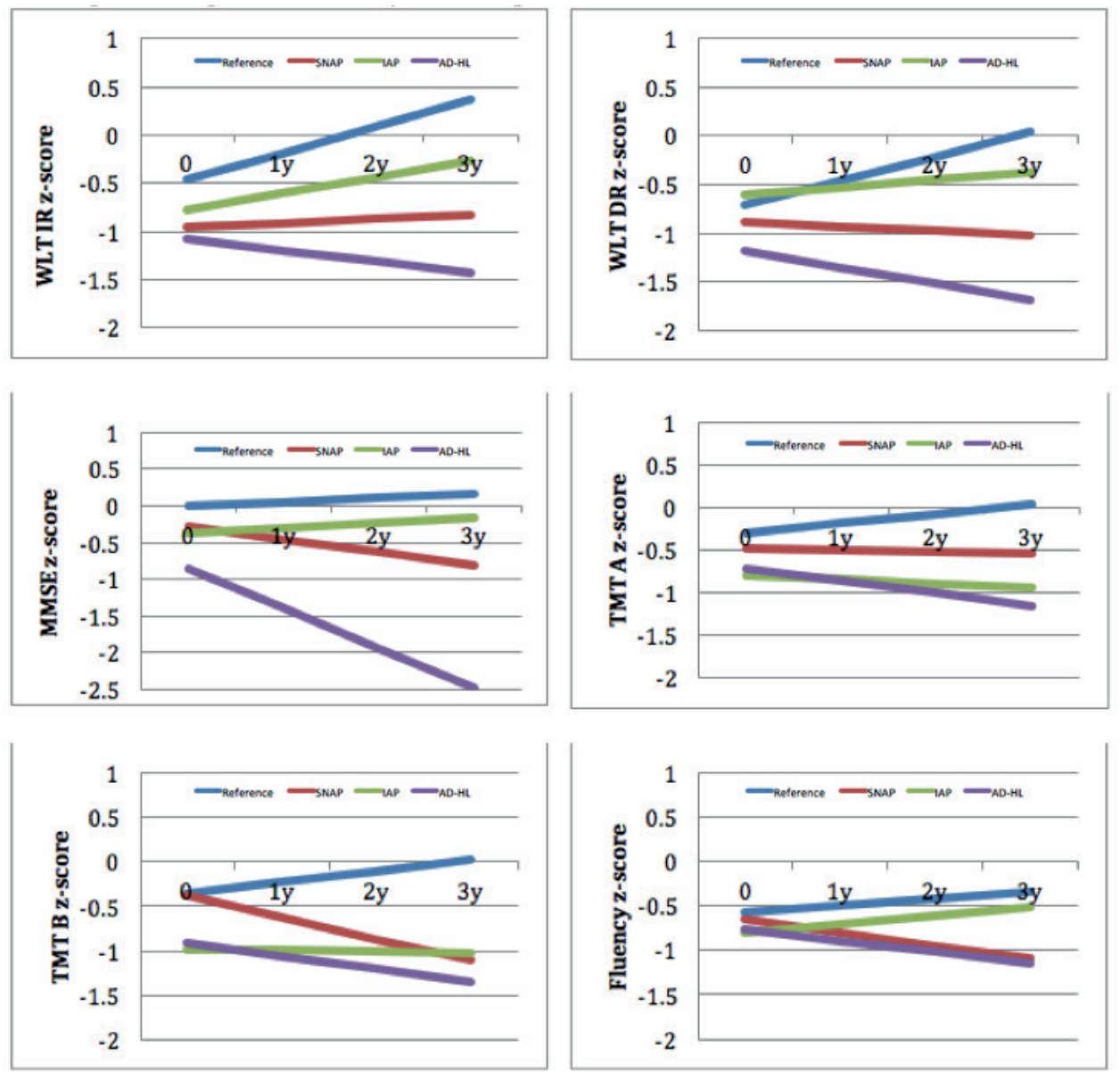

Figure 1. Cognitive decline by CSF AD profiles

Data represent age, sex and education corrected z-scores. MMSE: Mini Mental State Examination, WLT-IR: Word Learning Test-Immediate recall, WLT-DR: Word Learning Tests-Delayed recall, TMT A: Trail Making Test-part A, TMT B: Trail Making Testpart; Reference: reference group, SNAP: Suspected Non-Alzheimer Pathophysiology group; IAP: Isolated Amyloid pathology; AD-HL: Alzheimer's Disease-High Likelihood. 


\section{DISCUSSION}

In the present study, we investigated the effect of key in-vivo CSF A 42 and tau biomarkers on domain-specific cognitive decline in a clinical cohort of $\mathrm{MCl}$ subjects. The main finding of this study was that only CSF SNAP and AD-HL profiles were associated with cognitive decline, mainly in the domains memory and executive functioning.

In 39 (26\%) subjects, $\beta$-amyloid and tau biomarkers were both normal at baseline. These subjects had a good prognosis by showing a stable or improving cognitive profile over time. This improvement can be explained by a positive change in or recovery of other non-neurodegenerative causes of cognitive impairments (such as affective symptomatology) or may be due to a learning effect which is often seen in repeated measures of memory tasks due to the learning of content and procedural aspects of the tests.

Twenty-seven (18\%) subjects had isolated $A \beta 42$ abnormalities (IAP), which were not associated with a decline over time in any of the investigated cognitive domains. The cognitive improvement identified in the reference group, did not exist in the IAP group. A previous study, including a one-year follow-up, also found no converters to dementia in $\mathrm{MCl}$ subjects with an IAP biomarker profile [22]. Other studies found an increased risk for the development of AD dementia within three years in subjects with IAP compared to subjects with normal AD biomarkers [24], but also in this study a large variability in findings between centers was found. Longer follow-up periods of $\mathrm{MCl}$ cases would be helpful to clarify these conflicting findings and to investigate whether subjects with a CSF IAP profile will have CSF tau abnormalities in future and whether they will develop AD dementia.

In the present study, subjects with SNAP had more decline in memory performances and executive functioning compared to subjects from the reference group. The relation between abnormal CSF tau levels and memory performances is in line with previous studies [25-27] and may be linked to the time course and localization of neurofibrillary tangles starting in the memory related medial-temporal brain regions [28-30]. In addition, a steeper decline in performances on concept shifting and categorical fluency, both measures for executive functioning, was present in SNAP subjects. In addition, the relation between SNAP and executive functioning (TMT B) remained when TMT B performances were corrected for TMT A performances (simple mental processing speed), meaning that the effect tau abnormalities have on higher order aspects of executive functioning cannot be explained by a general reduction of mental speed related to normal aging processes. 
People with the AD-HL profile had the worst prognosis by showing decline in all cognitive tests compared to the reference group. Also compared to IAP subjects, the AD-HL subjects showed more decline in memory and verbal fluency tests. Previous literature found the AD-HL profile to be most accurate for predicting cognitive decline and conversion to AD dementia [24]. A decline in simple attention/mental speed performances was found only when both biomarkers were abnormal, thus at a relatively late point in the prodromal dementia disease course.

In general, we found that in $62 \%$ of the $\mathrm{MCl}$ subjects CSF $\mathrm{A} \beta 42$ and tau biomarkers were both normal or abnormal at baseline. In the remaining subjects, biomarker values were conflicting, including about one-fifth of the subjects having an IAP profile. An IAP profile might fit into the AD cascade model proposed by Jack et al. [31, 32], which assumes a temporal progression of biomarkers in Alzheimer's disease in which amyloid abnormalities precede abnormal markers for neurodegeneration. Longitudinal CSF measurements are interesting to investigate this hypothesis. The not existing cognitive decline within a three-year FU period in the present study does not confirm the hypothesis that IAP would be a transitional phase between $\mathrm{MCl}$ and AD dementia. Another $20 \%$ had conflicting biomarkers due to a SNAP profile. The prevalence of this SNAP group is comparable with other recent findings in clinical $\mathrm{MCl}$ cohorts [22, $23,33,34]$. This biomarker profile is not in line with the AD cascade model, as these subjects already have positive neurodegeneration markers in the absence of abnormal Amyloid levels. Our finding that executive deterioration is strongest in the SNAP group may imply that these deficits in $\mathrm{MCl}$ subjects are due to non-AD pathologies. However, other recent studies showed that executive functioning is also affected early in the predementia phase of $\operatorname{AD}[2,4]$. We found that the domain specific cognitive slope of SNAP was in line with that of the AD-HL group, suggesting that SNAP could be an early phase within the $A D$ cascade. In the present study, no cognitive decline could be identified without tau abnormalities, independent of $A \beta 42$ status (SNAP and AD$\mathrm{HL}$ ). These findings suggest that neurodegeneration markers may be more indicative for future cognitive decline than amyloid pathology. Our finding is also in line with previous studies that found measures for neurodegeneration such as hippocampal atrophy, FDG-PET hypometabolism, or temporal lobe related tau depositions were important in predicting cognitive functioning and decline [30, 35, 36]. It is also in line with recent community based findings showing that the neurodegeneration positive group had the highest rate of progression to dementia [22]. This implies that markers of neuronal dysfunctioning can be used as a prognostic marker, related to clinical disease progression. 
A limitation of the study is that CSF was only collected at baseline. Therefore, the effect of $A \beta 42$ and tau changes over time on cognitive decline or the order in which AD CSF markers become abnormal could not be investigated. In addition, the A $\beta 42$ and tau levels were dichotomized, based on published cut-off scores. Analyzing CSF, even in standardized procedures in the same center could lead to measure-errors resulting in classification errors, mainly for CSF values around the cut-off scores [37]. However, recent studies showed that IAP and SNAP profiles are not just resulting from a classification error [24,38]. Also linear mixed models with continuous CSF levels showed comparable results in the present study (data not shown). In addition, present analyses are not adjusted for multiple testing. Two centres $(n=30,19.6 \%)$ used the CERAD 10-WLT for measuring immediate and delayed recall, while in the other centres a 15-WLT was used. After excluding subjects who had a 10-WLT based memory performance from the analyses, the results remained essentially the same.

A strength of the present study was the use of well-standardized domain specific cognitive tests, of which well documented normative data exists. This allowed us to investigate the relation between specific cognitive test performances to specific CSF biomarkers, compared to cognitive compound scores or cognitive screening instruments often used in previous studies [8]. The present study was conducted in the DESCRIPA study, which is a clinical prospective cohort study of well-documented $\mathrm{MCl}$ subjects included from memory clinics across Europe. The multi-centre design increased the generalizability of the results. However, because these subjects were selected from memory clinics, the generalizability of these findings to populationbased studies or primary care settings may be limited. In addition, selecting subjects from memory clinics implicates the inclusion of subjects who already sought help for their experienced complaints in cognition. For future research, it would be interesting to focus on the most early cognitive changes related to AD pathology, which will be start long before subjects visit a memory clinic.

\section{ACKNOWLEDGEMENTS}

The DESCRIPA study was funded by the European Commission as part of the $5^{\text {th }}$ Framework Programme (QLT-6-CT-2002-02455). The authors thank Nico Rozendaal for his help with the design of the database and data management for the DESCRIPA study. 


\section{REFERENCES}

[1] Backman L, Small BJ (2007) Cognitive deficits in preclinical Alzheimer's disease and vascular dementia: patterns of findings from the Kungsholmen Project. Physiol Behav 92, 80-86.

[2] Tabert MH, Manly JJ, Liu X, Pelton GH, Rosenblum S, Jacobs M, Zamora D, Goodkind M, Bell K, Stern Y, Devanand DP (2006) Neuropsychological prediction of conversion to Alzheimer disease in patients with mild cognitive impairment. Arch Gen Psychiatry 63, 916-924.

[3] Wilson RS, Leurgans SE, Boyle PA, Bennett DA (2011) Cognitive decline in prodromal Alzheimer disease and mild cognitive impairment. Arch Neurol 68, 351-356.

[4] Hamel R, Kohler S, Sistermans N, Koene T, Pijnenburg Y, van der Flier W, Scheltens P, Aalten P, Verhey F, Visser PJ, Ramakers I (2015) The trajectory of cognitive decline in the pre-dementia phase in memory clinic visitors: findings from the 4C-MCl study. Psychol Med 45, 1509-1519.

[5] Donohue MC, Sperling RA, Salmon DP, Rentz DM, Raman R, Thomas RG, Weiner M, Aisen PS, Australian Imaging B, Lifestyle Flagship Study of A, Alzheimer's Disease Neuroimaging I, Alzheimer's Disease Cooperative S (2014) The preclinical Alzheimer cognitive composite: measuring amyloid-related decline. JAMA Neurol 71, 961-970.

[6] Mormino EC, Papp KV, Rentz DM, Donohue MC, Amariglio R, Quiroz YT, Chhatwal J, Marshall GA, Donovan N, Jackson J, Gatchel JR, Hanseeuw BJ, Schultz AP, Aisen PS, Johnson KA, Sperling RA (2017) Early and late change on the preclinical Alzheimer's cognitive composite in clinically normal older individuals with elevated amyloid-beta. Alzheimers Dement.

[7] Lo RY, Hubbard AE, Shaw LM, Trojanowski JQ, Petersen RC, Aisen PS, Weiner MW, Jagust WJ, Alzheimer's Disease Neuroimaging I (2011) Longitudinal change of biomarkers in cognitive decline. Arch Neurol 68, 1257-1266.

[8] Snider BJ, Fagan AM, Roe C, Shah AR, Grant EA, Xiong C, Morris JC, Holtzman DM (2009) Cerebrospinal fluid biomarkers and rate of cognitive decline in very mild dementia of the Alzheimer type. Arch Neurol 66, 638-645.

[9] Visser PJ, Verhey FR, Boada M, Bullock R, De Deyn PP, Frisoni GB, Frolich L, Hampel H, Jolles J, Jones R, Minthon L, Nobili F, Olde Rikkert M, Ousset PJ, Rigaud AS, Scheltens P, Soininen H, Spiru L, Touchon J, Tsolaki M, Vellas B, Wahlund LO, Wilcock G, Winblad B (2008) Development of screening guidelines and clinical criteria for predementia Alzheimer's disease. The DESCRIPA Study. Neuroepidemiology 30, 254-265.

[10] APA (1994) Diagnostic and Statistical Manual of Mental Disorders IV (IVth edn), American Psychiatric Association, Washington DC.

[11] McKhann G, Drachman D, Folstein M, Katzman R, Price D, Stadlan EM (1984) Clinical diagnosis of Alzheimer's disease: report of the NINCDS-ADRDA Work Group under the auspices of Department of Health and Human Services Task Force on Alzheimer's Disease. Neurology 34, 939-944.

[12] Folstein MF, Folstein SE, McHugh PR (1975) "Mini-mental state". A practical method for grading the cognitive state of patients for the clinician. J Psychiatr Res 12, 189-198. 
[13] Aisen PS, Petersen RC, Donohue MC, Gamst A, Raman R, Thomas RG, Walter S, Trojanowski JQ, Shaw LM, Beckett LA, Jack CR, Jr., Jagust W, Toga AW, Saykin AJ, Morris JC, Green RC, Weiner MW (2010) Clinical Core of the Alzheimer's Disease Neuroimaging Initiative: progress and plans. Alzheimers Dement 6, 239-246.

[14] Visser PJ, Verhey F, Knol DL, Scheltens P, Wahlund LO, Freund-Levi Y, Tsolaki M, Minthon L, Wallin AK, Hampel H, Burger K, Pirttila T, Soininen H, Rikkert MO, Verbeek MM, Spiru L, Blennow K (2009) Prevalence and prognostic value of CSF markers of Alzheimer's disease pathology in patients with subjective cognitive impairment or mild cognitive impairment in the DESCRIPA study: a prospective cohort study. Lancet Neuro/ 8, 619-627.

[15] Van der Elst W, van Boxtel MP, van Breukelen GJ, Jolles J (2005) Rey's verbal learning test: normative data for 1855 healthy participants aged 24-81 years and the influence of age, sex, education, and mode of presentation. J Int Neuropsychol Soc 11, 290-302.

[16] Welsh KA, Butters N, Mohs RC, Beekly D, Edland S, Fillenbaum G, Heyman A (1994) The Consortium to Establish a Registry for Alzheimer's Disease (CERAD). Part V. A normative study of the neuropsychological battery. Neurology 44, 609-614.

[17] Reitan R (1958) Validity of the Trial Making Test as an indication of organic brain damage. Percept Mot Skills 8, 271 - 276.

[18] van der Elst W, van Boxtel MP, van Breukelen GJ, Jolles J (2006) Normative data for the Animal, Profession and Letter M Naming verbal fluency tests for Dutch speaking participants and the effects of age, education, and sex. J Int Neuropsychol Soc 12, 80-89.

[19] Reijn TS, Rikkert MO, van Geel WJ, de Jong D, Verbeek MM (2007) Diagnostic accuracy of ELISA and XMAP technology for analysis of amyloid beta(42) and tau proteins. Clin Chem 53, 859-865.

[20] Albert MS, DeKosky ST, Dickson D, Dubois B, Feldman HH, Fox NC, Gamst A, Holtzman DM, Jagust WJ, Petersen RC, Snyder PJ, Carrillo MC, Thies B, Phelps CH (2011) The diagnosis of mild cognitive impairment due to Alzheimer's disease: recommendations from the National Institute on Aging-Alzheimer's Association workgroups on diagnostic guidelines for Alzheimer's disease. Alzheimers Dement 7, 270-279.

[21] Jack CR, Jr., Knopman DS, Weigand SD, Wiste HJ, Vemuri P, Lowe V, Kantarci K, Gunter JL, Senjem ML, Ivnik RJ, Roberts RO, Rocca WA, Boeve BF, Petersen RC (2012) An operational approach to National Institute on Aging-Alzheimer's Association criteria for preclinical Alzheimer disease. Ann Neurol 71, 765-775.

[22] Petersen RC, Aisen P, Boeve BF, Geda YE, Ivnik RJ, Knopman DS, Mielke M, Pankratz VS, Roberts R, Rocca WA, Weigand S, Weiner M, Wiste H, Jack CR, Jr. (2013) Mild cognitive impairment due to Alzheimer disease in the community. Ann Neurol 74, 199-208.

[23] Vos SJ, Xiong C, Visser PJ, Jasielec MS, Hassenstab J, Grant EA, Cairns NJ, Morris JC, Holtzman DM, Fagan AM (2013) Preclinical Alzheimer's disease and its outcome: a longitudinal cohort study. Lancet Neurol 12, 957-965. 
[24] Vos SJ, Verhey F, Frolich L, Kornhuber J, Wiltfang J, Maier W, Peters O, Ruther E, Nobili F, Morbelli S, Frisoni GB, Drzezga A, Didic M, van Berckel BN, Simmons A, Soininen H, Kloszewska I, Mecocci P, Tsolaki M, Vellas B, Lovestone S, Muscio C, Herukka SK, Salmon E, Bastin C, Wallin A, Nordlund A, de Mendonca A, Silva D, Santana I, Lemos R, Engelborghs S, Van der Mussele S, Alzheimer's Disease Neuroimaging I, Freund-Levi Y, Wallin AK, Hampel H, van der Flier W, Scheltens P, Visser PJ (2015) Prevalence and prognosis of Alzheimer's disease at the mild cognitive impairment stage. Brain 138, 1327-1338.

[25] Ivanoiu A, Sindic CJ (2005) Cerebrospinal fluid TAU protein and amyloid beta42 in mild cognitive impairment: prediction of progression to Alzheimer's disease and correlation with the neuropsychological examination. Neurocase 11, 32-39.

[26] Rolstad S, Berg Al, Bjerke M, Johansson B, Zetterberg H, Wallin A (2013) Cerebrospinal fluid biomarkers mirror rate of cognitive decline. J Alzheimers Dis 34, 949-956.

[27] Reijs BLR, Ramakers I, Kohler S, Teunissen CE, Koel-Simmelink M, Nathan PJ, Tsolaki M, Wahlund LO, Waldemar G, Hausner L, Vandenberghe R, Johannsen P, Blackwell A, Vanderstichele $H$, Verhey F, Visser PJ (2017) Memory Correlates of Alzheimer's Disease Cerebrospinal Fluid Markers: A Longitudinal Cohort Study. J Alzheimers Dis 60, 1119-1128.

[28] Price JL, Davis PB, Morris JC, White DL (1991) The distribution of tangles, plaques and related immunohistochemical markers in healthy aging and Alzheimer's disease. Neurobiol Aging 12, 295-312.

[29] Braak H, Braak E (1991) Neuropathological stageing of Alzheimer-related changes. Acta Neuropathol 82, 239-259.

[30] Brier MR, Gordon B, Friedrichsen K, McCarthy J, Stern A, Christensen J, Owen C, Aldea P, Su Y, Hassenstab J, Cairns NJ, Holtzman DM, Fagan AM, Morris JC, Benzinger TL, Ances BM (2016) Tau and Abeta imaging, CSF measures, and cognition in Alzheimer's disease. Sci Transl Med 8, 338ra366.

[31] Jack CR, Jr., Knopman DS, Jagust WJ, Shaw LM, Aisen PS, Weiner MW, Petersen RC, Trojanowski JQ (2010) Hypothetical model of dynamic biomarkers of the Alzheimer's pathological cascade. Lancet Neurol 9, 119-128.

[32] Jack CR, Jr., Knopman DS, Jagust WJ, Petersen RC, Weiner MW, Aisen PS, Shaw LM, Vemuri P, Wiste HJ, Weigand SD, Lesnick TG, Pankratz VS, Donohue MC, Trojanowski JQ (2013) Tracking pathophysiological processes in Alzheimer's disease: an updated hypothetical model of dynamic biomarkers. Lancet Neurol 12, 207-216.

[33] Prestia A, Caroli A, van der Flier WM, Ossenkoppele R, Van Berckel B, Barkhof F, Teunissen CE, Wall AE, Carter SF, Scholl M, Choo IH, Nordberg A, Scheltens P, Frisoni GB (2013) Prediction of dementia in $\mathrm{MCl}$ patients based on core diagnostic markers for Alzheimer disease. Neurology 80, 1048-1056. 
[34] Jack CR, Jr., Knopman DS, Chetelat G, Dickson D, Fagan AM, Frisoni GB, Jagust W, Mormino EC, Petersen RC, Sperling RA, van der Flier WM, Villemagne VL, Visser PJ, Vos SJ (2016) Suspected non-Alzheimer disease pathophysiology--concept and controversy. Nat Rev Neurol 12, 117 124.

[35] Landau SM, Harvey D, Madison CM, Reiman EM, Foster NL, Aisen PS, Petersen RC, Shaw LM, Trojanowski JQ, Jack CR, Jr., Weiner MW, Jagust WJ, Alzheimer's Disease Neuroimaging I (2010) Comparing predictors of conversion and decline in mild cognitive impairment. Neurology 75, 230-238.

[36] Heister D, Brewer JB, Magda S, Blennow K, McEvoy LK, Alzheimer's Disease Neuroimaging I (2011) Predicting $\mathrm{MCl}$ outcome with clinically available MRI and CSF biomarkers. Neurology 77, 1619-1628.

[37] Vos SJ, Visser PJ, Verhey F, Aalten P, Knol D, Ramakers I, Scheltens P, Rikkert MG, Verbeek MM, Teunissen CE (2014) Variability of CSF Alzheimer's disease biomarkers: implications for clinical practice. PLoS One 9, e100784.

[38] Mormino EC, Papp KV, Rentz DM, Schultz AP, LaPoint M, Amariglio R, Hanseeuw B, Marshall GA, Hedden T, Johnson KA, Sperling RA (2016) Heterogeneity in Suspected Non-Alzheimer Disease Pathophysiology Among Clinically Normal Older Individuals. JAMA Neurol 73, 1185 1191. 



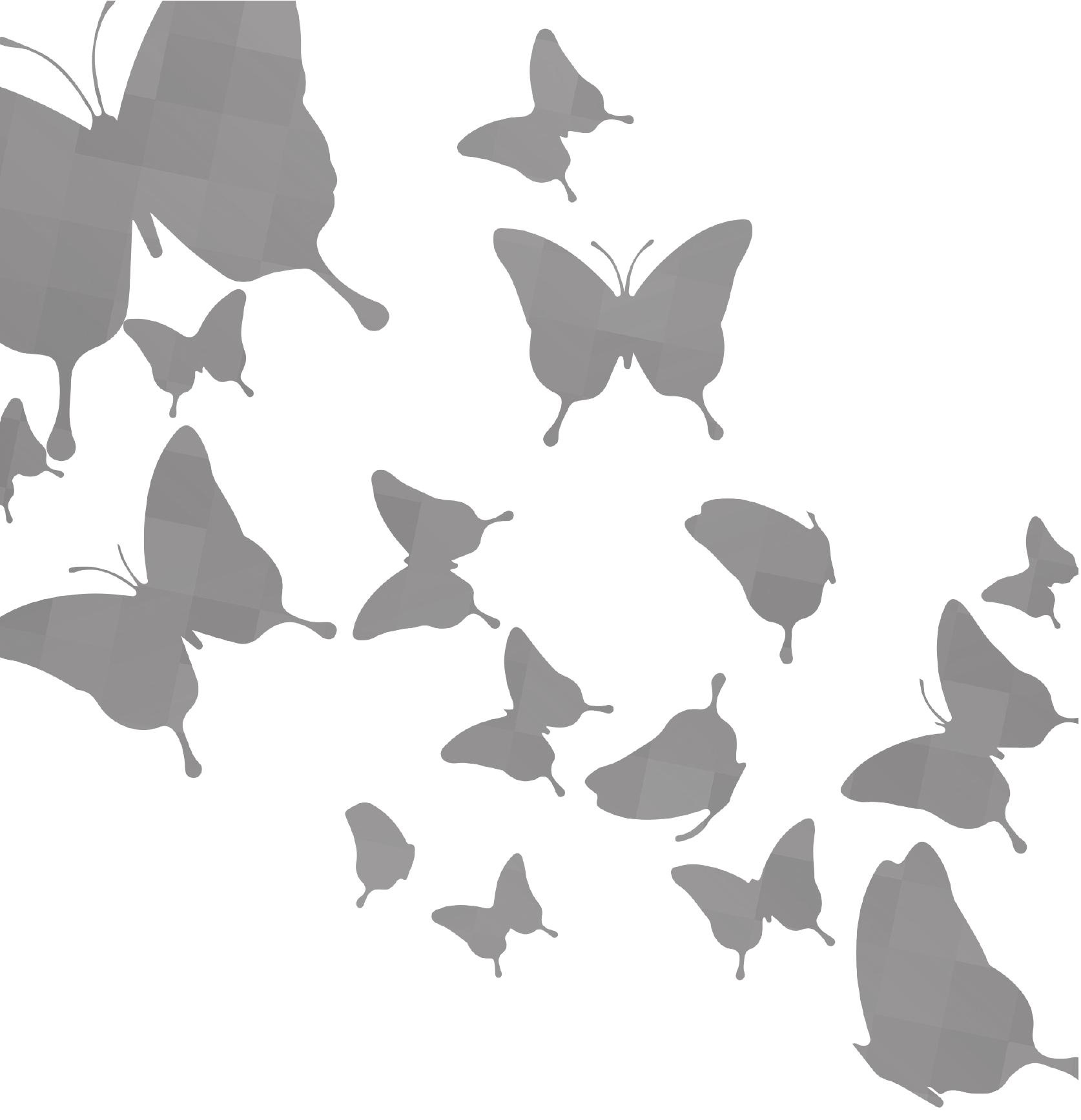




\section{Relation of odour identification with Alzheimer's disease markers in cerebrospinal fluid and cognition}

Babette L.R. Reijs

Inez H.G.B. Ramakers

Lyzel Elias-Sonnenschein

Charlotte E. Teunissen

Marleen Koel-Simmelink

Magda Tsolaki

Lars-Olof Wahlund

Gunhild Waldemar

Lucrezia Hausner

Peter Johannsen

Hugo Vanderstichele

Frans R.J. Verhey

D.P. Devanand

Pieter Jelle Visser

Published in: Journal of Alzheimer's

Disease (JAD) 2017;60:1025-1034.

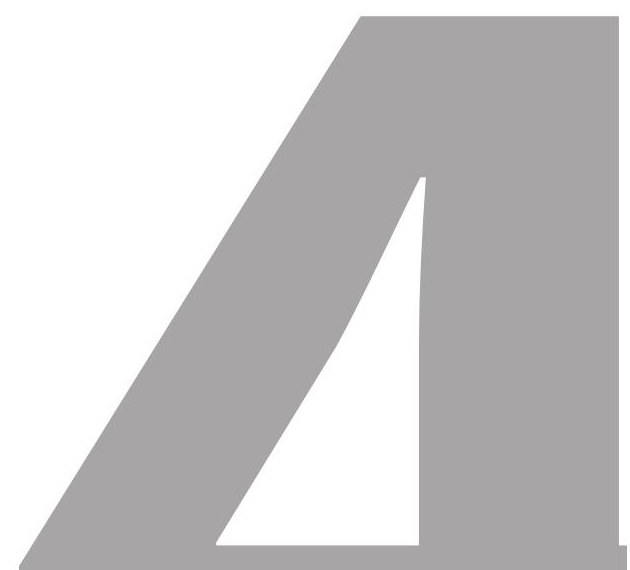




\section{ABSTRACT}

Background: Impaired olfactory function is an early characteristic of Alzheimer's disease (AD), but it remains unclear if odour identification also relates to early markers of $A D$ in cerebrospinal fluid (CSF).

Objective: To investigate the association between odour identification and beta amyloid 1-42 (aß42) and total tau (t-tau) concentrations in CSF. In addition, to examine the relation between odour identification and cognitive function at baseline and at follow-up, and whether these associations are moderated by CSF a 342 and t-tau and apolipoprotein E (APOE) genotype.

Methods: We included 160 individuals (40 with normal cognition, 45 with mild cognitive impairment $(\mathrm{MCl}), 42$ with AD-type dementia and 26 individuals with non$A D$ dementia) from the EDAR study. Individuals were recruited from six memory clinics across Europe. Odour identification was tested with the brief University of Pennsylvania Smell Identification Test (B-SIT). CSF a 342 and t-tau were assessed with INNO-BIA AlzBio3 Luminex assay. Neuropsychological assessment included tests for verbal memory, verbal fluency, attention, executive function, and visuoconstruction. Follow-up was performed within 3 years after baseline.

Results: Lower odour identification scores correlated with increased CSF t-tau concentrations and with lower scores on all cognitive measures at baseline independent of diagnostic group. Lower odour identification scores predicted decline on the MMSE in the total group, and decline on wordlist learning and delayed recall in APOE- $\varepsilon 4$ carriers and in individuals with abnormal a 342 .

Conclusion: Odour identification impairment may be an indicator of neuronal injury rather than amyloid pathology. 


\section{INTRODUCTION}

Impaired olfactory function is an early clinical feature of Alzheimer's disease (AD) [1, 2]. $A D$ is characterized by amyloid plaques, neurofibrillary tangles and neuronal loss in the brain. In early stages of the AD disease process, olfactory deficits have been correlated with neurofibrillary tangles in the central olfactory system and its olfactory projection areas [3-5]. Post-mortem studies have shown that the olfactory bulb is one of the first subcortical areas in which AD-related tau neurofibrillary tangles manifest $[3,6,7]$. In vivo, lower CSF beta amyloid 1-42 (aß42) reflects amyloid deposition and higher CSF total tau (t-tau) reflects neuroaxonal degeneration as assessed on neuropathological examination [8], but it remains unclear if odour identification is also correlated with these markers in CSF.

Olfactory identification deficits have also been correlated with memory functioning [9, 10] and with cognitive decline or conversion to AD-type dementia [11-13]. The central olfactory system projects to several regions in the Medial Temporal Lobe (MTL) [14], where episodic memory function is located. The association between olfaction and memory seems to be stronger in carriers of the apolipoprotein E (APOE)-e4 allele [15]. However, information is still limited on the association between odour identification and performance on non-memory tests, and whether this association is also modulated by APOE genotype and AD-related CSF markers. A commonly used test to assess odour identification deficits is the University of Pennsylvania Smell Identification Test (UPSIT) [16]. The UPSIT has a high sensitivity and specificity to detect olfaction deficits, and has been able to discriminate between individuals with Mild Cognitive Impairment (MCl), a possibly early stage of Alzheimer's disease (AD) and AD-type dementia, and between $\mathrm{MCl}$ and normal cognition [11]. In this study, we examined whether odour identification, measured by a brief version of the UPSIT (i.e. the Brief Smell Identification Test (B-SIT) [17], is associated with CSF a $\beta 42$ and t-tau concentrations. Second, we examined the relation between odour identification scores and cognitive function at baseline and follow-up, and whether these associations are dependent on AD-related CSF markers and APOE genotype. We tested these associations along the clinical spectrum from normal cognition to dementia. 


\section{MATERIALS AND METHODS}

\section{Individuals}

We included 160 individuals from the European study "Beta amyloid oligomers in the early diagnosis of $A D$ and as marker for treatment response" (acronym: EDAR) based on availability of CSF, cognition scores and scores on the B-SIT. Individuals were recruited from six memory clinics across Europe between 2008 and 2010 and represented individuals with normal cognition $(n=40)$, mild cognitive impairment $(M C l)(n=45)$, AD-type dementia ( $n=42)$, non-AD type dementia $(n=26$, FTD $(n=14), D L B(n=7)$ and $\operatorname{VaD}(n=5))$ and 7 individuals that were not demented but could not be classified to a diagnostic group (see below). Follow-up assessments were performed in $80(50 \%)$ individuals within 3 years after baseline.

Individuals with normal cognition were recruited among patients attending the memory clinic $(n=16)$ or from other settings (partners from patients or via advertisements, $n=24)$. Inclusion criteria for individuals with normal cognition were: age above 40 years, no cognitive impairment on neuropsychological tests and age and education corrected Mini Mental State Examination score (MMSE [18]) above the $10^{\text {th }}$ percentile based on local norms (unpublished data from Maastricht Aging Study). The MMSE cuts points for individuals aged respectively 40-53 years, 54-63 years, 64-73 years and age $>73$ years were for individuals with less than 8 years of education respectively $25,24,24$, and 23; for individuals with 8-12 years of education respectively $27,26,26$, and 24 ; and for individuals with more than 12 years of education respectively $27,27,26$, and 25. Individuals with normal cognition from outside the memory clinic did not differ from individuals with normal cognition from the memory clinic with respect to age, educational level, MMSE score, and neuropsychological test scores. Inclusion criteria for individuals with $\mathrm{MCl}$ were: memory clinic referral for the evaluation of cognitive complaints, age above 60 years, a MMSE-score above 19, a cognitive impairment on neuropsychological tests, defined as a z-score (corrected for age, gender and education) below -1.5 on one or more neuropsychological tests (for tests see section cognition measures) according to Petersen's criteria [19] and the absence of a clinical diagnosis of dementia. Inclusion criteria for individuals with dementia were age above 40 years and a clinical diagnosis of probable or possible AD-type dementia according to the NINCDSADRDA criteria [20], fronto-temporal dementia (FTD) [21], vascular dementia (VaD) according to the NINDS-AIREN criteria [22] or Lewy body dementia (DLB) [23]. Exclusion criteria for all individuals were contra-indications for lumbar puncture or any disorder probably related to cognitive impairment other than neurodegeneration. 
Seven individuals could not be classified to a diagnostic subgroup because they had no cognitive complaints but performed poorly on one or more cognitive tests at baseline with a z-score equal to or below -2 (2 controls) or because of missing test scores (5 individuals with cognitive complaints) but they were included in the total group analyses. All individuals provided written informed consent and the medical ethics committee at each centre approved the study.

\section{Baseline and follow-up assessment}

Baseline assessments included clinical history, physical examination, neuroimaging, routine laboratory tests for blood and CSF, the MMSE and the Clinical Dementia Rating scale (CDR [24]), Functional Assessment Questionnaire (FAQ [25]), a neuropsychological examination and an odour identification test (see below). Follow-up assessments were similar to baseline except for laboratory tests and neuroimaging and were performed once or twice within 3 years after baseline coded in 6-month intervals.

\section{Brief Smell Identification Test}

The Brief Smell Identification Test (B-SIT) is a brief 12-item version of the 40-item University of Pennsylvania Smell Identification Test (UPSIT) [17]. In the B-SIT 12 strips are embedded with microencapsulated odourants. After scratching the strip an odourant is released and the individual has to select the identity from 4 suggested odourants. The B-SIT was administered in the individual's own language. Scores ranged from 0 (no odour correctly identified) to 12 (all odours correctly identified). Individuals were excluded if they completed less than 10 items ( $n=11$; one individual without dementia with missing cognitive tests scores, three with $\mathrm{MCl}$, three with AD-type dementia; one with possible vascular dementia and two with FTD). In individuals with 1 or 2 missing scores, a chance-level score of 0.25 was imputed for each missing item.

\section{Cognition measures}

General cognitive function was assessed with the MMSE. The neuropsychological test battery included tests for memory (wordlist learning and delayed recall of the Consortium to Establish a Registry for Alzheimer's Disease neuropsychological battery (CERAD) [26]), semantic memory and language (animal fluency), information processing speed (Trail Making Test (TMT) A), executive function (TMT B), and visuoconstruction (CERAD copy figures). Z-scores (corrected for age, gender and education) for the CERAD wordlist learning and delayed recall, TMT A and B and copy figures were calculated according to the CERAD-Plus norms [26, 27]. For the animal fluency test, $z$-scores were calculated according to the norms by van der Elst et al. [28]. 


\section{CSF and DNA collection, storage and analysis}

CSF was collected via a lumbar puncture in $10 \mathrm{~mL}$ polypropylene tubes, centrifuged at 4 degrees at $2000 \times g$ and stored at $-80^{\circ} \mathrm{C}$ within one hour after collection. A $\beta 42$ and t-tau concentrations were measured with the INNO-BIA AlzBio3 Luminex assay (Fujirebio, formerly Innogenetics, Gent, Belgium). All CSF analyses were performed at the end of the study, in one batch, at the VU University Medical Centre (VUmc) in Amsterdam in the Netherlands. CSF concentrations below $389(\mathrm{pg} / \mathrm{ml})$ for aß42, and above $98(\mathrm{pg} / \mathrm{ml})$ for t-tau were considered abnormal according to local cut off values for this assay at the VUmc [29]. Investigators that collected the clinical data were blinded to the CSF results. APOE genotype was determined by Polymerase Chain Reaction (PCR) of genomic DNA extracted from EDTA anticoagulated blood.

\section{Statistical analyses}

Data were analysed with IBM SPSS statistics version 22. Group differences in baseline characteristics were examined with a one-way ANOVA for continuous variables and $X^{2}$ -tests for categorical variables. The relationship between B-SIT scores and CSF markers and between B-SIT scores and cognitive measures were analysed by performing linear mixed with random effects for individual intercepts within centre (nested design). Age, gender, and education were included as covariates when it would improve the model fit. Age was included in all analysis, and the analyses with cognitive outcomes were corrected for gender and education as well. In addition, we tested the association of a low B-SIT score (score $<9[30,31]$ ) and abnormal a 342 (score below 389) and abnormal tau (score above 98) with logistic regression corrected for age and centre.

The association of the B-SIT with cognitive decline over time was examined with linear mixed models analyses of the time-by-B-SIT interaction, corrected for age, gender and education with random effects for individual intercepts within centre (nested design). If required for a better fit according to likelihood ratio tests, random slopes were also included to allow for heterogeneity in individual trajectories over time. Post-hoc, a similar linear mixed model analysis was performed of a time-by-B-SIT performance level interaction to graphically display the association of MMSE scores over time in low and in high B-SIT performers. Current smoking (yes versus no) was not significant and therefore excluded from the models. The interaction effect of diagnosis and APOE-e4 status (carriers of one or two e4 alleles versus no e4 allele) were included separately in a second model to examine a possible moderator effect. For the cognition measures, the moderator effect of the CSF markers was also included. A p-value of $<0.05$ for two-sided tests was considered statistically significant. 


\section{RESULTS}

Baseline characteristics for the total group and the subgroups are presented in Table 1. Individuals were on average 67 years old, had 11 years of education and more than half of the individuals were male (57\%). Individuals with normal cognition, $\mathrm{MCl}, \mathrm{AD}$-type dementia and non-AD dementia did not differ on age or education. Males were more common in the non-AD dementia group than in the normal cognition, $\mathrm{MCl}$ and $\mathrm{AD}$-type dementia group. Scores on the MMSE, FAQ, CDR memory test, cognitive tests and CSF markers differed between groups as expected. APOE genotyping was available for 127 individuals (79\%). The number of carriers of one or more APOE-e4 alleles was high in the AD-type dementia (70\%) and $\mathrm{MCl}(62 \%)$ group and low in the non-AD dementia group (30\%). Lower B-SIT scores were found in individuals with AD-type dementia and with non-AD dementia compared with individuals with $\mathrm{MCl}$ or normal cognition.

\section{B-SIT scores and CSF markers}

In the total group, lower B-SIT scores were associated with increased CSF t-tau concentrations, but not with CSF a 342 concentrations (figure 1, table 2). The association between B-SIT scores and CSF markers was independent of diagnosis, APOE-e4 status and the other CSF marker. A low B-SIT score was associated with increased likelihood for abnormal tau $(\mathrm{OR}=2.84, \mathrm{p}<.05)$ but not abnormal a $\beta 42(\mathrm{OR}=1.88, \mathrm{p}=.12)$, table 3). The association with abnormal tau was strongest in individuals with $A D$-type dementia with a low B-SIT score ((OR=23.25, $\mathrm{p}<.05)$, table 3$)$.

\section{B-SIT scores and cognition}

In the total group, lower B-SIT scores were associated with lower scores on the MMSE, wordlist learning, wordlist delayed recall, animal fluency, TMT A, TMT B and copy figures (table 2, figure 2). The association differed between diagnostic groups for the MMSE and TMT part A. The relation between B-SIT and MMSE scores was stronger in individuals with AD-type dementia than in individuals with $\mathrm{MCl}$ (difference $\beta=0.60, p<0.01$ ). The relation between B-SIT scores and scores on the TMT part A was stronger in individuals with $A D$-type dementia than in individuals with $\mathrm{MCl}$ (difference $\beta=0.39, p<0.05$ ) and normal cognition (difference $\beta=0.38, p<0.05$ ). The association between B-SIT scores and cognition measures were independent of APOE-e4 carriership and independent of abnormal CSF aß42 and t-tau concentrations. 
Table 1. Baseline characteristics

\begin{tabular}{|c|c|c|c|c|c|}
\hline & All $(n=160)$ & $\begin{array}{l}\text { Normal } \\
\text { cognition } \\
(n=40)\end{array}$ & $\begin{array}{c}\mathrm{MCl} \\
(n=45)\end{array}$ & $\begin{array}{c}\text { AD-type } \\
\text { dementia } \\
(\mathrm{N}=42)\end{array}$ & $\begin{array}{c}\text { Non-AD } \\
\text { dementia } \\
(\mathrm{N}=\mathbf{2 6})\end{array}$ \\
\hline Age, mean (SD) & $67.3(9.4)$ & $65.8(10.6)$ & $69.5(9.4)$ & $66.6(8.4)$ & $66.9(9.6)$ \\
\hline Male, n (\%) & $91(57)$ & $21(53)^{+}$ & $25(56)$ & $21(50)^{+}$ & $20(77)^{\# \S}$ \\
\hline Education, mean y (SD) & $11.2(3.7)$ & $12.1(2.7)$ & $10.5(3.6)$ & $11.3(3.9)$ & $11.4(4.7)$ \\
\hline $\mathrm{FAQ}, \mathrm{n}$ & 134 & 36 & 43 & 32 & 18 \\
\hline Mean (SD) & $6.8(7.8)$ & $1.6(3.1)^{\wedge \text { §+ }}$ & $5.0(7.0)^{\# 5+}$ & $12.4(6.7)^{\# \wedge}$ & $12.4(9.1)^{\# \wedge}$ \\
\hline MMSE, $\mathrm{n}$ & 156 & 40 & 45 & 41 & 23 \\
\hline Mean (SD) & $26.3(3.2)$ & $28.9(1.3)^{\wedge \S+}$ & $27.2(1.8)^{\# \S+}$ & $23.2(3.2)^{\# \wedge+}$ & $25.5(3.4)^{\# \wedge \S}$ \\
\hline CDR-SOB, $\mathrm{n}$ & 138 & 37 & 45 & 32 & 19 \\
\hline Mean (SD) & $2.3(2.6)$ & $0.6(1.2)^{\wedge \S+}$ & $1.7(1.2)^{\# \S+}$ & $4.3(2.6)^{\# \wedge}$ & $4.5(3.6)^{\# \wedge}$ \\
\hline APOE-e4+, n (\%) & $72(57)$ & $11(48)$ & $23(62)^{+}$ & $26(70)^{+}$ & $7(30)^{\wedge \S}$ \\
\hline CSF markers, $\mathrm{n}$ & 132 & 25 & 39 & 36 & 25 \\
\hline $\mathrm{a} \beta 42(\mathrm{pg} / \mathrm{ml})$, mean (SD) & $357(152)$ & $418(158)^{\S}$ & $368(127)^{\S}$ & $278(132)^{\# \wedge+}$ & $381(175)^{\S}$ \\
\hline Abnormal a $\beta 42, \mathrm{n}(\%)$ & $79(60)$ & $9(38)^{\wedge \S}$ & $26(67)^{\#}$ & $29(81)^{\#+}$ & $12(48)^{5}$ \\
\hline t-tau (pg/ml), mean (SD) & $109(63)$ & $78(25)^{\wedge \S}$ & $111(68)^{\# 5+}$ & $150(73)^{\sharp \wedge+}$ & $81(36)^{\wedge \S}$ \\
\hline Abnormal t-tau, n (\%) & $66(50)$ & $5(21)^{\wedge \S}$ & $19(49)^{\# \S}$ & $30(83)^{\# \wedge+}$ & $9(36)^{\S}$ \\
\hline B-SIT, Mean (SD) & $6.8(2.6)$ & $8.7(2.1)^{\wedge \S+}$ & $6.7(2.4)^{\# 5+}$ & $5.7(2.4)^{\# \wedge}$ & $5.4(2.1)^{\# \wedge}$ \\
\hline Low B-SIT performers, n (\%) & $116(73)$ & $17(43)^{\wedge \S+}$ & $36(80)^{\#}$ & $36(86)^{\#}$ & $24(92)^{\#}$ \\
\hline Cognition (z-scores), n & 136 & 35 & 44 & 35 & 20 \\
\hline $\begin{array}{l}\text { Wordlist learning, } \\
\text { mean (SD) }\end{array}$ & $-1.6(1.8)$ & $0.2(1.0)^{\wedge \varsigma+}$ & $-2.0(1.5)^{\# \S}$ & $-2.8(1.3)^{\# \wedge+}$ & $-1.7(1.9)^{\# \S}$ \\
\hline $\begin{array}{l}\text { Wordlist delayed recall, } \\
\text { mean (SD) }\end{array}$ & $-1.4(1.7)$ & $0.1(0.9)^{\wedge \S+}$ & $-1.6(1.5)^{\# \S}$ & $-2.7(1.3)^{\# \wedge+}$ & $-1.3(1.8)^{\# \S}$ \\
\hline $\begin{array}{l}\text { Animal fluency, } \\
\text { mean (SD) }\end{array}$ & $-1.2(1.1)$ & $-0.3(0.8)^{\wedge \varsigma_{+}}$ & $-1.0(1.0)^{\# \S+}$ & $-1.5(0.9)^{\# \wedge}$ & $-1.9(1.1)^{\# \wedge}$ \\
\hline TMTA, mean (SD) & $-0.9(2.1)$ & $0.7(0.9)^{\wedge \S+}$ & $-0.9(1.8)^{\# \S}$ & $-2.2(2.3)^{\# \wedge}$ & $-1.7(1.9)^{\#}$ \\
\hline TMTB, mean (SD) & $-1.0(2.2)$ & $0.9(0.7)^{\wedge \S+}$ & $-0.5(1.5)^{\# \S+}$ & $-2.7(2.1)^{\# \wedge}$ & $-2.0(2.2)^{\# \wedge}$ \\
\hline Copy figures, mean (SD) & $-0.9(2.1)$ & $0.5(0.7)^{\wedge \S+}$ & $-0.9(2.1)^{\# \S}$ & $-1.7(2.4)^{\# \wedge}$ & $-1.7(2.0)^{\#}$ \\
\hline
\end{tabular}

Data are mean (SD) or valid percent. Abbreviations: FAQ, Functional Assessment Questionnaire; MMSE, Mini-Mental State Examination; CDR-SOB, Clinical dementia Rating, Sum of Boxes; APOE, Apolipoprotein E; CSF, Cerebrospinal fluid; A $\beta 42$, beta amyloid 1-42; t-tau, total tau; B-SIT; the Brief Smell Identification Test; TMT, Trail Making Test; MCl, Mild Cognitive Impairment, $A D$, Alzheimer's disease. ${ }^{*} p<.05$ compared to normal cognition, ${ }^{\wedge} p<.05$ compared to $M C l,{ }^{\S}$ compared to $A D$, ${ }^{+}$compared to non-AD dementia. 


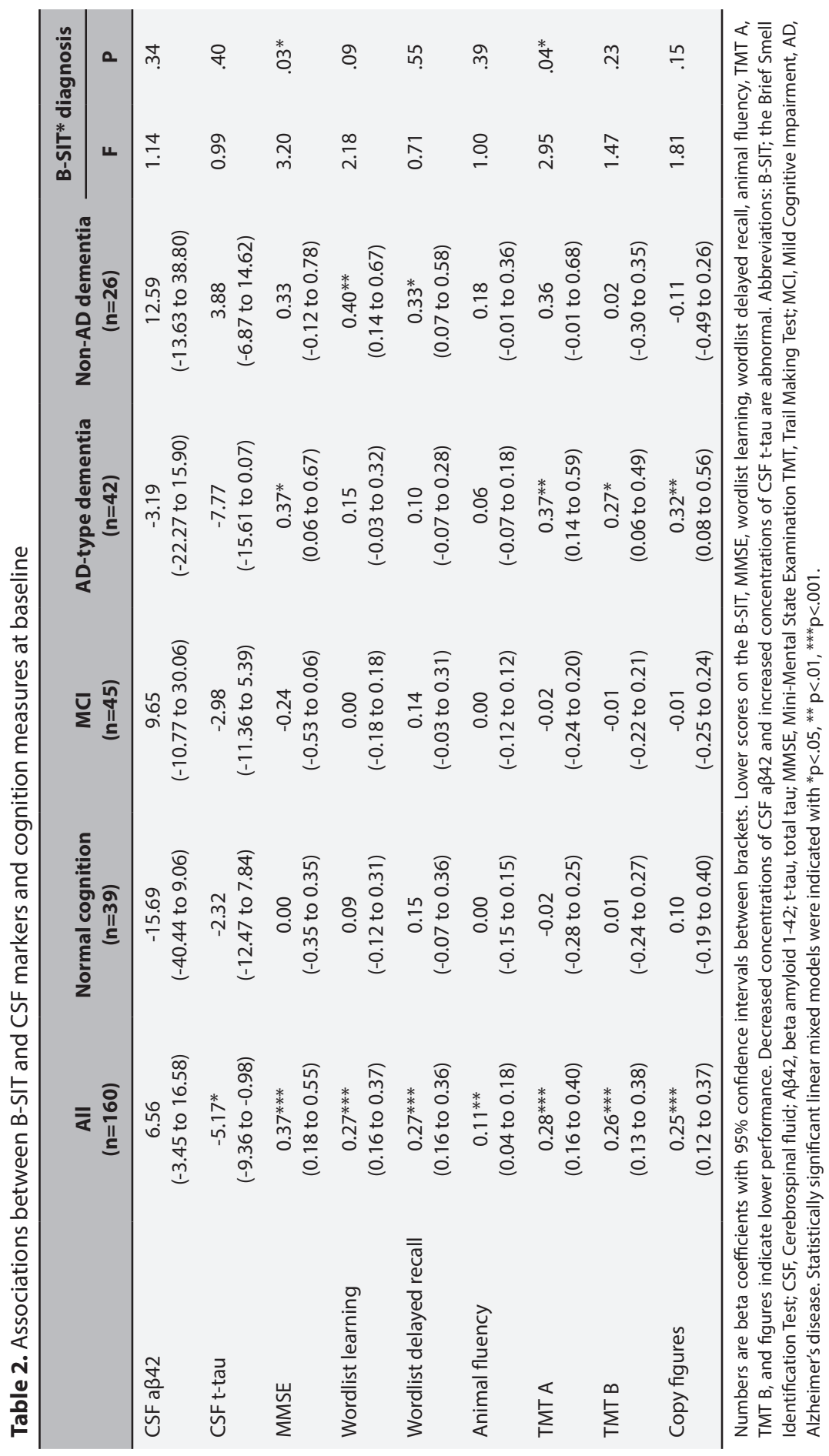




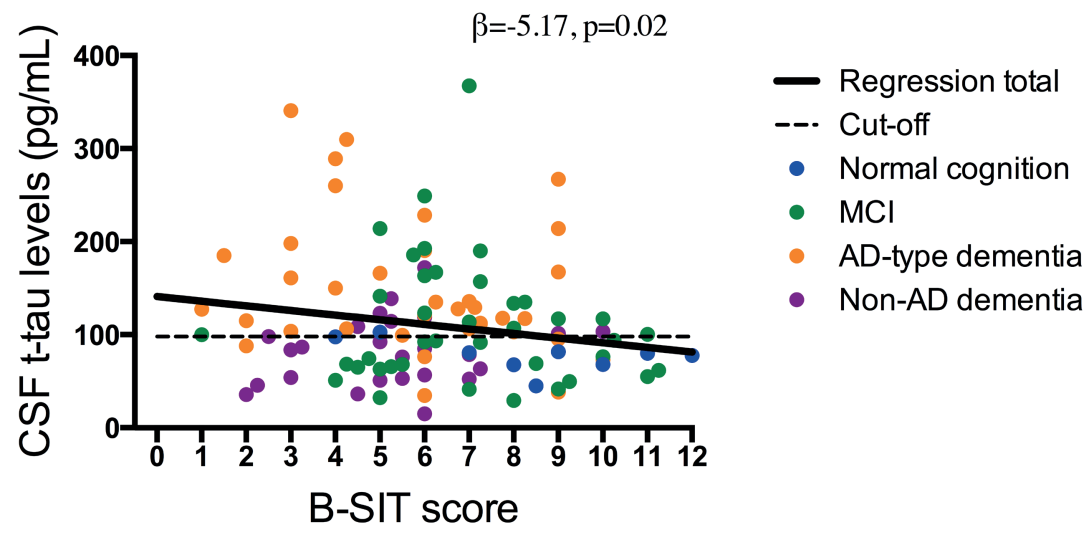

Figure 1. Associations at baseline between B-SIT scores and CSF t-tau concentrations

Figure displays count of individuals with normal cognition (blue), $\mathrm{MCl}$ (green), AD-type dementia (orange) and non- $\mathrm{AD}$ dementia (purple) with regression line of the total group and with a cut-off line for t-tau concentrations.

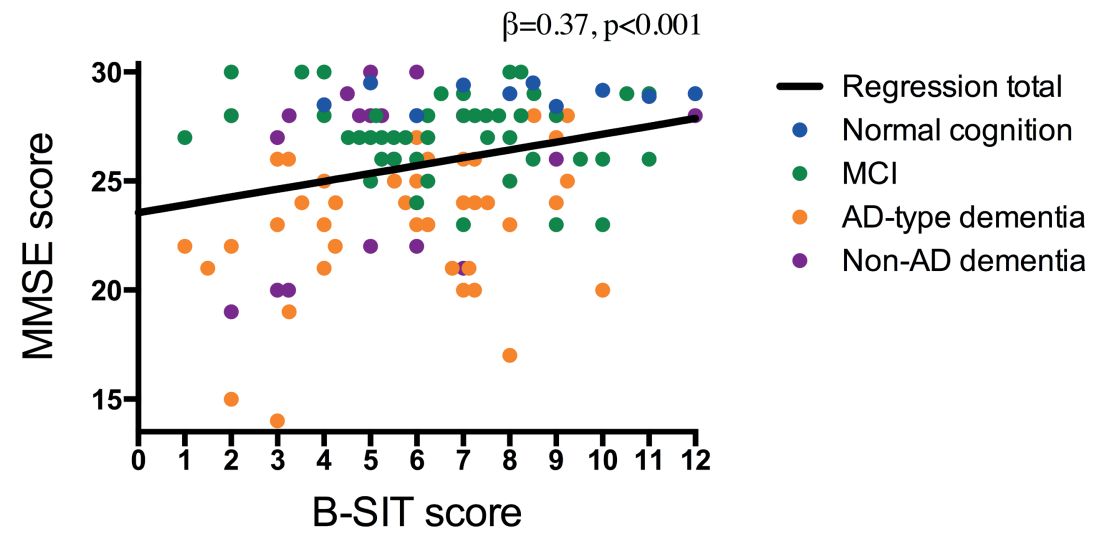

Figure 2. Associations at baseline between B-SIT scores and MMSE scores

Figure displays count of individuals with normal cognition (blue), $\mathrm{MCl}$ (green), AD-type dementia (orange) and non-AD dementia (purple) with regression line of the total group. 
Table 3. Association of low B-SIT scores with presence of abnormal a $\beta 42$ and abnormal tau

\begin{tabular}{lcc} 
& Abnormal a $\mathbf{\beta 4 2}$ & Abnormal t-tau \\
\hline Normal cognition $(n=25)$ & $0.96(0.16$ to 5.80$)$ & $2.58(0.17$ to 40.09$)$ \\
MCl $(n=39)$ & $0.93(0.19$ to 4.69$)$ & $2.20(0.44$ to 10.99$)$ \\
AD-type dementia $(n=36)$ & $0.79(0.07$ to 9.10$)$ & $23.25(1.39 \text { to } 388.05)^{*}$ \\
Not demented $(n=71)^{a}$ & $1.85(0.69$ to 4.98$)$ & $3.03(0.98$ to 9.34$)$ \\
Demented $(n=61)^{b}$ & $1.10(0.22$ to 5.45$)$ & $1.18(0.24$ to 5.79$)$ \\
All $(n=132)$ & $1.88(0.85$ to 4.19$)$ & $2.84(1.24 \text { to } 6.51)^{*}$ \\
\hline
\end{tabular}

Numbers are odds ratios with $95 \%$ confidence intervals between brackets. Abnormal a $\beta 42$ is defined as a score below 389 , abnormal tau as a score above 98 . No odds ratio could be estimated in individuals with non-AD dementia as none of the individuals had abnormal a 342 or tau in combination with a high B-SIT score. Individuals with normal cognition $(n=25)$, $\mathrm{MCl}(n=39)$ and individuals without dementia who could not be classified to a diagnostic group $(n=7) ;{ }^{b}$ Individuals with AD-type dementia $(n=36)$ and non-AD dementia $(n=25)$. Abbreviations: B-SIT; the Brief Smell Identification Test. * $p<.05$.

\section{B-SIT scores and cognitive decline over time}

Follow-up data were available for 80 individuals, including 20 individuals with normal cognition, 33 with $\mathrm{MCl}$ and 23 with AD-type dementia at baseline. Another 4 individuals without dementia were included who could not be classified to a diagnostic group because of no cognitive complaints but a z-score equal to or below -2 on neuropsychological tests ( 1 individual) or because of missing tests scores ( 3 individuals). Individuals with non-AD dementia ( 2 individuals) were excluded in the longitudinal analyses due to the small sample size. The average follow-up interval was 1.28 (SD= 0.52 ) years. Individuals with follow-up data, in the total group and in the subgroups, did not differ from individuals with only baseline data on MMSE score, age, gender, and education.

In the total group, lower baseline B-SIT scores at baseline were associated with decline on only the MMSE score at follow-up (table 4, figure 3). These associations were independent of diagnostic group. The relation between B-SIT scores and decline on the wordlist learning and delayed recall at follow-up was dependent on APOE-e4 carriership and a 342 status (supplementary table). The relation between lower B-SIT scores and decline on delayed recall was stronger in APOE-e4 carriers $(\beta=0.07, p<0.05)$ than in non-carriers $(\beta=-0.04, p=0.25)$. The relation between lower $B$-SIT scores and decline on wordlist learning and delayed recall was stronger in individuals with abnormal a $\beta 42$ concentrations (wordlist learning: $\beta=0.07, p<0.05$; wordlist delayed recall: $\beta=0.07$, $p<0.05$ than in individuals with normal a $\beta 42$ concentrations (wordlist learning: $\beta=-0.05$, $p=0.16$; wordlist delayed recall: $\beta=-0.06, p=0.09$ ). The associations between B-SIT scores and cognition were independent of t-tau status for all measures. 
Table 4. Associations between B-SIT and cognition performance at follow-up in the total group $(\mathrm{N}=80)$

\begin{tabular}{lcccc}
\hline & \multicolumn{1}{c}{ Time } & & Time*B-SIT*diagnosis \\
\cline { 4 - 5 } & $-1.56(-2.20 \text { to }-0.92)^{* * *}$ & $0.16(0.08 \text { to } 0.25)^{* * *}$ & 0.24 & .79 \\
\hline MMSE & $-0.19(-0.52$ to 0.15$)$ & $0.03(-0.02$ to 0.07$)$ & 1.06 & .35 \\
Wordlist learning & $-0.23(-0.53$ to 0.08$)$ & $0.03(-0.01$ to 0.06$)$ & 0.65 & .52 \\
Wordlist delayed recall & $-0.09(-0.32$ to 0.15$)$ & $0.01(-0.02$ to 0.04$)$ & 0.45 & .96 \\
Animal fluency & $0.07(-0.26$ to 0.40$)$ & $-0.10(-0.05$ to 0.03$)$ & 0.98 & .38 \\
TMT A & $-0.31(-0.70$ to 0.08$)$ & $0.03(-0.02$ to 0.08$)$ & 0.84 & .44 \\
TMT B & $0.01(-0.33$ to 0.36$)$ & $-0.01(-0.05$ to 0.04$)$ & 0.15 & .99 \\
Copy figures &
\end{tabular}

The slope for time indicates the change in cognitive score per 6 months follow-up in the total group. The time-by-B-SIT interaction indicates how the slope differs from the time slope as a function of B-SIT score. For example, the MMSE decline on average 1.56 per 6 months follow-up. For every increase in B-SIT score at baseline the slope on the MMSE improves with 0.16. Abbreviations: B-SIT; the Brief Smell Identification Test; MMSE, Mini-Mental State Examination; TMT, Trail Making Test; Numbers are beta coefficients with $95 \%$ confidence intervals between brackets. ${ }^{* *} p<.001$.

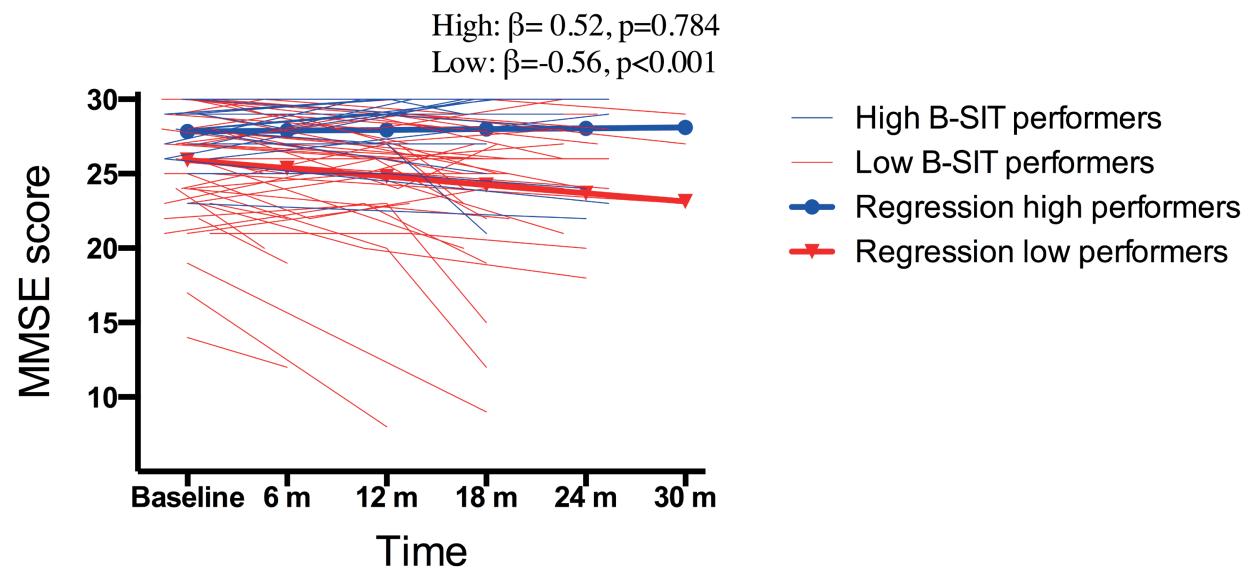

Figure 3. MMSE scores over time in high and low B-SIT performers

Figure displays thin individual lines of high B-SIT performers (thin blue lines, i.e. B-SIT score 9 or greater) $(n=22)$ and low B-SIT performers (thin red lines, i.e. B-SIT score less than 9) $(n=57)$ on the MMSE score over time with solid corresponding regression lines for the two groups. 


\section{DISCUSSION}

Our main results are that lower odour identification scores correlated with increased CSF t-tau concentrations and with lower scores on all cognition measures. Over time, lower identification scores at baseline were associated with a larger decline on the MMSE in the total group.

The observed relation between odour identification scores and CSF tau is in line with post-mortem research showing that in early stage of $A D$ neurofibrillary tangles are present in the olfactory bulb and the primary and secondary olfactory cortex, including the entorhinal cortex [5] and brain areas involved in transmodal object representation such as the temporal pole. We did not find an association between odour identification and $a \beta 42$ concentrations. Similarly, previous research also found that olfactory identification is not strongly related to amyloid deposition measured with in vivo amyloid imaging [32,33]. The associations between odour identification scores and CSF markers were independent of diagnostic group.

Lower scores on odour identification correlated with lower scores on all cognition measures at baseline. Stronger associations between odour identification and scores on the MMSE and TMT part A were found in individuals with AD-type dementia than in individuals that were not demented. For most other cognitive tests, the associations between odour identification scores and cognitive performances were stronger in individuals with dementia than in individuals without dementia although these differences were not statistically significant. This may suggest that odour identification scores become abnormal in more advanced stages of the disease. This could also explain the stronger correlations between odour identification scores and cognition than between odour identification scores and CSF biomarkers, which are suspected to become abnormal earlier in the AD disease course $[34,35]$.

Longitudinally, we found that in the total group lower odour identification scores at baseline correlated with larger decline in scores on the MMSE. These findings are consistent with previous community studies showing an association between odour identification scores and decline on a general cognitive functioning measure [12,36].The reason that we only found an association with the MMSE may be explained by the fact that the MMSE does not have a floor effect in mild-moderate dementia and is perhaps less vulnerable to practice effects as opposed to cognitive tests. The association between odour identification scores and cognitive decline was independent of APOE-e4 status and CSF markers except for decline in memory scores. For these memory measures, the association with odour identification scores was stronger in APOE-e4 allele carriers 
and in individuals with abnormal a $\beta 42$. This is in line with previous research showing solely an association in APOE-e4 allele carriers between odour identification scores and long-term episodic memory decline [15]. Conceivably, as both APOE-e4 and amyloid pathology are strongly associated with $A D$, the association between odour identification and memory decline may be stronger in these individuals because of more severe underlying $A D$ pathology.

Interestingly, the correlations of the B-SIT score with AD biomarkers tended to differ between individuals with AD-type dementia and individuals with non-AD dementia, despite similar odour impairments. B-SIT scores in the non-AD dementia group were as low as in the AD-type dementia group; yet only one-third (36\%) in the non-AD dementia group had abnormal t-tau concentrations compared with a majority (83\%) in the AD-type dementia group. In addition, the relationship between B-SIT scores and CSF tau concentrations was reversed in the non-AD dementia group. This suggests that different mechanisms underlie impaired odour recognition and that this impairment is not just an effect of the dementia itself.

Arguably, other pathologies may be the cause of impaired odour identification in individuals without dementia. Alpha-synucleinopathy has been found in the olfactory bulb in an early stage of DLB [37,38], and it has been linked to odour dysfunction. Indeed, in the non-AD dementia group, individuals with DLB $(n=7)$ had the lowest B-SIT scores (DLB: mean 4.71, $S D=2.98)$. B-SIT scores were also low in individuals with $\operatorname{VaD}(n=5$, mean $6.00, S D=2.12)$ and FTD ( $n=14$, mean: 5.51, SD=2.27), which is consistent with previous evidence suggesting impairment in odour identification in these disorders [39-41]. Yet, in these groups CSF tau concentrations are often not as high as in AD-type dementia [42]. This suggests that the underlying pathology for low B-SIT scores may depend on the clinical group in which the test is performed.

Although the memory and language component in the B-SIT is minimized due to multiple-choice options facilitating cueing, the impaired B-SIT scores may also result from AD memory dysfunction. However, after correction for semantic memory performance as assessed by verbal fluency, the relation between the B-SIT score and CSF $a \beta 42$ and tau remained similar ( $a \beta 42: \beta=7.44$ (-2.93 to 17.81$)$; $t$-tau: $\beta=-5.24$ (-9.44 to -1.03$)$ ). Previous studies showed that associations between odour recognition and neuropathology are independent of semantic memory [4]. This suggests that the effect of odour identification cannot only be explained by impairments in semantic memory. 
The limitations of the study are: first, the relatively small sample size of the subgroups could have resulted in a type II error. Second, our main outcome was the association of B-SIT scores with CSF and clinical markers in the total group for two biomarkers and seven cognitive markers, which may have resulted in a type I error. However, when corrected for multiple testing according to Benjami-Hochberg, all our findings remained significant. Third, the follow-up time was relatively short. Fourth, there is a possible selection bias due to the drop out at follow-up because of poor cognitive functioning. Individuals with follow-up data, however, did not differ on MMSE score, age gender or education from individuals with only baseline data, which makes selection bias less likely. Fifth, no imaging data was available for testing. Odour identification was associated with specific atrophy patterns [43-45]. Lastly, we used a brief version of the UPSIT. Previous studies have shown that the brief 12-item version has a somewhat lower reliability than the 40 -item version (.71 versus .95) and may have a lower predictive utility than the 40-item version for the transition from $\mathrm{MCl}$ to AD-type dementia [31], but the mean and frequency distribution were similar $[16,17]$. Furthermore, the reliability of the brief 12-item version is still high and because the administration time is less than 5 minutes it is easier to incorporate in clinical routine.

To conclude, our study shows a relationship between lower odour identification and increased tau concentration suggesting that odour identification correlates better with measures of tau than with amyloid markers. Still, in non-AD dementias low odour identification scores may be associated with non-tau pathologies as well. This limits the use of odour identification tests in the differential diagnosis of individuals with dementia. In addition, odour identification correlated with lower cognitive performances at baseline and with decline over time on the MMSE. Future longitudinal studies with a longer follow-up duration are recommended to further examine the prognostic value of odour identification tests in predicting AD-related pathology and cognitive decline.

\section{Acknowledgment}

The EDAR study was funded by the European Commission as part of the $6^{\text {th }}$ Framework Programme (contract \# 37670). We thank Nico Rozendaal for the provision of the IT infrastructure and Innogenetics for the provision of INNO-BIA AlzBio3 kits. 


\section{REFERENCES}

[1] Morgan CD, Nordin S, Murphy C (1995) Odor identification as an early marker for Alzheimer's disease: impact of lexical functioning and detection sensitivity. J Clin Exp Neuropsychol 17, 793-803.

[2] Velayudhan L (2015) Smell identification function and Alzheimer's disease: a selective review. Curr Opin Psychiatry 28, 173-179.

[3] Attems J, Thomas A, Jellinger K (2012) Correlations between cortical and subcortical tau pathology. Neuropathol Appl Neurobiol 38, 582-590.

[4] Wilson RS, Arnold SE, Schneider JA, Tang Y, Bennett DA (2007) The relationship between cerebral Alzheimer's disease pathology and odour identification in old age. J Neurol Neurosurg Psychiatry 78, 30-35.

[5] Franks KH, Chuah MI, King AE, Vickers JC (2015) Connectivity of Pathology: The Olfactory System as a Model for Network-Driven Mechanisms of Alzheimer's Disease Pathogenesis. Front Aging Neurosci 7, 234.

[6] Attems J, Lintner F, Jellinger KA (2005) Olfactory involvement in aging and Alzheimer's disease: An autopsy study. Journal of Alzheimers Disease 7, 149-157.

[7] Kovacs T, Cairns NJ, Lantos PL (2001) Olfactory centres in Alzheimer's disease: olfactory bulb is involved in early Braak's stages. Neuroreport 12, 285-288.

[8] Tapiola T, Alafuzoff I, Herukka SK, Parkkinen L, Hartikainen P, Soininen H, Pirttila T (2009) Cerebrospinal fluid \{beta\}-amyloid 42 and tau proteins as biomarkers of Alzheimer-type pathologic changes in the brain. Arch Neurol 66, 382-389.

[9] Djordjevic J, Jones-Gotman M, De Sousa K, Chertkow H (2008) Olfaction in patients with mild cognitive impairment and Alzheimer's disease. Neurobiol Aging 29, 693-706.

[10] Larsson M, Hedner M, Papenberg G, Seubert J, Backman L, Laukka EJ (2016) Olfactory memory in the old and very old: relations to episodic and semantic memory and APOE genotype. Neurobiol Aging 38, 118-126.

[11] Devanand DP, Lee S, Manly J, Andrews H, Schupf N, Doty RL, Stern Y, Zahodne LB, Louis ED, Mayeux R (2015) Olfactory deficits predict cognitive decline and Alzheimer dementia in an urban community. Neurology 84, 182-189.

[12] Graves AB, Bowen JD, Rajaram L, McCormick WC, McCurry SM, Schellenberg GD, Larson EB (1999) Impaired olfaction as a marker for cognitive decline: interaction with apolipoprotein E epsilon4 status. Neurology 53, 1480-1487.

[13] Conti MZ, Vicini-Chilovi B, Riva M, Zanetti M, Liberini P, Padovani A, Rozzini L (2013) Odor identification deficit predicts clinical conversion from mild cognitive impairment to dementia due to Alzheimer's disease. Arch Clin Neuropsychol 28, 391-399.

[14] Carmichael ST, Clugnet MC, Price JL (1994) Central olfactory connections in the macaque monkey. J Comp Neurol 346, 403-434. 
[15] Olofsson JK, Josefsson M, Ekstrom I, Wilson D, Nyberg L, Nordin S, Nordin Adolfsson A, Adolfsson R, Nilsson LG, Larsson M (2016) Long-term episodic memory decline is associated with olfactory deficits only in carriers of ApoE-e4. Neuropsychologia 85, 1-9.

[16] Doty RL, Shaman P, Dann M (1984) Development of the University of Pennsylvania Smell Identification Test: a standardized microencapsulated test of olfactory function. Physiol Behav 32, 489-502.

[17] Doty RL, Marcus A, Lee WW (1996) Development of the 12-item Cross-Cultural Smell Identification Test (CC-SIT). Laryngoscope 106, 353-356.

[18] Folstein MF, Folstein SE, McHugh PR (1975) "Mini-mental state". A practical method for grading the cognitive state of patients for the clinician. J Psychiatr Res 12, 189-198.

[19] Petersen RC (2004) Mild cognitive impairment as a diagnostic entity. J Intern Med 256, 183194.

[20] McKhann G, Drachman D, Folstein M, Katzman R, Price D, Stadlan EM (1984) Clinical diagnosis of Alzheimer's disease: report of the NINCDS-ADRDA Work Group under the auspices of Department of Health and Human Services Task Force on Alzheimer's Disease. Neurology 34, 939-944.

[21] Neary D, Snowden JS, Northen B, Goulding P (1988) Dementia of frontal lobe type. J Neurol Neurosurg Psychiatry 51, 353-361.

[22] Roman GC, Tatemichi TK, Erkinjuntti T, Cummings JL, Masdeu JC, Garcia JH, Amaducci L, Orgogozo JM, Brun A, Hofman A, et al. (1993) Vascular dementia: diagnostic criteria for research studies. Report of the NINDS-AIREN International Workshop. Neurology 43, 250260.

[23] McKeith IG, Galasko D, Kosaka K, Perry EK, Dickson DW, Hansen LA, Salmon DP, Lowe J, Mirra SS, Byrne EJ, Lennox G, Quinn NP, Edwardson JA, Ince PG, Bergeron C, Burns A, Miller BL, Lovestone S, Collerton D, Jansen EN, Ballard C, de Vos RA, Wilcock GK, Jellinger KA, Perry $\mathrm{RH}$ (1996) Consensus guidelines for the clinical and pathologic diagnosis of dementia with Lewy bodies (DLB): report of the consortium on DLB international workshop. Neurology 47, 1113-1124.

[24] Hughes CP, Berg L, Danziger WL, Coben LA, Martin RL (1982) A new clinical scale for the staging of dementia. Br J Psychiatry 140, 566-572.

[25] Pfeffer Rl, Kurosaki TT, Harrah CH, Jr., Chance JM, Filos S (1982) Measurement of functional activities in older adults in the community. J Gerontol 37, 323-329.

[26] Morris JC, Mohs RC, Rogers H, Fillenbaum G, Heyman A (1988) Consortium to establish a registry for Alzheimer's disease (CERAD) clinical and neuropsychological assessment of Alzheimer's disease. Psychopharmacol Bull 24, 641-652.

[27] Pflüger MA, C.; Monsch, A. U. (2003) in Zeitschrift für Klinische Psychologie und Psychotherapie, pp. 64-67. 
[28] van der Elst W, van Boxtel MP, van Breukelen GJ, Jolles J (2006) Normative data for the Animal, Profession and Letter M Naming verbal fluency tests for Dutch speaking participants and the effects of age, education, and sex. J Int Neuropsychol Soc 12, 80-89.

[29] Jongbloed W, Kester MI, van der Flier WM, Veerhuis R, Scheltens P, Blankenstein MA, Teunissen CE (2013) Discriminatory and predictive capabilities of enzyme-linked immunosorbent assay and multiplex platforms in a longitudinal Alzheimer's disease study. Alzheimers Dement $\mathbf{9}$, 276-283.

[30] Roberts RO, Christianson TJ, Kremers WK, Mielke MM, Machulda MM, Vassilaki M, Alhurani RE, Geda YE, Knopman DS, Petersen RC (2016) Association Between Olfactory Dysfunction and Amnestic Mild Cognitive Impairment and Alzheimer Disease Dementia. JAMA Neurol 73, 93-101.

[31] Tabert MH, Liu X, Doty RL, Serby M, Zamora D, Pelton GH, Marder K, Albers MW, Stern Y, Devanand DP (2005) A 10-item smell identification scale related to risk for Alzheimer's disease. Ann Neurol 58, 155-160.

[32] Bahar-Fuchs A, Chetelat G, Villemagne VL, Moss S, Pike K, Masters CL, Rowe C, Savage G (2010) Olfactory deficits and amyloid-beta burden in Alzheimer's disease, mild cognitive impairment, and healthy aging: a PiB PET study. J Alzheimers Dis 22, 1081-1087.

[33] Growdon ME, Schultz AP, Dagley AS, Amariglio RE, Hedden T, Rentz DM, Johnson KA, Sperling RA, Albers MW, Marshall GA (2015) Odor identification and Alzheimer disease biomarkers in clinically normal elderly. Neurology 84, 2153-2160.

[34] Jack CR, Jr., Knopman DS, Jagust WJ, Petersen RC, Weiner MW, Aisen PS, Shaw LM, Vemuri P, Wiste HJ, Weigand SD, Lesnick TG, Pankratz VS, Donohue MC, Trojanowski JQ (2013) Tracking pathophysiological processes in Alzheimer's disease: an updated hypothetical model of dynamic biomarkers. Lancet Neurol 12, 207-216.

[35] Jansen WJ, Ossenkoppele R, Knol DL, Tijms BM, Scheltens P, Verhey FR, Visser PJ, Amyloid Biomarker Study Group (2015) Prevalence of cerebral amyloid pathology in persons without dementia: a meta-analysis. JAMA 313, 1924-1938.

[36] Wilson RS, Arnold SE, Tang Y, Bennett DA (2006) Odor identification and decline in different cognitive domains in old age. Neuroepidemiology 26, 61-67.

[37] Donaghy PC, McKeith IG (2014) The clinical characteristics of dementia with Lewy bodies and a consideration of prodromal diagnosis. Alzheimers Res Ther 6, 46.

[38] Braak H, Del Tredici K (2004) Poor and protracted myelination as a contributory factor to neurodegenerative disorders. Neurobiol Aging 25, 19-23.

[39] Gray AJ, Staples V, Murren K, Dhariwal A, Bentham P (2001) Olfactory identification is impaired in clinic-based patients with vascular dementia and senile dementia of Alzheimer type. Int J Geriatr Psychiatry 16, 513-517.

[40] Luzzi S, Snowden JS, Neary D, Coccia M, Provinciali L, Lambon Ralph MA (2007) Distinct patterns of olfactory impairment in Alzheimer's disease, semantic dementia, frontotemporal dementia, and corticobasal degeneration. Neuropsychologia 45, 1823-1831. 
[41] McLaughlin NC, Westervelt HJ (2008) Odor identification deficits in frontotemporal dementia: a preliminary study. Arch Clin Neuropsychol 23, 119-123.

[42] Schoonenboom NS, Reesink FE, Verwey NA, Kester MI, Teunissen CE, van de Ven PM, Pijnenburg YA, Blankenstein MA, Rozemuller AJ, Scheltens P, van der Flier WM (2012) Cerebrospinal fluid markers for differential dementia diagnosis in a large memory clinic cohort. Neurology 78, 47-54.

[43] Kesslak JP, Nalcioglu O, Cotman CW (1991) Quantification of magnetic resonance scans for hippocampal and parahippocampal atrophy in Alzheimer's disease. Neurology 41, 51-54.

[44] Murphy C, Jernigan TL, Fennema-Notestine C (2003) Left hippocampal volume loss in Alzheimer's disease is reflected in performance on odor identification: a structural MRI study. J Int Neuropsychol Soc 9, 459-471.

[45] Thomann PA, Kaiser E, Schonknecht P, Pantel J, Essig M, Schroder J (2009) Association of total tau and phosphorylated tau 181 protein levels in cerebrospinal fluid with cerebral atrophy in mild cognitive impairment and Alzheimer disease. J Psychiatry Neurosci 34, 136-142. 


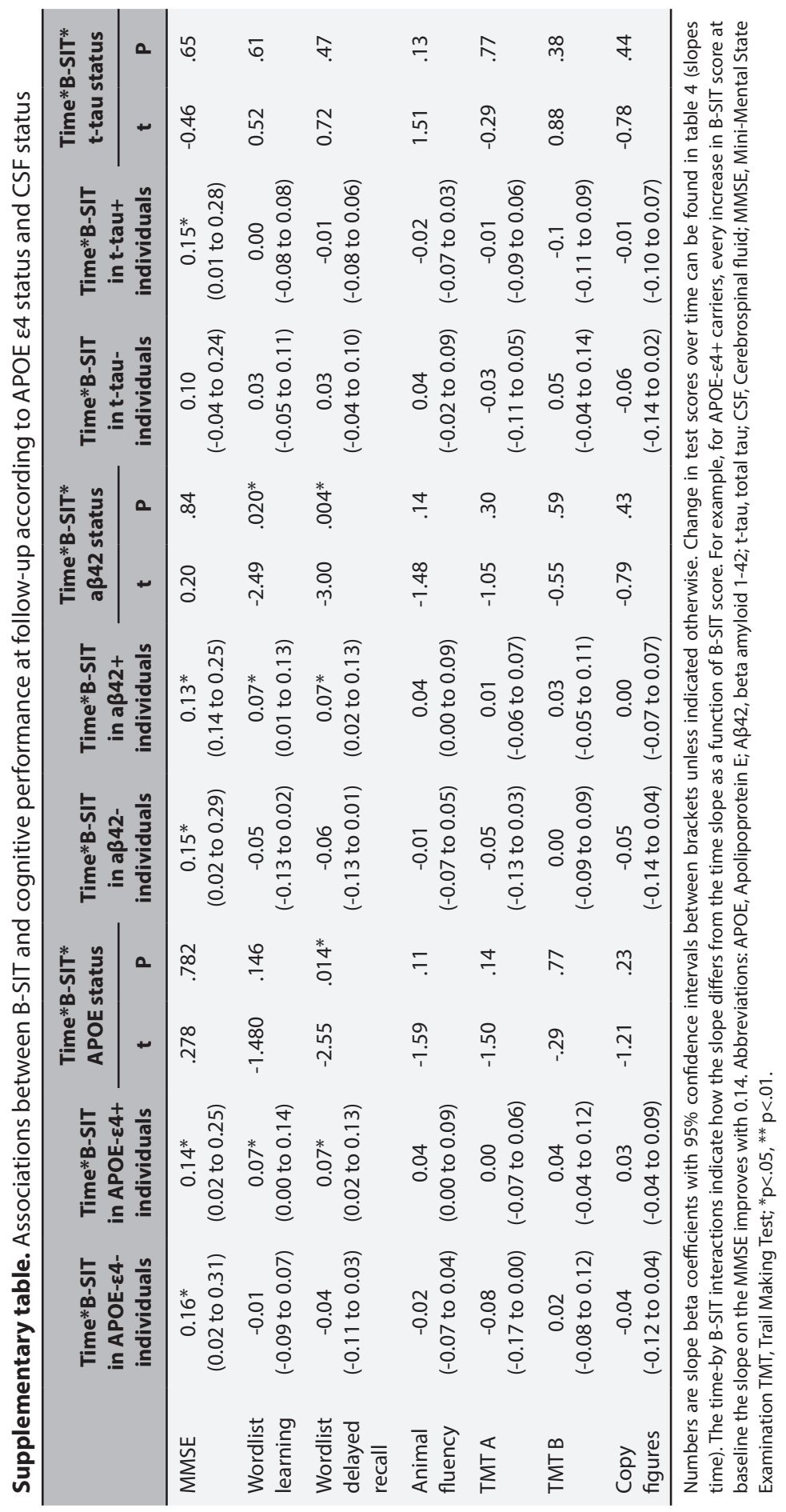





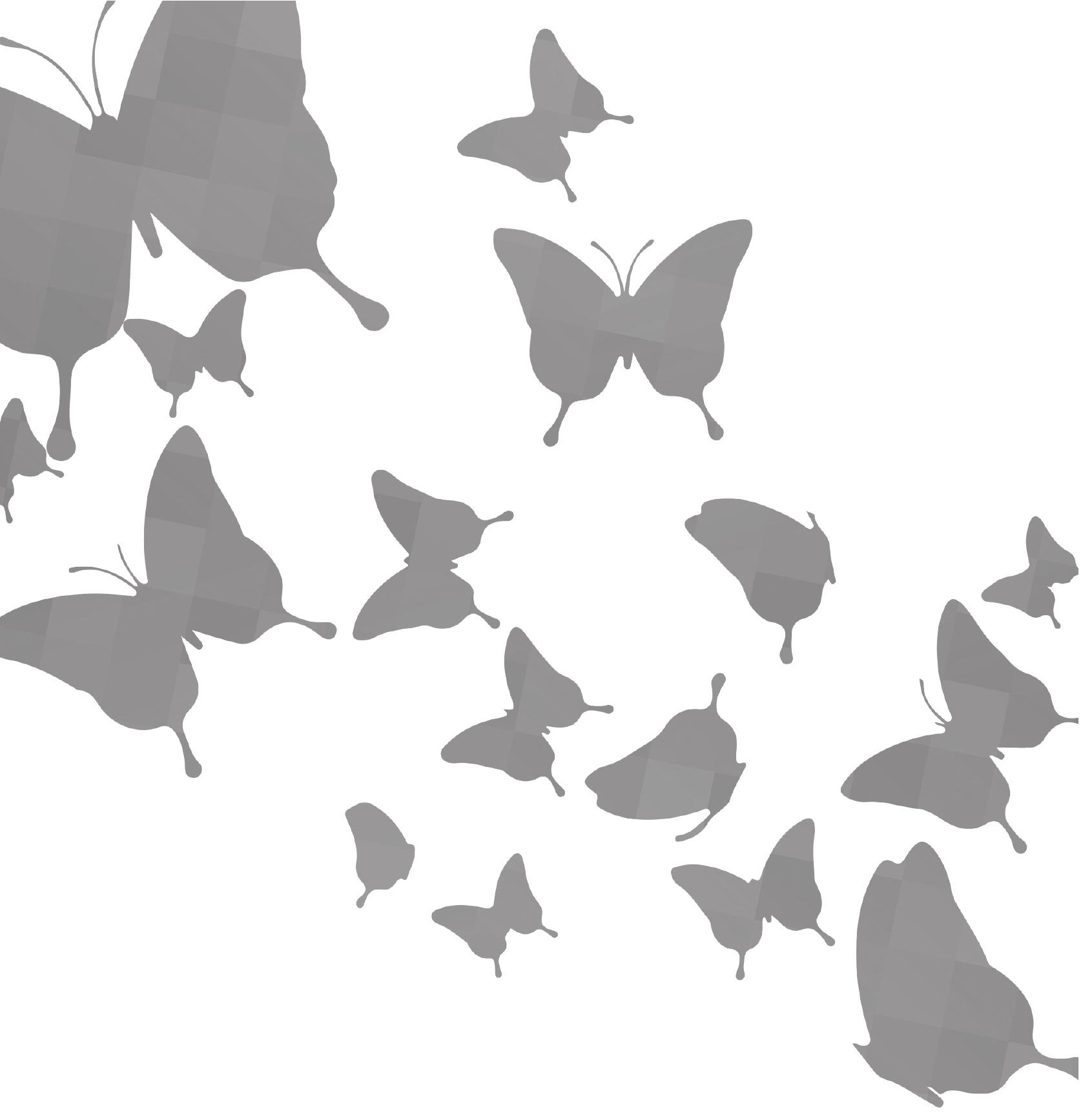




\section{Emerging cerebrospinal fluid markers of Alzheimer's disease related pathology}

Babette L.R. Reijs

Stephanie J.B. Vos

Charlotte E. Teunissen

Inez H.G.B. Ramakers

Marleen Koel-Simmelink

Magda Tsolaki

Lars-Olof Wahlund

Gunhild Waldemar

Lucrezia Hausner

Lutz Frölich

Rik Vandenberghe

Peter Johannsen

Alberto Lleó

Hugo Vanderstichele

Rob Veerhuis

Kaj Blennow

Henrik Zetterberg

Helma Rutjes

Philip Scheltens

Frans R.J. Verhey

Pieter Jelle Visser

In preparation

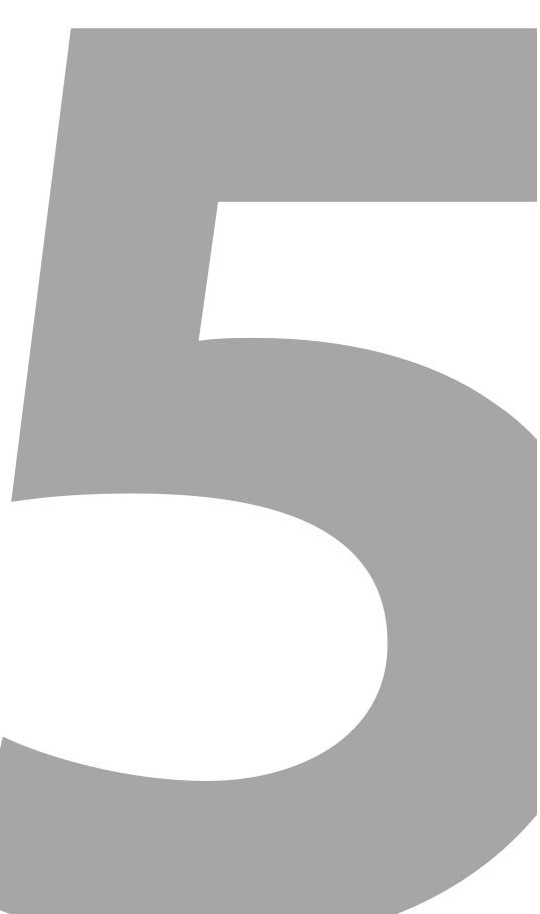




\section{ABSTRACT}

Background: Previous research has identified several promising biomarkers for Alzheimer's disease (AD), but their association with established AD biomarkers amyloid beta (1-42) a 342 and tau in cerebrospinal fluid (CSF) remains unknown.

Objective: To examine the association between complement factor 3a (C3a), complement factor 5a (C5a), membrane attack complex (MAC), Serum Amyloid-P (SAP), and heart fatty acid binding protein (hFABP) with CSF a 42 and total tau (t-tau) concentrations and general cognition.

Methods: We included 279 individuals ( 26 controls, 20 with subjective cognitive decline (SCD), 73 with mild cognitive impairment $(\mathrm{MCl}), 88$ with $A D$-type dementia and 53 with non-AD dementia) from the European multicenter memory-clinic based EDAR study. CSF a 42 and t-tau were assessed with INNO-BIA AlzBio3 Luminex assay and CSF C3a, C5a, MAC, SAP and hFABP with ELISA. General cognition was assessed with the MMSE. A follow-up was performed in a subset within 3 years after baseline with repeated MMSE $(\mathrm{n}=131)$ and CSF aß42 and t-tau measurements $(\mathrm{n}=83)$.

Results: At baseline, higher t-tau was associated with higher hFABP concentrations independent of APOE-e4 genotype and diagnostic group. In individuals with dementia, lower C3a concentrations were associated with lower aß42. C3a, MAC, SAP and hFABP were not associated with general cognition. Only lower CSF a $\beta 42$ levels at baseline were associated with accelerated cognitive decline.

Conclusions: hFABP may be a promising CSF biomarker for neuronal injury. Assessment of CSF aß42 can help to identify individuals who will show cognitive decline. 


\section{INTRODUCTION}

Alzheimer's disease (AD) is a neurodegenerative disorder and the most common cause of dementia. To facilitate care and accelerate the development of disease-modifying treatments, a better understanding of the early pathophysiological mechanism of $A D$ is required. The best validated biomarkers for $A D$ in cerebrospinal fluid (CSF) are beta amyloid 1-42 (aß42) reflecting amyloid disposition [1, 2], and tau reflecting neuronal injury $[3,4]$.

The last decades, several promising in vivo biomarkers for AD have been found. The presence of a chronic neuroinflammatory suggests a role of the complement system in the development of $A D$ [5]. Furthermore, a potential role has been found for proteins that bind lipids such as heart fatty acid binding protein (hFABP) [6-9] and serum amyloid-P (SAP) [10-13]. SAP may bind to amyloid fibrils and initiate the classical complement pathway [11-13], whereas hFABP may be involved in fatty acid metabolism and transport [14], and has been suggested as an important modifier for a $\beta$-associated neurodegeneration [9]. However, the role of these biomarkers in AD pathophysiology and the utility of these promising biomarkers for $A D$ diagnosis and prognosis are not clear.

In this study, we investigated how three complement factors (C3a-desArg (C3a), C5a, membrane attack complex (MAC)), and hFABP and SAP were associated with baseline $a \beta 42$ and tau concentration and with change in a $\beta 42$ and tau over time. In addition, we investigated whether these CSF biomarkers were associated with general cognition at baseline and at follow up. Furthermore, we examined whether these associations were dependent on APOE-e4 carriership, a major genetic risk factor for AD.

\section{MATERIALS AND METHODS}

\section{Individuals}

We selected 279 individuals from the study "Beta amyloid oligomers in the early diagnosis of AD and as marker for treatment response" (acronym: EDAR) based on the availability of CSF markers at baseline. Individuals were recruited from seven memory clinics across Europe between 2008 and 2010 and represented healthy controls ( $n=26)$, individuals with subjective cognitive decline $(S C D, n=20)$, mild cognitive impairment ( $M C l, n=73)$, AD-type dementia ( $n=88)$, non-AD dementia $(n=53)$ and 19 unclassified individuals without dementia (see below). Follow-up CSF assessments were performed in $83(30 \%)$ and MMSE assessment in $131(48 \%)$ individuals within 3 years after 
baseline. The average follow-up interval was 14.63 months $(S D=5.65)$ for individuals with consecutive CSF measurements and 16.78 months ( $S D=6.38$ ) for individuals with consecutive MMSE measurements.

Healthy controls $(n=26)$ were recruited outside memory clinics via advertisements or partners from patients. Individuals with $S C D, M C l, A D$-type dementia and non-AD dementia were recruited inside memory clinics. Inclusion criteria for healthy controls and individuals with SCD were: age above 40 years, no cognitive impairment on neuropsychological tests (i.e. for controls a z-score above -2 and for SCD a z-score above -1.5 on all neuropsychological tests) and age and education corrected Mini Mental State Examination score (MMSE [15]) above the $10^{\text {th }}$ percentile based on local norms [16]. Cognitive impairment was determined based on z-scores (corrected for age, gender and education) for the wordlist learning and delayed recall, trail making test (TMT) A and $B$ and copy figures calculated according to the Consortium to establish a registry for Alzheimer's disease (CERAD)-Plus norms [17, 18]; and based on z-scores for the animal fluency test calculated according to the norms by van der Elst et al. [19]. Inclusion criteria for individuals with $\mathrm{MCl}$ were: memory clinic referral for the evaluation of cognitive complaints, age above 60 years, a MMSE-score above 19, a cognitive impairment on neuropsychological tests, defined as a z-score (corrected for age, gender and education) below -1.5 on one or more neuropsychological tests according to Petersen's criteria [20] and the absence of a clinical diagnosis of dementia. Inclusion criteria for individuals with dementia were age above 40 years and a clinical diagnosis of probable or possible AD-type dementia according to the NINCDS-ADRDA criteria [21], fronto-temporal dementia (FTD) [22], vascular dementia (VaD) according to the NINDS-AIREN criteria [23] or Lewy body dementia (DLB) [24]. Exclusion criteria for all individuals were contraindications for lumbar puncture or any disorder related to cognitive impairment other than neurodegeneration.

Nineteen individuals could not be classified to a diagnostic subgroup because they had no cognitive complaints but performed poorly on one or more cognitive tests at baseline with a z-score equal to or below -2 (10 controls) or because of missing cognitive test scores (9 individuals with cognitive complaints), but they were included in the total group analyses. All individuals provided written informed consent and the medical ethics committee at each centre approved the study. 


\section{Baseline and follow-up assessment}

Baseline assessments included clinical history, physical examination, neuroimaging, routine laboratory tests for blood and CSF, the MMSE and the Clinical Dementia Rating scale (CDR) [25], Functional Assessment Questionnaire (FAQ) [26], and a neuropsychological examination. Follow-up assessments were similar to baseline except for laboratory tests and neuroimaging and were performed once or twice within 3 years after baseline.

\section{CSF and DNA collection, storage and analysis}

CSF was collected via a lumbar puncture in $10 \mathrm{~mL}$ polypropylene tubes, centrifuged at 4 degrees at $2000 \times g$ and stored at $-80^{\circ} \mathrm{C}$ within one hour after collection. $A \beta 42$ and $\mathrm{t}$-tau concentrations were measured with the INNO-BIA AlzBio3 Luminex assay (Fujirebio, Gent, Belgium). All baseline CSF analyses were performed at the end of the study, in one batch, at the VU University Medical Centre (VUmc) in Amsterdam in the Netherlands. CSF concentrations below $389(\mathrm{pg} / \mathrm{ml})$ for aß42, and above $98(\mathrm{pg} / \mathrm{ml})$ for t-tau were considered abnormal according to local cut off values for this assay at the VUmc [27]. Investigators that collected the clinical data were blinded to the CSF results. Longitudinal CSF analyses were performed at Sahlgrenska University hospital in Gothenburg in Sweden using commercial assays, which were assays from MSD (aß42) and Fujirebio (t-tau). Baseline and follow-up CSF samples were analysed in a single batch. Complement factor C3a, C5a, MAC, SAP and hFABP were measured with ELISA (Hycult Biotechnology, Uden, the Netherlands). C3a was assayed with HK354, C5a with HK349, MAC with HK328, SAP with HK331 and hFABP with HK402. Apolipoprotein E (APOE) genotype was determined by Polymerase Chain Reaction (PCR) of genomic DNA extracted from EDTA anticoagulated blood.

\section{Statistical analyses}

Data were analysed with IBM SPSS statistics version 24. Group differences in baseline characteristics were examined with one-way ANOVA for continuous variables and $\mathrm{X}^{2}$-tests for categorical variables. Inter CSF marker associations were analysed with Spearman rank correlations. The association between emerging CSF biomarkers and baseline CSF a 342 and tau, and change in CSF a $\beta 42$ and tau concentrations over time, were analysed with linear mixed models with random effects for individual intercepts within centre (nested design) corrected for baseline age and MMSE score. The association between CSF biomarkers with baseline and follow-up MMSE score were tested with linear mixed models with random effects for individual intercepts within centre (nested design) and with random slopes to allow for heterogeneity in individual trajectories over time, corrected for age and educational years. 
Longitudinal analyses with change in $a \beta 42$ as outcome were repeated in individuals without dementia and with normal a $\beta 42$ for change in a $\beta 42$ over time. Post-hoc, the interaction effect of APOE-e4 status (i.e. carriers of one or two e4 alleles versus no e4 allele) and the interaction effect of dementia status (individuals with versus without dementia) were included to examine a possible moderator effect. Five outliers with extreme elevated values ( $>3$ SD above the average) were excluded ( $C 3 a n=1, M A C$ $\mathrm{n}=2$ SAP $\mathrm{n}=2$ ). T-tau, C3a, MAC and SAP were log transformed to conform to a normal distribution. Associations with phosphorylated tau ( $p$-tau) were not described as $t$-tau and $p$-tau concentrations were highly correlated $(r=.73, p<.0001)$. A $p$-value of $<0.05$ for two-sided tests was considered statistically significant.

\section{RESULTS}

We included 279 individuals with at least one CSF marker available. Baseline characteristics are presented table 1. Individuals were on average $68.8(\mathrm{SD}=9.2)$ years old with 10.3 ( $S D=4.5$ ) years of education and the majority was male (55\%). Individuals with $\mathrm{MCl}$ and $\mathrm{AD}$-type dementia were slightly older and had fewer years of education than controls. As expected, individuals with $\mathrm{MCl}$ or dementia had more severe cognitive and functional impairment as assessed by the MMSE, FAQ and CDR than in controls. CSF a $\beta 42$ concentrations were lower and t-tau concentrations were higher in individuals with $\mathrm{MCl}$ and $\mathrm{AD}$-type dementia compared with healthy controls. Complement factor C3a was lower and hFABP was higher in individuals with $M C l, A D$-type dementia and non-AD-type dementia than in controls. APOE genotype and the other CSF markers did not differ between groups. C5a was above the detection limit in only 26 individuals and no further statistical analyses were performed. 


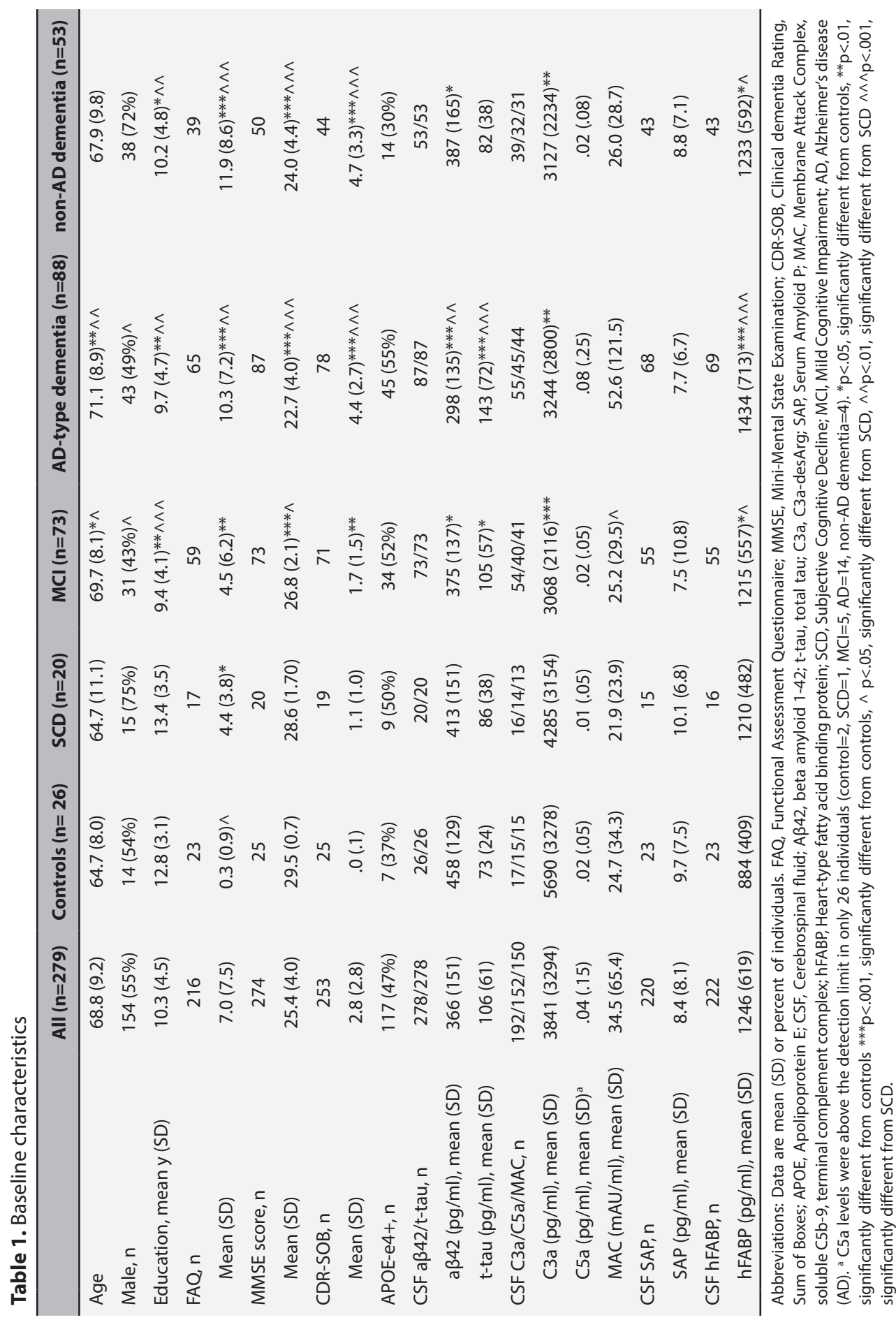


Table 2a. Correlations CSF markers at baseline in all individuals $(n=270)$

\begin{tabular}{lccccccc} 
& \multicolumn{2}{c}{ MAC } & \multicolumn{2}{c}{ SAP } & \multicolumn{2}{c}{ hFABP } \\
\cline { 2 - 7 } & rho & $\mathbf{p}$ & rho & $\mathbf{p}$ & rho & $\mathbf{p}$ \\
\hline C3a & $.40^{* * *}$ & $\mathrm{p}<.0001$ & $.37^{* * *}$ & $\mathrm{p}<.0001$ & .16 & .05 \\
MAC &. &. & $.38^{* * *}$ & $\mathrm{p}<.0001$ & .06 & .47 \\
SAP &. &. &. &. & $.17^{*}$ & .01 \\
\hline
\end{tabular}

Numbers are Spearman's rho correlation coefficients (two-tailed) with significance values. Abbreviations: C3a, C3a-desArg; MAC, Membrane Attack Complex, soluble C5b-9, terminal complement complex; SAP, Serum Amyloid P, hFABP, Heart-type fatty acid binding protein.

Table 2b. Correlations CSF markers at baseline in individuals with dementia $(n=141)$ and without dementia $(n=129)$

\begin{tabular}{lccccccccc}
\hline & \multicolumn{2}{c}{ C3a } & \multicolumn{2}{c}{ MAC } & \multicolumn{2}{c}{ SAP } & \multicolumn{2}{c}{ hFABP } \\
\cline { 2 - 9 } & rho & $\mathbf{p}$ & rho & $\mathbf{p}$ & rho & $\mathbf{p}$ & rho & $\mathbf{p}$ \\
\hline C3a & & $.47^{* * *}$ & $\mathrm{p}<.0001$ & $.38^{* *}$ & .00 & $.28^{*}$ & .02 \\
MAC & $.34^{* *}$ & .00 & & Nomentia & $.38^{* *}$ & .00 & .10 & .45 \\
SAP & $.36^{* *}$ & .00 & $.34^{* *}$ & .01 & & $.19^{*}$ & .05 \\
hFABP & .07 & .54 & -.03 & .79 & .12 & .22 & & \\
\hline
\end{tabular}

Numbers are Spearman's rho correlation coefficients (two-tailed) with significance values. Abbreviations: C3a, C3a-desArg; MAC, Membrane Attack Complex, soluble C5b-9, terminal complement complex; SAP, Serum Amyloid P, hFABP, Heart-type fatty acid binding protein. ${ }^{*} p<.05{ }^{* *} p<.01{ }^{* * *} p<.001$.

\section{Emerging CSF marker correlations}

The correlation between C3a, MAC, hAFBP and SAP are shown in table 2a and b. C3a, MAC and SAP showed a positive correlation with each other in the total group and also in individuals with and without dementia. Higher hFABP correlated with higher C3a and SAP in the total group and in individuals with dementia.

\section{Emerging CSF markers and $\mathrm{a} \beta 42$ and $\mathrm{t}$-tau concentrations}

Higher hFABP was associated with higher CSF t-tau $(\beta=.001, p<.001$, Table 3, Figure 1). Lower C3a tended to be associated with lower a $\beta 42(\beta=.001, p=0.08$, Table 3, Figure 2). All associations were independent of MMSE score and APOE-e4 carriership. Only the association between hFABP and a 342 differed between individuals with and without dementia ( $p<.01$, Figure 2). In individuals without dementia, higher hFABP was 
associated with lower $\mathrm{a} \beta 42(\beta=-.05, \mathrm{p}=.039)$, but no association was found in individuals with dementia $(\beta=.03 ; p=.14)$. Dementia status did not influence the association of emerging markers on CSF tau.

Table 3. Associations between emerging and established CSF markers and MMSE scores at baseline

\begin{tabular}{|c|c|c|c|c|c|c|}
\hline \multirow{2}{*}{$\begin{array}{l}\text { Independent } \\
\text { variable }\end{array}$} & \multicolumn{2}{|l|}{$a \beta 42$} & \multicolumn{2}{|l|}{ t-tau } & \multicolumn{2}{|c|}{ MMSE score } \\
\hline & Estimate & $\mathbf{p}$ & Estimate & $\mathbf{p}$ & Estimate & $\mathbf{p}$ \\
\hline $\mathrm{C} 3 \mathrm{a}$ & $\begin{array}{c}28.01 \\
(-3.13 \text { to } 59.2)\end{array}$ & .08 & $\begin{array}{c}.05 \\
(-.06 \text { to } .16)\end{array}$ & .36 & $\begin{array}{c}-.01 \\
(-.08 \text { to } .06\end{array}$ & .73 \\
\hline MAC & $\begin{array}{c}-2.31 \\
(-15.37 \text { to } 10.75)\end{array}$ & .73 & $\begin{array}{c}.00 \\
(-.05 \text { to } .04)\end{array}$ & .92 & $\begin{array}{c}-.01 \\
(-.04 \text { to } .02)\end{array}$ & 64 \\
\hline SAP & $\begin{array}{c}13.86 \\
(-5.88 \text { to } 33.56)\end{array}$ & .17 & $\begin{array}{c}-.06 \\
(-.14 \text { to } .02)\end{array}$ & .13 & $\begin{array}{c}.04 \\
(-.002 \text { to } .090)\end{array}$ & .06 \\
\hline hFABP & $\begin{array}{c}.003 \\
(-.027 \text { to } .032)\end{array}$ & .86 & $\begin{array}{c}.001^{* * *} \\
(.000 \text { to } .001)\end{array}$ & $\mathrm{p}<.001$ & $\begin{array}{c}-.001 \\
(-.002 \text { to } .000)\end{array}$ & .08 \\
\hline$a \beta 42$ & . & . & $\begin{array}{c}.000 \\
(-.001 \text { to } .000)\end{array}$ & .69 & $\begin{array}{c}.004 \\
(.001 \text { to } .007)\end{array}$ & .08 \\
\hline t-tau & $\begin{array}{c}-6.58 \\
(-39.73 \text { to } 26.57)\end{array}$ & .70 & . & . & $\begin{array}{c}-1.37^{* * *} \\
(-2.17 \text { to }-.56)\end{array}$ & $\mathrm{p}<.001$ \\
\hline
\end{tabular}

Numbers are beta coefficients with $95 \%$ confidence intervals between brackets. Outcome measures CSF markers are corrected for age, MMSE score and center, and outcome measure MMSE score is corrected for age, education and center. Abbreviations: aß42, beta amyloid 1-42; t-tau, total tau; MMSE, Mini-Mental State Examination; C3a, C3a-desArg; MAC, Membrane Attack Complex, soluble C5b-9, terminal complement complex; SAP, Serum Amyloid P, hFABP, Heart-type fatty acid binding protein. ${ }^{* * *} \mathrm{p}<.001$.

Post-hoc analyses revealed an association between $\mathrm{C} 3 \mathrm{a}$ and $\mathrm{a} \beta 42$ in individuals with dementia $(\beta=47.18, p=.03)$, but not in individuals without dementia $(\beta=7.07, p=.76)$ (Figure 2). The slopes of these groups did not significantly differ from each other.

\section{Emerging CSF markers and cognition}

Higher CSF t-tau concentrations were associated with lower baseline MMSE scores $(\beta=$ $-.014, \mathrm{p}<.001)$. Lower SAP, lower $\mathrm{a} \beta 42$ and higher hFABP showed a trend association with lower MMSE score ( $p<0.08$, Table 3$)$. There was no interaction with baseline $a \beta 42$ or tau concentration or APOE carriership in the association of C3a, MAC, SAP and hFABP with MMSE. Only for SAP, the association differed between individuals with and without dementia in MMSE score $(p=.009)$. In individuals with dementia, higher SAP was associated with higher MMSE scores $(\beta=.89 ; p=.004)$, but no association was found in individuals without dementia $\beta=-.28, p=.39$ ). 


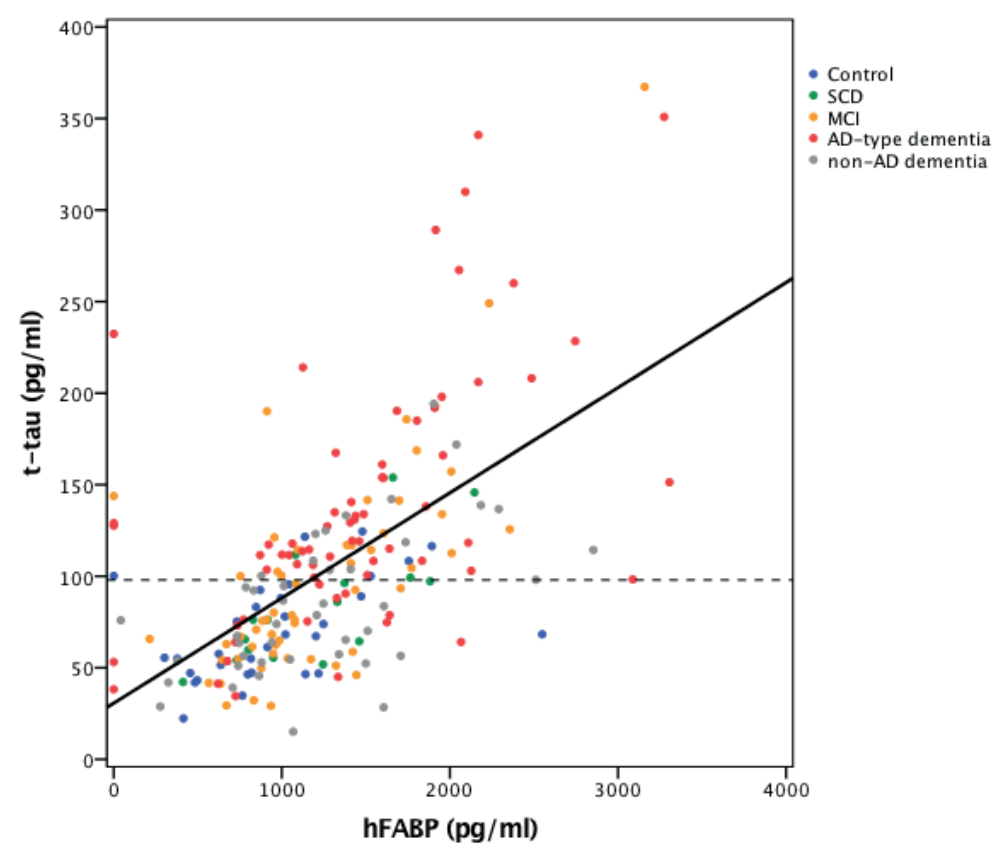

Figure 1. Baseline association between hFABP and t-tau

Figure displays count of controls (blue), individuals with SCD (green), $\mathrm{MCl}$ (orange), AD-type dementia (red) and non-AD dementia (grey), cut-off line for t-tau (dashed) and regression line total group (black solid). 


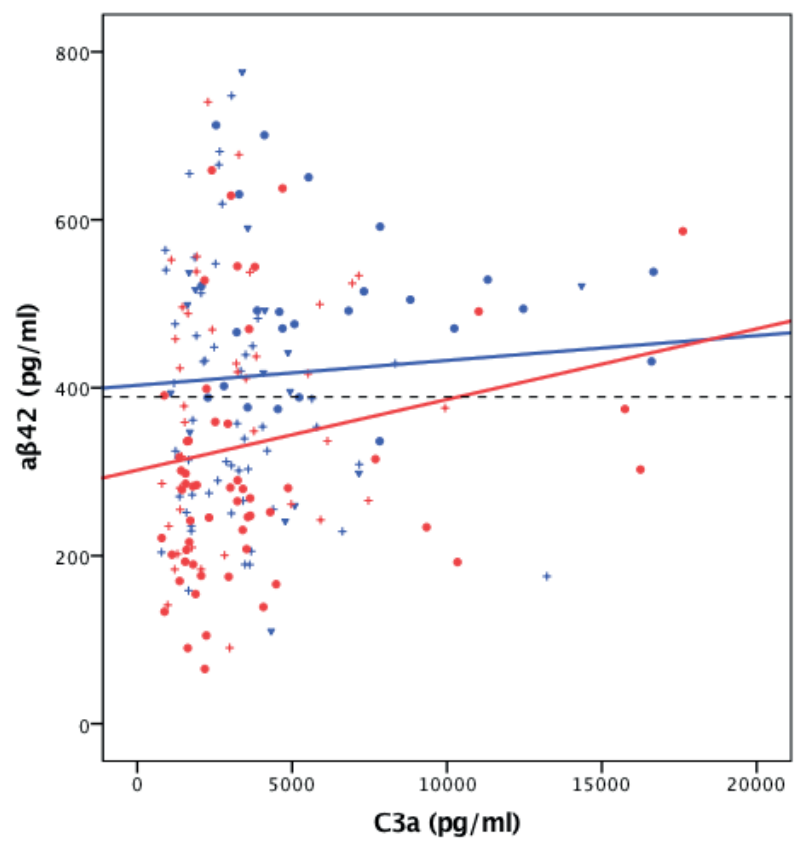

- Control

- SCD

- AD-type dementia

+ non-AD dementia

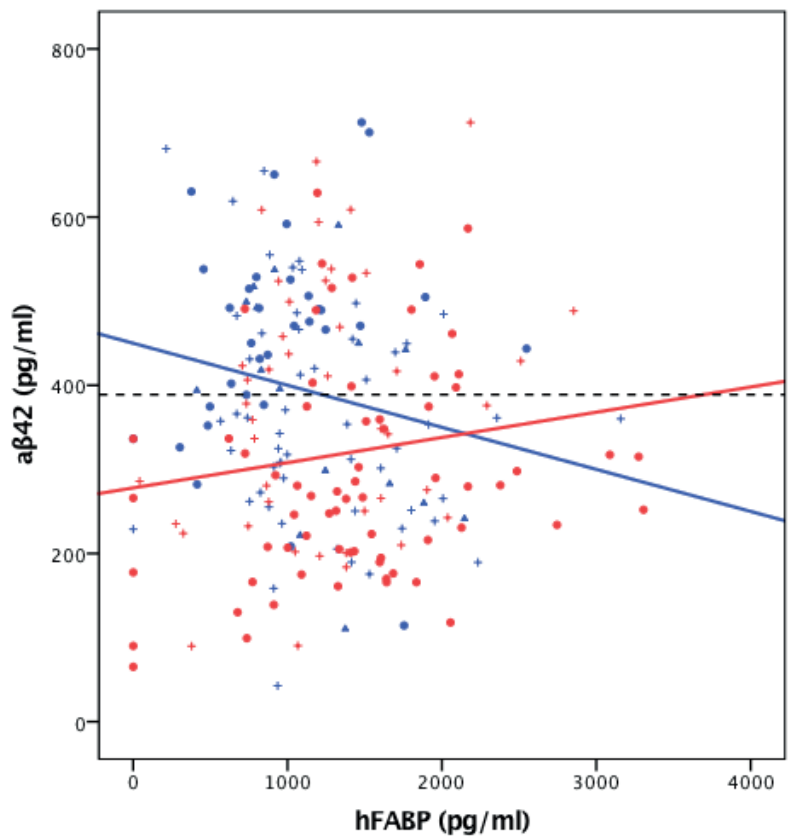

- Control

- SCD

$+\mathrm{MCl}$

- AD-type dementia

+ non-AD dementia

Figure 2. Baseline association for a $\beta 42$ with $C 3 a$ and $h F A B P$ according to dementia status

Figure displays count of controls (blue circle), individuals with SCD (blue triangle), MCI (blue cross), AD-type dementia (red circle) and non-AD dementia (red cross), cut-off line for $\mathrm{a} \beta 42$ (dashed) and regression lines for individuals without (blue solid) and with (red solid) dementia. 


\section{Emerging CSF markers and changes in a $\beta 42$ and t-tau concentration over time}

In the total group, CSF a 342 and t-tau concentrations did not change significantly over time (Table 4). C3a, MAC, SAP and hFABP levels at baseline were not associated with change in CSF a 342 and t-tau over time (interaction $p$-value $>0.05$ ). Associations remained similar after correction for baseline MMSE score or APOE-e4 carriership. Only for hFABP, the association differed between individuals with and without dementia in change in tau over time $(p=.021)$, but no significant associations were found in subgroups separately (without dementia: $\beta=-.000007, p=.078$; with dementia: $\beta=.000008, p=.11$ ). Dementia status did not influence the association of emerging markers on change in CSF aß42 over time.

We repeated analysis in individuals without dementia with normal a $\beta 42(n=55)$ as in more advanced stages of the disease a $\beta 42$ shows floor effects. $A \beta 42$ did not change over time $(\beta=.64, p=.61)$. Higher $C 3$ a concentration was associated with lower a $\beta 42$ over time $(\beta=-5.00, p=.006)$.

Table 4. Associations between emerging and established CSF markers and MMSE scores over time

\begin{tabular}{|c|c|c|c|c|c|c|}
\hline \multirow{2}{*}{$\begin{array}{l}\text { Independent } \\
\text { variable }\end{array}$} & \multicolumn{2}{|l|}{$a \beta 42$} & \multicolumn{2}{|l|}{ t-tau } & \multicolumn{2}{|c|}{ MMSE score } \\
\hline & Estimate & p & Estimate & $\mathbf{p}$ & Estimate & $\mathbf{p}$ \\
\hline Time & $\begin{array}{c}.576 \\
(-1.683 \text { to } 2.836)\end{array}$ & .61 & $\begin{array}{c}.001 \\
(-.002 \text { to } .004)\end{array}$ & .64 & $\begin{array}{c}-.098^{* * *} \\
(-.132 \text { to }-.064)\end{array}$ & $\mathrm{p}<.001$ \\
\hline C3a*time & $\begin{array}{c}-3.661 \\
(-9.149 \text { to } 1.828)\end{array}$ & .19 & $\begin{array}{c}-.004 \\
(-.010 \text { to } .002)\end{array}$ & .20 & $\begin{array}{c}-.014 \\
(-.084 \text { to } .057)\end{array}$ & .70 \\
\hline MAC*time & $\begin{array}{c}.134 \\
(-2.089 \text { to } 2.356)\end{array}$ & .90 & $\begin{array}{c}-.001 \\
(-.003 \text { to } .001)\end{array}$ & .50 & $\begin{array}{c}-.005 \\
-.033 \text { to } .024)\end{array}$ & .74 \\
\hline SAP*time & $\begin{array}{c}1.292 \\
(-2.130 \text { to } 4.713)\end{array}$ & .46 & $\begin{array}{c}.003 \\
(-.002 \text { to } .007)\end{array}$ & .23 & $\begin{array}{c}.040 \\
(-.004 \text { to } .084)\end{array}$ & .07 \\
\hline hFABP*time & $\begin{array}{c}-.0008 \\
(-.0056 \text { to } .0040)\end{array}$ & .75 & $\begin{array}{c}.0000 \\
(.0000 \text { to } .0000)\end{array}$ & .62 & $\begin{array}{c}.0000 \\
(-.0001 \text { to } .0000)\end{array}$ & .52 \\
\hline aß42*time & . & . & $\begin{array}{c}-.00001 \\
(-.00003 \text { to } .00000)\end{array}$ & .08 & $\begin{array}{c}.0003^{*} \\
(.0000 \text { to } .0006)\end{array}$ & .03 \\
\hline t-tau*time & $\begin{array}{c}-.296 \\
(-4.550 \text { to } 3.956)\end{array}$ & .89 & . & . & $\begin{array}{c}-.055 \\
(-.131 \text { to } .020)\end{array}$ & .15 \\
\hline
\end{tabular}

Numbers are beta coefficients with $95 \%$ confidence intervals between brackets. Outcome measures CSF markers were corrected for age, MMSE score and center, and outcome measure MMSE score was corrected for age, education and center. Abbreviations: a 342 , beta amyloid 1-42; t-tau, total tau; MMSE, Mini-Mental State Examination; C3a, C3a-desArg; MAC, Membrane Attack Complex, soluble C5b-9, terminal complement complex; SAP, Serum Amyloid P, hFABP, Heart-type fatty acid binding protein ${ }^{*} p<.05 * * \mathrm{p}<.001$. 


\section{Emerging CSF markers and cognitive decline over time}

MMSE scores declined over time in the total group $(\beta=-.098, p<.001)$, in individuals with dementia $(\beta=-.22, p<.001)$, but not in individuals without dementia $(\beta=-.01, p=.54$, p-difference slopes with versus without dementia <.0001).

Higher baseline a $\beta 42$ concentrations were associated with less decline in MMSE score in the total group only (Table 4, Figure 3). Baseline concentrations of the other CSF markers were not associated with decline in MMSE score. Associations were independent of baseline dementia status. APOE genotype modulated the relation between SAP levels at baseline and MMSE decline $(p<.01)$. Only in APOE-e4 non-carriers low SAP concentrations (i.e. below median of $6.68 \mathrm{pg} / \mathrm{ml}$ ) were associated with decline on the MMSE (Figure 4).

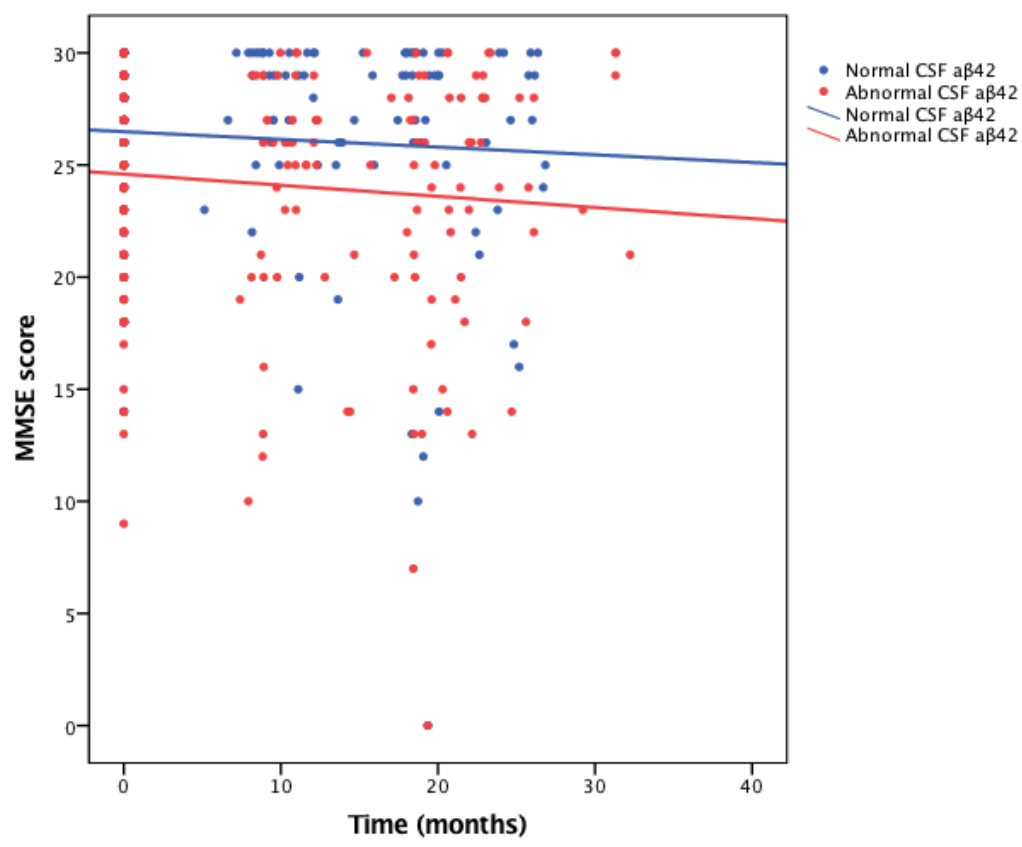

Figure 3. MMSE score over time according to CSF a 342 status

Figure displays count of individuals with normal a $\beta 42$ (blue) and individuals with abnormal a $\beta 42$ (red), and regression lines. 


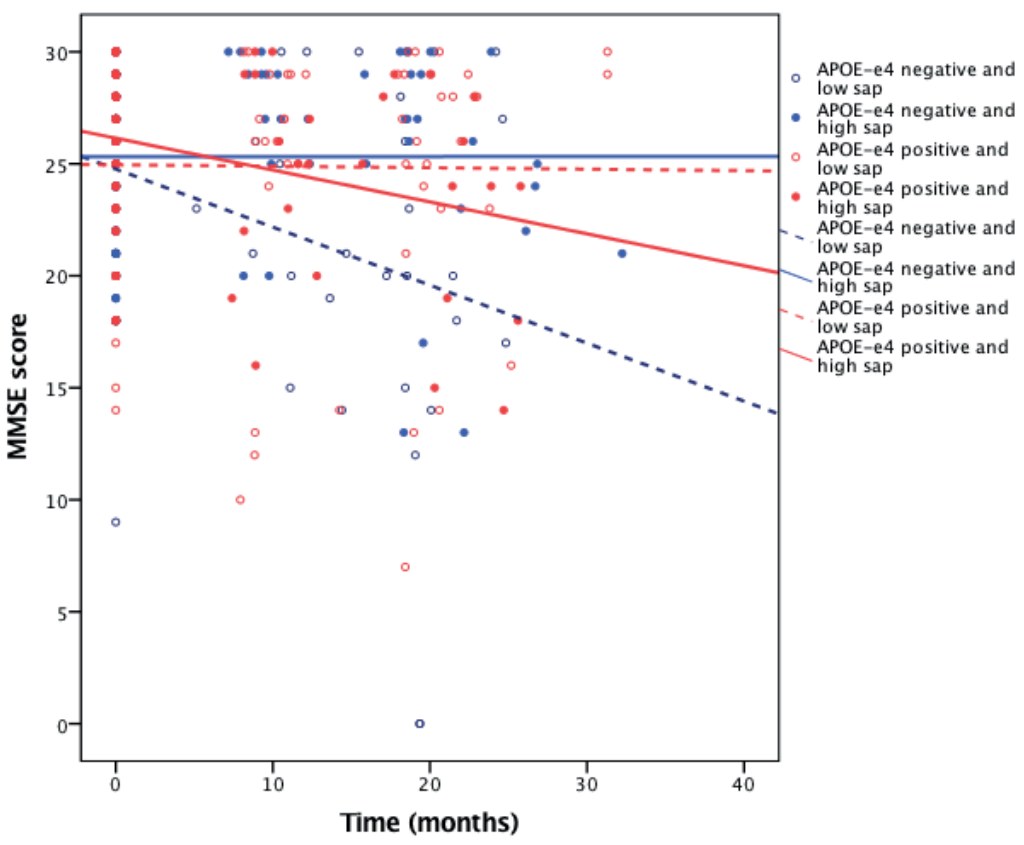

Figure 4. MMSE score over time according to SAP status and APOE-e4 genotype

Figure displays count of APOE-e4 carriers with low SAP $(<6.68 \mathrm{pg} / \mathrm{ml}$, red open circles) and high SAP concentrations (red closed circles), of APOE-e4 noncarriers with low (blue open circles) and high SAP concentrations (blue closed circles), and regression lines for individuals with low (dashed) and high SAP concentrations (solid).

\section{DISCUSSION}

We found that hFABP was higher and C3a concentration lower in individuals with $\mathrm{MCl}$ and dementia. Higher hFABP was associated with higher tau concentrations in all individuals and with lower aß42 in individuals without dementia. Higher C3a concentrations were associated with higher a 342 only in individuals with dementia. None of the emerging CSF markers were associated with changes in CSF a 42 and tau concentrations. Higher SAP was associated with higher MMSE scores in individuals with dementia and with less decline on the MMSE in APOE-e4 non-carriers.

As for the complement proteins we found a difference between diagnostic groups for C3a. MAC showed some non-significant increases in individuals with AD-type dementia, while C5a levels were typically below the detection level. As expected, C3a and MAC correlated. Interestingly, C3a concentrations were lower in individuals with $\mathrm{MCl}, \mathrm{AD}$ type dementia and non-AD dementia than in controls, despite accumulating evidence 
of complement activation of the inflammatory cascade in AD [28]. Previous studies are inconclusive when comparing complement C3a [29] or C3 [30] concentrations in CSF between individuals with $\mathrm{AD}$-type dementia and aged-matched controls. A possible explanation for our results could be reduced production of $\mathrm{C} 3 \mathrm{a}$ in individuals with $\mathrm{MCl}$, AD-type dementia and non-AD dementia interfering with its involvement in stimulating neural plasticity [31]. Another explanation could be increased use or binding of $\mathrm{C} 3$ to amyloid plaques [32] resulting in less of C3a in CSF. This may also explain the positive correlation between $\mathrm{C} 3 \mathrm{a}$ and $\mathrm{a} \beta 42$ concentration in individuals with dementia, in which the majority had AD-type dementia (62\%).

Similar to other CSF studies we did not find a difference in SAP concentrations between individuals with AD-type dementia and aged matched healthy controls [11, 12]. Possibly, SAP concentrations in CSF are too low to find a difference between diagnostic groups. SAP concentration levels in CSF can be 3,000-fold lower than in serum [12]. Although SAP is known to bind to amyloid plaques in AD brains [32], we only found a weak association of lower SAP levels with lower a $\beta 42$ in the total group. SAP correlated with C3a and MAC supporting its role in innate immunity [33]. This may be mediated by the binding of SAP to plaques, which leads to complement activation through the classical pathway [34, 35].

The increase of hFABP in individuals with $M C l, A D$-type dementia as well as non-AD dementia is in agreement with previous research [6, 7, 36-38]. The strong correlation between hFABP and tau and a trend association with MMSE score at baseline indicates that this marker reflects neurodegeneration. Our findings are in line with elevated hFABP concentrations found in several neurodegenerative diseases other than AD including Creuzfeldt-Jacob disease, Lewy body dementia, Parkinson's disease [37] and vascular dementia [36, 39]. hFABP was associated with lower aß42 in individuals without dementia, which may suggest a potential early role of hFABP as modifier of aß42-associated neurodegeneration in AD [9].

No association was found between the emerging CSF markers and MMSE score both at baseline and follow-up in the total group, while in this group CSF tau correlated with MMSE score at baseline and lower a $\beta 42$ accelerated decline in MMSE at follow-up. Higher SAP was associated with higher MMSE scores in individuals with dementia and with less decline in APOE-e4 carriers only. This suggests that C3a, MAC, SAP and hFABP have a limited role in tracking disease progression. 
Our study was one of the first to predict change in CSF a $\beta 42$ and tau concentrations over time by other CSF markers. In the total group C3a, MAC, SAP and hFABP did not correlate with change in these markers. In individuals without dementia and with normal $a \beta 42$, however, higher $\mathrm{C} 3$ a concentration was associated with decrease in a 342 . This suggests that complement activity may be an early feature of $A D$, or may reflect the physiological role of C3 in synaptic pruning [40-42].

The APOE genotype typically had no effect on the concentrations of the emerging CSF markers nor did it modulate the correlation of CSF markers with each other and with cognition, with one exception. Only in APOE-e4 non-carriers, low SAP concentrations were associated with decline on the MMSE. This finding needs to be replicated in future studies.

This study has a few limitations. First, the diagnostic subgroups were relatively small and therefore we performed post-hoc analysis in individuals with and without dementia, rather than in diagnostic subgroups. Second, the follow-up time was relatively short which limited the possibility to detect changes in CSF a 42 and tau over time. Third, we did not have follow data available for all individuals, which may have resulted in a selection bias although characteristics between those with and without follow-up were very similar. Lastly, we used new assays for C3a, MAC, SAP and hFABP used, which at the time of the assessment were not optimized yet.

To conclude, we showed that emerging biomarkers for $A D$ may be useful to understand the disease pathophysiology. Compared to CSF a 342 and tau the diagnostic and prognostic value may be limited. Future longitudinal studies with a longer follow-up duration are recommended to further examine the prognostic value of CSF markers in predicting AD-related pathology and cognitive decline.

\section{Acknowledgment}

The EDAR study was funded by the European Commission as part of the $6^{\text {th }}$ Framework Programme (contract \# 37670). We thank Nico Rozendaal for the provision of the IT infrastructure, Innogenetics for the provision of INNO-BIA AlzBio3 kits, Hycult Biotechnology for ELISA lab analyses of emerging CSF markers, and Sahlgrenska University hospital (Gothenburg, Sweden) for longitudinal CSF a 42 and tau analyses. 


\section{REFERENCES}

[1] Jansen WJ, Ossenkoppele R, Knol DL, Tijms BM, Scheltens P, Verhey FR, Visser PJ, Amyloid Biomarker Study Group (2015) Prevalence of cerebral amyloid pathology in persons without dementia: a meta-analysis. JAMA 313, 1924-1938.

[2] Vos SJ, Xiong C, Visser PJ, Jasielec MS, Hassenstab J, Grant EA, Cairns NJ, Morris JC, Holtzman DM, Fagan AM (2013) Preclinical Alzheimer's disease and its outcome: a longitudinal cohort study. Lancet Neurol 12, 957-965.

[3] Braak H, Braak E (1997) Frequency of stages of Alzheimer-related lesions in different age categories. Neurobiol Aging 18, 351-357.

[4] Jack CR, Jr., Knopman DS, Jagust WJ, Petersen RC, Weiner MW, Aisen PS, Shaw LM, Vemuri P, Wiste HJ, Weigand SD, Lesnick TG, Pankratz VS, Donohue MC, Trojanowski JQ (2013) Tracking pathophysiological processes in Alzheimer's disease: an updated hypothetical model of dynamic biomarkers. Lancet Neurol 12, 207-216.

[5] Finehout EJ, Franck Z, Lee KH (2005) Complement protein isoforms in CSF as possible biomarkers for neurodegenerative disease. Dis Markers 21, 93-101.

[6] Chiasserini D, Parnetti L, Andreasson U, Zetterberg H, Giannandrea D, Calabresi P, Blennow K (2010) CSF levels of heart fatty acid binding protein are altered during early phases of Alzheimer's disease. J Alzheimers Dis 22, 1281-1288.

[7] Steinacker P, Mollenhauer B, Bibl M, Cepek L, Esselmann H, Brechlin P, Lewczuk P, Poser S, Kretzschmar HA, Wiltfang J, Trenkwalder C, Otto M (2004) Heart fatty acid binding protein as a potential diagnostic marker for neurodegenerative diseases. Neurosci Lett 370, 36-39.

[8] Olsson B, Hertze J, Ohlsson M, Nagga K, Hoglund K, Basun H, Annas P, Lannfelt L, Andreasen N, Minthon L, Zetterberg H, Blennow K, Hansson O (2013) Cerebrospinal fluid levels of heart fatty acid binding protein are elevated prodromally in Alzheimer's disease and vascular dementia. J Alzheimers Dis 34, 673-679.

[9] Desikan RS, Thompson WK, Holland D, Hess CP, Brewer JB, Zetterberg H, Blennow K, Andreassen OA, McEvoy LK, Hyman BT, Dale AM, Alzheimer's Disease Neuroimaging I (2013) Heart fatty acid binding protein and Abeta-associated Alzheimer's neurodegeneration. Mol Neurodegener 8, 39.

[10] Crawford JR, Bjorklund NL, Taglialatela G, Gomer RH (2012) Brain serum amyloid P levels are reduced in individuals that lack dementia while having Alzheimer's disease neuropathology. Neurochem Res 37, 795-801.

[11] Mulder C, Schoonenboom SN, Wahlund LO, Scheltens P, van Kamp GJ, Veerhuis R, Hack CE, Blomberg M, Schutgens RB, Eikelenboom P (2002) CSF markers related to pathogenetic mechanisms in Alzheimer's disease. J Neural Transm (Vienna) 109, 1491-1498.

[12] Verwey NA, Schuitemaker A, van der Flier WM, Mulder SD, Mulder C, Hack CE, Scheltens P, Blankenstein MA, Veerhuis $R$ (2008) Serum amyloid p component as a biomarker in mild cognitive impairment and Alzheimer's disease. Dement Geriatr Cogn Disord 26, 522-527. 
[13] Yasojima K, Schwab C, McGeer EG, McGeer PL (2000) Human neurons generate C-reactive protein and amyloid P: upregulation in Alzheimer's disease. Brain Res 887, 80-89.

[14] Moulle VS, Cansell C, Luquet S, Cruciani-Guglielmacci C (2012) The multiple roles of fatty acid handling proteins in brain. Front Physiol 3, 385.

[15] Folstein MF, Folstein SE, McHugh PR (1975) "Mini-mental state". A practical method for grading the cognitive state of patients for the clinician. J Psychiatr Res 12, 189-198.

[16] Reijs BLR, Ramakers I, Elias-Sonnenschein L, Teunissen CE, Koel-Simmelink M, Tsolaki M, Wahlund LO, Waldemar G, Hausner L, Johannsen P, Vanderstichele H, Verhey F, Devanand DP, Visser PJ (2017) Relation of Odor Identification with Alzheimer's Disease Markers in Cerebrospinal Fluid and Cognition. J Alzheimers Dis 60, 1025-1034.

[17] Morris JC, Mohs RC, Rogers H, Fillenbaum G, Heyman A (1988) Consortium to establish a registry for Alzheimer's disease (CERAD) clinical and neuropsychological assessment of Alzheimer's disease. Psychopharmacol Bull 24, 641-652.

[18] Pflüger MA, C.; Monsch, A. U. (2003) in Zeitschrift für Klinische Psychologie und Psychotherapie, pp. 64-67.

[19] van der Elst W, van Boxtel MP, van Breukelen GJ, Jolles J (2006) Normative data for the Animal, Profession and Letter M Naming verbal fluency tests for Dutch speaking participants and the effects of age, education, and sex. J Int Neuropsychol Soc 12, 80-89.

[20] Petersen RC (2004) Mild cognitive impairment as a diagnostic entity. J Intern Med 256, 183194.

[21] McKhann G, Drachman D, Folstein M, Katzman R, Price D, Stadlan EM (1984) Clinical diagnosis of Alzheimer's disease: report of the NINCDS-ADRDA Work Group under the auspices of Department of Health and Human Services Task Force on Alzheimer's Disease. Neurology 34, 939-944.

[22] Neary D, Snowden JS, Northen B, Goulding P (1988) Dementia of frontal lobe type. J Neurol Neurosurg Psychiatry 51, 353-361.

[23] Roman GC, Tatemichi TK, Erkinjuntti T, Cummings JL, Masdeu JC, Garcia JH, Amaducci L, Orgogozo JM, Brun A, Hofman A, et al. (1993) Vascular dementia: diagnostic criteria for research studies. Report of the NINDS-AIREN International Workshop. Neurology 43, 250260.

[24] McKeith IG, Galasko D, Kosaka K, Perry EK, Dickson DW, Hansen LA, Salmon DP, Lowe J, Mirra SS, Byrne EJ, Lennox G, Quinn NP, Edwardson JA, Ince PG, Bergeron C, Burns A, Miller BL, Lovestone S, Collerton D, Jansen EN, Ballard C, de Vos RA, Wilcock GK, Jellinger KA, Perry $\mathrm{RH}$ (1996) Consensus guidelines for the clinical and pathologic diagnosis of dementia with Lewy bodies (DLB): report of the consortium on DLB international workshop. Neurology 47, $1113-1124$.

[25] Hughes CP, Berg L, Danziger WL, Coben LA, Martin RL (1982) A new clinical scale for the staging of dementia. Br J Psychiatry 140, 566-572. 
[26] Pfeffer Rl, Kurosaki TT, Harrah CH, Jr., Chance JM, Filos S (1982) Measurement of functional activities in older adults in the community. J Gerontol 37, 323-329.

[27] Jongbloed W, Kester MI, van der Flier WM, Veerhuis R, Scheltens P, Blankenstein MA, Teunissen CE (2013) Discriminatory and predictive capabilities of enzyme-linked immunosorbent assay and multiplex platforms in a longitudinal Alzheimer's disease study. Alzheimers Dement $\mathbf{9}$, 276-283.

[28] Heppner FL, Ransohoff RM, Becher B (2015) Immune attack: the role of inflammation in Alzheimer disease. Nat Rev Neurosci 16, 358-372.

[29] Loeffler DA, Brickman CM, Juneau PL, Perry MF, Pomara N, Lewitt PA (1997) Cerebrospinal fluid C3a increases with age, but does not increase further in Alzheimer's disease. Neurobiol Aging 18, 555-557.

[30] Bonham LW, Desikan RS, Yokoyama JS, Alzheimer's Disease Neuroimaging I (2016) The relationship between complement factor C3, APOE epsilon4, amyloid and tau in Alzheimer's disease. Acta Neuropathol Commun 4, 65.

[31] Stokowska A, Atkins AL, Moran J, Pekny T, Bulmer L, Pascoe MC, Barnum SR, Wetsel RA, Nilsson JA, Dragunow M, Pekna M (2017) Complement peptide C3a stimulates neural plasticity after experimental brain ischaemia. Brain 140, 353-369.

[32] Kolev MV, Ruseva MM, Harris CL, Morgan BP, Donev RM (2009) Implication of complement system and its regulators in Alzheimer's disease. Curr Neuropharmacol 7, 1-8.

[33] Noursadeghi M, Bickerstaff MC, Gallimore JR, Herbert J, Cohen J, Pepys MB (2000) Role of serum amyloid $\mathrm{P}$ component in bacterial infection: protection of the host or protection of the pathogen. Proc Natl Acad Sci U S A 97, 14584-14589.

[34] Hicks PS, Saunero-Nava L, Du Clos TW, Mold C (1992) Serum amyloid P component binds to histones and activates the classical complement pathway. J Immunol 149, 3689-3694.

[35] Wolbink GJ, Brouwer MC, Buysmann S, ten Berge IJ, Hack CE (1996) CRP-mediated activation of complement in vivo: assessment by measuring circulating complement-C-reactive protein complexes. J Immunol 157, 473-479.

[36] Bjerke M, Zetterberg H, Edman A, Blennow K, Wallin A, Andreasson U (2011) Cerebrospinal fluid matrix metalloproteinases and tissue inhibitor of metalloproteinases in combination with subcortical and cortical biomarkers in vascular dementia and Alzheimer's disease. J Alzheimers Dis 27, 665-676.

[37] Guillaume E, Zimmermann C, Burkhard PR, Hochstrasser DF, Sanchez JC (2003) A potential cerebrospinal fluid and plasmatic marker for the diagnosis of Creutzfeldt-Jakob disease. Proteomics 3, 1495-1499.

[38] Mollenhauer B, Steinacker P, Bahn E, Bibl M, Brechlin P, Schlossmacher MG, Locascio JJ, Wiltfang J, Kretzschmar HA, Poser S, Trenkwalder C, Otto M (2007) Serum heart-type fatty acid-binding protein and cerebrospinal fluid tau: marker candidates for dementia with Lewy bodies. Neurodegener Dis 4, 366-375. 
[39] Ohrfelt A, Andreasson U, Simon A, Zetterberg H, Edman A, Potter W, Holder D, Devanarayan V, Seeburger J, Smith AD, Blennow K, Wallin A (2011) Screening for new biomarkers for subcortical vascular dementia and Alzheimer's disease. Dement Geriatr Cogn Dis Extra 1, 3142.

[40] Schafer DP, Lehrman EK, Kautzman AG, Koyama R, Mardinly AR, Yamasaki R, Ransohoff RM, Greenberg ME, Barres BA, Stevens B (2012) Microglia sculpt postnatal neural circuits in an activity and complement-dependent manner. Neuron 74, 691-705.

[41] Stephan AH, Barres BA, Stevens B (2012) The complement system: an unexpected role in synaptic pruning during development and disease. Annu Rev Neurosci 35, 369-389.

[42] Stevens B, Allen NJ, Vazquez LE, Howell GR, Christopherson KS, Nouri N, Micheva KD, Mehalow AK, Huberman AD, Stafford B, Sher A, Litke AM, Lambris JD, Smith SJ, John SW, Barres BA (2007) The classical complement cascade mediates CNS synapse elimination. Cell 131, 1164-1178. 



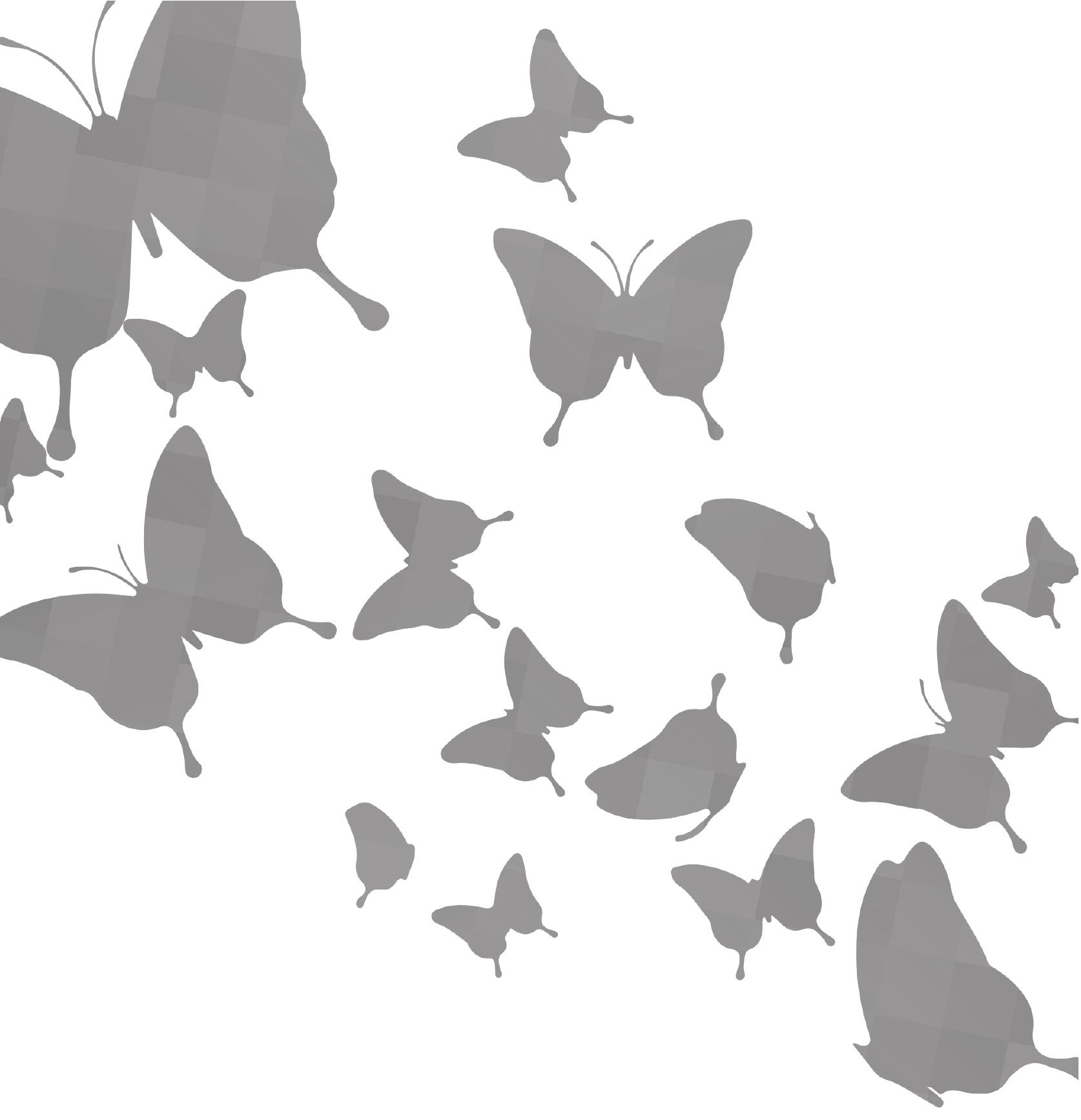




\section{Association between later life lifestyle factors and Alzheimer's disease biomarkers in non-demented individuals: a longitudinal descriptive cohort study}

Babette L.R. Reijs

Stephanie J.B. Vos

Hilkka Soininen

Jyrki Lötjonen

Juha Koikkalainen

Maria Pikkarainen

Anette Hall

Ritva Vanninen

Yawu Liu

Sanna-Kaisa Herukka

Yvonne Freund-Levi

Giovanni .B. Frisoni

Lutz Frölich

Flavio Nobili

Marcel Olde Rikkert

Luiza Spiru

Magda Tsolaki

Åsa K. Wallin

Philip Scheltens

Frans R.J. Verhey

Pieter Jelle Visser

Published in: Journal of Alzheimer's

Disease (JAD) 2017; 60:1387-1395. 


\section{ABSTRACT}

Background: Lifestyle factors have been associated with the risk of dementia, but the association with Alzheimer's disease (AD) remains unclear.

Objective: To examine the association between later life lifestyle factors and $A D$ biomarkers (i.e. beta amyloid 1-42 (aß42) and tau in cerebrospinal fluid (CSF), and hippocampal volume) in individuals with subjective cognitive decline (SCD) and mild cognitive impairment $(\mathrm{MCl})$. In addition, to examine the effect of later life lifestyle factors on developing AD-type dementia in individuals with $\mathrm{MCl}$.

Methods: We selected individuals with SCD $(n=111)$ and $M C I(n=353)$ from the DESCRIPA and Kuopio Longitudinal MCl studies. CSF a 342 and tau concentrations were assessed with ELISA assay and hippocampal volume with multi-atlas segmentation. Lifestyle was assessed by clinical interview at baseline for: social activity, physical activity, cognitive activity, smoking, alcohol consumption, and sleep. We performed logistic and Cox regression analyses adjusted for study site, age, gender, education and diagnosis. Prediction for AD-type dementia was performed in individuals with $\mathrm{MCl}$ only.

Results: Later life lifestyle factors were not associated with $A D$ biomarkers or with conversion to $A D$-type dementia. $A D$ biomarkers were strongly associated with conversion to AD-type dementia, but these relations were not modulated by lifestyle factors. Apolipoprotein E (APOE) genotype did not influence the results.

Conclusions: Later life lifestyle factors had no impact on key $A D$ biomarkers in individuals with $\mathrm{SCD}$ and $\mathrm{MCl}$ or on conversion to $\mathrm{AD}$-type dementia in $\mathrm{MCl}$. 


\section{INTRODUCTION}

The prevalence of Alzheimer's Disease (AD) is rising across the world, which increases the need for opportunities to delay or prevent the development of the disease. Population studies have found that targeting midlife lifestyle factors such as physical and cognitive activity may decrease the risk for AD-type dementia [1,2]. AD-type dementia is the most common form of dementia and is characterized by an accumulation of beta amyloid plaques, aggregation of tau tangles and hippocampal atrophy $[3,4]$. These $A D$ biomarkers are abnormal up to 25 years before the onset of AD-type dementia, which makes them valuable for early detection of $A D([5-7]$.

Previous research did not find an association between $A D$ biomarkers and cognitive and physical activity in non-demented individuals [8], but the association between a variety of later life lifestyle factors and AD biomarkers in individuals with normal cognition or mild cognitive impairment ( $\mathrm{MCl}$ ) have not been extensively examined. Understanding the relation between lifestyle factors and AD biomarkers in non-demented individuals at the time of diagnostic assessment at a memory clinic may be useful for the design of prevention studies in early stages of $A D$, and may be of direct value in advising later life lifestyle changes.

In this study, we examined the association between the potential modifiable risk factors social activity [9], physical activity and cognitive activity $[1,2,10]$, alcohol consumption $[11]$, current smoking $[1,2]$ and sleep problems $[1,2,12,13]$ with CSF tau and beta amyloid 1-42 (aß42) and hippocampal volume in individuals with subjective cognitive decline $(\mathrm{SCD})$ and $\mathrm{MCl}$. Secondly, we examined the effect of these lifestyle factors on the risk for AD-type dementia and whether these factors modulated the risk of $A D$ biomarkers for conversion to AD-type dementia in individuals with $\mathrm{MCl}$. We hypothesized that lifestyle factors at diagnostic assessment are associated with $A D$ biomarkers in individuals with $\mathrm{SCD}$ and $\mathrm{MCl}$ and with progression to $\mathrm{AD}$-type dementia in individuals with $\mathrm{MCl}$. Furthermore, we expected that lifestyle factors modulate the risk of $A D$ biomarkers for conversion to $\mathrm{AD}$-type dementia in individuals with $\mathrm{MCl}$.

\section{METHODS}

\section{Individuals}

We selected in total 464 individuals. $111 \mathrm{SCD}$ and $254 \mathrm{MCl}$ individuals were from the DESCRIPA study [14] and 99 individuals with $\mathrm{MCl}$ were from the Kuopio longitudinal$\mathrm{MCl}$ (Kuopio L-MCI) study [15-18]. The DESCRIPA study $(\mathrm{n}=881)$ recruited individuals 
from eleven memory clinics across Europe between 2003 and 2005. The KUOPIO L-MCI study ( $n=145$ ) pooled individuals from two population-based studies in Eastern Finland between 1996 and 2001 [15, 17-19].

Inclusion criteria for SCD were age above 55 years, referral to the memory clinic for an evaluation of complaints, no cognitive impairment on neuropsychological tests, and absence of dementia. Inclusion criteria for MCI in DESCRIPA were similar to the criteria for SCD except that a cognitive impairment was required on a neuropsychological test. Impairment was defined as age, gender and education corrected z-score below -1.5 in any cognitive domain [20]. In Kuopio L-MCl, MCl was defined as: 1) memory complaint by patient, family, or physician; 2) normal activities of daily living; 3) normal global cognitive function; 4) objective impairment below -1.5 SD in any cognitive domain; 5) CDR score of 0.5 ; and 6 ) absence of dementia [20, 21]. For both studies, the diagnosis of AD-type dementia was based on the NINCDS-ADRDA criteria [22]. From both studies we selected individuals based on the availability of CSF data or hippocampal volumes and at least one lifestyle factor.

\section{Baseline and follow-up assessment}

At baseline we performed an assessment of clinical history, Mini-Mental State Examination (MMSE; [23], lifestyle factors, and APOE-e4 genotyping, and performed medical, neuropsychological, neuroimaging and CSF assessments. At follow-up, the clinical and neuropsychological assessments were repeated. The average follow-up time was 2.4 years $(S D=1.3)$.

\section{Lifestyle factors}

Data on physical activity, alcohol consumption and current smoking were available in both the DESCRIPA study and the Kuopio L-MCI study. Data on social activity, cognitive activity, and sleep problems were only collected in DESCRIPA. All measures were selfreported and collected in a clinical interview unless reported otherwise.

Being socially active was defined as having at least one social activity reported several times a week or having at least two activities several times a month. Social activities included visiting family and friends, babysitting, going to church/church choir, club membership (e.g. pensioners, garden, social or golf club) and volunteer's work.

Being physically active was defined in DESCRIPA as either: 1) every day or about every day walking or cycling, or 2) at least several times a week one of the following self-reported activities: dancing, badminton, tennis, swimming, water exercise, squash, skating, or going to the gym. In KUOPIO L-MCl, being physically active was defined as either 1) a 
physical activity at least several times a week causing breathlessness or sweating, or 2) a physical activity of at least 2-4 hours or 15-30 km per week. This definition was more or less equivalent to the amount of exercise recommended by the Centers for Disease Control (CDC), the American College of Sports Medicine (ACSM) and the American Heart Association (ASA) (i.e. at least five days per week of 30 minutes moderate intensity activity or 3 days of 20 minutes vigorous intensity activity) [24, 25].

Cognitive activity was measured with the 7-item Cognitive Activity Scale (CAS) [26]. Cognitive activities measured in this CAS are viewing television; reading newspapers; reading magazines; reading books; playing games such as cards, checkers, crosswords, or other; and going to museums. For every activity, the individual had to rate the frequency on the following 5-point Likert scale: once a year or less (1), several times a year (2), several times a month (3), several times a week (4), every day or about every day (5). Individuals with an average frequency rating $>3.9$ were considered cognitively active. Individuals $(n=4)$ with more than 2 missing items on the CAS were excluded.

Mild to moderate alcohol consumption was defined in DESCRIPA as consumption of maximum two alcoholic units a day and in Kuopio L-MCl a consumption of maximum 14 alcoholic units per week. We compared individuals with mild to moderate alcohol consumption ( $n=249$ ) with individuals with no alcohol consumption $(n=169)$, and with individuals with severe alcohol consumption (i.e. more than two units a day or more than 14 per week, $n=39$ ).

Current smoking was defined as any present smoking in DESCRIPA and Kuopio-L MCI.

Sleep problems was defined as sleep problems reported by the patient and/or caregiver in clinical interview or a total score (i.e. frequency $\mathrm{x}$ severity) of more than two on the sleep item on the Neuropsychiatry Inventory (NPI, [27]).

\section{CSF collection, storage and analysis}

In DESCRIPA, CSF samples were collected in $10 \mathrm{~mL}$ polypropylene tubes and stored at $-80^{\circ} \mathrm{C}$ degrees. CSF analyses were centrally performed at the Clinical Neurochemistry Laboratory, Sahlgrenska University Hospital, Sweden. A $\beta 42$ and total tau (t-tau) were measured with single-parameter ELISA kits (Fujirebio, formerly, Innogenetics, Ghent, Belgium). Concentrations below $550 \mathrm{pg} / \mathrm{ml}$ for a $\beta 42$ and above $375 \mathrm{pg} / \mathrm{ml}$ for t-tau were considered abnormal according to local cut-off values [28]. In Kuopio L-MCl, CSF samples were collected in $10 \mathrm{~mL}$ polypropylene tubes and stored at $-70^{\circ} \mathrm{C}$ degrees. CSF analyses were measured with commercial ELISA (Fujirebio, formerly, Innogenetics, 
Ghent, Belgium). Concentrations below $452 \mathrm{pg} / \mathrm{ml}$ for aß42 and above $399 \mathrm{pg} / \mathrm{ml}$ for t-tau were considered abnormal according to local cut-off values [29]. In both studies, investigators were blinded to the CSF results.

\section{Hippocampal volume}

The scanning was performed at 1.0 or 1.5 Tesla and included for DESCRIPA 3DT1 weighed gradient echo and a fast fluid attenuated inversion recovery (FLAIR) sequence and for Kuopio L-MCI anatomical high-resolution T1-weighed images using a 3D-MPRAGE sequence $[21,30]$. The hippocampal volumes were computed from segmentations generated by a multi-atlas segmentation tool [31]. Age and gender corrected continuous hippocampal volumes were used, which were calculated by a linear regression model [32]. In addition, a cutoff was calculated in an independent cohort (ADNI) that could best discriminate controls from individuals with AD-type dementia when corrected to age of 70 years. Abnormal hippocampal volume was defined as a volume $<4216 \mathrm{~mm}^{3}$ for males and $<3930 \mathrm{~mm}^{3}$ for females (left and right side summed).

\section{APOE genotype}

In DESCRIPA, apolipoprotein E (APOE)- $\varepsilon 4$ genotyping was determined with polymerase chain reaction (PCR) of genomic DNA extracted from coagulated blood. In Kuopio L-MCl, the APOE genotype was determined from blood leukocytes and extracted by standard phenol-chloroform extraction, and analyzed by PCR and Hhal digestion [33].

\section{Statistical analyses}

Statistical analyses were conducted with IBM SPSS statistics version 24. Group differences at baseline were examined with independent t-tests for continuous variables and with $\mathrm{X}^{2}$ tests for categorical variables. All lifestyle factors were dichotomized into present versus absent. The association between lifestyle factors and dichotomous AD markers (i.e. abnormal aß42, abnormal tau, and abnormal hippocampal values) were analysed by logistic regression analyses corrected for age, gender, education, diagnosis and center in all individuals with SCD and $\mathrm{MCl}$.

The moderator effect of all lifestyle factors on continuous AD markers (i.e. CSF a 342 pg/ $\mathrm{ml}$ concentrations, CSF t-tau pg/ml concentrations, corrected hippocampal volumes) in converting to AD-type dementia were analysed by performing survival analyses with Cox Regression corrected for age, gender, education, and center (the 11 single centers) in individuals with $\mathrm{MCl}$. Assumptions of Cox regression were met. 
Post-hoc, analyses were repeated with correction for APOE- $\varepsilon 4$ carriership to control for a possible genetic predisposition for AD-type dementia. In addition, for lifestyle factors with data from both the DESCRIPA and Kuopio L-MCI study (i.e. physical activity, alcohol consumption and current smoking) analyses were repeated with correction for study (DESCRIPA versus Kuopio L-MCI). Furthermore, logistic regression analyses were also performed with age and gender corrected hippocampal volumes [32] as a continuous outcome measure.

\section{RESULTS}

We included 464 individuals (SCD $n=111, M C I n=353$ ). Baseline characteristics are presented in Table 1. Individuals were on average 70 years old $(S D=7.3)$, had 9 years of education ( $S D=4.0)$ and the majority was female (57\%). Individuals with $\mathrm{MCI}$ were slightly older than individuals with SCD, but did not differ on years of education and gender. As expected, individuals with $\mathrm{MCI}$ had lower MMSE scores, lower hippocampal volumes, higher CSF t-tau concentrations and converted more often to AD-type dementia. However, individuals with $\mathrm{MCl}$ did not differ on CSF aß42 concentrations and APOE-e4 carriership from individuals with SCD. With regard to lifestyle factors, individuals with $\mathrm{MCl}$ were less socially active and fewer individuals consumed mild to moderate quantity of alcohol than individuals with SCD. APOE- $\varepsilon 4$ carriership did not differ between groups. There was no difference between individuals with $\mathrm{MCl}$ from DESCRIPA $(n=254)$ and Kuopio L-MCI ( $\mathrm{n}=99$ ) on age (mean (SD): 70.3 (7.7) versus 71.5 (4.2)) and gender $(44.1 \%$ versus 33.3\% male), but they did differ on educational years (mean (SD): 9.4 (4.0) versus 7.1 (2.2), $\mathrm{p}<.001$ ) and MMSE scores (mean (SD): 27.1 (2.3) versus $23.8(2.7, \mathrm{p}<.001)$ ).

\section{Lifestyle factors and AD biomarkers}

Social activity, physical activity, cognitive activity, mild to moderate alcohol consumption, current smoking and sleep problems at time of diagnosis were not associated with abnormal aß42, abnormal tau or abnormal hippocampal volumes in individuals with SCD and $\mathrm{MCl}$ at baseline. Table 2 lists the relations between these lifestyle factors and $A D$ markers. Similar results were found when analyses were repeated with corrected continuous measures of hippocampal volumes or when analyses were corrected for study (DESCRIPA versus Kuopio L-MCI). Furthermore, there was no moderator effect of diagnosis and results were comparable when correcting for APOE- $\_4$ carriership (data not shown). 
Table 1. Baseline characteristics

\begin{tabular}{|c|c|c|c|}
\hline & All $(n=464)$ & $\operatorname{SCD}(n=111)$ & $\mathrm{MCl}(n=353)$ \\
\hline Age & $69.8(7.3)$ & $67.0(7.6)$ & $70.6(6.9)^{*}$ \\
\hline Male, $\mathrm{n}(\%)$ & 199 / 464 (43\%) & $54 / 111(49 \%)$ & 145 / 353 (41\%) \\
\hline Years of Education, mean (SD) & $9.4(4.0)$ & $11.4(4.1)$ & $8.7(3.8)$ \\
\hline MMSE score, mean (SD) & $26.7(2.8)$ & $28.5(1.5)$ & $26.2(2.9)^{* * *}$ \\
\hline APOE- $\varepsilon 4+, n(\%)$ & 185 / 407 (46\%) & $41 / 90$ (46\%) & 144 / 317 (45\%) \\
\hline Socially active, n (\%) & $53 / 119(45 \%)$ & 27 / 47 (57\%) & $26 / 72(36 \%)^{*}$ \\
\hline Physically active, n (\%) & 166 / 349 (48\%) & $46 / 85$ (54\%) & 120 / 264 (46\%) \\
\hline Cognitively active, n (\%) & $22 / 231(10 \%)$ & $12 / 85 /(14 \%)$ & $10 / 146(7 \%)$ \\
\hline Alcohol consumption, $\mathrm{n}$ & 457 & 111 & $346^{* * *}$ \\
\hline None, n (\%) & $169(37 \%)$ & $24(22 \%)$ & $145(42 \%)$ \\
\hline Mild to moderate, $\mathrm{n}(\%)$ & $249(55 \%)$ & $79(71 \%)$ & $170(49 \%)$ \\
\hline Severe, n (\%) & $39(9 \%)$ & $8(7 \%)$ & $31(9 \%)$ \\
\hline Current smoking, n (\%) & 52 / 457 (11\%) & $13 / 111(12 \%)$ & 39 / $346(11 \%)$ \\
\hline Sleep problems, n (\%) & 79 / $349(23 \%)$ & $27 / 108$ (25\%) & $52 / 241(22 \%)$ \\
\hline Abnormal CSF a $342, n$ (\%) & $101 / 205$ (49\%) & $26 / 65(40 \%)$ & 75 / 140 (54\%) \\
\hline Abnormal CSF t-tau, n (\%) & 107 / 205 (52\%) & $23 / 65$ (35\%) & $84 / 140(60 \%)^{* *}$ \\
\hline Abnormal CSF aß42 + t-tau, n (\%) & $63 / 205$ (31\%) & $10 / 65$ (15\%) & $53 / 140(38 \%)^{* *}$ \\
\hline $\mathrm{HCV}$, mean (SD) & $3939(606)$ & $4190(520)$ & $3869(610)^{*}$ \\
\hline Abnormal HCV, n (\%) & $216 / 402$ (54\%) & 28 / $88(32 \%)$ & $188 / 314(60 \%)^{* * *}$ \\
\hline Converted to AD-type dementia, n (\%) & $101 / 464(22 \%)$ & $2 / 111(2 \%)$ & $99 / 353(28 \%)^{* * *}$ \\
\hline Converted to Non-AD dementia, n (\%) & 17 / $464(4 \%)$ & $2 / 111(2 \%)$ & 15 / 353 (4\%) \\
\hline
\end{tabular}

Number of individuals for dichotomous variables: individuals with abnormal score or individuals that were active/ individuals with measurement. Abbreviations: MMSE, Mini-Mental State Examination; APOE, Apolipoprotein E; CSF, Cerebrospinal fluid; a 342 , beta amyloid 1-42; t-tau, total tau; HCV, hippocampal volume; SCD, Subjective Cognitive Impairment; $\mathrm{MCl}$, Mild Cognitive Impairment; $\mathrm{AD}$, Alzheimer's disease. Data are mean (SD) or valid percent. ${ }^{*} p<.05$, significantly different from the $S C D$ group ${ }^{* *} p<.01$, significantly different from the $S C D$ group ${ }^{* * *} p<.001$, significantly different from the SCD group 


\section{The effect of lifestyle factors on conversion to AD-type dementia}

Later life lifestyle factors were not associated with conversion to AD-type dementia in individuals with $\mathrm{MCl}$ (Table 3). Lower CSF a 342 concentrations ( $H R=0.998, p<0.01$ ), higher CSF t-tau concentrations $(H R=1.002, p<0.001)$ and lower hippocampal volumes $(\mathrm{HR}=0.999, \mathrm{p}<0.001)$ were associated with conversion to AD-type dementia, but these associations were not modulated by lifestyle factors except for mild to moderate alcohol consumption (Table 3). The effect of mild to moderate alcohol consumption relative to no alcohol intake on conversion to AD-type dementia was dependent on the CSF tau status. In individuals with normal tau concentrations, mild to moderate alcohol consumption tended to decrease the risk for conversion to AD-type dementia ( $H R=$ $0.178, p=0.081$, Figure 1), but in individuals with abnormal tau mild to moderate alcohol consumption did not decrease the risk for conversion to AD-type dementia ( $H R=0.949$, $\mathrm{p}=0.908$, Figure 1). Findings remained similar after correction for APOE- $\varepsilon 4$ genotype and also after correction for study (DESCRIPA versus Kuopio L-MCI) (data not shown).

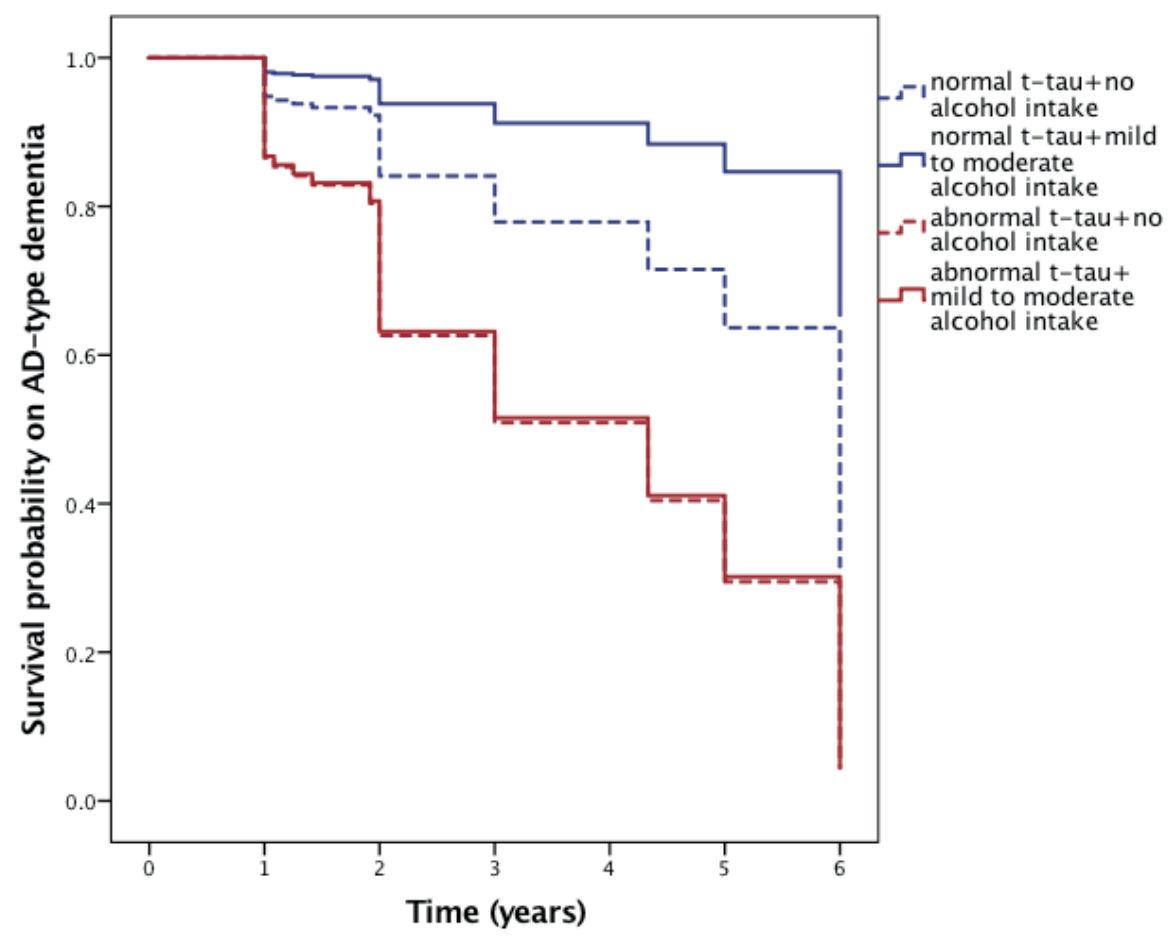

Figure 1. Association between CSF tau and mild to moderate alcohol consumption

Figure displays Cox regression lines of individuals with normal CSF tau (blue lines) and abnormal CSF tau concentrations (red lines) with mild to moderate alcohol consumption (solid lines) and with no alcohol consumption (dashed lines). 

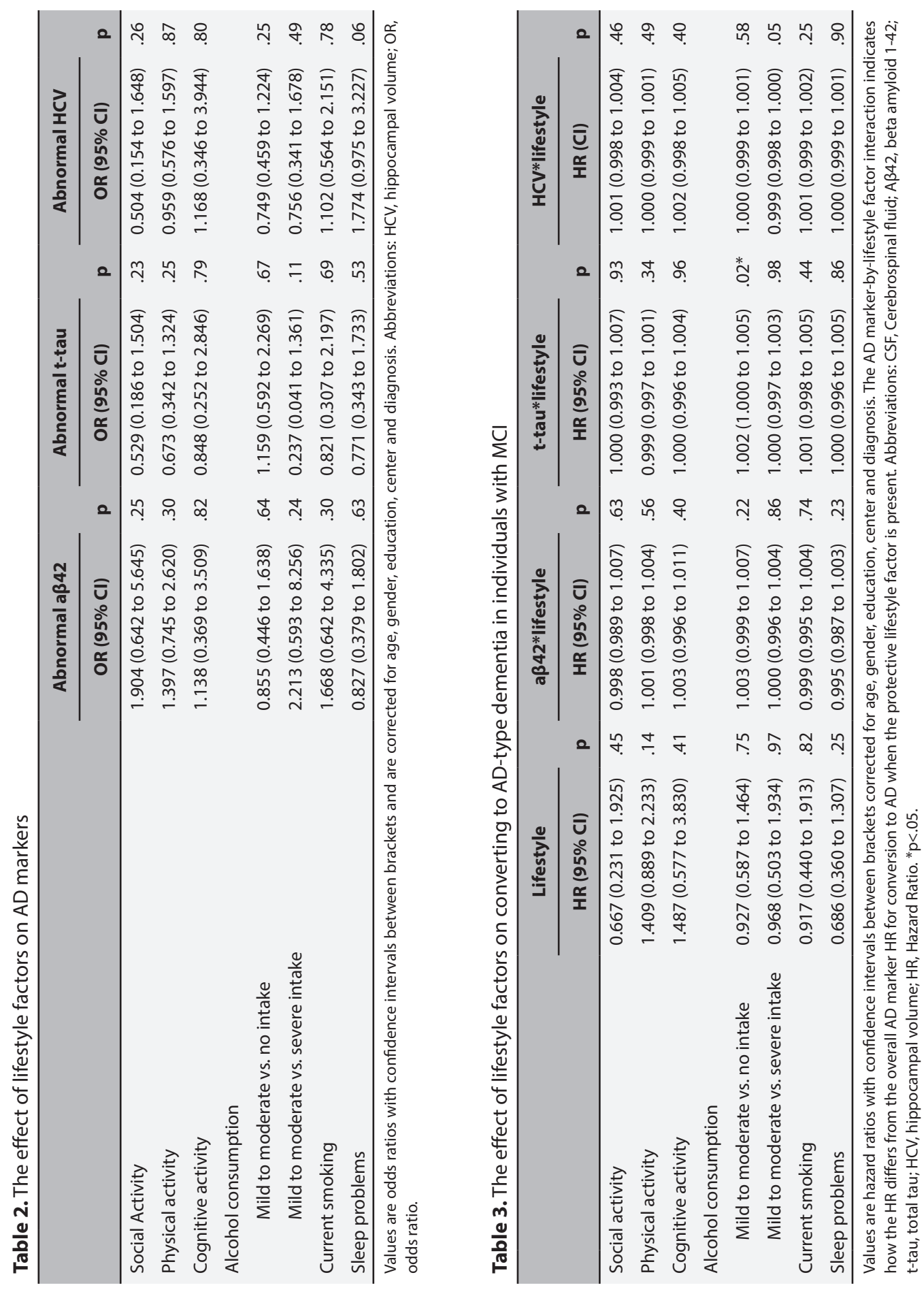


\section{DISCUSSION}

The main results of this study are that later life lifestyle factors were not associated with $A D$ biomarkers or with conversion to AD-type dementia in non-demented individuals. Lifestyle factors assessed at this stage also did not modify the relationship between $A D$ biomarkers and conversion to AD-type dementia in individuals with $\mathrm{MCl}$.

The association between lifestyle factors and $A D$ biomarkers have not yet been extensively examined. As far as we know, only Vemuri and colleagues [8] tested the association between cognitive and physical activity with amyloid deposition as assessed by Pittsburg compound B (PiB)-positron emission tomography (PET), metabolism as assessed by ${ }^{18} \mathrm{~F}$-fluorodeoxyglucose (FDG-PET), and hippocampal volume in cognitively normal older adults and in individuals with $\mathrm{MCl}$. In line with our study, they could not find an association between these lifestyle factors and AD biomarkers at later life.

Population studies found an association between lifestyle factors and conversion to ADtype dementia [1, 2]. Surprisingly, we could not find such an association. Our findings may be explained by the difference in recruitment and the timing of the assessment of the risk factors. We included individuals who experienced cognitive impairments from either a memory clinic setting (SCD or $\mathrm{MCl}$ ) or a population-based setting $(\mathrm{MCl})$. In addition, lifestyle factors may be less influential in individuals who already experience cognitive impairments. We collected lifestyle factors at the time of the baseline visit, typically around age 70, while several population-based studies often have tested risk factors at midlife. It is possible that the association with lifestyle factors and dementia risk is different for several age ranges, as lifestyle may also be affected by ongoing cognitive decline, and therefore may play a more important role in midlife, but this needs to be further explored. Furthermore, targeting lifestyle factors is perhaps also more effective in midlife before the accumulation of $A D$ pathology. Also, lifestyle factors may act mainly via non-AD pathways, for example via cerebrovascular or metabolic routes of damage accumulation. Exposure to cardiovascular risk factors, such as hypertension, hypercholesterolaemia and fasting blood glucose, has been linked to late-life cognitive functioning $[18,34,35]$, and may be influenced by lifestyle factors as physical activity.

As expected AD biomarkers had a strong effect on conversion to AD-type dementia in individuals with $\mathrm{MCl}$, but lifestyle factors did not have an impact on the predictive accuracy of these biomarkers. Only in individuals with $\mathrm{MCl}$, alcohol consumption modulated the risk of tau for AD-type dementia. However, since the sample size was small (no intake $n=25$, mild to moderate intake $n=28$ ) this finding needs further 
replication. Protective effects against cognitive decline have been found for mild to moderate alcohol consumption, but these findings are somewhat controversial and further research is needed to confirm this [11,36-38].

This study has several limitations. First, the follow-up period was relatively short with on average two years. Conceivably, with a longer follow-up period conversion rate to AD-type dementia could be higher. Second, our sample size was relatively small. Since, the influence of lifestyle factors might be subtle, a larger sample may be required to increase power and find an association. Third, like in other studies, participants agreed to undergo a neuroimaging scan and lumbar puncture so they may not be representative of the general population with memory complaints. Fourth, the measurement of lifestyle factors may be somewhat constrained. We only included self-reported questionnaires, which are subjective in nature and can be biased by recall and social desirability. Fifth, like in several others studies, we examined only current later life social-, cognitive- and physical activity and current alcohol consumption and smoking. Examining lifestyle factors over a longer period of time probably gives a better overall indication of the influence of these factors on risk for AD. Furthermore, lifestyle compliance could then be evaluated.

To conclude, our study shows no association between lifestyle factors and $A D$ biomarkers or conversion to AD-type dementia in non-demented individuals. Even though lifestyle factors were not associated with conversion to AD-type dementia, a few intervention studies did find beneficial effects of physical activity on improving cognitive performance in individuals with $\mathrm{MCI}[39,40]$. But the impact of lifestyle interventions may be small in size compared to the effect that might be achieved by acting on disease biology. Targeting modifiable lifestyle factors in non-demented individuals with cognitive complaints may still be beneficial to improve overall health, however chances for prognostic effects at the time of diagnostic work-up in memory clinics might be low.

\section{Acknowledgments}

This work has received funding from the European Union's Seventh Framework Programme under grant agreement no 601055 (VPH-DARE@IT). DESCRIPA was funded by the European Commission as part of the 5th Framework Program (QLK-6CT-2002-02455). Kuopio-L MCl study was funded by the European Union 7th Framework Program (FP7-224328-PredictAD). 


\section{REFERENCES}

[1] Barnes DE, Yaffe K (2011) The projected effect of risk factor reduction on Alzheimer's disease prevalence. Lancet Neurol 10, 819-828.

[2] Norton S, Matthews FE, Barnes DE, Yaffe K, Brayne C (2014) Potential for primary prevention of Alzheimer's disease: an analysis of population-based data. Lancet Neurol 13, 788-794.

[3] Braak H, Braak E (1991) Neuropathological stageing of Alzheimer-related changes. Acta Neuropathol 82, 239-259.

[4] Jack CR, Jr., Knopman DS, Jagust WJ, Petersen RC, Weiner MW, Aisen PS, Shaw LM, Vemuri P, Wiste HJ, Weigand SD, Lesnick TG, Pankratz VS, Donohue MC, Trojanowski JQ (2013) Tracking pathophysiological processes in Alzheimer's disease: an updated hypothetical model of dynamic biomarkers. Lancet Neurol 12, 207-216.

[5] Bateman RJ, Xiong C, Benzinger TL, Fagan AM, Goate A, Fox NC, Marcus DS, Cairns NJ, Xie X, Blazey TM, Holtzman DM, Santacruz A, Buckles V, Oliver A, Moulder K, Aisen PS, Ghetti B, Klunk WE, McDade E, Martins RN, Masters CL, Mayeux R, Ringman JM, Rossor MN, Schofield PR, Sperling RA, Salloway S, Morris JC, Dominantly Inherited Alzheimer N (2012) Clinical and biomarker changes in dominantly inherited Alzheimer's disease. N Engl J Med 367, 795-804.

[6] Jansen WJ, Ossenkoppele R, Knol DL, Tijms BM, Scheltens P, Verhey FR, Visser PJ, Amyloid Biomarker Study Group (2015) Prevalence of cerebral amyloid pathology in persons without dementia: a meta-analysis. JAMA 313, 1924-1938.

[7] Vos SJ, Xiong C, Visser PJ, Jasielec MS, Hassenstab J, Grant EA, Cairns NJ, Morris JC, Holtzman DM, Fagan AM (2013) Preclinical Alzheimer's disease and its outcome: a longitudinal cohort study. Lancet Neurol 12, 957-965.

[8] Vemuri P, Lesnick TG, Przybelski SA, Knopman DS, Roberts RO, Lowe VJ, Kantarci K, Senjem ML, Gunter JL, Boeve BF, Petersen RC, Jack CR, Jr. (2012) Effect of lifestyle activities on Alzheimer disease biomarkers and cognition. Ann Neurol 72, 730-738.

[9] Carlson MC, Helms MJ, Steffens DC, Burke JR, Potter GG, Plassman BL (2008) Midlife activity predicts risk of dementia in older male twin pairs. Alzheimers Dement 4, 324-331.

[10] Wilson RS, Scherr PA, Schneider JA, Tang Y, Bennett DA (2007) Relation of cognitive activity to risk of developing Alzheimer disease. Neurology 69, 1911-1920.

[11] Fratiglioni L, Winblad B, von Strauss E (2007) Prevention of Alzheimer's disease and dementia. Major findings from the Kungsholmen Project. Physiol Behav 92, 98-104.

[12] Osorio RS, Pirraglia E, Aguera-Ortiz LF, During EH, Sacks H, Ayappa I, Walsleben J, Mooney A, Hussain A, Glodzik L, Frangione B, Martinez-Martin P, de Leon MJ (2011) Greater risk of Alzheimer's disease in older adults with insomnia. J Am Geriatr Soc 59, 559-562.

[13] Yaffe K, Laffan AM, Harrison SL, Redline S, Spira AP, Ensrud KE, Ancoli-Israel S, Stone KL (2011) Sleep-disordered breathing, hypoxia, and risk of mild cognitive impairment and dementia in older women. JAMA 306, 613-619. 
[14] Visser PJ, Verhey FR, Boada M, Bullock R, De Deyn PP, Frisoni GB, Frolich L, Hampel H, Jolles J, Jones R, Minthon L, Nobili F, Olde Rikkert M, Ousset PJ, Rigaud AS, Scheltens P, Soininen H, Spiru L, Touchon J, Tsolaki M, Vellas B, Wahlund LO, Wilcock G, Winblad B (2008) Development of screening guidelines and clinical criteria for predementia Alzheimer's disease. The DESCRIPA Study. Neuroepidemiology 30, 254-265.

[15] Hanninen T, Hallikainen M, Tuomainen S, Vanhanen M, Soininen H (2002) Prevalence of mild cognitive impairment: a population-based study in elderly subjects. Acta Neurol Scand 106, 148-154.

[16] Julkunen V, Niskanen E, Koikkalainen J, Herukka SK, Pihlajamaki M, Hallikainen M, Kivipelto M, Muehlboeck S, Evans AC, Vanninen R, Hilkka S (2010) Differences in cortical thickness in healthy controls, subjects with mild cognitive impairment, and Alzheimer's disease patients: a longitudinal study. J Alzheimers Dis 21, 1141-1151.

[17] Julkunen V, Niskanen E, Muehlboeck S, Pihlajamaki M, Kononen M, Hallikainen M, Kivipelto M, Tervo S, Vanninen R, Evans A, Soininen H (2009) Cortical thickness analysis to detect progressive mild cognitive impairment: a reference to Alzheimer's disease. Dement Geriatr Cogn Disord 28, 404-412.

[18] Kivipelto M, Helkala EL, Laakso MP, Hanninen T, Hallikainen M, Alhainen K, Soininen $H$, Tuomilehto J, Nissinen A (2001) Midlife vascular risk factors and Alzheimer's disease in later life: longitudinal, population based study. BMJ 322, 1447-1451.

[19] Pennanen C, Kivipelto M, Tuomainen S, Hartikainen P, Hanninen T, Laakso MP, Hallikainen M, Vanhanen M, Nissinen A, Helkala EL, Vainio P, Vanninen R, Partanen K, Soininen H (2004) Hippocampus and entorhinal cortex in mild cognitive impairment and early AD. Neurobiol Aging 25, 303-310.

[20] Petersen RC (2004) Mild cognitive impairment as a diagnostic entity. J Intern Med 256, 183194.

[21] Hall A, Munoz-Ruiz M, Mattila J, Koikkalainen J, Tsolaki M, Mecocci P, Kloszewska I, Vellas B, Lovestone S, Visser PJ, Lotjonen J, Soininen H, Alzheimer Disease Neuroimaging I, AddNeuroMed c, Descripa, Kuopio LM (2015) Generalizability of the disease state index prediction model for identifying patients progressing from mild cognitive impairment to Alzheimer's disease. J Alzheimers Dis 44, 79-92.

[22] McKhann G, Drachman D, Folstein M, Katzman R, Price D, Stadlan EM (1984) Clinical diagnosis of Alzheimer's disease: report of the NINCDS-ADRDA Work Group under the auspices of Department of Health and Human Services Task Force on Alzheimer's Disease. Neurology 34, 939-944.

[23] Folstein MF, Folstein SE, McHugh PR (1975) "Mini-mental state". A practical method for grading the cognitive state of patients for the clinician. J Psychiatr Res 12, 189-198. 
[24] Haskell WL, Lee IM, Pate RR, Powell KE, Blair SN, Franklin BA, Macera CA, Heath GW, Thompson PD, Bauman A (2007) Physical activity and public health: updated recommendation for adults from the American College of Sports Medicine and the American Heart Association. Med Sci Sports Exerc 39, 1423-1434.

[25] Pate RR, Pratt M, Blair SN, Haskell WL, Macera CA, Bouchard C, Buchner D, Ettinger W, Heath GW, King AC, et al. (1995) Physical activity and public health. A recommendation from the Centers for Disease Control and Prevention and the American College of Sports Medicine. JAMA 273, 402-407.

[26] Wilson R, Barnes L, Bennett D (2003) Assessment of lifetime participation in cognitively stimulating activities. J Clin Exp Neuropsychol 25, 634-642.

[27] Cummings JL (1997) The Neuropsychiatric Inventory: assessing psychopathology in dementia patients. Neurology 48, S10-16.

[28] Mulder C, Verwey NA, van der Flier WM, Bouwman FH, Kok A, van Elk EJ, Scheltens P, Blankenstein MA (2010) Amyloid-beta(1-42), total tau, and phosphorylated tau as cerebrospinal fluid biomarkers for the diagnosis of Alzheimer disease. Clin Chem 56, 248253.

[29] Herukka SK, Hallikainen M, Soininen H, PirttilaT (2005) CSF Abeta42 and tau or phosphorylated tau and prediction of progressive mild cognitive impairment. Neurology 64, 1294-1297.

[30] Clerx L, van Rossum IA, Burns L, Knol DL, Scheltens P, Verhey F, Aalten P, Lapuerta P, van de Pol L, van Schijndel R, de Jong R, Barkhof F, Wolz R, Rueckert D, Bocchetta M, Tsolaki M, Nobili F, Wahlund LO, Minthon L, Frolich L, Hampel H, Soininen H, Visser PJ (2013) Measurements of medial temporal lobe atrophy for prediction of Alzheimer's disease in subjects with mild cognitive impairment. Neurobiol Aging 34, 2003-2013.

[31] Lotjonen J, Wolz R, Koikkalainen J, Julkunen V, Thurfjell L, Lundqvist R, Waldemar G, Soininen H, Rueckert D, Alzheimer's Disease Neuroimaging I (2011) Fast and robust extraction of hippocampus from MR images for diagnostics of Alzheimer's disease. Neuroimage 56, 185196.

[32] Koikkalainen J, Polonen H, Mattila J, van Gils M, Soininen H, Lotjonen J, Alzheimer's Disease Neuroimaging I (2012) Improved classification of Alzheimer's disease data via removal of nuisance variability. PLoS One 7, e31112.

[33] Tsukamoto K, Watanabe T, Matsushima T, Kinoshita M, Kato H, Hashimoto Y, Kurokawa K, Teramoto T (1993) Determination by PCR-RFLP of apo E genotype in a Japanese population. J Lab Clin Med 121, 598-602.

[34] Biessels GJ, Staekenborg S, Brunner E, Brayne C, Scheltens P (2006) Risk of dementia in diabetes mellitus: a systematic review. Lancet Neurol 5, 64-74.

[35] Whitmer RA, Sidney S, Selby J, Johnston SC, Yaffe K (2005) Midlife cardiovascular risk factors and risk of dementia in late life. Neurology 64, 277-281. 
[36] Beydoun MA, Beydoun HA, Gamaldo AA, Teel A, Zonderman AB, Wang Y (2014) Epidemiologic studies of modifiable factors associated with cognition and dementia: systematic review and meta-analysis. BMC Public Health 14, 643.

[37] Kalmijn S, van Boxtel MP, Verschuren MW, Jolles J, Launer LJ (2002) Cigarette smoking and alcohol consumption in relation to cognitive performance in middle age. Am J Epidemiol 156, 936-944.

[38] Launer LJ, Masaki K, Petrovitch H, Foley D, Havlik RJ (1995) The association between midlife blood pressure levels and late-life cognitive function. The Honolulu-Asia Aging Study. JAMA 274, 1846-1851.

[39] Baker LD, Frank LL, Foster-Schubert K, Green PS, Wilkinson CW, McTiernan A, Plymate SR, Fishel MA, Watson GS, Cholerton BA, Duncan GE, Mehta PD, Craft S (2010) Effects of aerobic exercise on mild cognitive impairment: a controlled trial. Arch Neurol 67, 71-79.

[40] van Uffelen JG, Chinapaw MJ, van Mechelen W, Hopman-Rock M (2008) Walking or vitamin B for cognition in older adults with mild cognitive impairment? A randomised controlled trial. Br J Sports Med 42, 344-351. 



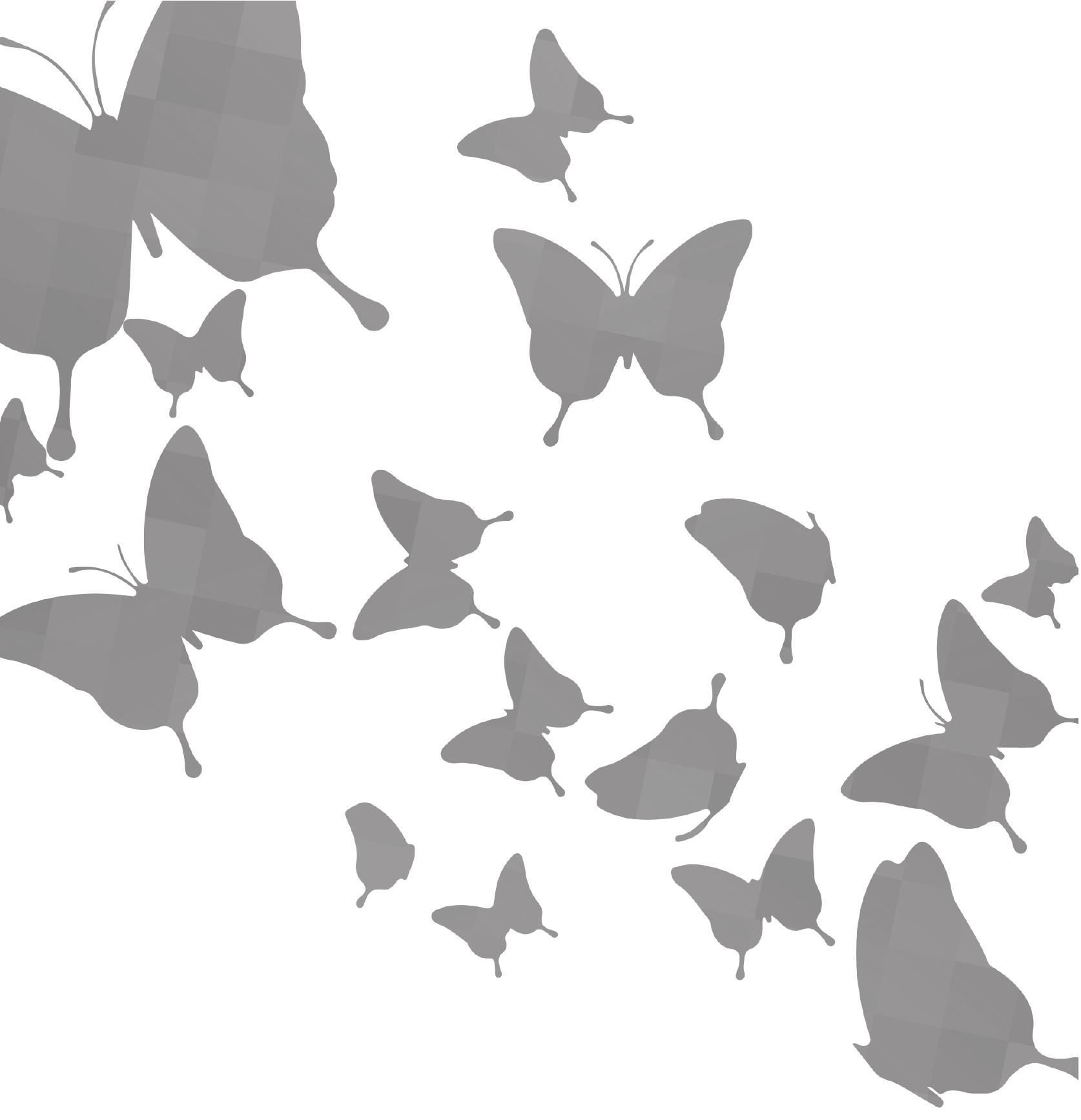




\section{The central biobank and virtual biobank of BIOMARKAPD: a resource for studies on neurodegenerative diseases}

$\begin{array}{ll}\text { Babette L.R. Reijs } & \text { Walter Maetzler } \\ \text { Charlotte E. Teunissen } & \text { Alexandre de Mendonça } \\ \text { Nikolai Goncharenko } & \text { Anne-Marie Miller } \\ \text { Fay Betsou } & \text { José L. Molinuevo } \\ \text { Kaj Blennow } & \text { Brit Mollenhauer } \\ \text { Inês Baldeiras } & \text { Lucilla Parnetti } \\ \text { Frederic Brosseron } & \text { Uros Rot } \\ \text { Enrica Cavedo } & \text { Anja Schneider } \\ \text { Tormod Fladby } & \text { Anja Hviid Simonsen } \\ \text { Lutz Frölich } & \text { Fabrizio Tagliavini } \\ \text { Tomasz Gabryelewicz } & \text { Magda Tsolaki } \\ \text { Hakan Gurvit } & \text { Marcel Verbeek } \\ \text { Elisabeth Kapaki } & \text { Frans R.J.Verhey } \\ \text { Peter Koson } & \text { Marzena Zboch } \\ \text { Luka Kulic } & \text { Bengt Winblad } \\ \text { Sylvain Lehmann } & \text { Philip Scheltens } \\ \text { Piotr Lewczuk } & \text { Henrik Zetterberg } \\ \text { Alberto Lleó } & \text { Pieter Jelle Visser }\end{array}$

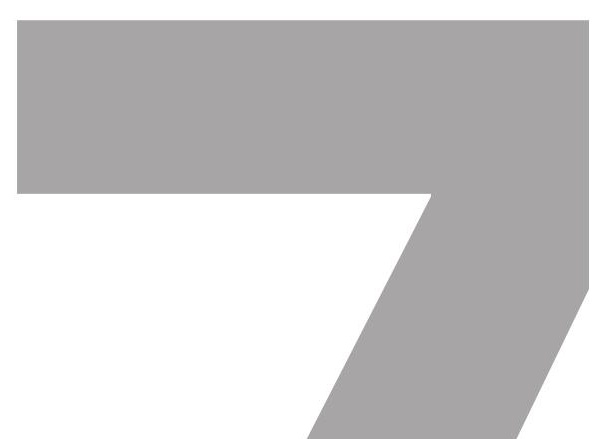

Published in: Frontiers Neurology 2015;6:216. 


\section{ABSTRACT}

Biobanks are important resources for biomarker discovery and assay development. Biomarkers for Alzheimer's and Parkinson's Disease (BIOMARKAPD) is a European multicenter study, funded by the EU Joint Programme - Neurodegenerative Disease Research (JPND), that aims to improve the clinical use of body fluid markers for the diagnosis and prognosis of Alzheimer's disease (AD) and Parkinson's disease (PD). The objective was to standardize the assessment of existing assays and to validate novel fluid biomarkers for AD and PD. To support the validation of novel biomarkers and assays, a central and a virtual biobank for body fluids and associated data from subjects with neurodegenerative diseases have been established. In the central biobank, cerebrospinal fluid (CSF) and blood samples were collected according to the BIOMARKAPD standardized preanalytical procedures (SOP) and stored at Integrated BioBank of Luxembourg (IBBL). The virtual biobank provides an overview of available CSF, plasma, serum, and DNA samples at each site. Currently, at the central biobank of BIOMARKAPD samples are available from over 400 subjects with normal cognition, mild cognitive impairment $(\mathrm{MCl}), A D$, frontotemporal dementia (FTD), vascular dementia $(\mathrm{VaD})$, multiple system atrophy (MSA), progressive supranuclear palsy (PSP), PD, PD with dementia, and dementia with Lewy bodies (DLB). The virtual biobank contains information on over 8600 subjects with varying diagnoses from 21 local biobanks. A website has been launched to enable sample requests from the central biobank and virtual biobank. 


\section{INTRODUCTION}

There is an urgent need for biomarkers facilitating diagnosis of Alzheimer's disease (AD) and Parkinson's disease (PD) at an early stage in the disease course before the onset of clinical symptoms and to predict disease progression. For $A D$, the 42 amino acid form of $\beta$-amyloid ( $A \beta 42$ ) reflecting $A \beta$ deposition in plaques, total tau ( $T$-tau) reflecting the intensity of neuroaxonal degeneration, and phosphorylated tau ( $\mathrm{P}$-tau) reflecting the amount of brain tangle pathology are promising cerebrospinal fluid (CSF) biomarkers for early detection (Blennow, Hampel, Weiner, \& Zetterberg, 2010), but they do not cover all the neurodegenerative processes involved. For PD and dementia with Lewy bodies (DLB), no diagnostic or prognostic CSF or blood biomarkers exist, except for a-synuclein in CSF (Mollenhauer et al., 2011). The use of A 342 , tau proteins, and a-synuclein for the diagnosis and prognosis of $A D$ and PD is challenged by the high intra- and inter-center variability in biomarker concentration measurements (Mattsson et al., 2011; Mollenhauer, El-Agnaf, Marcus, Trenkwalder, \& Schlossmacher, 2010; Verwey et al., 2009). The variability in measurements is likely caused by differences in preanalytical and analytical protocols for sample collection, sample handling and local assay handling (Bibl et al., 2004; Bjerke et al., 2010; Lewczuk et al., 2006; Mattsson et al., 2011; Schoonenboom et al., 2005; Teunissen, Verwey, Kester, van Uffelen, \& Blankenstein, 2010), as well as by inconsistencies in kit production with batch-to-batch and even within-plate variation (Mattsson et al., 2012; Vos et al., 2014).

Biomarkers for Alzheimer's and Parkinson's Disease (BIOMARKAPD) was a European multicenter study, funded by EU Joint Programme-Neurodegenerative Disease Research (JPND), designed to standardize the assessment of existing assays and to validate novel fluid biomarkers for AD and PD. To support these objectives, BIOMARKAPD has established a central biobank and a virtual biobank for neurodegenerative diseases. Samples for the central biobank have been collected and handled according to standardized operating procedures (del Campo et al., 2012). The virtual biobank provides an overview of the local sample stock at each site. In this article, we will give an overview of clinical data, availability of samples, and the methods for sample collection and processing. Finally, we will explain the procedures for requesting samples. 


\section{MATERIAL AND METHODS}

\section{Central biobank}

\section{Study population}

Inclusion criteria for subjects in the central biobank of BIOMARKAPD were a diagnosis of normal cognition, mild cognitive impairment $(M C l), A D, P D$, dementia with Lewy bodies (DLB), frontotemporal dementia (FTD), vascular dementia (VaD), progressive supranuclear palsy (PSP), multiple system atrophy (MSA) or another type of dementia. Subjects were required to be at least 55 years old (in the $\mathrm{MCl}$ group) or at least 40 years old (in all other diagnostic groups). Subjects with normal cognition were clinically evaluated and were required to score above the $10^{\text {th }}$ percentile on the age and education corrected Mini-Mental State Examination (MMSE) (Folstein, Folstein, \& McHugh, 1975). MCI was defined as referral to a memory clinic because of cognitive complaints in the absence of dementia. $\mathrm{MCl}$ subtypes could be defined post-hoc based on neuropsychological test performance or CDR score. Subjects with PD were clinically diagnosed according to the UKPDBB criteria (Hughes, Daniel, Kilford, \& Lees, 1992) or Gelb criteria (Gelb, Oliver, \& Gilman, 1999). Subjects with dementia had a minimum score of 18 on the Mini-Mental State Examination (MMSE) and were clinically diagnosed according to the NINCDSADRDA criteria for probable or possible AD (McKhann et al., 1984), Neary criteria for FTD (Neary, Snowden, Northen, \& Goulding, 1988), NINDS-AIREN criteria for VaD (Roman et al., 1993), and McKeith criteria for DLB (McKeith et al., 1996). Exclusion criteria for all subjects were contra-indications for lumbar puncture and other obvious causes of cognitive impairment such as strokes, severe depression or endocrine disorders.

\section{Clinical data}

The central biobank collected information on age, gender, education, clinical history (e.g. diagnosis, medication use, a selection of co-morbid disorders (cardiovascular, cerebrovascular, neurological, endocrine, somatic, and psychiatric disorders)), smoking habits and alcohol intake, physical examination (i.e. blood pressure, height, weight, and Body Mass Index (BMI)), general cognition (CDR, and MMSE), neuropsychological test performance for the domains of memory, fluency, visuospatial construction, attention, and executive functioning (expressed as raw scores and as z-scores according to local norms corrected for age, gender, and education), procedures for sample collection and processing, and the availability of imaging data (e.g. MRI, PET). Clinical data were collected within a timeframe of 6 months around blood/CSF collection. 


\section{Standardized operating procedures}

Samples for the central biobank were collected according to defined biobanking preanalytical Standard Operating Procedures (SOPs) of the BIOMARKAPD project. For CSF collection, processing and storage we adhered to the BIOMARKAPD SOP published by del Campo et al. (2012). For plasma and serum samples, we adhered to the biobanking guidelines published by Teunissen, Tumani, Engelborghs, and Mollenhauer (2014). In addition, we recommended a 60 minutes minimum clotting time for blood for serum samples in accordance with the instructions of the tube manufacturer. For blood for DNA samples we recommended storage at maximal $-20^{\circ} \mathrm{C}$ consistent with the guidelines by Teunissen et al. (2009). Centers were asked to report deviations from the SOP.

\section{Sample collection, processing and storage}

Tubes for sample collection and storage were distributed by IBBL. Blood samples were collected in the following polypropylene tubes: $10 \mathrm{~mL}$ EDTA (Becton, Dickinson and Company (BD), ref. 367525) for plasma, $4 \mathrm{~mL}$ EDTA (BD, ref. 368861) for whole blood, and $10 \mathrm{~mL}$ Clot Activator Tubes (CAT) (BD, ref. 367896) for serum. CSF was collected in $10 \mathrm{~mL}$ polypropylene tubes (Sarstedt, ref. 62.610.018). Blood samples for DNA were not centrifuged and stored at maximal $-20^{\circ} \mathrm{C}$. All other samples were centrifuged at room temperature at $2000 \mathrm{G}$ ( $\min 1800 \mathrm{G}$, max $2200 \mathrm{G}$ ) and stored at $-80^{\circ} \mathrm{C}$. A maximum of 2 hours was allowed between collection and freezing. A more detailed description of the SOP used for the collection of samples for the central biobank can be found elsewhere (del Campo et al., 2012). For every subject $2 \mathrm{~mL}$ CSF, $2 \mathrm{~mL}$ serum, and $2 \mathrm{~mL}$ plasma were stored in 0.5 aliquots (in $0.5 \mathrm{~mL}$ Matrix 2D Thermo tubes) and $4 \mathrm{~mL}$ blood was stored for DNA isolation. Primary specimens and samples derivatives were coded with a 3-letter center code and a subject number. Samples were at first stored locally, and then shipped on dry ice to IBBL for long-term storage. DNA extraction was performed at the IBBL. Samples and associated data were processed and stored at IBBL in compliance with ISO 9001:2008, NF S96-900: 2011 and ISO 17025:2005 standards and the ISBER Best Practices.

\section{Virtual biobank}

The virtual biobank provides an estimation of the number of samples, and clinical (i.e. age, gender, education, CDR scores, MMSE scores, Parkinson scales, neuropsychological test results, information on medication use and co-morbid disorders) and other biomarker data (i.e. MRI data, amyloid PET, dopamine SPECT) available at each center of subjects with normal cognition, $\mathrm{MCl}, \mathrm{AD}, \mathrm{PD}, \mathrm{PD}$ with dementia, DLB, FTD, VaD, PSP, MSA, and other types of dementia. Retrospectively collected samples had been 
collected according to the center's own SOPs. Centers that changed to the standardized BIOMARKAPD SOP during the project reported the transition date. All samples remained stored on site.

\section{Ethics}

Centers received approval from their local Ethical Committee and all subjects provided informed consent. All human research was conducted in accordance with the principles of the Declaration of Helsinki.

\section{RESULTS}

\section{Central biobank}

Sample collection for the central biobank was performed in the period October 2013- December 2015. A total of 14 European centers have contributed samples and data to the central biobank. Currently, the central biobank database contains clinical information on 419 subjects, of which 49 had normal cognition, $117 \mathrm{MCl}, 164 \mathrm{AD}, 24$ FTD, 3 VaD, 11 DLB, 25 PD, 5 PD with dementia, 3 PSP, 1 MSA, and 18 other types of dementia (i.e. either unknown or mixed pathology). From almost all subjects CSF samples $(n=410)$, plasma samples $(n=413$ subjects), serum samples $(n=414)$ and DNA samples $(n=414)$ are available at the central biobank. At the local sites, MRI imaging data are available from 299 subjects, SPECT from 6 subjects, amyloid PET from 14 subjects and FDG-PET from 28 subjects. Table 1 lists demographic information, neuropsychological tests results, and available imaging data according to diagnostic group. At least one neuropsychological test result was available from 307 subjects. The deviations reported from the SOP are shown in Table 2. The most common deviation (82\%) was the use of a different needle than the $25 \mathrm{G}$ atraumatic needle. For most lumbar punctures this needle was unavailable $(n=239)$, it was impossible to collect CSF with this needle $(n=19)$ or the neurologist preferred a traumatic needle $(n=79)$. None of the samples had more than the maximum of two freeze and thaw cycles, while $12 \%$ of the CSF samples, $1 \%$ of the plasma samples, and $13 \%$ of the serum samples underwent one freeze and thaw cycle. If the deviation related to needle use and number of freeze and thaw cycles was not taken into account, adherence to the BIOMARKAPD SOP was $91 \%$ for CSF collection and centrifugation, $96 \%$ for plasma collection and centrifugation, $93 \%$ for serum collection and centrifugation, and $100 \%$ for DNA collection and processing. 


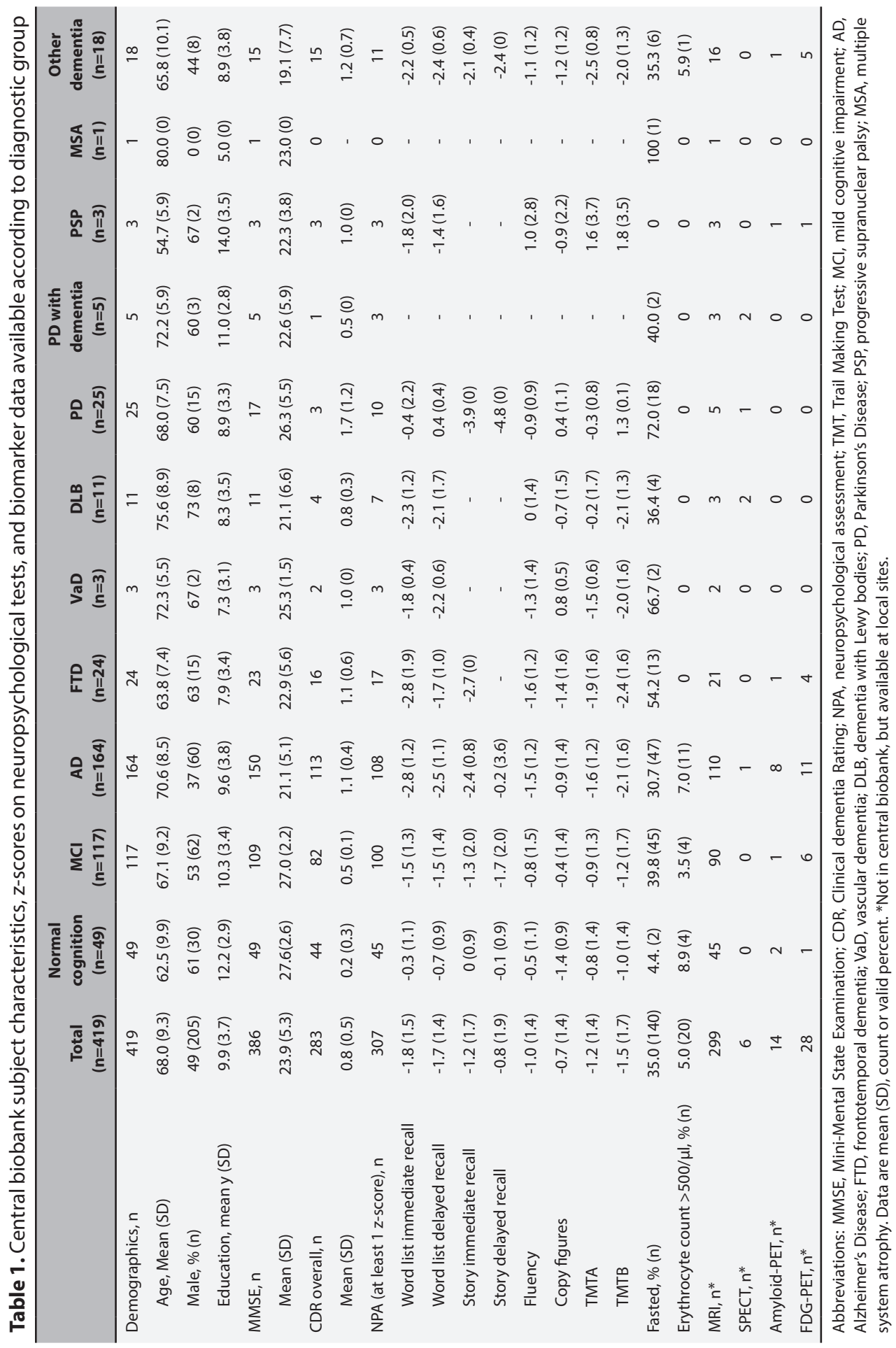


Table 2. Deviations from the SOP reported for samples in the central biobank

\begin{tabular}{|c|c|c|}
\hline SOP recommendation & $\begin{array}{l}\text { Number of } \\
\text { deviations }\end{array}$ & Reason (number of subjects) \\
\hline \multicolumn{3}{|l|}{ CSF Collection } \\
\hline $\begin{array}{l}\text { Withdrawal of } 10 \mathrm{ml} \mathrm{CSF} \mathrm{(+2} \mathrm{mL} \text { for clinical } \\
\text { purposes) }\end{array}$ & 14 & $\begin{array}{l}\text { Slow flow/flow stopped (2); Unknown (7); } \\
\text { Difficulty with positioning (1); Patient did not want } \\
\text { to continue (2); Impossible, no reason specified (2) }\end{array}$ \\
\hline $25 \mathrm{G}$ atraumatic needle & 336 & $\begin{array}{l}\text { Neurologist preferred traumatic needle (79); } \\
\text { Atraumatic used, but different diameter: } 25 \mathrm{G} \text { not } \\
\text { available (238), impossible with } 25 \mathrm{G}(19)\end{array}$ \\
\hline LP location: intervertebral space L3-L5 & 0 & - \\
\hline Polypropylene tubes & 0 & - \\
\hline Erythrocyte count $<500 / \mu l$ & 20 & Unknown (20) \\
\hline \multicolumn{3}{|l|}{ CSF Processing } \\
\hline $\begin{array}{l}\text { Centrifuge at } 2000 \mathrm{G} \text { (or between } 1800-2200 \mathrm{G} \text { ) } \\
\text { for } 10 \mathrm{~min} \text { at RT }\end{array}$ & 5 & $\begin{array}{l}2000 \mathrm{G} \text { centrifuge not available (centrifuged at } \\
\qquad 1120 \mathrm{G})(5)\end{array}$ \\
\hline $\begin{array}{l}\text { Maximum } 2 \text { hours between collection and } \\
\text { freezing (or temporarily store at } 4^{\circ} \mathrm{C} \text { ) }\end{array}$ & 1 & Delay in sample delivery (1) \\
\hline Freeze at $-80^{\circ} \mathrm{C}$ & 0 & - \\
\hline Maximum of 2 freeze and thaw cycles & 0\# & - \\
\hline \multicolumn{3}{|l|}{ Blood for plasma, Processing } \\
\hline $\begin{array}{l}\text { Centrifuge at } 2000 \mathrm{G} \text { (or between } 1800-2200 \mathrm{G} \text { ) } \\
\text { for } 10 \mathrm{~min} \text { at RT }\end{array}$ & 5 & $\begin{array}{l}2000 \mathrm{G} \text { centrifuge not available (centrifuged at } \\
\qquad 1120 \mathrm{G})(5)\end{array}$ \\
\hline $\begin{array}{l}\text { Maximum } 2 \text { hours between collection and } \\
\text { freezing (or temporarily store at } 4^{\circ} \mathrm{C}\end{array}$ & 13 & Delay in sample delivery (1); Unknown (12) \\
\hline Freeze at $-80^{\circ} \mathrm{C}$ & 0 & - \\
\hline Limit freeze and thaw cycles & 0\# & - \\
\hline \multicolumn{3}{|l|}{ Blood for serum, Processing } \\
\hline $\begin{array}{l}\text { Centrifuge at } 2000 \mathrm{G} \text { (or between } 1800-2200 \mathrm{G} \text { ) } \\
\text { for } 10 \mathrm{~min} \text { at RT }\end{array}$ & 5 & $\begin{array}{l}2000 \mathrm{G} \text { centrifuge not available (centrifuged at } \\
\qquad 1120 \mathrm{G})(5)\end{array}$ \\
\hline $\begin{array}{l}\text { Maximum } 2 \text { hours between collection and } \\
\text { freezing (or temporarily store at } 4^{\circ} \mathrm{C} \text { ) }\end{array}$ & 13 & Delay in sample delivery (1); Unknown (12) \\
\hline $\begin{array}{l}\text { At least } 30 \text { minutes (but preferably } \\
>60 \text { minutes) between collection and } \\
\text { centrifugation }\end{array}$ & $10^{*}$ & Mistake <30 minutes (10) \\
\hline Freeze at $-80^{\circ} \mathrm{C}$ & 0 & - \\
\hline Limit freeze and thaw cycles & $0 \#$ & - \\
\hline \multicolumn{3}{|l|}{ Whole blood for DNA, processing } \\
\hline Freeze below $-20^{\circ} \mathrm{C}$ & 0 & - \\
\hline
\end{tabular}

Abbreviations: SOP, Standardized operating procedures; LP, Lumbar puncture; RT, Room temperature. Data are number of subjects in which a deviation of the SOP occurred. \#One cycle: CSF 50, plasma 5 and serum 55. *Clotting time: between 30-50 minutes (23) and between 50-59 minutes (35). 


\section{Virtual biobank}

Currently, 21 centers have contributed data to the virtual biobank of BIOMARKAPD. The virtual biobank contains information on CSF samples from 7550 subjects, EDTA plasma samples from 8676 subjects, and serum samples from 8141 subjects. So far, 11 centers have reported that they followed, or changed to, the BIOMARKAPD SOP for sample collection and processing. Table 3 lists the number of subjects per diagnostic group with CSF, EDTA plasma, and serum samples available.

Table 3. Number of subjects in virtual biobank with CSF, EDTA plasma, and serum samples available according to diagnostic group.

\begin{tabular}{lccc}
\hline & CSF & EDTA plasma & Serum \\
\hline Normal cognition, $\mathrm{n}$ & 890 & 1831 & 1316 \\
MCl, $\mathrm{n}$ & 1969 & 1894 & 2066 \\
$\mathrm{AD}, \mathrm{n}$ & 2420 & 2440 & 2349 \\
FTD, $\mathrm{n}$ & 612 & 621 & 647 \\
VaD, $\mathrm{n}$ & 156 & 187 & 151 \\
DLB, $\mathrm{n}$ & 277 & 282 & 279 \\
PD & 439 & 720 & 748 \\
PD with dementia, $\mathrm{n}$ & 157 & 243 & 219 \\
PSP, $\mathrm{n}$ & 148 & 146 & 115 \\
MSA, $\mathrm{n}$ & 68 & 57 & 38 \\
Other dementia, $\mathrm{n}$ & 414 & 255 & 213 \\
Total & 7550 & 8676 & 8141 \\
\hline
\end{tabular}

Abbreviations: CSF, cerebrospinal fluid; $M C l$, mild cognitive impairment; $A D$, Alzheimer's Disease; FTD, frontotemporal dementia; VaD, vascular dementia; DLB, dementia with Lewy bodies; PD, Parkinson's Disease; PSP, progressive supranuclear palsy; MSA, multiple system atrophy. Data are number of subjects with CSF, EDTA plasma, or serum samples available.

\section{DISCUSSION}

As part of BIOMARKAPD, a large central and virtual biobank with body fluids were established from over 9000 subjects with neurodegenerative disorders. The central biobank contains samples from more than 400 subjects of which nearly $40 \%$ have AD. Adherence to the BIOMARKAPD SOP was high $(>91 \%)$ for the collection and processing of CSF, plasma, and serum and blood samples. The virtual biobank contains CSF samples from over 7500 subjects, plasma samples from over 8600 subjects and serum samples 
from over 8100 subjects. Samples for the virtual biobank have been collected according to varying local SOPs. However, so far more than half of the centers have reported adopting the BIOMARKAPD SOP in the course of the project.

\section{Requesting samples from the central or virtual biobank}

Researchers in the field of neurodegenerative disorders interested in requesting samples from the central biobank or from the virtual biobank of BIOMARKAPD are invited to consult the following website: http://jpnd.arone.com/. Requests should meet the objectives of BIOMARKAPD project, i.e. to standardize the assessment of existing assays and to validate novel fluid biomarkers for $A D$ and $P D$. Sample requests will be evaluated by the Analysis Advisory Board (AAB). Approval from the AAB will depend on scientific quality, whether the sample request meets the objectives of BIOMARKAPD, and sample availability. Furthermore, the sample request must meet the following three criteria. First, the researcher must demonstrate that the analysis complies with local medical ethical standards, for example by showing regulatory approval of a Medical Ethical Committee (MEC), Institutional Review Board (IRB) or equivalent. Second, technical characteristics of assays such as linearity, recovery, specificity, imprecision, sensitivity, and lot-to-lot variability have already been established and of sufficient performance. Third, prior to the request, the diagnostic or prognostic value of the assay should have been already demonstrated in at least 20 controls and 20 diseased subjects. For the central biobank, fees will apply to cover the costs for sample and data collection, processing, and sample storage. Before shipment a Material Transfer Agreement (MTA) needs to be signed.

For the virtual biobank, individual centers can decide on a case-to-case basis whether or not they would like to provide samples and which conditions will apply. When requesting samples from the virtual biobank, contact details will be provided of centers that are interested in meeting the sample request. Centers may use the MTA from the central biobank for the shipment of samples. Detailed information on the methodology of sample preparation and handling, and available clinical information should be requested directly from the center.

\section{Conclusion}

The central and virtual biobanks of BIOMARKAPD provide access to a large repository of CSF and blood samples for researchers in the field of neurodegenerative disorders, enabling progress in the clinical use of biomarkers for the diagnosis and prognosis of neurodegenerative disorders. 


\section{Conflict of interest statement}

The authors declare that the research was conducted in the absence of any commercial or financial relationships that could be construed as a potential conflict of interest.

\section{Acknowledgments}

This is an EU Joint Programme - Neurodegenerative Disease Research (JPND) project. This project is supported through the following funding organizations under the aegis of JPND - www.jpnd.eu

\begin{tabular}{ll}
\hline Country & Funding organization \\
\hline Belgium & IWT \\
Canada & Fonds de la Recherche en Santé du Québec FRSQ \\
Denmark & Danish Strategic Research Council \\
Finland & The Academy of Finland AoF \\
France & French National Research Agency \\
Germany & German Bundesministerium für Bildung und Forschung \\
Greece & Ministry of Education, Life Long Learning and Religious Affairs, General Secretariat \\
& for Research and Technology \\
Ireland & Health Research Board \\
Italy & Ministero della Salute \\
Luxembourg & Fonds National de la Recherche, Luxembourg \\
The Netherlands & ZonMW-The Netherlands Organisation for Health Research and Development \\
Norway & The Research Council of Norway \\
Poland & National Centre for Research and Development \\
Portugal & Fundação para a Ciência e a Tecnologia (FCT) \\
Slovakia & Ministry of Education, Science, Research and Sports of the Slovak Republic \\
Slovenia & Javna agencija za raziskovalno dejavnost Republike Slovenije \\
Spain & Instituto de Salud Carlos III (ISCII) \\
Sweden & Swedish Research Council (SRC) \\
Switzerland & Swiss National Science Foundation (SNSF) \\
Turkey & Türkiye Bilimsel ve Teknolojik Araştırma Kurumu \\
United Kingdom & Medical Research Council \\
\hline
\end{tabular}

We thank IBBL for their various contributions in kind to the project, in particular for the provision of the IT infrastructure for the central and virtual biobanks, and for the continuing storage of samples after the project. 


\section{REFERENCES}

Bibl, M., Esselmann, H., Otto, M., Lewczuk, P., Cepek, L., Ruther, E., et al. (2004). Cerebrospinal fluid amyloid beta peptide patterns in Alzheimer's disease patients and nondemented controls depend on sample pretreatment: indication of carrier-mediated epitope masking of amyloid beta peptides. Electrophoresis, 25(17), 2912-2918. doi: 10.1002/elps.200305992

Bjerke, M., Portelius, E., Minthon, L., Wallin, A., Anckarsater, H., Anckarsater, R., et al. (2010). Confounding factors influencing amyloid Beta concentration in cerebrospinal fluid. Int $J$ Alzheimers Dis, 2010. doi: 10.4061/2010/986310

Blennow, K., Hampel, H., Weiner, M., \& Zetterberg, H. (2010). Cerebrospinal fluid and plasma biomarkers in Alzheimer disease. Nat Rev Neurol, 6(3), 131-144. doi: 10.1038/nrneurol.2010.4

del Campo, M., Mollenhauer, B., Bertolotto, A., Engelborghs, S., Hampel, H., Simonsen, A. H., et al. (2012). Recommendations to standardize preanalytical confounding factors in Alzheimer's and Parkinson's disease cerebrospinal fluid biomarkers: an update. Biomark Med, 6(4), 419430. doi: $10.2217 / \mathrm{bmm} .12 .46$

Folstein, M. F., Folstein, S. E., \& McHugh, P. R. (1975). "Mini-mental state". A practical method for grading the cognitive state of patients for the clinician. J Psychiatr Res, 12(3), 189-198.

Gelb, D. J., Oliver, E., \& Gilman, S. (1999). Diagnostic criteria for Parkinson disease. Arch Neurol, 56(1), 33-39.

Hughes, A. J., Daniel, S. E., Kilford, L., \& Lees, A. J. (1992). Accuracy of clinical diagnosis of idiopathic Parkinson's disease: a clinico-pathological study of 100 cases. J Neurol Neurosurg Psychiatry, 55(3), 181-184.

Lewczuk, P., Beck, G., Esselmann, H., Bruckmoser, R., Zimmermann, R., Fiszer, M., et al. (2006). Effect of sample collection tubes on cerebrospinal fluid concentrations of tau proteins and amyloid beta peptides. Clin Chem, 52(2), 332-334. doi: 10.1373/clinchem.2005.058776

Mattsson, N., Andreasson, U., Persson, S., Arai, H., Batish, S. D., Bernardini, S., et al. (2011). The Alzheimer's Association external quality control program for cerebrospinal fluid biomarkers. Alzheimers Dement, 7(4), 386-395 e386. doi: 10.1016/j.jalz.2011.05.2243

Mattsson, N., Zegers, I., Andreasson, U., Bjerke, M., Blankenstein, M. A., Bowser, R., et al. (2012). Reference measurement procedures for Alzheimer's disease cerebrospinal fluid biomarkers: definitions and approaches with focus on amyloid beta42. Biomark Med, 6(4), 409-417. doi: 10.2217/bmm.12.39

McKeith, I. G., Galasko, D., Kosaka, K., Perry, E. K., Dickson, D. W., Hansen, L. A., et al. (1996). Consensus guidelines for the clinical and pathologic diagnosis of dementia with Lewy bodies (DLB): report of the consortium on DLB international workshop. Neurology, 47(5), 1113-1124.

McKhann, G., Drachman, D., Folstein, M., Katzman, R., Price, D., \& Stadlan, E. M. (1984). Clinical diagnosis of Alzheimer's disease: report of the NINCDS-ADRDA Work Group under the auspices of Department of Health and Human Services Task Force on Alzheimer's Disease. Neurology, 34(7), 939-944. 
Mollenhauer, B., El-Agnaf, O. M., Marcus, K., Trenkwalder, C., \& Schlossmacher, M. G. (2010). Quantification of alpha-synuclein in cerebrospinal fluid as a biomarker candidate: review of the literature and considerations for future studies. Biomark Med, 4(5), 683-699. doi: 10.2217/ bmm.10.90

Mollenhauer, B., Locascio, J. J., Schulz-Schaeffer, W., Sixel-Doring, F., Trenkwalder, C., \& Schlossmacher, M. G. (2011). alpha-Synuclein and tau concentrations in cerebrospinal fluid of patients presenting with parkinsonism: a cohort study. Lancet Neurol, 10(3), 230-240. doi: 10.1016/S1474-4422(11)70014-X

Neary, D., Snowden, J. S., Northen, B., \& Goulding, P. (1988). Dementia of frontal lobe type. J Neurol Neurosurg Psychiatry, 51(3), 353-361.

Roman, G. C., Tatemichi, T. K., Erkinjuntti, T., Cummings, J. L., Masdeu, J. C., Garcia, J. H., et al. (1993). Vascular dementia: diagnostic criteria for research studies. Report of the NINDS-AIREN International Workshop. Neurology, 43(2), 250-260.

Schoonenboom, N. S., Mulder, C., Vanderstichele, H., Pijnenburg, Y. A., Van Kamp, G. J., Scheltens, P., et al. (2005). Differences and similarities between two frequently used assays for amyloid beta 42 in cerebrospinal fluid. Clin Chem, 51(6), 1057-1060. doi: 10.1373/clinchem.2005.048629

Teunissen, C. E., Petzold, A., Bennett, J. L., Berven, F. S., Brundin, L., Comabella, M., et al. (2009). A consensus protocol for the standardization of cerebrospinal fluid collection and biobanking. Neurology, 73(22), 1914-1922. doi: 10.1212/WNL.0b013e3181c47cc2

Teunissen, C. E., Tumani, H., Engelborghs, S., \& Mollenhauer, B. (2014). Biobanking of CSF: international standardization to optimize biomarker development. Clin Biochem, 47(4-5), 288-292. doi: 10.1016/j.clinbiochem.2013.12.024

Teunissen, C. E., Verwey, N. A., Kester, M. I., van Uffelen, K., \& Blankenstein, M. A. (2010). Standardization of Assay Procedures for Analysis of the CSF Biomarkers Amyloid beta((1-42)), Tau, and Phosphorylated Tau in Alzheimer's Disease: Report of an International Workshop. Int J Alzheimers Dis, 2010. doi: 10.4061/2010/635053

Verwey, N. A., van der Flier, W. M., Blennow, K., Clark, C., Sokolow, S., De Deyn, P. P., et al. (2009). A worldwide multicentre comparison of assays for cerebrospinal fluid biomarkers in Alzheimer's disease. Ann Clin Biochem, 46(Pt 3), 235-240. doi: 10.1258/acb.2009.008232

Vos, S. J., Visser, P. J., Verhey, F., Aalten, P., Knol, D., Ramakers, I., et al. (2014). Variability of CSF Alzheimer's disease biomarkers: implications for clinical practice. PLoS One, 9(6), e100784. doi: 10.1371/journal.pone.0100784 
Supplementary Table. Centers that have contributed samples to the central biobank and virtual biobank

\begin{tabular}{|c|c|c|c|c|}
\hline Center & City & Country & $\begin{array}{c}\text { Central } \\
\text { biobank }\end{array}$ & $\begin{array}{c}\text { Virtual } \\
\text { biobank }\end{array}$ \\
\hline Rigshospitalet- Copenhagen University Hospital & Copenhagen & Denmark & & Yes \\
\hline Hôpital ST ELOI & Montpellier & France & & Yes \\
\hline Central Institute of Mental Health & Mannheim & Germany & Yes & \\
\hline University of Tübingen & Tübingen & Germany & Yes & Yes \\
\hline Universitätsklinikum Erlangen & Erlangen & Germany & & Yes \\
\hline University Clinic Bonn & Bonn & Germany & & Yes \\
\hline Universitätsmedezin Göttingen & Göttingen & Germany & & Yes \\
\hline Aristotle University of Thessaloniki & Thessaloniki & Greece & Yes & Yes \\
\hline National and Kapodistrian University of Athens & Athens & Greece & & Yes \\
\hline $\begin{array}{l}\text { Mercer's Institute for Successful Ageing, St. } \\
\text { James's Hospital }\end{array}$ & Dublin & Ireland & Yes & Yes \\
\hline Università di Perugia & Perugia & Italy & Yes & \\
\hline $\begin{array}{l}\text { IRCCS Istituto Centro San Giovanni di Dio } \\
\text { Fatebenefratelli }\end{array}$ & Brescia & Italy & & Yes \\
\hline $\begin{array}{l}\text { IRCCS Foundation "Carlo Besta" Neurological } \\
\text { Institue }\end{array}$ & Milan & Italy & & Yes \\
\hline VU university medical center (VUMC) & Amsterdam & Netherlands & Yes & Yes \\
\hline Maastricht University Medical Center (MUMC) & Maastricht & Netherlands & Yes & Yes \\
\hline $\begin{array}{l}\text { Radboud University Nijmegen Medical Center } \\
\text { (RUNMC) }\end{array}$ & Nijmegen & Netherlands & & Yes \\
\hline Akershus Univiversity Hospital & Lørenskog & Norway & & Yes \\
\hline Wroclaw Medical University & Scinawa & Poland & Yes & Yes \\
\hline $\begin{array}{l}\text { Mossakowski Medical Research Centre Polish } \\
\text { Academy of Sciences }\end{array}$ & Warsaw & Poland & Yes & Yes \\
\hline University of Coimbra Hospital Center & Coimbra & Portugal & Yes & Yes \\
\hline Instituto de Medicina Molecular & Lisbon & Portugal & Yes & \\
\hline Institute of Neuroimmunology & Bratislava & Slovakia & Yes & \\
\hline University Medical Centre Ljubljana & Ljubljana & Slovenia & Yes & \\
\hline Hospital de la Santa Creu i Sant Pau & Barcelona & Spain & & Yes \\
\hline $\begin{array}{l}\text { ICN Hospital Clinic i Universitari and Pasqual } \\
\text { Maragall Foundation }\end{array}$ & Barcelona & Spain & & Yes \\
\hline Istanbul University, Istanbul Faculty of Medicine & Istanbul & Turkey & Yes & \\
\hline University of Zurich & Zurich & Switzerland & & Yes \\
\hline
\end{tabular}





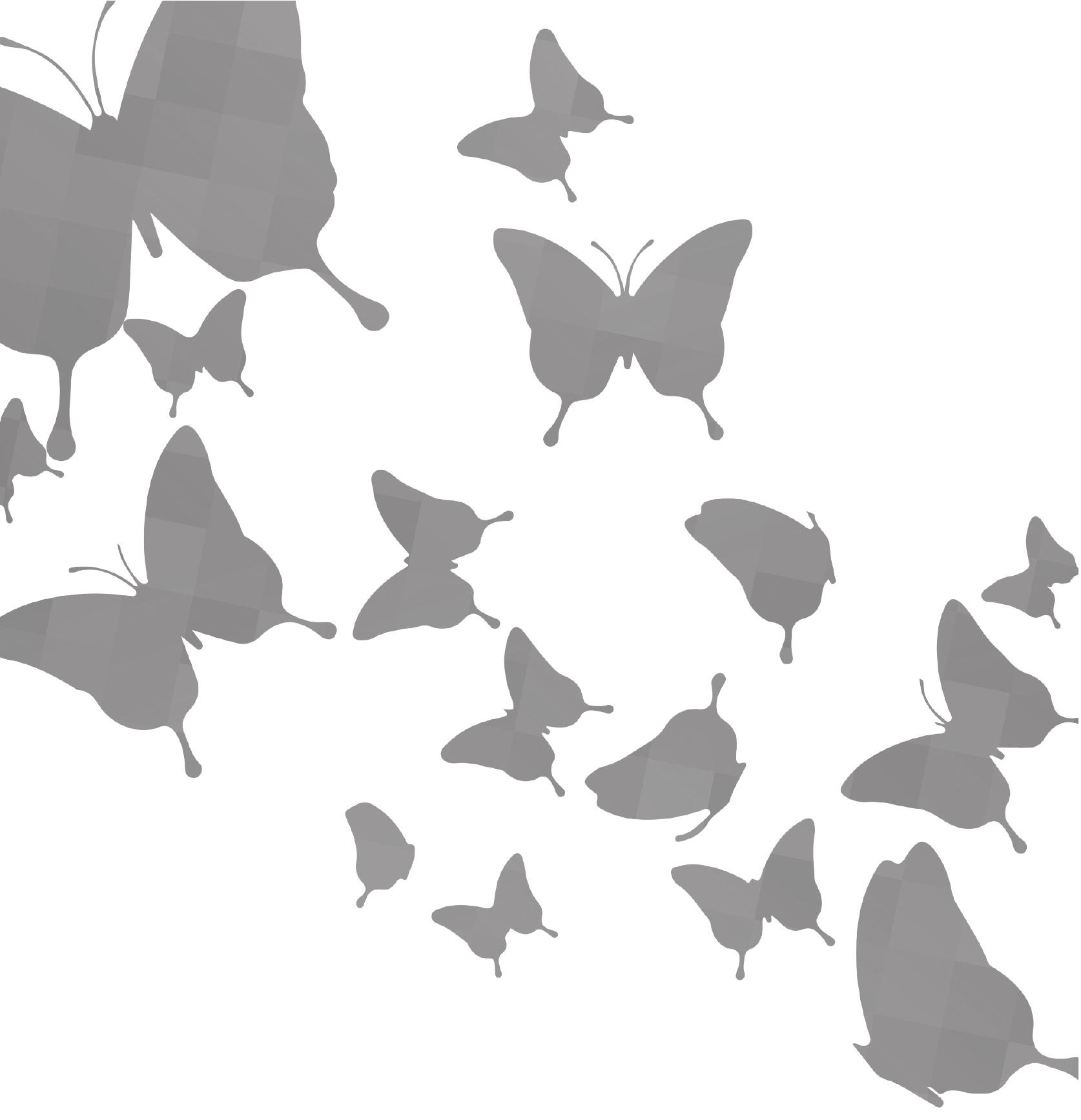


General discussion 



\section{GENERAL DISCUSSION}

Early identification of AD before the onset of dementia, and a better understanding of the pathophysiological mechanism of $A D$ and predictors of disease expression is required to prevent disease progression in an early stage by facilitating development of disease-modifying treatments. Furthermore, early identification of $A D$ and a better understanding of clinical disease progression will benefit present patient care. In this thesis, we investigated the relation between established $A D$ biomarkers and cognition across the clinical $A D$ spectrum ranging from preclinical $A D$ to mild dementia. Additionally, we investigated for a number of emerging markers and risk factors their role in $A D$ pathophysiology and their association with cognitive test performance and utility for diagnosis and prognosis. Our research findings are presented in figure 1.

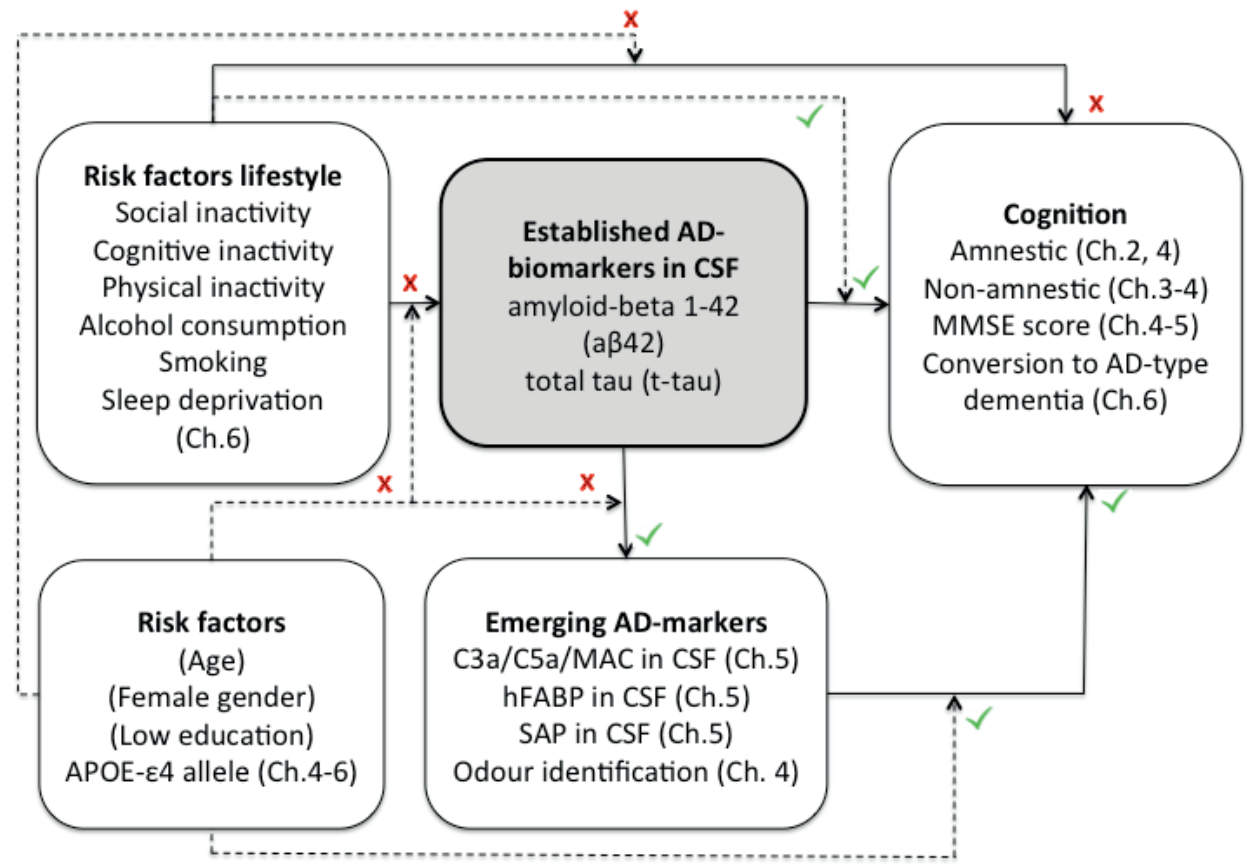

Figure 1. Summary research findings. Established CSF AD-biomarkers ( $a \beta 42$ and tau) were associated with cognition. Lifestyle factors were not associated with established AD CSF markers and partly modulated the association between established CSF markers and cognitive decline. hFABP and odour identification correlated with tau and C3a correlated with aß42. SAP and odour identification were associated with cognition. APOE-e4 carriership only modulated the association between SAP and cognition, and odour identification and cognition. $x=$ no association, $\mathrm{v}=$ association present. 


\section{Established AD-biomarkers and cognition across the clinical AD spectrum}

To obtain a better understanding of the clinical progression of the disease we tested the association between established biomarkers of AD pathology and performance on memory domains and specific non-memory domains across the AD spectrum. We examined these associations cross-sectionally and longitudinally. In addition, we examined whether lifestyle influenced the association between established AD biomarkers and conversion to AD-type dementia in individuals with $\mathrm{MCl}$.

\section{Cross-sectional association}

In individuals with normal cognition, $\mathrm{MCl}$ and dementia from the EDAR study, we found that lower a $\mathrm{\beta} 42$ and higher tau were most strongly associated with lower scores on episodic memory independent of diagnostic group (chapter 2 ) and that tau but not $\mathrm{a} \beta 42$, was associated with global cognition independent of dementia status (chapter 5). In individuals with MCI from the DESCRIPA study (chapter 3) we found that individuals with both abnormal a 342 and tau concentrations had lower scores on episodic memory and global cognition than individuals with both biomarkers normal.

Overall, these results suggest that a) measures of episodic memory is the most sensitive cognitive marker for a 342 pathology in $\mathrm{CSF}$, and b) that global cognition becomes abnormal if there is tau pathology.

\section{Cognitive decline}

In the EDAR study we found a weak association between a $\beta 42$ and decline in episodic memory, and a strong association for tau with decline in episodic and semantic memory (chapter 2). In chapter 5 we found that a 342 , but not tau, was associated with decline in global cognition. In individuals with MCI from the DESCRIPA study (chapter 3), we found that compared to individuals with $\mathrm{MCl}$ with normal CSF markers, individuals with only tau abnormal showed decline on episodic memory, executive function, and fluency while individuals with both biomarkers abnormal declined in all cognitive domains. Individuals with only a $\beta 42$ abnormal did not decline. In chapter 6 , we found that both $a \beta 42$ and tau were associated with conversion to AD-type dementia in individuals with $\mathrm{MCl}$.

In summary, these findings corroborate that CSF a $\beta 42$ has a cross-sectional relation with memory impairment but less so with impairments in non-memory domains and with longitudinal decline. CSF tau is a better prognostic marker, and as a marker of neuronal injury reflects changes in cognition better. 


\section{Lifestyle factors}

Population studies have found potential for targeting lifestyle factors to prevent dementia in older adults $[1,2]$. In chapter 6 , we selected 353 individuals with $\mathrm{MCl}$ and 111 with SCD and examined the association between lifestyle factors and AD CSF a 342 , CSF tau and hippocampal volume. In addition, we examined the association between lifestyle factors and conversion to AD-type dementia in individuals with $\mathrm{MCl}$. In individuals with normal tau, mild to moderated alcohol consumption (maximum of two alcohol units a day) decreased the risk for conversion to AD-type dementia, but further research is needed to confirm this. The other lifestyle factors did not influence the association between AD-biomarkers and conversion to AD-type dementia. Furthermore, no direct effect was found of lifestyle factors on AD-biomarkers or conversion to ADtype dementia in $\mathrm{MCl}$. Possibly, the association between lifestyle factors and dementia risk is different at midlife. In our study, individuals were at baseline around 70 years old as opposed to midlife in population-based studies. Furthermore, lifestyle factors may also act via non-AD pathways, for example, via cerebrovascular or metabolic routes of damage accumulation.

\section{Emerging AD-biomarkers across the clinical AD spectrum}

To obtain a better understanding of AD pathophysiology, we examined the association for inflammation markers and lipid binding proteins in CSF with established biomarkers in chapter 5, and the association between odour identification and established biomarkers in chapter 4 (Figure 1). We also tested whether these emerging AD markers correlated with cognition. We examined these associations in individuals with normal cognition, $\mathrm{MCl}$ and dementia from the EDAR study cross-sectionally and longitudinally. The influence of APOE-e4 carriership on these associations was also examined.

\section{Inflammation markers}

Association with established biomarkers

$\mathrm{C} 3 \mathrm{a}$ and MAC were correlated. In individuals with dementia, lower C3a concentrations were associated with lower $a \beta 42$, which may be explained by increased binding to amyloid plaques [3] or a reduced production of $\mathrm{C} 3 \mathrm{a}$, for example through dysfunction of astrocytes [4]. In the pre-amyloid stage of AD (i.e. in individuals without dementia and normal a 342 ), higher $C 3 a$ was associated with decrease in a $\beta 42$ over time suggesting that C3a may trigger amyloid aggregation. 


\section{Association with cognition}

C3a concentrations were lower in individuals with dementia and $\mathrm{MCl}$ than in controls, but MAC concentrations did not differ between groups. C3a and MAC were not associated with global cognition at baseline or at follow-up suggesting that these markers are not sensitive for detecting cognitive impairment

\section{Lipid binding proteins}

Association with established biomarkers

SAP concentrations were not associated with a 342 or tau at baseline or follow-up. HfABP was strongly associated with tau concentration independent of dementia status, and higher HfABP was associated with lower a 342 in individuals without dementia. In $A D$, HfABP may play a role in early a 342 -associated neurodegeneration [5]. Abnormal HfABP concentrations, however, have been found in several other neurodegenerative diseases other than AD-type dementia [6-8] suggesting that HfABP is a general neuronal injury marker.

\section{Association with cognition}

SAP concentrations did not differ between diagnostic groups conceivably due to its low concentrations in CSF [9]. Consistent with other research [10], higher SAP was associated with a higher global cognition score in individuals with dementia and a trend was found in the total group. HfABP was higher in individuals with dementia and $\mathrm{MCl}$ than in controls or SCD, and a trend was found with global cognition. Longitudinally, no associations were found on global cognition. This suggests that SAP and HfABP may have potential as diagnostic marker, but have limited value in tracking disease progression.

\section{Odour identification}

Association with established biomarkers

A modest association was found between odour identification scores and tau suggesting that odour identification may have some potential as neuronal injury marker.

Association with cognition

Odour identification scores were lower in individuals with $\mathrm{MCl}$ and dementia than in the normal cognition group. Lower odour identification scores correlated with lower scores on all cognitive measures at baseline and predicted decline on the MMSE independent of diagnosis. This suggests that odour identification impairment may have potential as diagnostic and prognostic marker, but added value over established cognitive tests may be limited. 


\section{APOE genotype}

APOE-e4 carriership did not influence the association between a $\beta 42$ or tau and emerging AD-biomarkers (chapter 5) or odour identification (chapter 4).

APOE genotype modified the relation of two emerging AD markers with cognition. In non-APOE-e4 carriers, low SAP concentrations were associated with stronger decline in MMSE score, which needs further replication. Furthermore, in APOE-e4 carriers and in individuals with abnormal a $\beta 42$, odour identification was more strongly associated with episodic memory decline. These results may suggest that APOE only has a direct role in AD by mainly acting on amyloid aggregation [11].

\section{Methodological considerations}

\section{Strengths}

Strengths of our study are the use of multiple center data and relative large sample sizes. The longitudinal design allowed us to investigate the prognostic value of CSF markers for cognitive decline, but also to examine variability in CSF markers over time (chapter 5). We included individuals across the clinical spectrum of AD. We investigated innovative measures, with computerized tests (chapter 2), emerging CSF biomarkers (chapter 5), and emerging risk factors that could possibly prevent AD (chapter 6).

\section{Limitations}

Our research has several limitations. First, we pooled data from multiple centers, which may have introduced bias. There may be inter-center differences in neuropsychological assessment and diagnosis. Second, individuals participating in our studies may not be representative of the general population. Healthy controls were self-selected and individuals with $\mathrm{MCl}, \mathrm{AD}$-type dementia and non-AD dementia were recruited from the memory clinic and may not be representative of the general population with cognitive complaints. Furthermore, in chapter 6 we pooled data from two different populations, i.e. memory clinic setting (DESCRIPA) and population-based (Kuopio L-MCI), which may interfere with the generalizability of tests results. Third, the longitudinal analyses on EDAR (chapter 2, 4 and 5) and DESCRIPA data (chapter 3 and 6) were relatively short with follow-up assessment within 3 years after baseline. With a longer follow-up interval, we may have detected a larger cognitive decline (in chapter 2-5), changes in a 342 and tau over time (in chapter 5), and more individuals converting to AD-type dementia (in chapter 5). Fourth, we did not have follow-up data available for all individuals introducing potential selection bias. Fifth, in our explorative studies we tested multiple comparisons (in chapter 2-6), which may have resulted in a problem of multiple testing. Sixth, in chapter 5 the association between emerging and established biomarkers 
and cognition may be mediated by, for example, other inflammatory or lipid binding proteins. Seventh, in chapter 6 lifestyle factors were measured cross-sectionally rather than over a longer period of time and compliance could not be examined. Seventh, although standard operating procedures (SOPs) were applied in EDAR and DESCRIPA, there may still be intra- and intercenter variability is CSF collection, handling and laboratory assessments [12-15]. In addition, CSF assays used for emerging biomarkers in chapter 5 were not optimized yet at the time of the assessment. At last, there was no pathological data to confirm the etiology of the clinical diagnoses.

\section{Implications of AD biomarkers}

\section{Amyloid cascade hypothesis}

The findings described in this thesis may have implication for the amyloid cascade hypothesis [16]. According to this hypothesis the pathophysiological mechanism of $A D$ is initiated with amyloid deposition leading to neurodegeneration and eventually cognitive impairment. In congruency with this hypothesis, we found in chapter 3 that in individuals with both abnormal $\mathrm{a} \beta 42$ and tau more cognitive decline was detected than in individuals with only abnormal a $\beta 42$. This may imply that these individuals are further down the disease process. However, there were also some inconsistencies. Individuals with abnormal levels of tau but normal levels of $a \beta 42$, also had more cognitive decline (than individuals with both biomarkers normal), which has also been found in other research [17]. A possible explanation is that the cutoff values for CSF a $\beta 42$ may be too conservative [18]. It is also possible that these individuals have other non-AD pathologies or comorbidities leading to cognitive decline. Overall, the amyloid cascade is a useful model to conduct research, but careful interpretation is required as the model is simplified representation of reality. Including inflammatory and lipid binding proteins may refine the model.

\section{Clinical trials}

This thesis has implications for clinical trials. Early identification of individuals with $A D$ pathology is relevant for prevention trials aimed at modifying the underlying pathophysiological processes. Assessment for amyloid or tau pathology is costly or invasive, which makes prescreening individuals at risk for $A D$ pathology valuable. We found that low memory scores and odour identification were associated with abnormal amyloid or tau pathology, but their value was limited in individuals without dementia with odds ratios of 2 to 3 . Because individuals with $\mathrm{MCl}$ with both amyloid and tau biomarkers abnormal may show a faster decline than individuals with $\mathrm{MCl}$ with only one biomarker abnormal, selection of these individuals for trial may reduce the sample size for trials to detect an effect on cognition decline. However, because the faster decline 
is also associated with a greater disease burden, treatments may be less effective at that stage. In chapter 5 we showed that CSF a 342 and tau were stable over time, which makes these measures less useful for tracking treatment response with therapies that aim to slow down the disease. Possibly emerging biomarkers may be better suited for tracking disease progression, but we have not yet measured these longitudinally.

\section{Clinical practice}

An advantage of CSF assessments in the early clinical diagnostics of cognitive impairments is that it may give a better indication of the underlying etiology, than a clinical diagnosis alone. This knowledge can lead to a better understanding of what is causing the complaints, a better anticipation for the future and possibly obtaining personalized care in an earlier stage, which all might positively affect patients' and caregivers quality of life. The major drawback is that at the moment there are no treatment consequences of the assessment of AD biomarker status, as there are no modifying drugs available. Moreover, disclosure of AD biomarker status may cause uncertainty and stress, in particular in individuals without dementia as in these individuals it is difficult to predict time to dementia [19]. While tau was associated with future decline in our study, the predictive accuracy was moderate, limiting accurate prediction on the individual level. Moreover, emerging CSF markers did not improve predictive accuracy over tau.

The correlation with AD biomarkers was equivalent if not stronger for paper-and-pencil administered episodic memory tests than for computerized tests, suggesting that on this aspect paper-and-pencil episodic memory tests may be preferable in clinical practice.

The analysis of the association between lifestyle factors and AD biomarkers suggested that reduction of alcohol intake may slow down cognitive decline, but this needs to be validated in prospective studies.

\section{Future directions}

The last decades, progression has been made in the AD field for early detection of individuals with underlying AD pathology and prevention of AD. Still, effective therapies and prevention approaches are lacking. In this thesis we evaluated a number of emerging biomarkers and tested the association of lifestyle factors with AD biomarkers. Based on our findings we recommend the following topics to be addressed in future studies: 
- Longitudinal studies with a longer follow-up duration are necessary to obtain a better understanding of the dynamics between AD markers and cognition. These studies need also to investigate how change in AD biomarkers over time correlate with changes in cognition over time. Such studies are in particular useful in individuals without dementia, as neuronal damage is still limited

- To gain a better understanding of the utility of emerging biomarkers, the association between baseline $\mathrm{a} \beta 42$ and tau markers and change in inflammatory markers and lipid binding proteins over time in CSF needs to be examined. Preferably, by examining a large number of proteins and protein-protein interactions.

- Modifiable risk factors such as lifestyle and their association with AD biomarkers in CSF and other in vivo measures and conversion to AD-type dementia need to be further explored. Lifestyle factors need to be examined over a longer period of time in population based studies, in memory clinic patients, by different measures and at different ages.

- Lastly, the time to AD-type dementia differs between individuals, which needs further exploration in combination with risk and protective factors such as age, APOE-e4 carriership, vascular factors, cognitive reserve and lifestyle.

To support validation of emerging biomarkers for the diagnosis of neurodegenerative disorders, we have established a European biobank with CSF and blood samples for the BIOMARKAPD study funded by Joint Programming Initiative Neurodegenerative Diseases (JPND). These samples are accessible for researchers in the field of dementia and neurodegenerative diseases. 


\section{REFERENCES}

[1] Barnes DE, Yaffe K (2011) The projected effect of risk factor reduction on Alzheimer's disease prevalence. Lancet Neurol 10, 819-828.

[2] Norton S, Matthews FE, Barnes DE, Yaffe K, Brayne C (2014) Potential for primary prevention of Alzheimer's disease: an analysis of population-based data. Lancet Neurol 13, 788-794.

[3] Kolev MV, Ruseva MM, Harris CL, Morgan BP, Donev RM (2009) Implication of complement system and its regulators in Alzheimer's disease. Curr Neuropharmacol 7, 1-8.

[4] Stokowska A, Atkins AL, Moran J, Pekny T, Bulmer L, Pascoe MC, Barnum SR, Wetsel RA, Nilsson JA, Dragunow M, Pekna M (2017) Complement peptide C3a stimulates neural plasticity after experimental brain ischaemia. Brain 140, 353-369.

[5] Desikan RS, Thompson WK, Holland D, Hess CP, Brewer JB, Zetterberg H, Blennow K, Andreassen OA, McEvoy LK, Hyman BT, Dale AM, Alzheimer's Disease Neuroimaging I (2013) Heart fatty acid binding protein and Abeta-associated Alzheimer's neurodegeneration. Mol Neurodegener 8, 39.

[6] Bjerke M, Zetterberg H, Edman A, Blennow K, Wallin A, Andreasson U (2011) Cerebrospinal fluid matrix metalloproteinases and tissue inhibitor of metalloproteinases in combination with subcortical and cortical biomarkers in vascular dementia and Alzheimer's disease. $J$ Alzheimers Dis 27, 665-676.

[7] Guillaume E, Zimmermann C, Burkhard PR, Hochstrasser DF, Sanchez JC (2003) A potential cerebrospinal fluid and plasmatic marker for the diagnosis of Creutzfeldt-Jakob disease. Proteomics 3, 1495-1499.

[8] Ohrfelt A, Andreasson U, Simon A, Zetterberg H, Edman A, Potter W, Holder D, Devanarayan V, Seeburger J, Smith AD, Blennow K, Wallin A (2011) Screening for new biomarkers for subcortical vascular dementia and Alzheimer's disease. Dement Geriatr Cogn Dis Extra 1, 31 42.

[9] Verwey NA, Schuitemaker A, van der Flier WM, Mulder SD, Mulder C, Hack CE, Scheltens P, Blankenstein MA, Veerhuis $R$ (2008) Serum amyloid p component as a biomarker in mild cognitive impairment and Alzheimer's disease. Dement Geriatr Cogn Disord 26, 522-527.

[10] Kimura M, Asada T, Uno M, Machida N, Kasuya K, Taniguchi Y, Fujita T, Nishiyama E, Iwamoto $\mathrm{N}$, Arai $\mathrm{H}$ (1999) Assessment of cerebrospinal fluid levels of serum amyloid $\mathrm{P}$ component in patients with Alzheimer's disease. Neurosci Lett 273, 137-139.

[11] Ellis RJ, Olichney JM, Thal LJ, Mirra SS, Morris JC, Beekly D, Heyman A (1996) Cerebral amyloid angiopathy in the brains of patients with Alzheimer's disease: the CERAD experience, Part XV. Neurology 46, 1592-1596. 
[12] del Campo M, Mollenhauer B, Bertolotto A, Engelborghs S, Hampel H, Simonsen AH, Kapaki E, Kruse N, Le Bastard N, Lehmann S, Molinuevo JL, Parnetti L, Perret-Liaudet A, Saez-Valero J, Saka E, Urbani A, Vanmechelen E, Verbeek M, Visser PJ, Teunissen C (2012) Recommendations to standardize preanalytical confounding factors in Alzheimer's and Parkinson's disease cerebrospinal fluid biomarkers: an update. Biomark Med 6, 419-430.

[13] Verwey NA, van der Flier WM, Blennow K, Clark C, Sokolow S, De Deyn PP, Galasko D, Hampel H, Hartmann T, Kapaki E, Lannfelt L, Mehta PD, Parnetti L, Petzold A, Pirttila T, Saleh L, Skinningsrud A, Swieten JC, Verbeek MM, Wiltfang J, Younkin S, Scheltens P, Blankenstein MA (2009) A worldwide multicentre comparison of assays for cerebrospinal fluid biomarkers in Alzheimer's disease. Ann Clin Biochem 46, 235-240.

[14] Vos SJ, Visser PJ, Verhey F, Aalten P, Knol D, Ramakers I, Scheltens P, Rikkert MG, Verbeek MM, Teunissen CE (2014) Variability of CSF Alzheimer's disease biomarkers: implications for clinical practice. PLoS One 9, e100784.

[15] Reijs BLR, Teunissen CE, Goncharenko N, Betsou F, Blennow K, Baldeiras I, Brosseron F, Cavedo E, Fladby T, Froelich L, Gabryelewicz T, Gurvit H, Kapaki E, Koson P, Kulic L, Lehmann S, Lewczuk P, Lleo A, Maetzler W, de Mendonca A, Miller AM, Molinuevo JL, Mollenhauer B, Parnetti L, Rot U, Schneider A, Simonsen AH, Tagliavini F, Tsolaki M, Verbeek MM, Verhey FR, Zboch M, Winblad B, Scheltens P, Zetterberg H, Visser PJ (2015) The Central Biobank and Virtual Biobank of BIOMARKAPD: A Resource for Studies on Neurodegenerative Diseases. Front Neurol 6, 216.

[16] Hardy J, Selkoe DJ (2002) The amyloid hypothesis of Alzheimer's disease: progress and problems on the road to therapeutics. Science 297, 353-356.

[17] Vos SJ, Verhey F, Frolich L, Kornhuber J, Wiltfang J, Maier W, Peters O, Ruther E, Nobili F, Morbelli S, Frisoni GB, Drzezga A, Didic M, van Berckel BN, Simmons A, Soininen H, Kloszewska I, Mecocci P, Tsolaki M, Vellas B, Lovestone S, Muscio C, Herukka SK, Salmon E, Bastin C, Wallin A, Nordlund A, de Mendonca A, Silva D, Santana I, Lemos R, Engelborghs S, Van der Mussele S, Alzheimer's Disease Neuroimaging I, Freund-Levi Y, Wallin AK, Hampel H, van der Flier W, Scheltens P, Visser PJ (2015) Prevalence and prognosis of Alzheimer's disease at the mild cognitive impairment stage. Brain 138, 1327-1338.

[18] Tijms BM, Bertens D, Slot RE, Gouw AA, Teunissen CE, Scheltens P, van der Flier WM, Visser PJ (2017) Low normal cerebrospinal fluid Abeta42 levels predict clinical progression in nondemented subjects. Ann Neurol 81, 749-753.

[19] Savva GM, Wharton SB, Ince PG, Forster G, Matthews FE, Brayne C, Medical Research Council Cognitive F, Ageing S (2009) Age, neuropathology, and dementia. N Engl J Med 360, 23022309. 



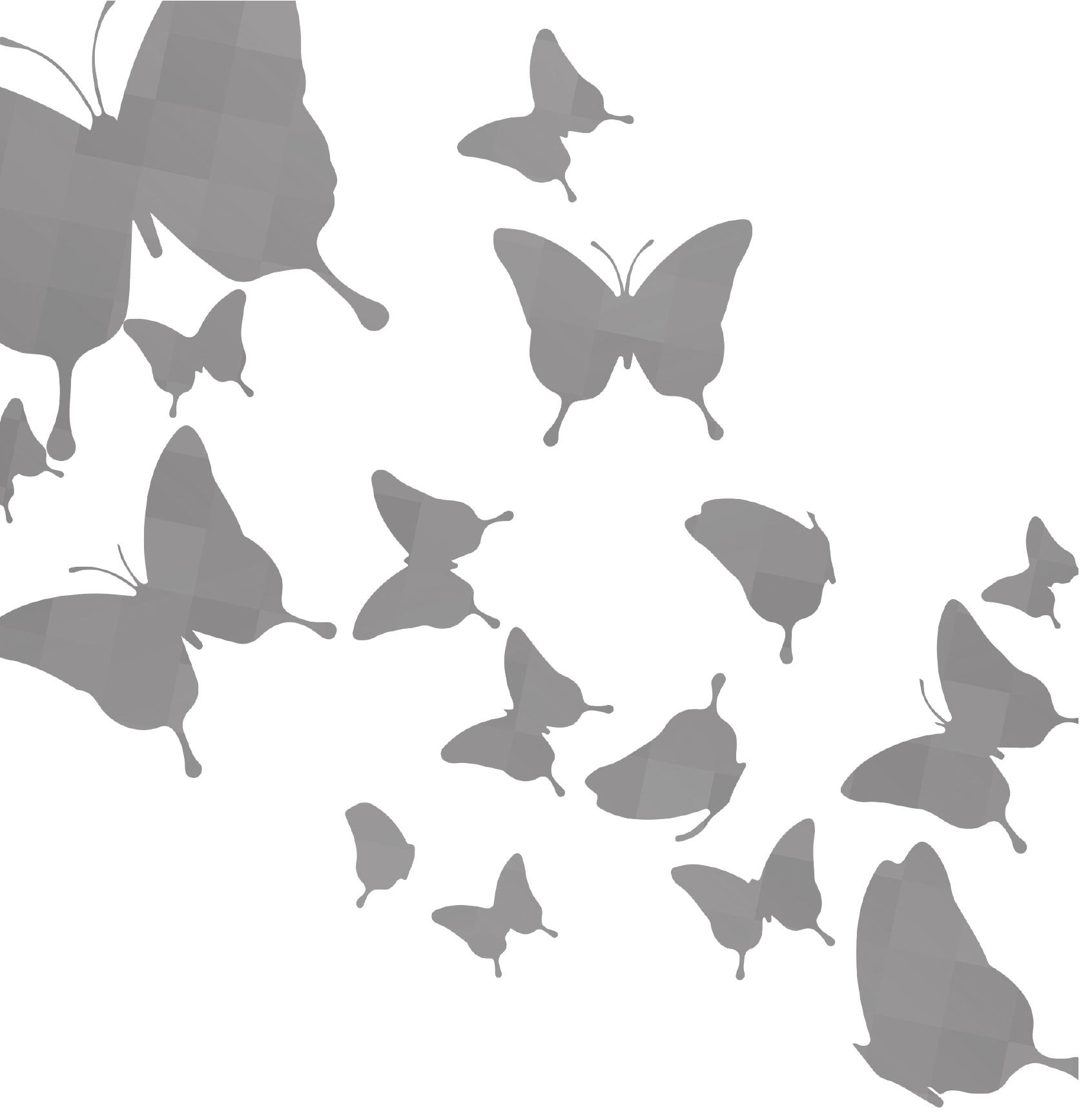




\section{Addendum}

Summary

Samenvatting (Dutch summary)

Knowledge valorization

Author affiliations

List of publications

Thesis defences from MHeNs

Dankwoord (Acknowledgments)

Curriculum Vitae 



\section{SUMMARY}

With the aging population, the number of patients with Alzheimer disease (AD) is increasing. This places a huge burden on patients, caregivers and society. As of today, no effective disease modifying treatments exist. To facilitate treatment development, there is an urgent need to better understand the pathophysiological mechanism of $A D$, to detect $A D$ in an early stage before the onset of dementia, and to better understand predictors of disease expression. Furthermore, early detection of AD and a better understanding of disease progression will benefit present patient care. The availability of biomarkers for AD-related brain changes makes it now possible to study the development of the disease in-vivo. In this thesis we tested associations between in-vivo established and emerging AD biomarkers and risk factors, and cognitive decline across the clinical spectrum of $A D$ ranging from preclinical $A D$ to mild dementia.

In chapter 2, we examined the association of CSF a 342 and tau biomarkers with performance on different memory domains at baseline and at follow-up. The main finding was that both CSF a 342 and tau were most strongly associated with episodic memory independent of diagnostic group. This suggests that episodic memory is the most sensitive cognitive marker for AD pathology reflected in CSF.

In chapter 3, we examined the association of CSF a 342 and tau biomarkers with performance on multiple cognitive domains at baseline and follow-up in individuals with Mild Cognitive Impairment $(\mathrm{MCl})$. When both biomarkers were abnormal, lower scores were found on episodic memory and global cognition. Cognitive decline was only detected in individuals with abnormal tau, suggesting that tau is a better prognostic marker than abnormal aß42.

In chapter 4, we examined the association of odour identification with CSF biomarkers at baseline, and with performance on several cognitive domains at baseline and over time. Odour identification was associated with tau, with multiple cognitive domains at baseline and with decline in global cognition at follow-up independent of diagnostic group. These findings suggest that odour identification may have potential as marker for tau pathology, and as diagnostic and prognostic marker.

In chapter 5, we examined the association of emerging biomarkers in CSF (i.e. C3a, C5a, MAC, hFABP and SAP) with CSF a 342 and tau, and with global cognition over time. We found that lower $\mathrm{C} 3 \mathrm{a}$ was associated with lower $\mathrm{a} \beta 42$ in individuals with dementia, and higher C 3 a was associated with stronger decline in a $\beta 42$ in individuals without dementia 
with normal aß42. Higher HfAPB was associated with higher tau independent of dementia status and was increased in individuals with dementia and $\mathrm{MCl}$. This suggests that C3a is involved in amyloid aggregation, while HfABP is a marker of neuronal injury.

In chapter 6, we examined the association of lifestyle risk factors for dementia with $A D$ biomarkers in CSF and hippocampal volume in individuals with Subjective Cognitive Decline $(\mathrm{SCD})$ and $\mathrm{MCl}$. In addition, we examined the association of lifestyle risk factors with risk for converting to AD-type dementia in individuals with $\mathrm{MCl}$. Lifestyle risk factors were not associated with AD biomarkers or conversion to AD-type dementia. This indicates that lifestyle risk factors may contribute to dementia through non- $A D$ processes.

In chapter 7, an overview is provided of CSF and blood samples collected for the European study BIOMARKAPD funded by Joint Programming Initiative Neurodegenerative Diseases (JPND). The biobank was set-up to support validation of emerging biomarkers for the diagnosis of neurodegenerative disorders. Samples are accessible for researchers in the field of dementia and other neurodegenerative diseases.

In chapter 8, we described a general discussion of our results, its methodological considerations, implications and future directions. 


\section{SAMENVATTING}

Door de vergrijzing blijft het aantal mensen met de ziekte van Alzheimer toenemen. De ziekte van Alzheimer is zeer belastend voor mensen die de ziekte hebben, voor mantelzorgers en voor de samenleving. Op dit moment bestaat er geen effectief medicijn wat het ziekte proces kan beïnvloeden. Om de ontwikkeling van effectieve medicatie te bevorderen is het noodzakelijk dat we het pathofysiologische mechanisme van Alzheimer beter kunnen begrijpen, dat we Alzheimer in een vroeg stadium kunnen detecteren voordat er sprake is van dementie en dat we een beter begrip krijgen van ziekte voorspellers. Daarnaast zal ook de patiëntenzorg er baat bij hebben wanneer we Alzheimer al in een vroeg stadium kunnen detecteren en we een beter begrip hebben van het beloop van de ziekte. Inmiddels kunnen we de ontwikkeling van de ziekte van Alzheimer al in-vivo bestuderen door middel van biomarkers die een weerspiegeling geven van Alzheimer gerelateerde veranderingen in het brein. In deze thesis onderzoeken we de associaties tussen in-vivo bestaande en opkomende biomarkers en risicofactoren voor de ziekte van Alzheimer en achteruitgang in cognitie over het brede klinische spectrum van Alzheimer beginnend van preklinisch tot een milde vorm van dementie.

In hoofdstuk 2, onderzochten we de relatie tussen hersenvocht biomarkers betaamyloïde-42 (CSF aß42) en tau en prestatie op verschillende geheugendomeinen gemeten op baseline en follow-up. De hoofdbevinding was dat zowel CSF aß42 als tau sterk gecorreleerd waren met episodisch geheugen onafhankelijk van diagnostische groep. Dit suggereert dat episodisch geheugen de meest gevoelige cognitieve voorspeller is van Alzheimer pathologie gemeten in het hersenvocht.

In hoofdstuk 3, onderzochten we de relatie tussen biomarkers CSF aß42 en tau en prestatie op verschillende cognitieve domeinen gemeten op baseline en op follow-up in mensen met milde cognitieve beperkingen $(\mathrm{MCl})$. Lagere scores werden gevonden op het episodische geheugen en globale cognitie bij mensen met abnormale waardes van beide biomarkers. Cognitieve achteruitgang werd alleen gevonden in mensen met abnormaal tau wat suggereert dat tau een betere prognostische voorspeller is dan abnormaal a $\beta 42$.

In hoofdstuk 4, onderzochten we de relatie tussen geur identificatie en CSF biomarkers op baseline en de relatie tussen geur identificatie en scores op meerdere cognitieve domeinen op baseline en over tijd. Geur identificatie was geassocieerd met tau, met scores op meerdere cognitieve domeinen op baseline en met achteruitgang in 
globale cognitie op follow-up onafhankelijk van diagnostische groep. Deze resultaten suggereren dat geur identificatie mogelijk potentie heeft als marker voor tau pathologie en als diagnostische en prognostische marker.

In hoofdstuk 5, onderzochten we de relatie tussen opkomende biomarkers in hersenvocht (namelijk C3a, C5a, MAC, hFABP en SAP) met CSF aß42 en tau en met score op globale cognitie over tijd. Wij vonden dat lager C3a geassocieerd was met lager a $\beta 42$ in mensen met dementie en dat hoger C3a geassocieerd was met sterkere achteruitgang in a $\beta 42$ in mensen zonder dementie met normaal a $\beta 42$. Hoger HfAPB was geassocieerd met hoger tau onafhankelijk of iemand wel of niet dementie had en HfAPB was verhoogd in mensen met dementie en $\mathrm{MCl}$. Dit suggereert dat C3a betrokken is bij de stapeling van amyloïde terwijl HfABP een betere marker is voor neuronale schade.

In hoofdstuk 6, onderzochten we de relatie tussen levensstijl risicofactoren voor dementie en Alzheimer biomarkers in CSF en hippocampus volume in mensen met subjectieve cognitieve klachten en $\mathrm{MCl}$. Daarnaast onderzochten we de relatie tussen levensstijl risicofactoren en het risico voor conversie naar dementie van het Alzheimer type in mensen met $\mathrm{MCl}$. Levensstijl risicofactoren waren niet geassocieerd met Alzheimer biomarkers of met conversie naar dementie van het Alzheimer type. Dit suggereert dat levensstijl risicofactoren mogelijk bijdragen aan dementie door niet Alzheimer gerelateerde ziekte processen.

In hoofdstuk 7, wordt er een overzicht gegeven van hersenvocht en bloed materiaal verzameld voor de Europese studie BIOMARKAPD gesubsidieerd door "Joint Programming Initiative Neurodegenerative Diseases" (JPND). De biobank was opgezet om opkomende biomarkers voor de diagnose van neurodegeneratieve ziektes te kunnen valideren.

In hoofdstuk 8, wordt er een algemene discussie van onze resultaten beschreven met bijbehorende methodologische overwegingen, implicaties en aanbevelingen voor verder onderzoek. 


\section{KNOWLEDGE VALORIZATION}

The overall aim of our studies was to aid in the early identification of AD before the onset of dementia and to obtain a better understanding of the pathophysiological mechanism of $A D$ and predictors of disease expression in order to facilitate treatment development. In addition, early identification of $A D$ and a better understanding of clinical disease progression will benefit present patient care by allowing for timely psychosocial interventions and to assist patients and caregivers in an early stage. For this purpose, we examined associations between established and emerging biomarkers and risk factors for $A D$, and cognitive decline across the clinical spectrum of $A D$ ranging from preclinical $A D$ to mild dementia. This chapter addresses the clinical and societal relevance and implications of our studies.

\section{Societal relevance}

Dementia may be one of the greatest global health challenges of our time due to its impact, size and costs. With the aging of the population, the number of individuals with dementia has increased up to approximately 50 million in 2017 worldwide, and is expected that it will double every 20 years. AD is the most common form of dementia and contributes to $60-70 \%$ of cases with dementia. Dementia is the seventh leading cause of death and places a huge burden on patients and caregivers. The increasing prevalence imposes an enormous challenge for society and the health care system. Worldwide the costs for dementia have been estimated as $\$ 818$ billion in 2015 , which increased by 35\% since 2010. The World Health Organization (WHO) considers dementia as a public health priority and recommends every country to develop a national dementia plan and a framework for action. More resources are needed to facilitate treatments studies, care for patients and prevention studies.

At present no disease modifying treatment for AD exists. Future disease modifying treatments are most effective when neuronal damage is still limited before the onset of dementia. Still it is challenging to find individuals without dementia with AD. Studies in this thesis may aid in the early identification of non-demented individuals without dementia with underlying amyloid or tau pathology. This can be valuable for prescreening of the population for treatment studies such that these trials can recruit participants faster and at lower costs. This may ultimately benefit patient care. Our results showed that early episodic memory dysfunction is a sensitive cognitive marker for early AD pathology, although the diagnostic accuracy was modest. In addition, we provided further evidence for the role of complement dysfunction in early AD pathophysiology, which may also guide future treatment development. 
Studies in this thesis may also benefit present patient care by aiding in our understanding of predictors of clinical disease progression. We tested the association between established and emerging AD biomarkers and cognition over time. We demonstrated that in particular tau, but also odour dysfunction may be useful as marker for predicting future cognitive decline. We also tested the association between modifiable lifestyle factors and $A D$ biomarkers and conversion to AD-type dementia in individuals without dementia with cognitive complaints. Previous studies showed that lifestyle risk factors increase the risk for dementia. We did not find an association between modifiable lifestyle factors and AD biomarkers or conversion to AD-type dementia in individuals without dementia with cognitive complaints. This suggests that targeting lifestyle may have limiting effect on AD pathology or conversion to AD-type dementia in individuals with cognitive complaints, and that these lifestyle risk factors likely impact dementia through non-AD related pathways. This information can be valuable for future dementia prevention programs.

\section{Target audience}

The findings described in this thesis are relevant for clinicians by increasing knowledge of utility of established and emerged AD markers for diagnosis and prognosis, and the utility of risk factors for predicting disease progression. In turn, this will aid in our ability to inform patients and caregivers in the future about the underlying etiology of the clinical diagnosis and future cognitive decline, which can benefit patient care.

Our findings on pathophysiological mechanism of AD, clinical disease expression, and risk factors may be relevant for researchers for planning future studies such as prevention trials aimed at modifying pathophysiological processes and studies targeting modifiable lifestyle factors to prevent dementia and AD pathology. In addition, the European central and virtual biobank of BIOMARKAPD we established is a valuable resource for researchers to validate emerging biomarkers for neurodegenerative disorders.

Furthermore, the rapidly increasing prevalence of dementia with little progress in treatment development and high costs for testing treatments emphasizes the need to prescreen individuals suitable for treatment intervention studies. Studies in this thesis may be useful for pharmaceutical companies to design future treatment trials and to help identify individuals suitable for treatment. 


\section{Products}

The main products of this thesis are the results that may guide future studies and clinical practice. Almost all manuscripts have been published in scientific journals and presented at international conferences. Furthermore, for future biomarker development a biobank has been set-up of CSF and blood samples for the European study BIOMARKAPD funded by JPND. This biobank was set up to support the validation of emerging biomarkers for diagnosis of neurodegenerative diseases and promotes data sharing. The stimulate use of the biobank a website has been made available for BIOMARKAPD sample requests (http://jpnd.arone.com/) and we described the biobank in a publication.

\section{Innovation and implementation}

In this thesis, we investigated established but also innovative measures with computerized tests, emerging CSF biomarkers, and emerging risk factors. This may aid in our understanding of the pathophysiological mechanism of AD and predictors of disease expression in order to facilitate treatment development. In addition, it aids in our understanding of clinical disease progression, which may benefit patient care. The knowledge obtained by our studies can be used for planning for future studies by researchers and drug developers. 



\section{AUTHOR AFFILIATIONS}

Inês Baldeiras

(CNC) Center for Neuroscience and Cell Biology, CNC.IBILI, Faculty of Medicine, University of Coimbra, Coimbra, Portugal

Fay Betsou

IBBL (Integrated Biobank of Luxembourg), Luxembourg, Luxembourg

Andrew Blackwell

Cambridge Cognition, Cambridge, UK

Kaj Blennow

Clinical Neurochemistry Lab, Dept. of Neuroscience and Physiology, The Sahlgrenska Academy at University of Gothenburg, Sahlgrenska University Hospital, Mölndal, Sweden

\section{Frederic Brosseron}

German Center for Neurodegenerative Diseases (DZNE) e.V. Clinical Neuroscience and Biomarkers, Bonn, Germany

\section{Enrica Cavedo}

Lab Alzheimer's Neuroimaging \& Epidemiology, IRCCS Fatebenefratelli, Brescia, Italy

\section{D.P. Devanand}

Division of Geriatric Psychiatry, New York State Psychiatric Institute and Columbia University Medical Center, New York, NY, USA

\section{Lyzel Elias-Sonnenschein}

Department of Psychiatry and Neuropsychology, School for Mental Health and Neuroscience, Alzheimer Centre Limburg, Maastricht University, Maastricht, The Netherlands

\section{Tormod Fladby}

Department of Neurology, Akershus University Hospital, Lørenskog, Norway; Institute of Clinical Medicine, Campus Ahus, University of Oslo, Oslo, Norway

Yvonne Freund-Levi

Clinical Neurochemistry Laboratory, Göteborg University, Guldhedsgatan 19, Sahlgrenska University Hospital, Mölndal, Sweden 


\section{Lutz Frölich}

Dept. of Geriatric Psychiatry, Central Institute of Mental Health, Medical Faculty Mannheim, University of Heidelberg, Germany

\section{Tomasz Gabryelewicz}

Department of Neurodegenerative Disorders, Mossakowski Medical Research Centre Polish Academy of Sciences, Warszawa, Poland

Nikolai Goncharenko

IBBL (Integrated Biobank of Luxembourg), Luxembourg, Luxembourg

\section{Hakan Gurvit}

Behavioural Neurology and Movement Disorders Unit, Department of Neurology, Istanbul Faculty of Medicine, Istanbul University, Istanbul, Turkey

\section{Harald Hampel}

Department of Psychiatry, Psychosomatic Medicine, \& Psychotherapy, University of Frankfurt, Frankfurt am Main, Germany

\section{Lucrezia Hausner}

Department of Geriatric Psychiatry, Central Institute of Mental Health, Medical Faculty of Mannheim, Heidelberg University, Germany

\section{Peter Johannsen}

Danish Dementia Research Centre, Rigshospitalet, Copenhagen University Hospital, Copenhagen, Denmark

\section{Elisabeth Kapaki}

Division of Cognitive and Movement Disorders, Neurochemistry Unit, 1st Department of Neurology, National and Kapodistrian University of Athens, Athens, Greece

\section{Marleen Koel-Simmelick}

Neurochemistry Laboratory and Biobank, Dept. of Clinical Chemistry, Neuroscience Campus Amsterdam, VU University Medical Center Amsterdam, The Netherlands.

\section{Sebastian Köhler}

Department of Psychiatry and Neuropsychology, School for Mental Health and Neuroscience, Alzheimer Center Limburg, Maastricht University Medical Center, Maastricht, The Netherlands 
Peter Koson

Department of Neurology of Slovak Medical University, University Hospital Bratislava, Bratislava, Slovakia; Institute of Neuroimmunology, Slovak Academy of Sciences, Bratislava, Slovakia

\section{Luka Kulic}

Division of Psychiatry Research, University of Zurich, Campus Schlieren, Schlieren, Switzerland

\section{Sylvain Lehmann}

CHRU de Montpellier, Université de Montpellier and INSERM U1183, IRMB, Laboratoire de Biochimie Protéomique Clinique, Montpellier, France

\section{Piotr Lewczuk}

Department of Psychiatry and Psychotherapy, Universitätsklinikum Erlangen and Friedrich-Alexander Universität Erlangen-Nürnberg, Erlangen, Germany; Department of Neurodegeneration Diagnostics, Medical University of Bialystok, Bialystok, Poland

\section{Alberto Lleó}

Memory Unit, Department of Neurology, Hospital de la Santa Creu i Sant Pau- Biomedical Research Institute Sant Pau. Barcelona, Spain; Centro de Investigación Biomédica en Red de Enfermedades Neurodegenerativas CIBERNED, Spain

\section{Walter Maetzler}

Department of Neurodegeneration, Hertie Institute for Clinical Brain Research, University of Tübingen, Tübingen, Germany; German Center for Neurodegenerative Diseases, University of Tübingen, Tübingen, Germany

\section{Alexandre de Mendonça}

Faculty of Medicine, University of Lisbon, Lisbon, Portugal

\section{Anne-Marie Miller}

Medical Gerontology, School of Medicine, Trinity College Dublin, Dublin, Ireland

José L. Molinuevo

ICN Hospital Clinic i Universitari, IDIBAPS, Barcelona, Spain

\section{Brit Mollenhauer}

Paracelsus-Elena-Klinik, Kassel, Germany; University Medical Center Göttingen, Department of Neuropathology and Neurosurgery, Göttingen, Germany 


\section{Pradeep J. Nathan}

Department of Psychiatry, University of Cambridge, United Kingdom; School of Psychological Sciences, Monash University, Melbourne, Australia

\section{Marcel Olde Rikkert}

Department of Geriatrics, Radboud University Nijmegen Medical Center, Nijmegen, the Netherlands

\section{Lucilla Parnetti}

Centre for Memory Disturbances, Section of Neurology, University of Perugia, Perugia, Italy

\section{Lieke van Praag}

Department of Psychiatry and Neuropsychology, Maastricht University, School for Mental Health and Neuroscience, Alzheimer Center Limburg, Maastricht, the Netherlands

\section{Inez H.G.B. Ramakers}

Department of Psychiatry and Neuropsychology, School for Mental Health and Neuroscience, Alzheimer Center Limburg, Maastricht University, Maastricht, The Netherlands

Uros Rot

Laboratory for CSF diagnostics, Department of Neurology, University Medical Centre, Ljubljana, Slovenia

\section{Helma Rutjes}

Pivot Park Screening Centre, Oss, The Netherlands

\section{Philip Scheltens}

Department of Neurology and Alzheimer Center, VU University Medical Center, Amsterdam, The Netherlands

\section{Anja Schneider}

Dept. of Psychiatry and Psychotherapy, University Medical Center Göttingen and Translational Dementia Research Group, German Center for Neurodegenerative Diseases, DZNE Göttingen, Göttingen, Germany

Anja Hviid Simonsen

Danish Dementia Research Centre, Rigshospitalet, Copenhagen University Hospital, Copenhagen, Denmark 
Hilkka Soininen

Department of Neurology, University and University Hospital of Kuopio, Kuopio, Finland

Luiza Spiru

"Carol Davila" University of Medicine and Pharmacy, 8 Bulevardul Eroii Sanitari, Bucharest, Romania

Fabrizio Tagliavini

Unit of Neuropathology, Department of Diagnostics and Technology, IRCCS Foundation "Carlo Besta" Neurological Institute, Milano, Italy

Charlotte E. Teunissen

Neurochemistry Laboratory and Biobank, Dept. of Clinical Chemistry, Neuroscience Campus Amsterdam, VU University Medical Center Amsterdam, The Netherlands.

\section{Magda Tsolaki}

3rd Department of Neurology, Aristotle University of Thessaloniki, Macedonia, Hellas, Greece

Rik Vandenberghe

University Hospital Leuven, Leuven, Belgium

Hugo Vanderstichele

ADx NeuroSciences, Gent, Belgium

Marcel Verbeek

Department of Neurology, Department of Laboratory Medicine, Donders Institute for Brain, Cognition and Behaviour, Radboud Alzheimer Centre, Radboud University Medical Centre, Nijmegen, The Netherlands

Frans R.J. Verhey

Department of Psychiatry and Neuropsychology, School for Mental Health and Neuroscience, Alzheimer Center Limburg, Maastricht University Medical Center, Maastricht, The Netherlands

Pieter Jelle Visser

Department of Psychiatry and Neuropsychology, School for Mental Health and Neuroscience, Alzheimer Center Limburg, Maastricht University Medical Center, Maastricht, The Netherlands; Department of Neurology and Alzheimer Center, VU University Medical Center, Amsterdam, The Netherlands 


\section{Stephanie Vos}

Department of Psychiatry and Neuropsychology, School for Mental Health and Neuroscience, Alzheimer Center Limburg, Maastricht University, Maastricht, The Netherlands

\section{Lars-Olof Wahlund}

Karolinska Institutet, Karolinska University Hospital, Huddinge, Sweden

Gunhild Waldemar

Danish Dementia Research Centre, Rigshospitalet, Copenhagen University Hospital, Copenhagen, Denmark

Asa Wallin

University of Lund, Malmo, Sweden

\section{Bengt Winblad}

Karolinska Institutet, Department of NVS, Center for Alzheimer Research, Division of Neurogeriatrics, Huddinge, Sweden

Marzena Zboch

Research-Scientific-Didactic Centre of Dementia-Related Diseases, Wrocław Medical University, Scinawa, Poland

\section{Henrik Zetterberg}

Institute of Neuroscience and Physiology, Department of Psychiatry and Neurochemistry, the Sahlgrenska Academy at the University of Gothenburg, Mölndal, Sweden; UCL Institute of Neurology, London, United Kingdom 


\section{LIST OF PUBLICATIONS}

\section{Journal Articles}

Reijs B.L.R., Ramakers I.H.G.B., Kohler S., et al. Memory Correlates of Alzheimer's Disease Cerebrospinal Fluid Markers: A Longitudinal Cohort Study. J Alzheimers Dis 2017;60:1119-1128.

Reijs B.L.R., Ramakers I.H.G.B., Elias-Sonnenschein L., et al. Relation of Odor Identification with Alzheimer's Disease Markers in Cerebrospinal Fluid and Cognition. J Alzheimers Dis 2017;60:1025-1034.

Reijs B.L.R., Vos S.J.B., Soininen H., et al. Association Between Later Life Lifestyle Factors and Alzheimer's Disease Biomarkers in Non-Demented Individuals: A Longitudinal Descriptive Cohort Study. J Alzheimers Dis 2017.

Reijs B.L.R., Teunissen C.E., Goncharenko N., et al. The Central Biobank and Virtual Biobank of BIOMARKAPD: A Resource for Studies on Neurodegenerative Diseases. Front Neurol 2015;6:216.

\section{Conference Contributions}

Reijs, B.L.R., Vos, S.J.B., Jansen, W.J., Verhey, F.R.J., \& Visser, PJ, and VPH-DARE/DESCRIPA study group. Relation Between Lifestyle Factors and Alzheimer Disease Biomarkers in Subjects with SCI or MCI. Alzheimer's Association International Conference (AAIC) 2016, Toronto (Canada).

Reijs, B.L.R., Ramakers, I.H.G.B., Teunissen, Devanand, D.P., Verhey, F.R.J., Tsolaki, M, Wahlund, LO., Waldemar, G., Hausner, L., Johannsen, P., \& Visser, PJ. Olfactory dysfunction may predict Alzheimer's disease related tau pathology in cerebrospinal fluid (CSF). Alzheimer's \& Dementia: The Journal of the Alzheimer's Association, Volume 11 , Issue 7 , P130. Alzheimer's Association International Conference (AAIC) 2015, Washington D.C. (USA).

Reijs, B.L.R., Ramakers, I.H.G.B., Teunissen, C.E., Natan, P.J., Verhey, F.R.J., Tsolaki, M, Wahlund, LO., Waldemar, G., Hausner, L., Vandenberghe , R., Johannsen, P., Blackwell, A., \& Visser, PJ. Early detection of Alzheimer's disease (AD)-related amyloid and tau pathology: A computerized versus a paper-and-pencil memory test. Alzheimer's \& Dementia: The Journal of the Alzheimer's Association, Volume 11 , Issue 7 , P272. Alzheimer's Association International Conference (AAIC) 2015, Washington D.C. (USA). 
Reijs, B.L.R., Teunissen, C. E., Goncharenko, N., Blennow, K., Zetterberg, H., Maetzeler, W., Mollenhauer, B., Winblad, B., Scheltens, P., Verhey, F.R.J., \& Visser, PJ. A European biobank for the validation of new markers for Alzheimer and Parkinson's disease. Alzheimer's \& Dementia: The Journal of the Alzheimer's Association, Volume 10, Issue 4, P148. Alzheimer's Association Interantional Conference (AAIC) 2014, Copenhagen (Denmark). 


\section{THESIS DEFENCES FROM MHENS (SCHOOL FOR MENTAL HEALTH AND NEUROSCIENCE)}

\section{3}

Rob Havermans: Bipolar disorder in daily life; Mood and cortisol responses to naturally occurring events. Supervisor: Prof.dr. M. de Vries; Co-Supervisor: Dr. N. Nicolson.

Véronique Moers-Hornikx: Deep brain stimulation and the cerebellum. Supervisors:

Prof.dr. J. Vles / Prof.dr. Y. Temel; Co-Supervisor: Dr. G. Hoogland.

Nicole Veldhorst-Janssen: Intranasal delivery of rapid acting drugs. Supervisors: Prof. dr. M. Marcus / Prof.dr. C. Neef; Co-Supervisor: Dr. P.H. van der Kuy.

Stéphanie Knippenberg: Vitamin D and Multiple Sclerosis: immunological and clinical outcome. Supervisor: Prof.dr. J. Cohen-Tervaert; Co-Supervisors: Dr. J. Damoiseaux / Dr. Y. Bols.

Erik D. Gommer: Dynamic Cerebral Autoregulation: from methodology towards clinical application. Supervisors: Prof.dr. W.H. Mess / Prof.dr. R.B. Panerai, UK; CoSupervisor: Dr.ir. J.P.H. Reulen.

Olga A.H. Reneerkens: Can PDE inhibition improve cognition ? Translational insights. Supervisor: Prof.dr. H.W.M. Steinbusch; Co-Supervisor: Dr. J. Prickaerts;.

Lyzel S. Elias-Sonnenschein: Clinical and biomarker correlates of genetic risk factors for Alzheimer's disease. Supervisor: Prof.dr. F.R.J. Verhey; Co-Supervisor: Dr. P.J. Visser.

Diego F. Mastroeni: Epigenetic Dysregulation and the Pathophysiology of of Alzheimer's Disease. Supervisors: Prof.dr. H.W.M. Steinbusch / Prof.dr. P.D. Coleman, Sun City, Arizona; Co-Supervisors: Dr. B.P.F. Rutten / Dr. D.L.A. van den Hove.

Leonidas Chouliaras: Epigenetic Regulation in Aging and Alzheimer's disease: A translational perspective. Supervisor: Prof.dr. H.W.M. Steinbusch; Co-Supervisors: Dr. B.P.F. Rutten / Dr. D.L.A. van den Hove.

Liesbeth Knaepen: Perinatal events and altered pain sensitivity in later life. Supervisors: Prof.dr. E.A.J. Joosten / Prof.dr. D. Tibboel, EUR; Co-Supervisor: Dr. J. Patijn.

Marisela Martinez-Claros: Hippocampal plasticity and corticosterone: From dendrites to behaviour. Supervisor: Prof.dr. H.W.M. Steinbusch; Co-Supervisors: Dr. J.L. Pawluski /Dr. J. Prickaerts.

Marcus D. Lancé: A circle of improvement in bleeding management: from laboratory to clinic and back. Supervisors: Prof.dr. M.A.E. Marcu / Prof.dr. J.W.M. Heemskerk; Co-Supervisor: Dr. Y.M.C. Henskens. 
Hilde Braakman: Imaging the brain; neuronal correlates of cognitive impairment in children with frontal lobe epilepsy. Supervisors: Prof.dr. A.P. Aldenkamp / Prof.dr. J.S.H. Vles; Co-Supervisors: Dr.ir. W.H. Backes / Dr. P.A.M. Hofman.

Willem H. van Zwam: Aneurysmal subarachnoid hemorrhage: imaging strategies and cost-effectiveness aspects in diagnostic work-up and post-therapeutic follow-up. Supervisors: Prof.dr. J.T. Wilmink / Prof.dr. J.E. Wildberger; Co-Supervisor: Dr. P.A.M. Hofman.

Klara De Cort: The Pathogenesis of Panic Disorder. Supervisors: Prof.dr. I. MyinGermeys / Prof.dr. E.J.L. Griez; Co-Supervisors: Dr. K.R.J. Schruers / Dr. I. Van Diest, Leuven.

Kim van Wijck: Mind the Gap; experimental studies on splanchnic hyperfusion and gastrointestinal integrity loss in man. Supervisors: Prof.dr. W.A. Buurman / Prof. dr. C.H.C. Dejong; Co-Supervisor: Dr. K. Lenaerts.

Yvette Roke: Antipsychotic-induced hyperprolactinemia in children and adolescents with mainly autism spectrum disorders. Prevalence, symptoms, clinical consequences and genetic risk factors. Supervisors: Prof.dr. P.N. van Harten / Prof.dr. J.K. Buitelaar (RUN); Co-Supervisor: Dr. A. Boot (UMCG).

Fleur Goezinne: Retinal detachment surgery: pre and postoperative prognostic factors. Supervisors: Prof.dr. F. Hendrikse / Prof.dr. C.A.B. Webers; Co-Supervisor: Dr. E.C. La Heij (Amsterdam).

Ralph L.J.G. Maassen: The Merits of Videolaryngoscopy during Glottic Visualisation for Endotracheal Intubation. Supervisors: Prof.dr. M. Marcus / Prof.dr. A. van Zundert (University of Queensland).

Maria J. de Sousa Guerreiro: The role of sensory modality in age-related distraction. Supervisor: Prof.dr. C.M. van Heugten; Co-Supervisor: Dr. P.W.M. van Gerven.

Ine Rayen: Effects of developmental fluoxetine exposure on neurobehavioral outcomes. Supervisor: Prof.dr. H.W.M. Steinbusch; Co-Supervisors: Dr. J.L. Pawluski / Dr. T.D. Charlier (Ohio University, USA).

Nynke M.G. Bodde: Psychogenic non-epileptic seizures; a separate disorder or part of a continuum? Supervisors: Prof.dr. R. van Oostenbrugge / Prof.dr. K. Vonck (UZ Gent); Co-Supervisors: Dr. R. Lazeron / Dr. A. de Louw (Epilepsiecentrum Kempenhaeghe, Heeze).

Alejandro M. Gomez: Novel strategies for making myasthenia less gravis: targeting plasma cells and the neuromuscular junction. Supervisor: Prof.dr. M.H. De Baets; Co-Supervisors: Dr. M. Losen / Dr. P. Martinez-Martinez.

Mohammad S. Rahnama'i: Prostaglandins and Phosphodiesterases in the Urinary Bladder Wall. Supervisors: Prof.dr. Ph. Van Kerrebroeck / Prof.dr. S. de Wachter (Universiteit Antwerpen); Co-Supervisor: Dr. G. van Koeveringe. 
Mariken B. de Koning: Studying biomarkers in populations at genetic and clinical high risk for psychosis. Supervisors: Prof.dr. T. Amelsvoort / Prof.dr. J. Booij (AMC). Fabien Boulle: Epigenetic regulation of BDNF/TrkB signaling in the pathophysiology and treatment of mood disorders. Supervisors: Prof.dr. H.W.M. Steinbusch / Prof. dr. L. Lanfumey (Universiteit Parijs); Co-Supervisors: Dr. D. van den Hove / Dr. G. Kenis.

\section{4}

Iris Nowak-Maes: Tinnitus; assessment of quality of life \& cost-effectiveness. Supervisors: Prof.dr. M. Peters / Prof.dr. B. Kremer; Co-Supervisors: Dr. M. Joore / Dr. L. Anteunis.

Marjolein Huijts: Cognitive function in patients with cerebral small vessel disease. Supervisor: Prof.dr. R.J. van Oostenbrugge; Co-Supervisors: Dr. A.A. Duits / Dr. J. Staals.

Markus Gantert: Fetal inflammatory injury as origin of long term disease: Lessons from animal models. Supervisors: Prof.dr. B. Kramer / Prof.dr. L. Zimmermann; CoSupervisor: Dr. A. Gavilanes.

Elke Kuypers: Fetal development after antenatal exposures: Chorioamnionitis and maternal glucocorticoids. Supervisors: Prof.dr. B.W. Kramer / Prof.dr. H.W. Steinbusch / Prof.dr. Suhas G. Kallapur (University of Cincinnati, Ohio, USA).

Pieter Kubben: Ultra low-field strength intraoperative MRI for Glioblastoma Surgery. Supervisor: Prof.dr. J.J. van Overbeeke; Co-Supervisor: Dr. H. van Santbrink.

Laura Baijens: Surface electrical stimulation of the neck for oropharyngeal dysphagia in Parkinson's disease: therapeutic aspects and reliability of measurement. Supervisor: Prof.dr. B. Kremer; Co-Supervisor: Dr. R. Speyer, Townsville.

Janneke Hoeijmakers: Small fiber neuropathy and sodium channels; a paradigm shift. Supervisor: Prof.dr. R.J. van Oostenbrugge; Co-Supervisors: Dr. C.G. Faber / Dr. I.S.J. Merkies.

Stephanie Vos: The Role of biomarkers in preclinical and prodromal Alzheimer's disease. Supervisor: Prof.dr. F.R. Verhey; Co-Supervisor: Dr. P.J. Visser.

Muriël Doors: The Value of Optical Coherence Tomography in Anterior Segment Surgery. Supervisors: Prof.dr. R.M. Nuijts / Prof.dr. C.A. Webers; Co-Supervisor: Dr. T.T.J.M. Berendschot.

Anneke Maas: Sleep problems in individuals with genetic disorders associated with intellectual disability. Supervisors: Prof.dr. I. Curfs / Prof.dr. R. Didden. 
Sebastiaan van Gorp: Translational research on spinal cord injury and cell-based therapies; a focus on pain and sensorimotor disturbances. Supervisors: Prof.dr. B. Joosten / Prof.dr. M. van Kleef; Co-Supervisors: Dr. J. Patijn /Dr. R. Deumens, KU Leuven.

Andrea Sannia: High risk newborns and brain biochemical monitoring. Supervisor: Prof.dr. J.S.H. Vles; Co-Supervisors: Dr. D. Gazzolo, Alessandria, Italy / Dr. A.W.D. Gavilanes.

Julie A.D.A. Dela Cruz: Dopamine mechanisms in learning and memory: Evidence from rodent studies. Supervisors: Prof.dr. H.W.M. Steinbusch / Prof.dr. R.J. Bodnar, New York; Co-Supervisor: Dr. B.P.F. Rutten.

René Besseling: Brain wiring and neuronal dynamics; advances in MR imaging of focal epilepsy. Supervisors: Prof.dr. A.P. Aldenkamp / Prof.dr.ir. W.H. Backes; CoSupervisor: dr. J.F.A. Jansen.

Maria Quint-Fens: Long-term care after stroke; development and evaluation of a long-term intervention in primary care. Supervisors: Prof.dr. J.F.M. Metsemakers / Prof.dr. C.M. van Heugten / Prof.dr. M. Limburg, Almere; Co-Supervisor: dr. G.H.M.I. Beusmans.

Veronique Moulaert: Life after survival of a cardiac arrest; the heart of the matter. Supervisors: Prof.dr. J.A. Verbunt / Prof.dr. C.M. van Heugten / Prof.dr. D.T. Wade, Oxford, UK.

Feikje Smeets: The hallucinatory-delusional state: a crucial connection in the psychosis symptom network. Supervisor: Prof.dr. J. van Os; Co-Supervisor: Dr. T. Lataster.

Lies Clerx: Alzheimer's disease through the MR-eye; novel diagnostic markers and the road to clinical implementation". Supervisor: Prof.dr. F. Verhey; CoSupervisors: Dr. P.J. Visser / P. Aalten.

Sonny Tan: The subthalamic nucleus in Parkinson's disease. Supervisors: Prof.dr. Y. Temel / Prof.dr. H.W.M. Steinbusch / Prof.dr. T. Sharp, Oxford, UK / Prof.dr. V. VisserVandewalle, Koln.

Koen van Boxem: The use of pulsed radiofrequency in the management of chronic Iumbosacral radicular pain. Supervisors: Prof.dr. M. van Kleef / Prof.dr. E.A.J. Joosten; Co-Supervisor: Assoc. Prof.dr. J. van Zundert.

Jérôme Waterval: Hyperostosis cranialis interna. Supervisors: Prof.dr. J.J. Manni / Prof. dr. R.J. Stokroos.

Sylvie Kolfschoten-van der Kruijs: Psychogenic non-epileptic seizures; the identification of neurophysiological correlates. Supervisors: Prof.dr. A.P. Aldenkamp / Prof.dr. K.E.J. Vonck, Universiteit Gent; Co-Supervisors: Dr. J.F.A. Jansen / Dr. R.H.C. Lazeron, Kempenhaeghe. 
Wouter Pluijms: Spinal cord stimulation and pain relief in painful diabetic: polyneuropathy, a translational approach. Supervisors: Prof.dr. M. van Kleef / Prof.dr. E.A. Joosten; Co-supervisor: Dr. C.G. Faber.

Ron Handels: Health technology assessment of diagnostic strategies for Alzheimer's disease. Supervisors: Prof.dr. F.R.J. Verhey / Prof.dr. J.L. Severens (EUR); Co-Supervisor: Dr. M.A. Joore / Dr. C.A.G. Wolfs.

Evelyn Peelen: Regulatory T cells in the pathogenesis of Multiple Sclerosis: potential targets for vitamin D therapy. Supervisors: Prof.dr. R.M.M. Hupperts / Prof.dr. J.W. Cohen Tervaert; Co-Supervisor: Dr. J.G.M.C. Damoiseaux / Dr. M.M.G.L.Thewissen, Diepenbeek.

Reint Jellema: Cell-based therapy for hypoxic-ischemic injury in the preterm brain.

Supervisors: Prof.dr. B.W.W. Kramer / Prof.dr. H.W.M. Steinbusch; Co-Supervisor: Dr.

W.T.V. Germeraad / Dr. P. Andriessen, Veldhoven.

Maria Wertli: Prognosis of Chronic Clinical Pain Conditions: The Example of Complex

Regional Pain Syndrome 1 and Low Back Pain. Supervisors: Prof.dr. M. van Kleef;

Co-Supervisor: Dr. F. Brunner, Zürich / Dr. R. Perez, VUmc.

Dagmar Zeef: An experimental model of Huntington's disease: Validation \&

Stimulation. Supervisors: Prof.dr. Y. Temel / Prof.dr. H.W.M. Steinbusch; Cosupervisor: Dr. A. Jahanshahi.

Jeroen Decoster: Breaking Down Schizophrenia into phenes, genes and

environment. Supervisors: Prof.dr. I. Myin-Germeys / Prof.dr. M. De Hert, KU Leuven; Co-Supervisor: Dr. R. van Winkel.

Eaja Anindya Sekhar Mukherjee: Fetal Alcohol Spectrum Disorders: exploring prevention and management. Supervisor: Prof.dr. L.M.G. Curfs; Co-Supervisor: Prof. S. Hollins, St. George's University of London, UK.

Catherine van Zelst: Inside out; On stereotype awareness, childhood trauma and stigma in psychosis. Supervisors: Prof.dr. Ph. Delespaul / Prof.dr. J. van Os.

Ibrahim Tolga Binbay: Extended Psychosis Phenotype in the Wider Social Environment. Supervisor: Prof.dr. J. van Os; Co-Supervisor: Dr. M. Drukker.

Frank Van Dael: OCD matters in psychosis. Supervisors: Prof.dr. J. van Os / Prof.dr. I. Myin-Germeys.

Pamela Kleikers: NOXious oxidative stress: from head toe too and back. Supervisors: Prof.dr. H.H.H.W. Schmidt / Prof.dr. H.W.M. Steinbusch; Co-Supervisor: Dr. B. Janssen. José Luis Gerardo Nava: In vitro assay systems in the development of therapeutic interventions strategies for neuroprotection and repair. Supervisors: Prof. dr.med. J. Weis / Prof.dr. H.W.M. Steinbusch; Co-Supervisor: Dr. G.A. Brook, RWTH Aachen. 
Eva Bollen: Cyclic nucleotide signaling and plasticity. Supervisors: Prof.dr. H.W.M. Steinbusch / Prof.dr. R. D'Hooge, KU Leuven; Co-Supervisor: Dr. J. Prickaerts.

\section{5}

Jessica A. Hartmann: A good laugh and a long sleep; Insights from prospective and ambulatory assessments about the importance of positive affect and sleep in mental health. Supervisor: Prof.dr. J. van Os; Co-Supervisors: C.J.P. Simons / Dr. M. Wichers.

Bart Ament: Frailty in old age; conceptualization and care innovations. Supervisors: Prof.dr. G.I.J.M. Kempen / Prof.dr. F.R.J. Verhey; Co-Supervisor: Dr. M.E. de Vugt.

Mayke Janssens: Exploring course and outcome across the psychosis-continuum.

Supervisor: Prof.dr. I. Myin-Germeys; Co-Supervisor: Dr. T. Lataster.

Dennis M.J. Hernau: Dopayours is not dopamine: genetic, environmental and pathological variations in dopaminergic stress processing. Supervisor: Prof.dr. I. Myin-Germeys; Co-Supervisors: Prof.dr. F.M. Mottaghy / Dr. D. Collip.

Ingrid M.H. Brands: The adaptation process after acquired brain injury Pieces of the puzzle. Supervisors: Prof.dr. C.M. van Heugten / Prof.dr. D.T. Wade, Oxford UK; CoSupervisors: Dr. S.Z. Stapert / Dr. S. Köhler.

Francesco Risso: Urinary and salivary S100B monitoring in high risk infants. Supervisor: Prof.dr. J.S.H. Vles; Co-Supervisors: Dr. D. Gazzolo, Genoa,Italy / Dr. A.W.D. Gavilanes.

Alessandro Borghesi: Stem and Progenitor Cells in Preterm Infants: Role in the Pathogenesis and Potential for Therapy. Supervisor: Prof.dr. L. Zimmermann; Prof.dr. B. Kramer; Co-Supervisors: Dr. D. Gazzolo, Genoa,Italy / Dr. A.W.D. Gavilanes. Claudia Menne-Lothmann: Affect dynamics; A focus on genes, stress, and an opportunity for change. Supervisor: Prof.dr. J. van Os; Co-Supervisors: Dr. M. Wichers / Dr. N. Jacobs.

Martine van Nierop: Surviving childhood new perspectives on the link between childhood trauma and psychosis. Supervisors: Prof.dr. I. Myin-Germeys / Prof.dr. J. van Os; Co-Supervisor: Dr. R. van Winkel.

Sylvia Klinkenberg: VNS in children; more than just seizure reduction. Supervisors: Prof.dr. J. Vles / Prof.dr. A. Aldenkamp; Co-Supervisor: Dr. H. Majoie.

Anouk Linssen: Considerations in designing an adult hearing screening programme.

Supervisor: Prof.dr. B. Kremer; Co-Supervisors: Dr. L. Anteunis / Dr. M. Joore.

Janny Hof: Hearing loss in young children; challenges in assessment and intervention. Supervisors: Prof.dr. B. Kremer / Prof.dr. R. Stokroos / Prof.dr. P. van Dijk, RUG; Co-Supervisor: Dr. L. Antheunis. 
Kimberly Cox-Limpens: Mechanisms of endogenous brain protection; Clues from the transcriptome. Supervisors: Prof.dr. J. Vles / Prof.dr. L. Zimmermann; CoSupervisor: Dr. A. Gavilanes.

Els Vanhoutte: Peripheral Neuropathy outcome measures; Standardisation (PeriNomS) study part 2: Getting consensus. Supervisors: Prof.dr. C. Faber / Prof. dr. P. van Doorn; Co-Supervisor: Dr. I. Merkies, Spaarne ziekenhuis Hoofddorp.

Mayienne Bakkers: Small fibers, big troubles; diagnosis and implications of small

fiber neuropathy. Supervisors: Prof.dr. C. Faber / Prof.dr. M. de Baets; Co-Supervisor:

Dr. I. Merkies, Spaarne ziekenhuis Hoofddorp.

Ingrid Kramer: Zooming into the micro-level of experience: An approach for understanding and treating psychopathology. Supervisor: Prof.dr. J. van Os; CoSupervisors: Dr. M. Wichers, UMC Groningen / Dr. C. Simons.

Esther Bouman: Risks and Benefits of Regional Anesthesia in the Perioperative Setting. Supervisors: Prof.dr. M. van Kleef / Prof.dr. M. Marcus, HMC, Qatar / Prof.dr. E. Joosten; Co-Supervisor: Dr. H. Gramke.

Mark Janssen: Selective stimulation of the subthalamic nucleus in Parkinson's disease; dream or near future. Supervisors: Prof.dr. Y. Temel / Prof.dr. V. VisserVandewalle, Keulen / Prof.dr. A. Benazzouz, Bordeax, France.

Reina de Kinderen:Health Technology Assessment in Epilepsy; economic evaluations and preference studies. Supervisors: Prof.dr. S. Evers / Prof.dr. A. Aldenkamp; CoSupervisor: Dr. H. Majoie / Dr. D. Postulart, GGZ O-Brabant.

Saskia Ebus: Interictal epileptiform activity as a marker for clinical outcome.

Supervisors: Prof.dr. A. Aldenkamp / Prof.dr. J. Arends, TUE / Prof.dr. P. Boon, Universiteit Gent, België.

Inge Knuts: Experimental and clinical studies into determinants of panic severity.

Supervisor: Prof.dr. I. Myin-Germeys; Co-Supervisor: Dr. K. Schruers; Influencing panic.

Nienke Tielemans: Proactive coping post stroke: The Restored4Stroke SelfManagement study. Supervisors: Prof.dr. C. van Heugten / Prof.dr. J. VisserMeily,UMC Utrecht; Co-Supervisor: Dr. V. Schepers, UMC Utrecht.

Tom van Zundert: Improvements Towards Safer Extraglottic Airway Devices. Supervisors: Prof.dr. A.E.M. Marcus / Prof.dr. W. Buhre / Prof.dr. J.R. Brimacombe, Queensland, Australia / Prof.dr. C.A. Hagberg.

Tijmen van Assen: Anterior Cutaneous Nerve Entrapment Syndrome Epidemiology and surgical management. Supervisors: Prof.dr. G.L. Beets / Prof.dr. M. van Kleef / Dr. R.M.H. Roumen / Dr. M.R.M. Scheltinga, MMC Veldhoven. 
Rohit Shetty: Understanding the Clinical, Immunological and Genetic Molecular Mechanisms of Keratoconus. Supervisors: Prof.dr. R.M.M.A. Nuijts / Prof.dr. C.A.B. Webers.

Christine van der Leeuw: Blood, bones and brains; peripheral biological endophenotypes and their structural cerebral correlates in psychotic disorder. Supervisor: Prof.dr. J. van Os; Co-supervisor: Dr. M. Marcelis.

Sanne Peeters: The Idle Mind Never Rests; functional brain connectivity across the psychosis continuum. Supervisor: Prof.dr. J. van Os; Co-supervisor: dr. M. Marcelis.

Nick van Goethem: a7 nicotinic acetylcholine receptors and memory processes: mechanistic and behavioral studies. Supervisor: Prof.dr. H.W.M. Steinbusch; Cosupervisor: Dr. J. Prickaerts.

Nicole Leibold: A Breath of fear; a translational approach into the mechanisms of panic. Supervisor: Prof.dr. H.W.M. Steinbusch; Co-supervisors: Dr. K.R.J. Schruers / Dr. D.L.A. van den Hove.

Renske Hamel: The course of mild cognitive impairment and the role of comorbidity. Supervisor: Prof.dr. F.R.J. Verhey; Co-supervisors: Dr. I.H.G.B. Ramakers / Dr. P.J. Visser. Lucia Speth: Effects of botulinum toxin A injections and bimanual task-oriented therapy on hand functions and bimanual activities in unilateral Cerebral Palsy. Supervisors: Prof.dr. J. Vles; Prof.dr. R. Smeets; Co-supervisor: Dr. Y. JanssenPotten, Adelante Hoensbroek.

Yuan Tian: The effects of Lutein on the inflammatory pathways in age-related macular degeneration (AMD). Supervisors: Prof.dr. C. Webers; Prof.dr. A. Kijlstra, WUR; Co-supervisor: Dr. M. Spreeuwenberg; Dr. H. Tange.

Peggy Spauwen: Cognition and Type 2 diabetes; the interplay of risk factors. Supervisors: Prof.dr. F. Verhey; Prof.dr. C. Stehouwer; Co-supervisor: Dr. M. van Boxtel Marc Hilhorst: Crescentic glomerulonephritis in ANCA associated vasculitis. Supervisors: Prof.dr. J. Cohen-Tervaert; Co-supervisor: Dr. P. van Paassen

Martin Gevonden: The odd one out: exploring the nature of the association between minority status and psychosis. Supervisors: Prof.dr. J-P. Selten; Prof.dr. J. Booij, Uva; Prof.dr. I. Myin-Germeys

Bart Biallosterski: Structural and functional aspects of sensory-motor Interaction in the urinary bladder. Supervisors: Prof.dr. Ph. Van Kerrebroeck; Prof.dr. S. De Wachter, UvAntwerpen; Co-supervisors: Dr. G. van Koeveringe; Dr. M. Rahnama'i.

Alexandra König: The use of information and communication technologies (ICT) for the assessment of patients with Alzheimer's Disease and related disorders. Supervisors: prof.dr. F. Verhey; prof.dr. Ph. Robert, Nice, Fr; Co-supervisors: dr. P. Aalten; dr. R. David, Nice. Fr. 
Michelene Chenault: Assessing Readiness for Hearing Rehabilitation. Supervisors: prof.dr. M.P.F. Berger; prof.dr. B. Kremer; Co-supervisor: dr. L.J.C. Anteunis.

Anand Vinekar: Retinopathy of Prematurity. Recent advances in tele-medicine screening, risk factors and spectral domain optical coherence tomography imaging. Supervisor: prof.dr. C.A.B. Webers; Co-supervisor: dr. N.J. Bauer

Fleur van Dooren: Diabetes and Depression: exploring the Interface between Pathophysiological and Psychological factors. Supervisors: prof.dr. F.R.J. Verhey; prof.dr. J.K.L. Denollet, UvT; prof.dr. F. Pouwer, UvT; Co-supervisor: dr. M.T. Schram. Gabriëlla Pons van Dijk: Taekwondo and physical fitness components in middleaged healthy volunteers; the Sekwondo study. Supervisors: prof.dr. J. Lodder; prof.dr. H. Kingma; Co-supervisor: dr. A.F. Lenssen.

Yara Pujol López: Development and psychoneuroimmunological mechanisms in depression. Supervisor: prof.dr. H.W.M. Steinbusch; Co-supervisors: Dr. G. Kenis; Dr. D. van den Hove; Dr. Aye Mu Myint, München.

Romina Gentier: $\mathrm{UBB}^{+1}$; an important switch in the onset of Alzheimer's disease.

Supervisors: Prof. H. Steinbusch; Prof. D. Hopkins; Co-supervisor: Dr. F. van Leeuwen. Sanne Smeets: Insights into insight: studies on awareness of deficits after acquired brain injury. Supervisor: Prof. C. van Heugten; Prof. R. Ponds; Co-supervisor: Dr. I. Winkens

Kim Beerhorst: Bone disease in chronic epilepsy: fit for a fracture. Supervisor: Prof. A. Aldenkamp; Prof. R. van Oostenbrugge; Co-supervisor: Dr. P. Verschuure.

Alex Zwanenburg: Cerebral and cardiac signal monitoring in fetal sheep with hypoxic-ischemic encephalopathy. Supervisor: Prof. T. Delhaas; Prof. B. Kramer; Co-supervisors: Dr. T. Wolfs; Dr. P. Andriessen, MMC.

Ismail Sinan Guloksuz: Biological mechanisms of environmental stressors in psychiatry. Supervisor: Prof. J. van Os; Co-supervisors: Dr. B. Rutten; Dr. M. Drukker. Seyed Ehsan Pishva MD: Environmental Epigenetics in mental health and illness. Supervisor: Prof.dr. J. van Os; Co-supervisors: Dr. B.P.F. Rutten; Dr. G. Kenis.

Ankie Hamaekers: Rescue ventilation using expiratory ventilation assistance; innovating while clutching at straws. Supervisors: Prof.dr. W.F. Buhre; Prof.dr. M. van Kleef.

Rens Evers. 22q11.2 deletion syndrome: intelligence, psychopathology and neurochemistry at adult age. Supervisors: Prof.dr. L.M.G. Curfs; Prof.dr. T. v. Amelsvoort.

Sarah-Anna Hescham. Novel insights towards memory restoration. Supervisor: Prof. dr. Y. Temel; Co-supervisor: Dr. A. Blokland; Dr. A. Jahanshahi. 
João P. da Costa Alvares Viegas Nunes. Insulin receptor sensitization improves affective pathology in various mouse models. Supervisor: Prof.dr. H.W.M. Steinbusch; Co-supervisors: Dr. K-P. Lesch; Dr. T. Strekalova; Dr.B.H. Cline, Oxford. Yanny Ying-Yee Cheng. Clinical Outcomes After Innovative Lamellar Corneal Transplantation Surgery. Supervisor: Prof.dr. R.M.M.A. Nuijts; Co-supervisor: Dr. J.S.A.G. Schouten.

\section{6}

Oliver Gerlach. Parkinson's disease, deterioration during hospitalization. Supervisor: Prof.dr. R. van Oostenbrugge; Co-supervisor: Dr. W. Weber.

Remo Arts. Intracochlear electrical stimulation to suppress tinnitus. Supervisor: Prof.dr. R.J. Stokroos; Co-supervisor: Dr. E.L.J. Georg.

Mitchel van Eeden. The $\boldsymbol{\epsilon}$ - Restore4stroke study: Economic evaluation of stroke care in the Netherlands. Supervisors: Prof.dr.mr. S.M.A.A. Evers; Prof.dr. C.M. v. Heugten; Co-supervisor: dr. G.A.P. van Mastrigt.

Pim Klarenbeek. Blood pressure and cerebral small vessel disease. Supervisor: Prof. dr. R.J. van Oostenbrugge; Co-supervisor: Dr. J. Staals.

Ramona Hohnen. Peripheral pharmacological targets to modify bladder contractility. Supervisor: Prof.dr. Ph.E.V. van Kerrebroeck; Co-supervisors: Dr. G.A. van Koeveringe; Dr. M.A. Sahnama'i; Dr. C. Meriaux.

Ersoy Kocabicak. Deep brain stimulation of the subthalamic nucleus: Clinical and scientific aspects. Supervisors: Prof.dr. Y. Temel; Prof.dr. K. van Overbeeke;Cosupervisor: Dr. A. Jahanshahi.

Sven Akkerman. Temporal aspects of cyclic messenger signaling in object recognition memory; a pharmalogical approach. Supervisor: Prof.dr. H.W.M. Steinbusch; Co-supervisors: dr. J. Prickaerts; dr. A. Blokland.

Anja Moonen. Emotion and Cognition in Parkinson's disease; etiology and neurobiological mechanisms. Supervisor: Prof.dr. F.R.J. Verhey; Co-supervisor: dr. A.F.G. Leentjens.

Anna Schüth. Three-dimensional bladder tissue morphology. Supervisors: Prof.dr. G.A. van Koeveringe; Prof.dr. M. v. Zandvoort, Aachen; Prof.dr. Ph. V. Kerrebroeck.

Elisabeth van der Ven. Ethnic minority position as risk indicator for autism-Spectrum and psychotic disorders. Supervisors: Prof.dr. J.P. Selten; Prof.dr. J. van Os.

Zuzana Kasanova. Environmental reactivity for better or worse; The impact of stress and reward on neurochemistry, affect and behavior across the psychosis continuum.Supervisor: Prof.dr. I. Myin-Germeys, KU Leuven/UM; Co-supervisor: dr. D. Collip. 
Danielle Lambrechts. Ketogenic diet therapies; treatment for children and adults with refractory epilepsy. Supervisors: Prof.dr. H.J.M. Majoie; Prof.dr. J.S.H. Vles;Prof. dr. A.P. Aldenkamp; Co-supervisor: dr. A.J.A. de Louw, Kempenhaghe, Heeze.

Frank van Bussel. Advanced MRI in diabetes; cerebral biomarkers of cognitive decrements. Supervisors: Prof.dr.ir. W.H. Backes; Prof.dr. P.A.M. Hofman;Cosupervisor: dr. J.F.A. Jansen.

Lisa Schönfeldt. Neurostimulation to treat brain injury? Supervisors: Prof.dr. Y. Temel; Prof.dr. S. Hendrikx, Hasselt; Co-supervisor: dr. A. Jahanshahi.

Rianne Geerlings. Transition in patients with childhood-onset epilepsy; a long way to adulthood. Supervisor: Prof.dr. A.P. Aldenkamp; Co-supervisors:dr. A.J.A. de Louw, dr. L.M.C. Gottmer, Kempenhaeghe.

Nele Claes. B cells as multifactorial players in multiple sclerosis pathogenesis: insights from therapeutics. Supervisors: Prof.dr. V. Somers, Hasselt; Prof.dr. R. HuppertsCo-supervisors: Prof.dr. P. Stinissen, dr. J. Fraussen, Hasselt.

Olaf Schijns. Epilepsy surgery and biomarkers from history to molecular imaging.

Supervisors: Prof.dr. J.J. van Overbeeke; Prof.dr. H. Clustermann, Aachen; Cosupervisors: dr. G. Hoogland; dr. M.J.P. v. Kroonenburgh.

Lizzy Boots. Balanced and Prepared; development and evaluation of a supportive e-health intervention for caregivers of people with early-stage dementia. Supervisors: Prof.dr. F.R.J. Verhey; Prof.dr. G.I.J.M. Kempen; Co-supervisor: dr. M.E. de Vugt.

Wouter Donders. Towards patient-specific (cerebro-) vascular model applications.

Supervisors: Prof.dr. T. Delhaas; Prof.dr.ir. F.N. van de Vosse, TUE; Co-supervisor: dr.ir. W. Huberts.

Sizzle Vanterpool. The implications of intrauterine invasion by microbes for placental

Pathology and the occurrence of adverse pregnancy outcomes. Supervisor:

Prof.dr. B.W. Kramer. Co-supervisors: dr. J.V. Been, Erasmus MC Rotterdam, dr. U von Rango.

Manuela Heins. The Relationship between Social Adversity, Psychosis, and Depression across an Individual's Life Span. Supervisor: Prof.dr. I. Myin-Germeys. Christianus van Ganzewinkel. NEONATAL PAIN; Out of Sight, Out of Mind? Supervisor:

Prof.dr. B.W.W. Kramer; Co-supervisor: dr. P. Andriessen, MMC Veldhoven.

Anne-Hilde Muris. Hype or hope? Vitamin D in multiple sclerosis; A clinical and immunological perspective. Supervisor: Prof.dr. R.M.M. Hupperts; Co-supervisor: dr. J.G.M.C. Damoiseaux.

Gerard Bode. The link between ceramide transporters, innate Immunity and Alzheimer's disease. Supervisor: Prof.dr. M.H.V. de Baets; Co-supervisors: dr. P. Martinez, dr. M. Losen. 
Jo Stevens. Advanced diagnostics and therapeutics for Alzheimer's disease. Supervisor: Prof.dr. M. de Baets; Co-supervisors: dr. M. Losen, dr. P. MartinezMartinez.

Rosan Luijcks. Stress and pain in muscles and brain; developing psychophysiological paradigms to examine stress and pain interactions. Supervisors: Prof.dr. J.J. van Os; Prof.dr.ir. H.J. Hermens, UT; Co-supervisor: dr. R. Lousberg.

M.C. Haanschoten. Towards efficient cardiac surgery - the integrating role of anesthesiology and intensive care. Supervisors: Prof. dr. W. Buhre; Prof. dr. A. van Zundert (Queensland); Co-supervisors: Dr. M.A. Soliman Hamad; Dr. A. van Straten (Catharina zkhs.)

Harmen Jan van de Haar. Microvascular and blood-brain barrier dysfunction in Alzheimer's disease. Supervisor: Prof.dr.ir. W. Backes; Prof.dr. F. Verhey; Cosupervisor: Dr. J. Jansen; Dr.ir. M. v. Osch, LUMC.

Coenraad Itz. Chronic low back pain, considerations about: Natural Course, Diagnosis, Interventional Treatment and Costs. Supervisor: Prof.dr. M. van Kleef; Prof.dr. F. Huygen, EUR; Co-supervisor: Dr. B. Ramaekers.

Willemijn Jansen. The Path of Alzheimer's disease: from neuropathology to clinic. Supervisor: Prof.dr. F. Verhey; Co-supervisors: Dr. P.J. Visser; Dr. I. Ramakers.

Ligia dos Santos Mendes Lemes Soares. Phosphodiesterase inhibitors: a potential therapeutic approach for ischemic cerebral injury. Supervisor: Prof.dr. H.W.M. Steinbusch; Co-supervisors: Dr. R.M. Weffort de Oliveira, Brazil; Dr. J. Prickaerts

Martijn Broen. Anxiety and depression in Parkinson's disease. Supervisor: Prof.dr. R.J. van Oostenbrugge; Co-supervisors: Dr. A.F.G. Leentjens; Dr. M.L. Kuijf.

Sandra Schipper. Extrasynaptic receptors as a treatment target in epilepsy. Supervisor: Prof.dr. J.H.S. Vles; Co-supervisors: Dr. G. Hoogland; Dr. S. Klinkenberg; Dr. M.W. Aalbers, RUG.

João Casaca Carreira. Making sense of Antisense Oligonucleotides Therapy in Experimental Huntington's disease. Supervisor: Prof.dr. Y. Temel; Co-supervisors: Dr. A. Jahanshahi; Dr. W. van Roon-Mom, LUMC.

Dominique IJff. Trick or Treat? Cognitive side-effects of antiepileptic treatment. Supervisors: Prof.dr. A.P. Aldenkamp; Prof.dr. M. Majoie; Co-supervisors: Dr. J. Jansen; Dr. R. Lazeron, Kempenhaeghe.

Alfredo Ramirez. Neurogenetic approach in neurodegenerative disorders.

Supervisors: Prof.dr. B.P.F. Rutten; Prof.dr. H.W.M. Steinbusch; Prof.dr. M.M. Nöthen, University of Bonn.

Nienke Visser. Toric Intraocular lenses in cataract surgery. Supervisor: Prof.dr. R.M.M.A. Nuijts; Co-supervisor: Dr. N.J.C. Bauer. 
Jakob Burgstaller. Prognostic indicators for patients with degenerative lumbar spinal stenosis. Supervisor: Prof.dr. M. van Kleef; Co-supervisors: Dr. M.M. Wertli, University of Zurich; Dr. H.F. Gramke.

Mark van den Hurk. Neuronal Identity and Maturation: Insights from the Single-Cell Transcriptome. Supervisors: Prof.dr. H.W.M. Steinbusch; Prof.dr. B.P.F. Rutten; Cosupervisors: Dr. G. Kenis; Dr. C. Bardy, Adelaide.

Maria Nikiforou. Prenatal stress and the fetal gut. Potential interventions to prevent adverse outcomes. Supervisors: Prof.dr. B.W. Kramer; Prof.dr. H.W. Steinbusch; Cosupervisor: Dr. T.G. Wolfs.

Janneke Peijnenborgh. Assessment of cognition, time perception, and motivation in children. Supervisors: Prof.dr. J.S.H. Vles; Prof.dr. A.P. Aldenkamp; Co-supervisors: Dr. J. Hendriksen; Dr. P. Hurks.

Joany Millenaar. Young onset dementia; towards a better understanding of care needs and experiences. Supervisors: Prof.dr. F. Verhey; Prof.dr. R. Koopmans, RUN; Co-supervisors: Dr. M. de Vugt; Dr. C. Bakker, RUN.

\section{7}

Adriana Smits. Perinatal factors and hearing outcome. Supervisors: Prof.dr. R.J. Stokroos; Prof.dr. B.W. Kramer; Prof.dr. B. Kremer.

Angela Bouwmans. Transcranial sonography in parkinsonian disorders: clear window or blurred vision. Supervisor: Prof.dr. W.H. Mess; Co-promotores: Dr. W.E.J. Weber; Dr. A.F.G. Leentjens.

Björn K. Stessel. Patient centred care after day surgery: scope for improvement. Supervisors: Prof.dr. W. Buhre; Prof.dr. B. Joosten. Co-supervisor: Dr. A.H. Gramke. Jan Guy Bogaarts. Quantitative EEG and machine learning methods for the detection of epileptic seizures and cerebral asymmetry. Supervisor: Prof.dr. W.M. Mess; Cosupervisor: Dr.ir. J.P.H. Reulen; Dr.ir. E.D. Gommer.

Martin M. Müller. Pregnancy derived products for treatment of perinatal brain injuries. Supervisors:Prof.dr. B.W.W. Kramer; Prof.dr. D. Surbek, Bern; Co-supervisors: Dr. T. Wolfs; Dr. G. Gavilanes.

Daan Ophelders. Novel treatment strategies for the protection of the preterm brain; Re-balancing inflammation and regeneration. Supervisor: Prof.dr. B. Kramer; Cosupervisor: Dr. T. Wolfs; Dr. R. Jellema.

Rosalie van Knippenberg. Experience sampling in dementia care; an innovative intervention to support caregivers in daily life. Supervisors: Prof.dr. F. Verhey; Prof.dr. R. Ponds; Prof.dr. I. Myin-Germeys, KU Leuven; Co-supervisor: Dr. M. de Vugt. 
Claudia Vingerhoets. Investigating neurobiological mechanisms underlying comorbid cognitive symptoms in psychosis and substance use. Supervisors: Prof.dr. T. van Amelsvoort; Prof.dr. J. Booij, UvA; Co-supervisor: Dr. O. Bloemen

Dennis Oerlemans. Evolution of Neuromodulation for Lower Urinary Tract Dysfunction; Past, Present and Future. Supervisors: Prof.dr. Ph. van Kerrebroeck; Prof.dr. G. van Koeveringe. Co-supervisors: Dr. E. Weil; Dr. T. Marcelissen.

Marion Levy. Evaluation of BDNF/TrkB signaling as a common target in the treatment of major depression and Alzheimer's disease. Supervisors: Prof.dr. $\mathrm{H}$. Steinbusch; Prof. L. Lanfumey, Université Paris Descartes, France. Co-supervisors: Dr. G. Kenis; Dr. D. van den Hove.

Patrick Domen. Stay connected: a family-based diffusion imaging study in psychotic disorder. Supervisor: Prof.dr. J. van Os. Co-supervisor: Dr. M. Marcelis

Geor Bakker. Innovative Approaches to Understanding the Neurobiology of Psychosis. Supervisors: Prof.dr. T. van Amelsfoort; Prof.dr. J. Booij, UvA. Cosupervisor: dr. M. Caan, UvA; dr. O. Bloemen.

Wilma Boevink. HEE! Over Herstel, Empowerment en Ervaringsdeskundigheid in de psychiatrie. Supervisors: Prof.dr. J. van Os; Prof.dr. Ph. Delespaul. Co-supervisor: dr. H. Kroon.

Nataliia Markova. Modified swim test as a mouse depression paradigm of enhanced Cognitive processing: the role of GSK3 $\beta$. Supervisor: Prof.dr. H. Steinbusch; Prof. dr. K-P. Lesch, University of Wuerzburg. Co-supervisor: Dr. T. Strekalova.

Merijn van de Laar. Individual differences in insomnia; implications of Psychological factors for diagnosis and treatment. Supervisor: Prof.dr. A. Aldenkamp; Prof.dr. D. Pevernagie, Universiteit Gent. Co-supervisor: Dr. S. Overeem, TUE.

Willem Buskermolen. If only I could tell ...; Measuring predictors for challenging behaviour in people with both intellectual disability and hearing impairment. Supervisor: Prof.dr. A. Aldenkamp. Co-supervisor: Dr. J. Hoekman, UL.

Kay Deckers. The role of lifestyle factors in primary prevention of dementia; an epidemiological perspective. Supervisor: Prof.dr. F. Verhey. Co-supervisor: Dr. M. van Boxtel; Dr. S. Köhler.

Brechje Dandachi-FitzGerald. Symptom validity in clinical assessments. Supervisors: Prof.dr. R. Ponds; Prof.dr. F. Verhey.

Maurice Theunissen. Understanding factors affecting postoperative Quality of Life.

Supervisors: Prof.dr. M. Peters, Prof.dr. M. Marcus. Co-supervisor: Dr. H. Gramke.

Anna Cleutjens. COgnitive-Pulmonary Disease? Neuropsychological functioning in patients with COPD. Supervisors: Prof.dr. E. Wouters, Prof.dr. R. Ponds. Cosupervisors: Dr. D. Janssen, Horn, Dr. J. Dijkstra. 
Laura Serpero. Next Generaton Biomarkers in Perinatal Medicine: S100B Protein. Supervisors: Prof.dr. D. Gazzalo, Alessandria, Italy; Prof.dr. B..W.W. Kramer. Cosupervisor: Dr. A.W.D. Gavilanes.

Alessandro Varrica. S100B Protein and Congential Heart Diseases: Brain Aspects. Supervisors: Prof.dr. D. Gazzalo, Alessandria, Italy; Prof.dr. J.S.H. Vles; Prof.dr. L.J.I. Zimmermann. Co-supervisor: Dr. A.W.D. Gavilanes.

Pim R.A. Heckman. Targeting phosphodiesterase type 4 for improving cognitive fronto-striatal function: a translational approach. Supervisor: Prof.dr. J.G. Ramaekers. Co-supervisors: Dr. J.H.H.J.. Prickaerts; Dr. A. Blokland.

Sven van Poucke. Platelets, form sample to big data; exploring granularity in platelet research. Supervisors: Prof.dr. M.A.E. Marcus; Prof.dr. W. Buhre. Co-supervisor: Dr. M. Lancé.

Désirée M.J.Vrijens. Dysfunctions of the Lower Urinary Tract and Affective Symptoms. Supervisors: Prof.dr. Ph.E.V. van Kerrebroeck; Prof.dr. G.A. van Koeveringe. Cosupervisors: Dr. C. Leue.

Tamar van Veenendaal. Neurotransmitters \& Networks. An MR view on epilepsy and antiepileptic drugs. Supervisors: Prof.dr.ir. W.H. Backes; Prof.dr. A.P. Aldenkamp. Co-supervisor: Dr. J.F.A. Jansen.

Evelien M. Barendse. Autism Spectrum Disorders in High functioning Adolescents; Diagnostic considerations (AHA). Supervisors: Prof.dr. A.P. Aldenkamp; Prof.dr. R.P.C. Kessels, Radboud University.

Roy Lardenoije. A venture into the epigenetics of aging and Alzheimer's Disease.

Supervisors: Prof.dr. B.P.F. Rutten; Prof.dr. H.W.M. Steinbusch. Co-supervisors: Dr. D. van den Hove; Dr. C.A. Lemere, USA.

Charlotte L. Mentzel. The course recognition and treatment of movement disorders in severe mental illness. Supervisors: Prof.dr. P.N. van Harten; Prof.dr. M.A.J. de Koning-Tijssen, UMCG. Co-supervisor: Dr. P.R. Bakker.

Tim Batink. Third Wave Behaviour Therapy: Process Measures and Contextual Interventions. Supervisors: Prof.dr. F.P.M.L. Peeters; Prof.dr. J.J. van Os; Prof.dr. M.C. Wichers, UMC Groningen.

Kevin L.J. Rademakers. Detrusor Underactivity: From Theory To Clinical Assessment. Supervisors: Prof.dr. G.A. van Koeveringe; Prof.dr. Ph.E.V. van Kerrebroeck. Cosupervisor: Dr. M. Oelke.

Iris M.J. Lange. Should I stay or should I go ? Brain mechanisms underlying fear and safety learning, and explosure therapy outcome. Supervisors: Prof.dr. K.R.J. Schruers;Prof.dr. T.A.M.J. van Amelsfoort. Co-supervisor: Dr. L. Goossens. 
Ruben G.F. Hendriksen. Evidence for a dystrophin-associated encephalopathy in Duchenne Muscular Dystrophy. Supervisor: Prof.dr. J.S.H. Vles. Co-supervisors: Dr. G. Hoogland; Dr. M.W. Aalbers, UMC Groningen.

Michael Gofeld. Strengths and limitations of the lumbar spine ultrasound-guided interventions. Supervisor: Prof.dr. M. van Kleef. Co-supervisor: Dr. M. Sommer.

Willem A.R. Zwaans. Strategies for chronic inguinal pain. Supervisor: Prof.dr. M. van Kleef. Co-supervisors: Dr. R.H.M. Roumen; Dr. M.R.M. Scheltinga, MMC Veldhoven.

Linda M. Rolf. Mapping the effects of vitamin D in multiple sclerosis A 3D Perspective.

Supervisor: Prof.dr. R.M.M. Hupperts. Co-supervisors: Dr. J.G.M.C. Damoiseaux; Dr. J.J.F.M. Smolders, CWZ Nijmegen.

Maarten van Beek. Spinal Cord Stimulation in Clinical and Experimental Painful Diabetic Polyneuropathy. Supervisors: Prof.dr. E.A. Joosten; Prof.dr. M. van Kleef. Co-supervisor: Dr. S.M.J. van Kuijk.

Melina Barkhuizen. Genetic and perinatal risk factors for movement disorders. Supervisors: prof.dr. B.W.W. Kramer, prof.dr. H.W.M. Steinbusch, Prof.dr. A.F. Grobler. Co-supervisor: dr. A.W.D.Gavilanes-Jimenez.

Renske Uiterwijk. Cognitive function and cerebral small vessel disease in hypertension. Supervisor: prof.dr. R.J. van Oostenbrugge. Co-supervisor: Dr. J.E.A. Staals.

Elles Douven. Depression and apathy after stroke. Supervisor: prof.dr. F.R.J. Verhey. Co-supervisors: Dr. P. Aalten, dr. J. Staals.

Mauro Pessia. Brain K+ Channels: from molecular and physiological features to autism spectrum disorder and intellectual disability. Supervisors: prof.dr. H.W.M. Steinbusch, prof.dr. M.B. Donati, It.

Carsten Leue. Hyperarousal in the Hospital and what to do about it: the MEDPSYCH-NET - a transitional network approach fostering personalized care in psychosomatic medicine. Supervisors: Prof.dr. J. van Os, Prof.dr. A. Masclee. Cosupervisors: Dr. J. Strik, Dr. J. Kruimel

Andrea S. Herrera Soto. Aminochrome, an endotoxin for inducing a new rat model of Parkinson's Disease. Supervisor: prof.dr. H.W.M. Steinbusch. Co-supervisors: Prof. dr. Juan Segura-Aquilar; prof. G. Diaz-Veliz, Santiago of Chile

Eline E.B. de Clerck. Ocular neurodegenerative changes and macular cysts in prediabetes and type 2 diabetes. Supervisors: Prof.dr. C.A.B. Webers, Prof.dr. C.D.A. Stehouwer. Co-supervisor: Dr. J.S.A.G. Schouten

Steven T.H. Honings. Exploring psychosis and multidirectional violence: a prospective study in the general population. Supervisor: Prof.dr. J. van Os. Cosupervisor: Dr. M. Drukker 


\section{DANKWOORD}

Na ruim 4 jaar met veel plezier aan dit proefschrift gewerkt te hebben en een berg aan ervaring rijker is het eindresultaat daar. Ook al staat mijn naam op de kaft heb ik dit niet alleen gedaan en wil ik bij deze graag een aantal mensen bedanken.

Allereest mijn promotieteam bestaande uit Prof. dr. Verhey, dr. Pieter Jelle Visser, en dr. Inez Ramakers.

Beste Frans, je liet me altijd weer nadenken over de klinische relevantie van mijn artikelen. Je hebt een lading aan klinische ervaring waar ik veel profijt van heb gehad. Bedankt dat je me de kans hebt gegeven om te promoveren op deze afdeling.

Beste Pieter Jelle, PJ, ondanks je vele promovendi en dat je maar één dag in de week in Maastricht bent is het verbazingwekkend dat je toch altijd tijd voor mij vrij hebt kunnen maken. Ik waardeer jouw altijd kritische blik en dankzij jou ben ik enorm gegroeid als wetenschapper. Ook mede door jou heb ik veel mensen leren kennen in ons vakgebied zowel nationaal als internationaal. Bedankt voor alles!

Beste Inez, jouw input op artikelen heb ik erg gewaardeerd. Ook kon ik altijd bij jou langs voor input bij onderzoekspatiënten. Je bent altijd erg betrokken gebleven ondanks dat je ook parttime in Aachen werkt. Bedankt!

All members of the reading committee: Prof. dr. Rudolf Ponds, Dr. Jurgen Claassen, Prof. dr. Caroline van Heugten, Prof. dr. Eric Salmon and Dr. leke Winkens, and also additional members of the corona thank you for taking the time to read and judge this dissertation.

Alle patiënten en mantelzorgers wil ik graag bedanken voor het meedoen aan het onderzoek. Door jullie verhalen wist ik altijd weer waar we het uiteindelijk voor doen. Ook wil ik graag Carla en Tanja bedanken. Het was prettig om met jullie samen te werken bij de begeleiding van de lumbaal puncties. Daarnaast wil ik graag alle stagiaires bedanken die zich voor onze studies hebben ingezet en die ik de afgelopen jaren heb begeleidt. Graag bedank ik ook Claudia Bosma en alle andere medewerkers van de biobank in Maastricht. Jullie hebben mij goed op weg geholpen en waren altijd bereid om mee te denken.

Many thank to my colleagues of the BIOMARKAPD project. Thank you for your pleasant collaboration. IBBL, in particular Nicolai Goncharencko en Fay Betsou, thank you for your collaboration and setting up the infrastructure for the biobanks and the storage of samples. It was a pleasure working together. 
I would like to thank all the co-authors and centres for their collaboration, and their contribution and thoughtful comments improving the quality of this dissertation.

Graag wil ik ook alle mijn (oud)-collega's van de afdeling Psychiatrie en Neuropsychologie bedanken voor al jullie hulp en de goede sfeer op de afdeling.

Mijn super paranimfen, Willemijn en Isabelle, met jullie aan mijn zijde gaat het zeker goedkomen. Willemijn, wat kan ik met je lachen en ik waardeer je altijd ontspannen houding en positieve instelling. Ik hoop dat onze wegen blijven kruisen. Laten we contact houden! Isabelle, het is altijd gezellig met jou. En met jou konden we op elk AAIC congres de weg wel vinden. Fijn dat ook jij nu weer naast me staat!

Mijn (ex-)kamergenoten Syenna, Kay, Inge, Elles en Lotte, bedankt voor alle steun en gezelligheid. Wat heb ik met jullie kunnen lachen! Ook Whitney en Alieske bedankt voor alle gezellige bij-klets momenten. Succes met het afronden van jullie proefschrift! Stephanie, bedankt voor al je input op onze papers. Het was een plezier om met je samen te mogen werken. Ook wil ik graag Nico, Astrid, Danielle en Els bedanken voor al jullie ondersteuning.

Lieve familie, schoonfamilie en vrienden bedankt voor alle steun bij het afronden van dit proefschrift. In het bijzonder, bedankt mam en pap. Jullie staan werkelijk altijd dag en nacht voor ons klaar. Bedankt voor jullie onvoorwaardelijke steun, liefde en vertrouwen tijdens mijn hele leven! Jullie zijn een geweldige opa en oma en ik hoop mijn eigen kindjes hetzelfde mee te kunnen geven.

Lieve Stefan, bedankt voor je geloof en vertrouwen in mij en dat je er altijd voor me bent. Wat hebben we al veel samen beleefd, een mooi thuis gecreëerd en ook mooie reizen gemaakt. Ik ken je nu inmiddels al weer bijna 13 jaar. Je bent mijn maatje, een geweldige papa en ik hou zielsveel van jou. Het is nu al volop genieten. Ik kijk uit naar alle drukke gezelligheid die ons nog te wachten staat!

En dan nu het állerbelangrijkste persoontje in mijn leven. Lieve Belle, kleine Isabelle, ons al zo gróte kleine meisje. Wat heb je ons leven veranderd en veel gezelligheid, chaos en momenten van intens geluk in ons leven gebracht. Jij doet me altijd weer realiseren wat écht belangrijk is. Vanaf het eerste moment hoor je er helemaal bij en ik kan me het leven niet meer zonder jou voorstellen. Wat ben ik supertrots dat ik jouw mama mag zijn! Dit proefschrift is voor jou en ons tweede kleine wondertje op komst. Ik hoop altijd een goed voorbeeld voor jullie te kunnen zijn. Hou van jullie tot aan de maan en terug!

Op naar de volgende uitdaging! 


\section{CURRICULUM VITAE}

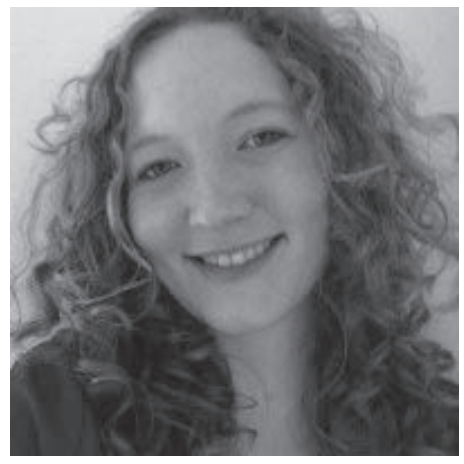

Babette Reijs was born on December $6^{\text {th }} 1985$ in Mook and Middelaar, the Netherlands. After she finished Gymnasium in Nijmegen the Netherlands, she moved to Maastricht to study Psychology. During her bachelor she also followed courses at Dalhousie University, Halifax, Canada. In 2009 she received her bachelor degree and a Cum Laude master degree in Health and Social Psychology at Maastricht University. In 2010 she started a twoyear research program in Neuropsychology at Maastricht University. She did a clinical internship at the memory clinic at Maastricht University Medical Centre (MUMC) where she obtained her psychodiagnostic registration (BAPD). She did a research internship at UMC Radboud Geriatrics \& Donders Institute for Brain, Cognition and Behaviour, where she examined prefrontal recruitment during working memory-performance with functional Near-Infrared Spectroscopy (fNIRS) in healthy older individuals and in individuals with Mild Cognitive Impairment. Aside to her studies, she worked as a researcher evaluating e-health intervention programs at Maastricht University. Babette received her second master degree and started as a PhD student at the Department of Psychiatry and Neuropsychology at Maastricht University in 2013. Here she was co-responsible for establishing and managing a biobank of CSF and blood samples for the European study BIOMARKAPD funded by Joint Programming Initiative Neurodegenerative Diseases (JPND). In addition, she was involved as a neuropsychologist in patient research at the memory clinic; she performed several teaching activities and conducted research resulting in this dissertation.

Babette Reijs is geboren op 6 december 1985 in Mook en Middelaar. Na het behalen van haar Gymnasium diploma in Nijmegen verhuisde ze naar Maastricht om Psychologie te studeren. Tijdens haar bachelor volgde ze ook vakken op 'Dalhousie University' in Halifax Canada. In 2009 behaalde ze haar bachelor diploma en een cum laude Master diploma in 'Health and Social Psychology' aan de Universiteit Maastricht. In 2010 begon ze aan een tweejarige onderzoeksmaster met specialisme in Neuropsychologie in Maastricht. Ze deed een klinische stage op de geheugenpoli in het Maastricht Universitair Medisch centrum (MUMC), waarbij ze haar Basis Aantekening Psychodiagnostiek (BAPD) behaalde. Ze deed een onderzoeksstage op het Radboud UMC Geriatrie \& Donders Instituut voor Brein, Cognitie en Gedrag, waar ze onderzoek deed naar prefrontale activatie tijdens prestaties op een werkgeheugentaak met 
behulp van 'functional Near-Infrared Spectroscopy (fNIRS)' in gezonde ouderen en in mensen met milde cognitieve beperkingen (MCl). Naast haar studie werkte ze als onderzoeker in het evalueren van e-health interventie programma's aan de Universiteit Maastricht. Babette behaalde haar tweede Master diploma en startte als promovendus op de afdeling Psychiatrie en Neuropsychologie van de Universiteit Maastricht in 2013. Hier was ze medeverantwoordelijk voor het opzetten en managen van een biobank met hersenvocht en bloed materiaal voor de Europese studie BIOMARKAPD gesubsidieerd door 'Joint Programming Initiative Neurodegenerative Diseases" (JPND). Ze was betrokken als Neuropsycholoog in patiënten onderzoek op de geheugenpoli, ze vervulde diverse onderwijstaken en deed onderzoek resulterend in dit proefschrift. 